DIEGO DE OLIVEIRA MARTINS

\title{
DETERMINAÇÃO DE COORDENADAS ESPACIAIS A PARTIR DO MÉTODO DAS DISTÂNCIAS MÍNIMAS
}

Dissertação apresentada à Escola de Engenharia de São Carlos da Universidade de São Paulo, como parte dos requisitos para a obtenção do título de Mestre em Ciências, Programa de Pós-Graduação em Engenharia de Transportes. Área de Concentração: Infraestrutura de Transportes.

Orientador: Prof. Dr. Irineu da Silva.

São Carlos 
AUTORIZO A REPRODUÇ̃̃O TOTAL OU PARCIAL DESTE TRABALHO, POR QUALQUER MEIO CONVENCIONAL OU ELETRÔNICO, PARA FINS DE ESTUDO E PESQUISA, DESDE QUE CITADA A FONTE.

M379d Martins, Diego de Oliveira

Determinação de coordenadas espaciais a partir do método das distâncias mínimas / Diego de Oliveira Martins; orientador Irineu da Silva. São Carlos, 2013.

Dissertação (Mestrado) - Programa de Pós-Graduação em Engenharia de Transportes e Area de Concentração em Infra-Estrutura de Transporte -- Escola de Engenharia de São Carlos da Universidade de São Paulo, 2013.

1. Determinação de coordenadas espaciais. 2. Método das distâncias mínimas. 3. Automação de estações totais robóticas. 4. Ajustamento de observações. 5. Monitoramento de estruturas. 6. Análise de deslocamentos controlados. 7. Auscultação estrutural . 8. Mensuração. I. Título. 


\section{FOLHA DE JULGAMENTO}

Candidato: Engenheiro DIEGO DE OLIVEIRA MARTINS.

Título da dissertação: "Determinação de coordenadas espaciais a partir do método das distâncias mínimas".

Data da defesa: $14 / 06 / 2013$

\section{Comissão Julgadora:}

Prof. Dr. Irineu da Silva (Orientador)

(Escola de Engenharia de São Carlos/EESC)

Prof. Associado Paulo César Lima Segantine

(Escola de Engenharia de São Carlos/EESC)

\section{Resultado:}
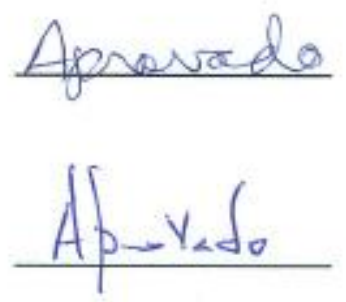

Prof. Dr. João Carlos Chaves

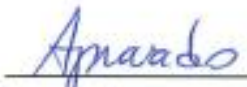

(Universidade Estadual Paulista "Júlio de Mesquita Filho"/UNESP-Presidente Prudente)

Coordenador do Programa de Pós-Graduação em Engenharia de Transportes: Prof. Associado Antônio Nélson Rodrigues da Silva

Presidente da Comissão de Pós-Graduação:

Prof. Titular Denis Vinicius Coury 



\section{DEDICATÓRIA}

À minha amada família, que sempre acreditou em mim e apoiou meu trabalho. 
A Deus, pela oportunidade e dom da vida.

Aos meus amados pais Lauriberto e Arlete pela formação do alicerce da minha vida, por todo amor, ensinamentos, incentivos e esforços nunca medidos.

Aos meus inestimáveis irmãos Ariel e Carolina pela união, companheirismo, amizade e alegria.

À minha amada e adorável Ana Carolina, a quem também dedico este trabalho, e agradeço por seu incondicional amor, compreensão, força e carinho.

À maravilhosa Maria Luiza que, desde sua graciosa chegada, transborda amor e alegria em nossas vidas e que, a cada dia, encanta-nos mais.

Ao meu tio Altamir, tia Marta e Gabriel pelos conselhos, fraternidade, ajuda e por sempre acreditarem no meu potencial.

A todo restante da minha família, tios, primos, cunhados e, em especial, ao Almir, Aílton, Carolina T. e Marcel.

Ao Conselho Nacional de Desenvolvimento Científico e Tecnológico - CNPQ, pela bolsa de estudo concedida.

Ao Departamento de Engenharia de Transportes e a Escola de Engenharia de São Carlos - STT/EESC/USP, pela oportunidade de realização do curso.

Ao meu orientador Prof. Dr. Irineu da Silva, pela amizade, confiança, orientações, discussões, sinceridade, apoio e paciência.

Aos professores e funcionários do Departamento de Engenharia de Transportes, pela contribuição para minha evolução profissional e atenção dispensada ao longo do curso.

Em especial, ao Prof. Dr. Paulo C. L. Segantine e Prof. Dr. Ricardo E. Schaal e ao técnico do laboratório de mensuração, Paulo Batista, pela amizade, apoio técnico e moral, sugestões, firmeza e confiança. 
Ao meu querido amigo Moisés Ap. Nascimento, pela dedicação e ajuda no desenvolvimento das modelagens matemáticas.

Ao Dr. Antônio Carlos Dinato, companheiro de sala e vizinho de mesa, pela amizade e ajuda diária, o que fortaleceu muito este trabalho.

A todos os colegas e amigos do departamento que conviveram no dia a dia comigo e que, direta ou indiretamente, sempre estiveram dispostos a me ajudar e contribuíram para a realização e êxito deste trabalho.

Ao Departamento de Engenharia de Estruturas - SET/EESC/USP, em especial ao chefe Prof. Dr. Mounir Khalil El Debs pela concessão do espaço laboratorial e aos seus técnicos, em especial Luís Vareda, pela força e apoio durante os ensaios e realizações.

A Leica Geosystems Sudamérica - São Carlos - SP, especialmente aos funcionários Mariovaldo "Fio", José Carlos, Sérgio e Rene, pelo suporte, certificações e serviços executados com excelência.

Aos que, desde o princípio, não acreditaram neste trabalho, pois foi o diferencial de força na conquista desta vitória. 


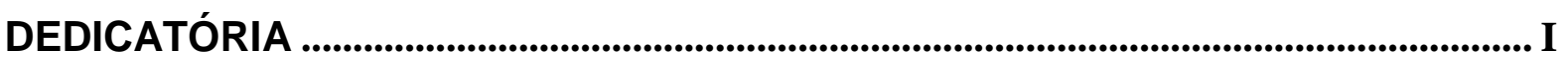

AGRADECIMENTOS ...............................................................................................

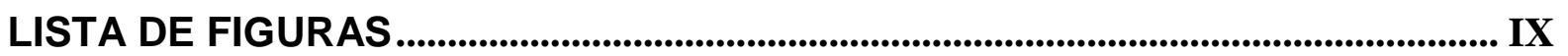

LISTA DE TABELAS ....................................................................................... XII

LISTA DE SIGLAS E ABREVIATURAS .............................................................XIX

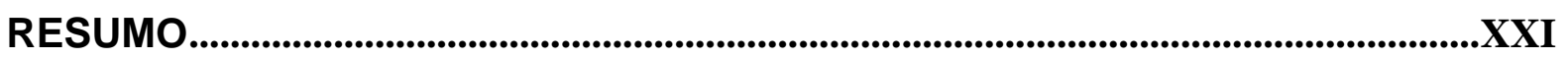

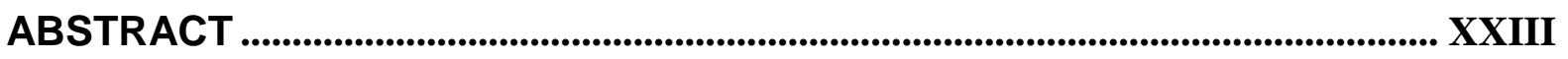

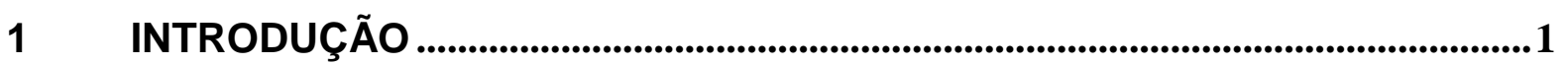

1.1 Caracterização do problema ................................................................

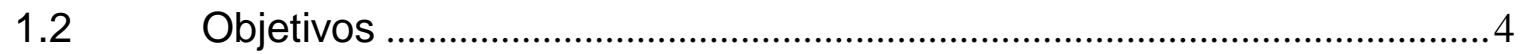

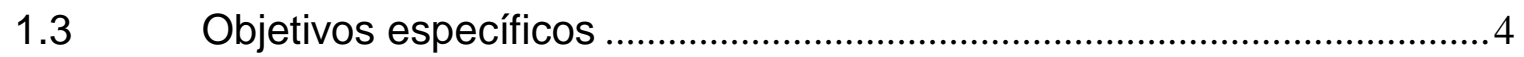

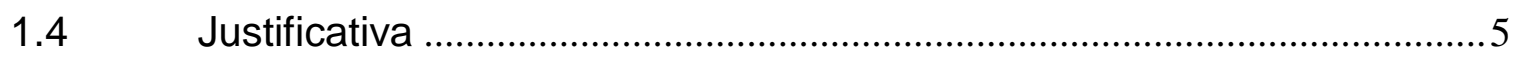

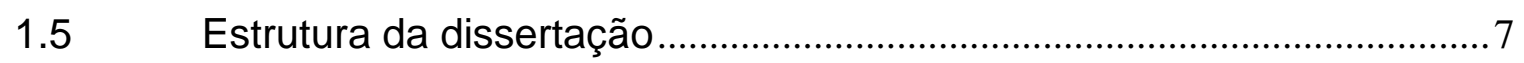

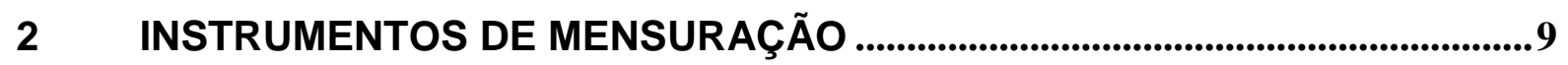

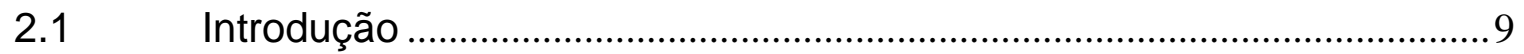

2.2 Instrumentos e softwares utilizados........................................................11

2.2.1 Estação Total Robotizada Leica Theomat Coaxial Automated Total

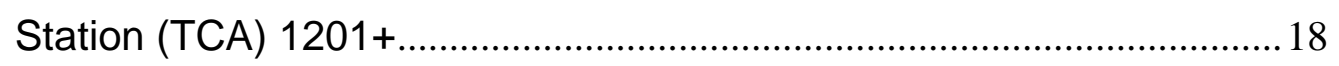

2.2.3 Estação Total Robotizada Leica Theomat Coaxial Reflectorless

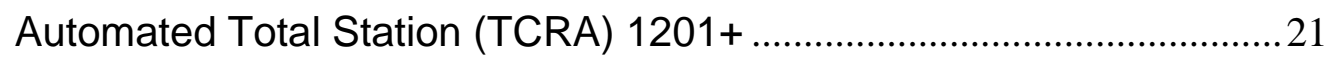

2.3 Automação e controle das observações ..................................................22

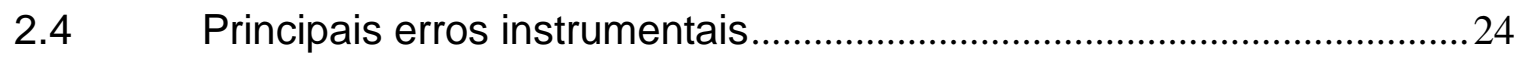

3 REVISÃO BIBLIOGRÁFICA ................................................................................27

3.1 SISTEMAS DE MONITORAMENTO DE ESTRUTURAS …..................27

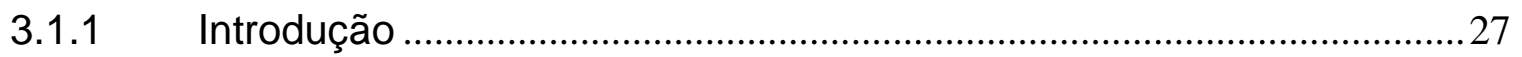

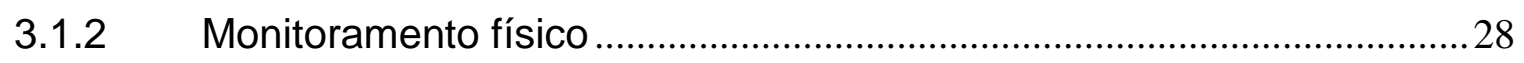

3.1.3 Monitoramento com técnicas de mensuração .........................................29

3.2 MENSURAÇÃO APLICADA À AUSCULTAÇÃO DE ESTRUTURAS..29

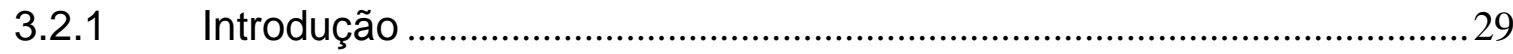

3.3 Métodos e técnicas de mensuração aplicados ............................................30

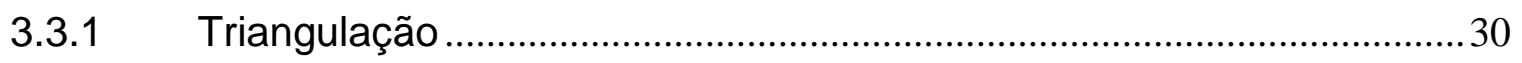




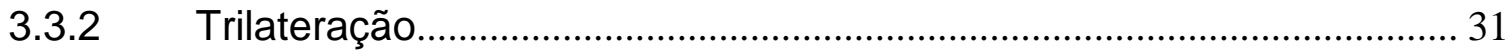

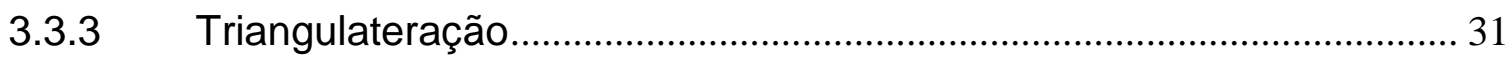

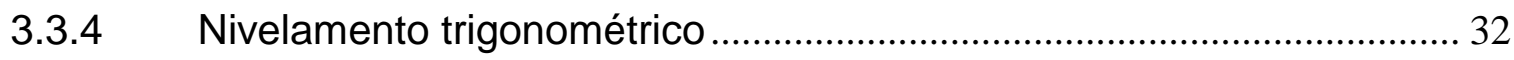

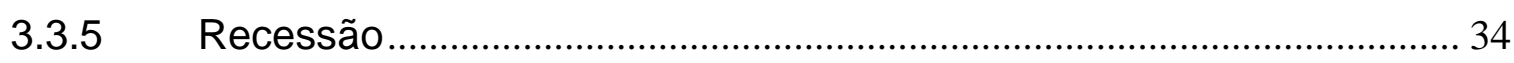

3.3.6 Rede de referência absoluta de apoio ao monitoramento....................... 35

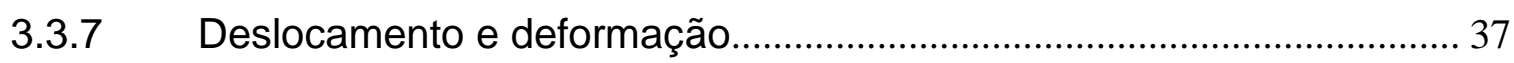

3.3.8 Controle de qualidade das observações e ajustamento da rede absoluta de referência - Teste Bilateral do Qui-Quadrado $(\boldsymbol{\chi} \mathbf{2})$.......... 39

3.3.9 Elipse de erros ................................................................................... 41

3.4 APRESENTAÇÃO DOS PRINCIPAIS MÉTODOS DE CÁLCULO DE COORDENADAS ESPACIAIS ............................................................... 43

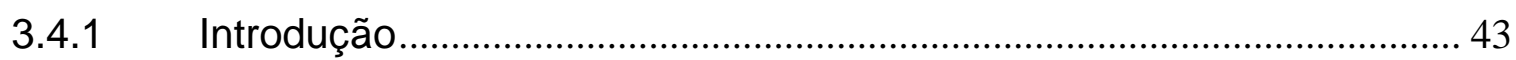

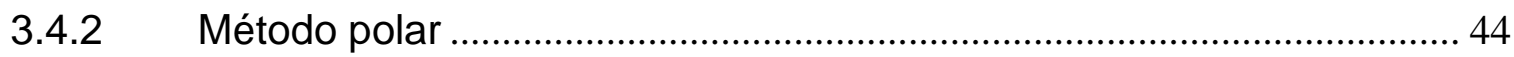

3.4.3 Método de interseção espacial trigonométrico ........................................... 46

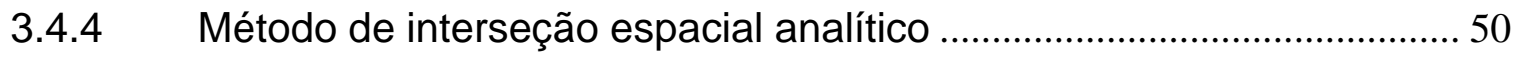

3.3.5 Método de interseção espacial analítico com superdeterminação de

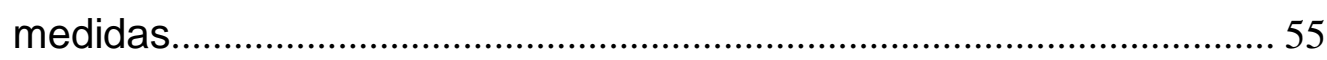

4 METODOLOGIA E DESENVOLVIMENTO ..................................................67

4.1 DESCRIÇÃO DO LOCAL DE ESTUDO ……………………..................... 67

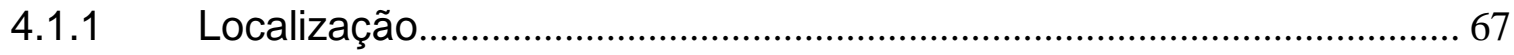

4.2 IMPLANTAÇÃO DA REDE ABSOLUTA DE REFERÊNCIA ..................68

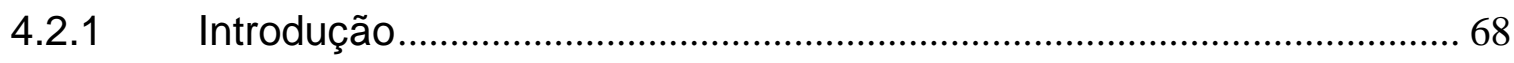

4.2.2 Determinação das coordenadas espaciais das estações base que compõem a rede absoluta de referência para a monitoração de estruturas

4.3 PLANEJAMENTO PARA AUSCULTAÇÃO ESTRUTURAL.................... 76

4.3.1 Critérios adotados para a execução das observações ……………….... 76

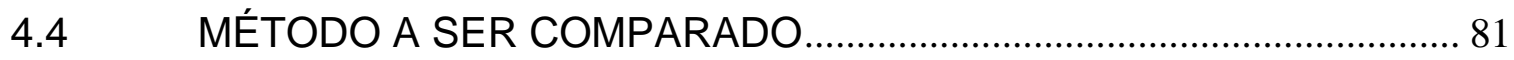

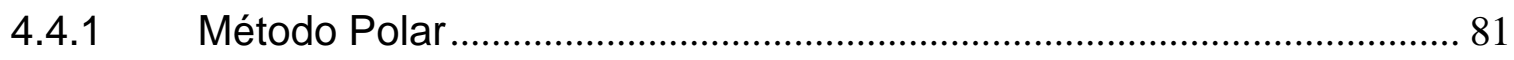

4.5 PROPOSTA PARA O CÁLCULO DE COORDENADAS ESPACIAIS PELO MÉTODO DAS DISTÂNCIAS MÍNIMAS...................................... 86

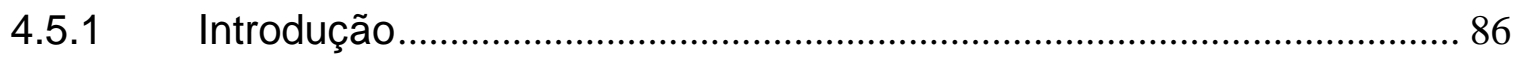


4.5.2 Modelo matemático proposto. .87

4.5.2.1 Determinação das equações das retas definidas pelas linhas de visadas dos dois instrumentos até o alvo $P$ 89

4.5.2.2 Determinação de um ponto genérico $G \boldsymbol{i}(\boldsymbol{t} \boldsymbol{i})$ sobre a reta $r \boldsymbol{i}$..................90

4.5.2.3 Determinação da distância entre os pontos genéricos e o alvo $P$........91

4.5.2.4 Determinação da distância entre os pontos genéricos e 0 alvo $P$........92

4.5.2.5 Determinação das derivadas parciais em função das incógnitas .........93

4.5.2.6 Formulação matricial ............................................................................96

4.5.2.7 Determinação das coordenadas dos pontos de distância mínima (Gi), entre as linhas de visada e o alvo $\mathrm{P}$......................................................98

4.5.2.8 Determinação das distâncias entre os pontos (Gi) e o alvo $\mathrm{P}$..............99

4.5.2.9 Determinação das distâncias mínima, média e máxima entre os pontos (Gi) e o alvo $\mathrm{P}$

4.5.2.10 Determinação da precisão aparente das coordenadas dos pontos (Gi), sobre as retas definidas pelas linhas de visada

4.5.2.11 Determinação da precisão aparente das coordenadas finais do alvo $P$ 101

4.5.2.12 Determinação da precisão do posicionamento espacial do alvo $P$....102

4.5.3 Validação do modelo matemático 103

4.5.3.1 Determinação e análise das coordenadas espaciais calculadas para a variação do alvo GPR111

4.6 PROPOSTA PARA O CÁLCULO DE COORDENADAS ESPACIAIS PELO MÉTODO DAS DISTÂNCIAS MÍNIMAS COM AJUSTAMENTO DAS OBSERVAÇÕES

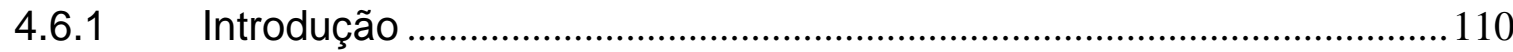

4.6.2 Modelo matemático proposto.................................................................112

4.6.3 Determinação das coordenadas dos versores das linhas de visadas 112

4.6.4 Determinação das equações de erros ....................................................113

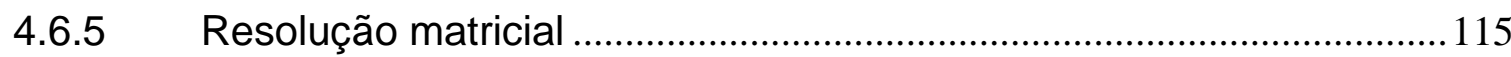

4.6.6 Aplicação do modelo para observações mediatas utilizando o M.M.Q.

4.6.7 Cálculo dos erros e das matrizes variância-covariância (MVC).

4.6.8 Validação do modelo matemático proposto 
4.6.9 Determinação e análise das coordenadas espaciais calculadas para o alvo GPR111

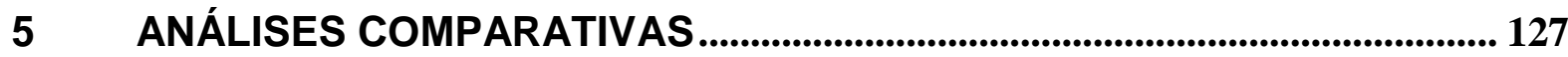

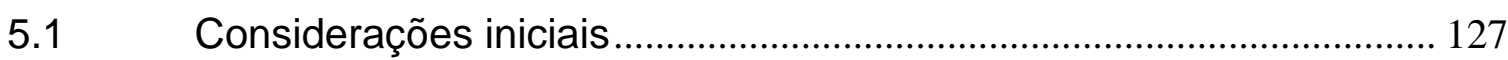

5.2 Análise comparativa entre os métodos.................................................. 128

6 CONCLUSÕES E RECOMENDAÇÕES............................................................... 135

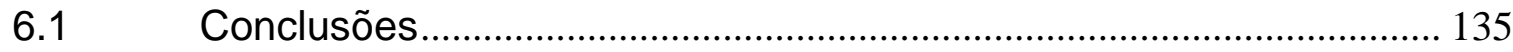

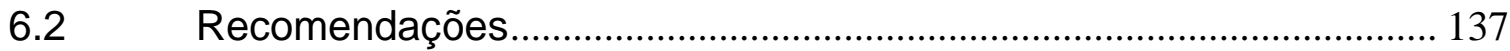

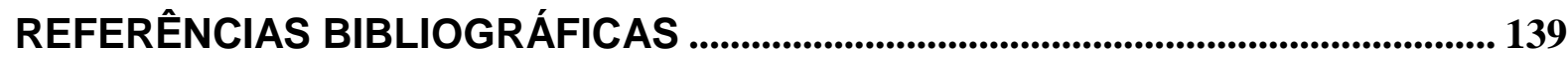

APÊNDICE A - ROtINA COMPUTACIONAL PARA DETERMINAÇÃo DAS COORDENADAS PLANIMÉTRICAS DA REDE ABSOLUTA DE REFERÊNCIA ….................................................. 143 APÊNDICE B - ROTINA COMPUTACIONAL PARA DETERMINAÇÃo DAS COORDENADAS ALTIMÉTRICAS DA REDE ABSOLUTA DE REFERÊNCIA.......................................................... 160 APÊNDICE C - ROTINA COMPUTACIONAL PARA DETERMINAÇÕES DAS COORDENADAS ESPACIAIS DOS ALVOS POR MEIO DO MÉTODO POLAR ...................................................... 163 APÊNDICE D - VALIDAÇÃO DO MÉTOdO POLAR PARA OS ALVOS ESTUDADOS ............... 165 APÊNDICE E - ROTINA COMPUTACIONAL PARA DETERMINAÇÕES DAS COORDENADAS ESPACIAIS DOS ALVOS POR MEIO DO MÉTODO DAS DISTÂNCIAS MÍNIMAS .............................. 186 APÊNDICE F - VALIDAÇÃo DO MÉTODO DAS DISTÂNCIAS MÍNIMAS PARA OS ALVOS

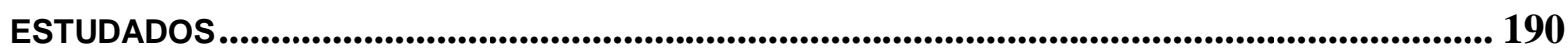

APÊNDICE G - ROTINA COMPUTACIONAL PARA DETERMINAÇÕES DAS COORDENADAS ESPACIAIS DOS ALVOS POR MEIO DO MÉTODO DAS DISTÂNCIAS MÍNIMAS COM AJUSTAMENTO DAS OBSERVAÇÕES 216

APÊNDICE H - VALIDAÇÃO DO MÉTOdO DAS DISTÂNCIAS MínIMAS COM AJUSTAMENTO DAS OBSERVAÇÕES PARA OS ALVOS ESTUDADOS............................................................ 220

ANEXO A - Certificado de Serviço da TCRA 1201+ (Leica HeerbrugG) .............. 246

ANEXO B - Certificado de SERVIÇO DA TCA 1201+ (WILD CoMerCIAL).................... 249

ANEXO C - CerTIFICADO DE SERVIÇO DA TCRA 1201+ (WILD ComerCIAL)................ 252

ANEXO D - Projeto do SUPORTE AJUStáVEL PARA ALVOS REFLETORES..................... 255

ANEXO E - PROJETO DO SUPORTE PARA FITAS REFLETIVAS ............................................ 256 


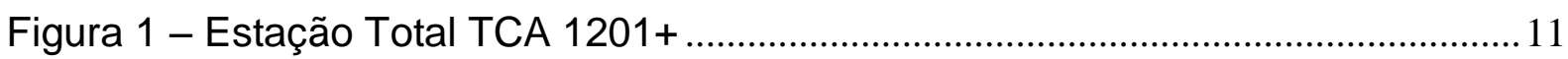

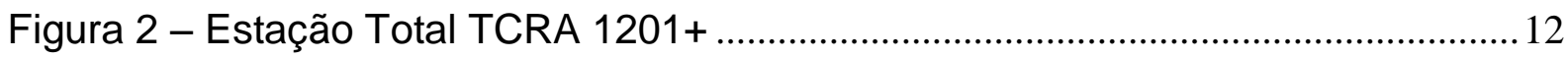

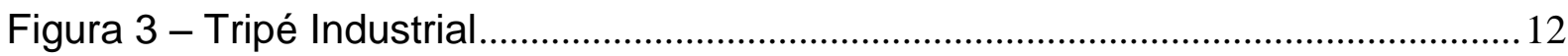

Figura 4 - Jogo composto por base nivelante, Carrier e prisma GPR-111 ................13

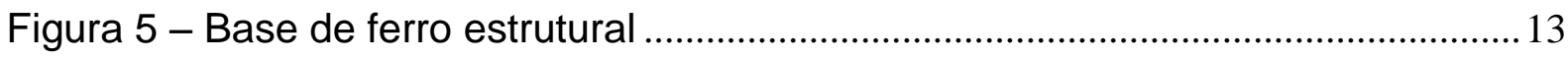

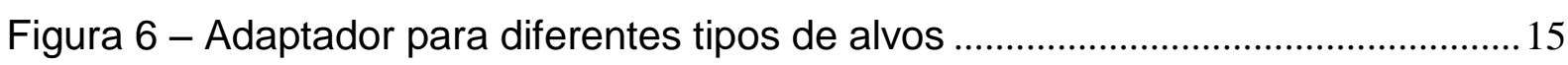

Figura 7 - Suporte para alvos com dispositivo de controle milimétrico ............................ 15

Figura 8 - Adaptador para Carrier e colagem de fitas refletivas .................................. 16

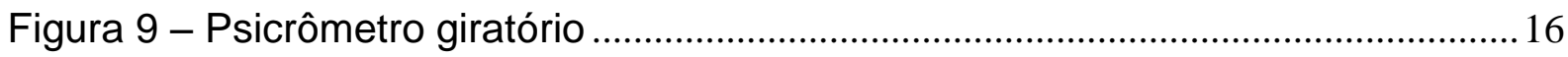

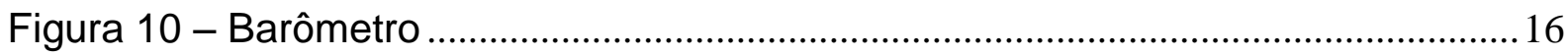

Figura 11 - Cartões compact flash e seu leitor ............................................................. 17

Figura 12 - Posicionamento automático do alvo ATR..................................................19

Figura 13 - Série de ângulos e monitoramento estrutural ............................................20

Figura 14 - Diagrama simplificado de um sistema de controle automático..................23

Figura 15 - Erros de colimação da função automática ATR ............................................25

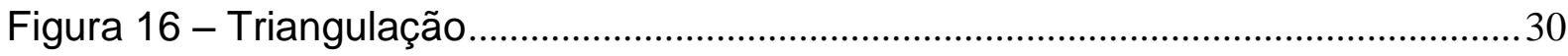

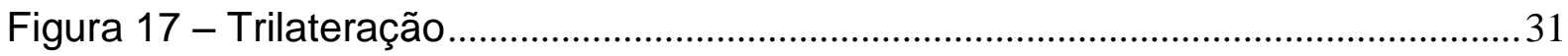

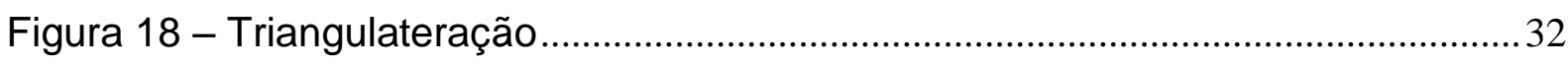

Figura 19 - Nivelamento trigonométrico ……………………....................................... 33

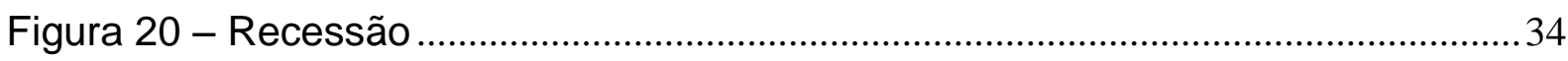

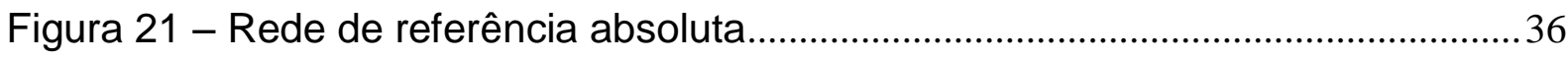

Figura 22 - Influência de um ponto de referência que não seja estável .........................36

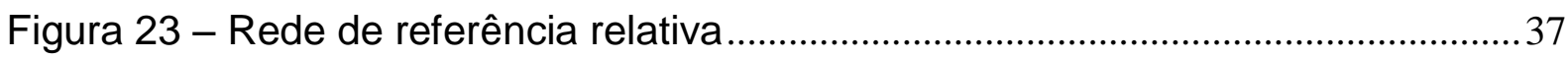

Figura 24 - Deformação de um objeto entre duas épocas..............................................38

Figura 25 - Deslocamento de um objeto entre duas épocas ..........................................38

Figura 26 - Esquema representativo do método polar ................................................4 45

Figura 27 - Representação gráfica do método de interseção plana...............................46

Figura 28 - Representação da discrepância no posicionamento do ponto calculado pelo método de interseção espacial trigonométrico ........................................................4

Figura 29 - Representação gráfica do método de interseção espacial analítica.........51

Figura 30 - Coordenadas espaciais do alvo $\mathrm{P}$, utilizando-se vetores ...........................51 
Figura 31 - Representação dos ângulos de referência entre $O P$ e os semieixos positivos

Figura 32 - Posicionamento dos equipamentos nas estações de referência 53

Figura 33 - Esquema representativo do método de interseção espacial analítica com superdeterminação de medidas...... 56

Figura 34 - Representação gráfica do método de interseção espacial analítica 57

Figura 35 - Representação da reta perpendicular comum pertencente aos planos Aij e Aji ......

Figura 36 - Representação do plano Aij formado pelo versor wi e pelo versor perpendicular comum nij com origens no ponto $i$ 59

Figura 37 - Representação da reta de interseção $r j$ com origem no ponto $j$. 61

Figura 38 - Representação do posicionamento do ponto de interseção Pji,

Figura 39 - Esquema de posicionamento dos pontos de interseção Pij e Pji e o ponto médio $P$ utilizando o método de interseção espacial analítica 65

Figura 40 - Laboratório de Estruturas (SET/EESC/USP) 67

Figura 41 - Organização do instrumental no laboratório. 68

Figura 42 - Rede absoluta de referência e respectivas elipses de erros 74

Figura 43 - Suporte com dispositivo ajustável engastado na estrutura... 77

Figura 44 - Critério para variação controlada nos eixos $(X, Z)$ dos alvos 78

Figura 45 - Observações obtidas em campo para o alvo GPRC00. 79

Figura 46 - Observações obtidas em campo para o alvo GPRC com todas as variações. .. 80

Figura 47 - Variação das coordenadas para o prisma GPR111 (Método Polar) ....... 85

Figura 48 - Representação genérica dos elementos que compõem o método .......... 88

Figura 49 - Pontos de distância mínima entre as linhas de visadas e o alvo 98

Figura 50 - Variação das coordenadas para o prisma GPR111 (Distância Mínima)

Figura 51 - Variação das coordenadas espaciais para o prisma GPR111 (Distância Mínima e Ajuste).....

Figura 52 - Variação das coordenadas para o prisma GPR112 (Método Polar) ..... 169

Figura 53 - Variação das coordenadas para o prisma GMP111-0 (Método Polar) . 173

Figura 54 - Variação das coordenadas para o prisma GMP104 (Método Polar)..... 177 
Figura 55 - Variação das coordenadas para o prisma GRZ101 (Método Polar) ...... 181

Figura 56 - Variação das coordenadas para a Fita Refletiva (Método Polar) ........... 185

Figura 57 - Variação das coordenadas para o prisma GPR112 (Distância Mínima)

Figura 58 - Variação das coordenadas para o prisma GMP111-0 (Distância Mínima) 200

Figura 59 - Variação das coordenadas para o prisma GMP104 (Distância Mínima) 205

Figura 60 - Variação das coordenadas para o prisma GRZ101 (Distância Mínima)210 Figura 61 - Variação das coordenadas para Fita refletiva (Distância Mínima).........215 Figura 62 - Variação das coordenadas para o alvo GPR112 (Distância Mínima e Ajuste) 225

Figura 63 - Variação das coordenadas para o alvo GMP111-0 (Distância Mínima e Ajuste) 230

Figura 64 - Variação das coordenadas para o alvo GMP104 (Distância Mínima e Ajuste) 235

Figura 65 - Variação das coordenadas para o alvo GRZ101 (Distância Mínima e Ajuste) 240

Figura 66 - Variação das coordenadas para Fita refletiva (Distância Mínima e Ajuste) 


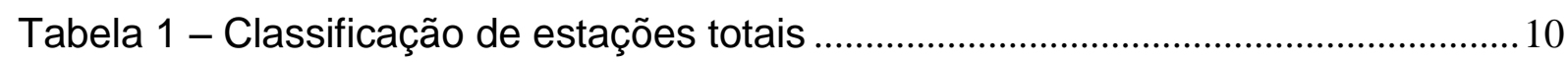

Tabela 2 - Modelos de alvos usados na Pesquisa ........................................................ 14

Tabela 3 - Principais características da RTS da série TPS do tipo 1201+_.................22

Tabela 4 - Coordenadas arbitradas para Base 1......................................................... 70

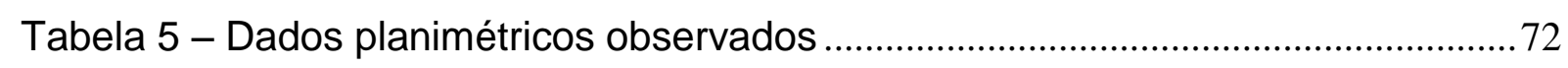

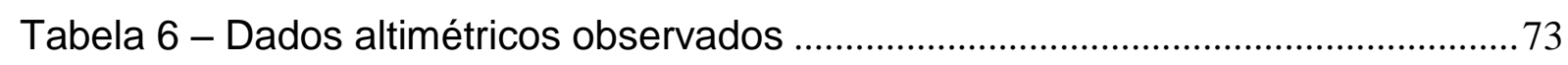

Tabela 7 - Coordenadas aproximadas ............................................................................ 73

Tabela 8 - Coordenadas e precisões planialtimétricas ajustadas................................ 74

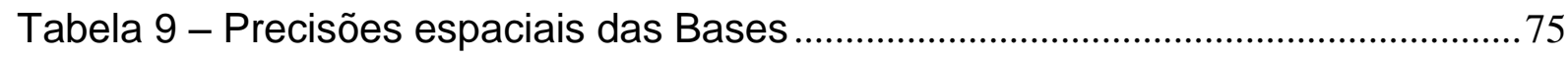

Tabela 10 - Teste do $(\chi 2)$ para o ajustamento das redes plana e altimétrica.............75

Tabela 11 - Dados observados e verificação da estabilidade da Base 1 (Método

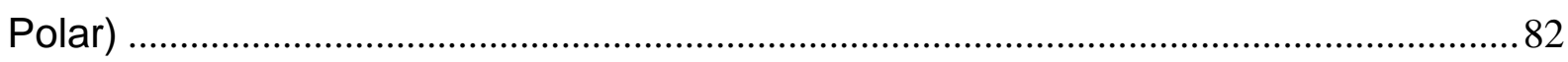

Tabela 12 - Coordenadas e precisões ajustadas dos alvos (Método Polar)................ 83

Tabela 13 - Variação controlada, variação das coordenadas e diferença entre

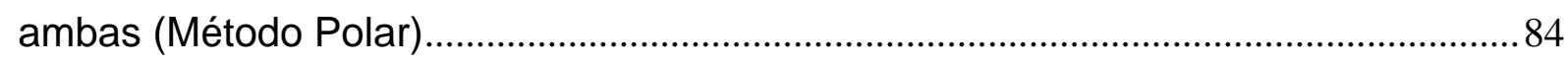

Tabela 14 - Dados observados e verificação da estabilidade da Base 1 (Distância Mínima)...

Tabela 15 - Dados observados e verificação da estabilidade da Base 2 (Distância Mínima). 106

Tabela 16 - Coordenadas dos alvos e precisões aparentes (Distância Mínima) .....107 Tabela 17 - Variação controlada, variação das coordenadas e diferença entre

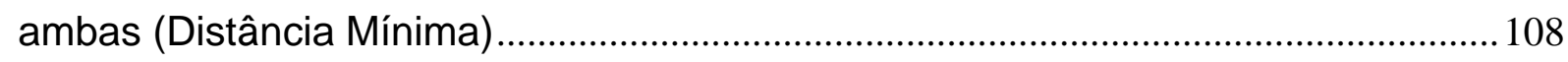

Tabela 18 - Dados observados e verificação da estabilidade da Base 1 (Distância Mínima e Ajuste)

Tabela 19 - Dados observados e verificação da estabilidade da Base 2 (Distância Mínima e Ajuste)

Tabela 20 - Coordenadas e precisões ajustadas dos alvos (Distância Mínima e Ajuste).

Tabela 21 - Variação controlada, variação das coordenadas ajustadas e diferença entre ambas (Distância Mínima e Ajuste) 
Tabela 22 - Coordenadas e precisões espaciais obtidas pelos métodos de determinações validados

Tabela 23 - Diferença entre o controle e a variação das coordenadas ajustadas em cada método

Tabela 24 - Dados observados e verificação da estabilidade da Base 1 (Método Polar - GPR112) 166

Tabela 25 - Coordenadas e precisões ajustadas dos alvos (Método Polar GPR112)

Tabela 26 - Variação controlada, variação das coordenadas e diferença entre ambas (Método Polar - GPR112) 168

Tabela 27 - Dados observados e verificação da estabilidade da Base 1 (Método Polar - GMP111-0) 170

Tabela 28 - Coordenadas e precisões ajustadas dos alvos (Método Polar - GMP111$0)$.

Tabela 29 - Variação controlada, variação das coordenadas e diferença entre ambas (Método Polar - GMP111-0)

Tabela 30 - Dados observados e verificação da estabilidade da Base 1 (Método Polar - GMP104). 174

Tabela 31 - Coordenadas e precisões ajustadas dos alvos (Método Polar - GMP104) 175

Tabela 32 - Variação controlada, variação das coordenadas e diferença entre ambas (Método Polar - GMP104) 176

Tabela 33 - Dados observados e verificação da estabilidade da Base 1 (Método Polar - GRZ101) 178

Tabela 34 - Coordenadas e precisões ajustadas dos alvos (Método Polar - GRZ101)

Tabela 35 - Variação controlada, variação das coordenadas e diferença entre ambas (Método Polar - GRZ101)

Tabela 36 - Dados observados e verificação da estabilidade da Base 1 (Método Polar - Fita Refletiva).

Tabela 37 - Coordenadas e precisões ajustadas dos alvos (Método Polar - Fita Refletiva). 
Tabela 38 - Variação controlada, variação das coordenadas e diferença entre ambas (Método Polar - Fita Refletiva)

Tabela 39 - Dados observados e verificação da estabilidade da Base 1 (Distância Mínima - GPR112)

Tabela 40 - Dados observados e verificação da estabilidade da Base 2 (Distância Mínima - GPR112) 192

Tabela 41 - Coordenadas dos alvos e precisões aparentes (Distância Mínima GPR112)

Tabela 42 - Variação controlada, variação das coordenadas e diferença entre ambas (Distância Mínima - GPR112)

Tabela 43 - Dados observados e verificação da estabilidade da Base 1 (Distância Mínima - GMP111-0) 196

Tabela 44 - Dados observados e verificação da estabilidade da Base 2 (Distância Mínima - GMP111-0)

Tabela 45 - Coordenadas dos alvos e precisões aparentes (Distância Mínima GMP111-0)

Tabela 46 - Variação controlada, variação das coordenadas e diferença entre ambas (Distância Mínima - GMP111-0)

Tabela 47 - Dados observados e verificação da estabilidade da Base 1 (Distância Mínima - GMP104) 201

Tabela 48 - Dados observados e verificação da estabilidade da Base 2 (Distância Mínima - GMP104) 202

Tabela 49 - Coordenadas dos alvos e precisões aparentes (Distância Mínima GMP104) 203

Tabela 50 - Variação controlada, variação das coordenadas e diferença entre ambas (Distância Mínima - GMP104) 204

Tabela 51 - Dados observados e verificação da estabilidade da Base 1 (Distância Mínima - GRZ101) 206

Tabela 52 - Dados observados e verificação da estabilidade da Base 2 (Distância Mínima - GRZ101) 207

Tabela 53 - Coordenadas dos alvos e precisões aparentes (Distância Mínima GRZ101) 208

Tabela 54 - Variação controlada, variação das coordenadas e diferença entre ambas (Distância Mínima - GRZ101) 
Tabela 55 - Dados observados e verificação da estabilidade da Base 1 (Distância Mínima - Fita Refletiva)

Tabela 56 - Dados observados e verificação da estabilidade da Base 2 (Distância Mínima - Fita Refletiva) 212

Tabela 57 - Coordenadas dos alvos e precisões aparentes (Distância Mínima - Fita Refletiva).

Tabela 58 - Variação controlada, variação das coordenadas e diferença entre ambas (Distância Mínima - Fita Refletiva)

Tabela 59 - Dados observados e verificação da estabilidade da Base 1 (Distância Mínima e Ajuste - GPR112).

Tabela 60 - Dados observados e verificação da estabilidade da Base 2 (Distância Mínima e Ajuste - GPR112)

Tabela 61 - Coordenadas dos alvos e precisões aparentes (Distância Mínima e Ajuste - GPR112)

Tabela 62 - Variação controlada, variação das coordenadas e diferença entre ambas (Distância Mínima e Ajuste - GPR112).

Tabela 63 - Dados observados e verificação da estabilidade da Base 1 (Distância Mínima e Ajuste - GMP111-0). 226

Tabela 64 - Dados observados e verificação da estabilidade da Base 2 (Distância Mínima e Ajuste - GMP111-0).

Tabela 65 - Coordenadas dos alvos e precisões aparentes (Distância Mínima e Ajuste - GMP111-0) 228

Tabela 66 - Variação controlada, variação das coordenadas e diferença entre ambas (Distância Mínima e Ajuste - GMP111-0).

Tabela 67 - Dados observados e verificação da estabilidade da Base 1 (Distância Mínima e Ajuste - GMP104)

Tabela 68 - Dados observados e verificação da estabilidade da Base 2 (Distância Mínima e Ajuste - GMP104) ...

Tabela 69 - Coordenadas dos alvos e precisões aparentes (Distância Mínima e Ajuste - GMP104)

Tabela 70 - Variação controlada, variação das coordenadas e diferença entre ambas (Distância Mínima e Ajuste - GMP104) 
Tabela 71 - Dados observados e verificação da estabilidade da Base 1 (Distância Mínima e Ajuste - GRZ101) 236

Tabela 72 - Dados observados e verificação da estabilidade da Base 2 (Distância Mínima e Ajuste - GRZ101)

Tabela 73 - Coordenadas dos alvos e precisões aparentes (Distância Mínima e Ajuste - GRZ101) 238

Tabela 74 - Variação controlada, variação das coordenadas e diferença entre ambas (Distância Mínima e Ajuste - GRZ101)

Tabela 75 - Dados observados e verificação da estabilidade da Base 1 (Distância Mínima e Ajuste - Fita Refletiva) 241

Tabela 76 - Dados observados e verificação da estabilidade da Base 2 (Distância Mínima e Ajuste - Fita Refletiva) 242

Tabela 77 - Coordenadas dos alvos e precisões aparentes (Distância Mínima e Ajuste - Fita Refletiva) 243

Tabela 78 - Variação controlada, variação das coordenadas e diferença entre ambas (Distância Mínima e Ajuste - Fita Refletiva) 
ABNT - Associação Brasileira de Normas Técnicas

ATR - Automatic Target Recognition

CCD - Charge-Coupled Device

CLP - Controlador Lógico Programável

DIN - Deutsches Institut für Normung

EESC - Escola de Engenharia de São Carlos

GNSS - Global Navigation Satellite System

ISO - International Organization for Standardization

LGO - Leica Geo Office

MATLAB - Matrix Laboratory

MLE - Maximum Likelihood Estimators

MVC - Matriz variância-covariância

NBR - Norma Brasileira

RTK - Real Time Kinematic

RTS - Robotic Total Station

SP - Estado de São Paulo

TCA - Theomat Coaxial Automated Total Station

TCRA - Theomat Coaxial Automated Reflectorless Total Station

TPS - Total Station Positioning System

USB - Universal Serial Bus

USP - Universidade de São Paulo 


\section{RESUMO}

MARTINS, D. O. Determinação de coordenadas espaciais a partir do método das distâncias mínimas. São Carlos, 2013, 256p. Dissertação (Mestrado) - Escola de Engenharia de São Carlos, Universidade de São de Paulo.

O monitoramento de grandes estruturas está diretamente ligado à segurança das mesmas, pois sendo elas naturais ou artificiais, estão sempre sujeitas a variações em suas dimensões e posições, no espaço e no tempo, o que pode representar riscos sociais, ambientais e econômicos. Dessa maneira, a presente pesquisa apresenta um estudo sobre métodos de determinação de coordenadas espaciais, disponíveis na literatura e empregados atualmente nos trabalhos práticos de engenharia, quanto aos aspectos de monitoração estrutural, tendo por finalidade simular e determinar deslocamentos controlados de alvos. A dissertação tem como principal objetivo testar as vantagens dos procedimentos automáticos realizados por meio de estações totais robóticas a partir do uso de métodos de medição em estudo no Laboratório de Mensuração do Departamento de Transportes da Escola de Engenharia de São Carlos (STT/EESC/USP), em comparação com o método polar, convencionalmente utilizado na maioria dos projetos de monitoração estrutural. $O$ principal método aplicado nesta dissertação é denominado Método das Distâncias Mínimas, o qual se fundamenta no princípio da minimização de funções matemáticas definidas pelo somatório das distâncias entre os pontos de medição e os alvos definidos para o monitoramento. As distâncias, neste caso, são determinadas a partir das medições de ângulos zenitais e azimutais medidos com estações totais robóticas e automáticas. Com isso, pretende-se mostrar que o uso de equipamentos topográficos modernos com capacidade para desenvolver rotinas de automação de busca e medição de alvos permite realizar medidas com alto nível de automação, controle e qualidade. Mostra-se nesta dissertação que a tecnologia de busca automática de prismas permite automatizar os procedimentos de mensuração aplicados ao monitoramento de estruturas, possibilitando auscultar estruturas de maneira contínua sem a interferência do operador, o que aumenta sensivelmente a qualidade dos resultados.

Palavras-chave: Monitoramento de Estruturas, Análise de Deslocamentos, Ajustamento de Observações, Automação e Controle, Estações Totais Robóticas. 


\section{ABSTRACT}

MARTINS, D. O. Determination of spatial coordinates by the method of minimum distances. São Carlos, 2013, 256p. Master thesis - School of Engineering of São Carlos, University of São Paulo.

The monitoring of large structures is directly linked to their safety, because they are always subject to variations in their dimensions and positions in space and time, which can pose social, environmental and economic risks, being the structures natural or artificial. Thus, the following research presents a study about the methods to determine spatial coordinates, available in the literature and currently employed in practical engineering, and also includes the structural issues of monitoring, aiming to simulate and determine controlled displacements of targets. This paper has as main objective to test the advantages of automatic procedures performed using robotic total stations using measurement methods in a study at the Measurement Transport Department Laboratory of the São Carlos School of Engineering (STT/EESC/USP), in comparison to the polar method, conventionally used in most structural monitoring projects. The main method applied in this thesis is called Minimum Distances Method, which is based on the principle of mathematical functions minimization defined by the sum of the distances between the measurement points and the targets set for the monitoring. The distances, in this case, are determined from the measurements of azimuth and zenithal angles measured with automatic and total robotic stations. The main purpose is to show that the use of modern surveying equipment with capacity to develop automation routines of search and targets measurement allows performing measurements with high level of automation, control and quality. It is shown in this paper that the technology of prisms automatic search permit to automate the measurement procedures applied to the monitoring of structures, enabling to continuously auscultate the structures without the operator interference, which significantly improves the quality of results.

Keywords: Structures Monitoring, Analysis, Displacement, Observations Adjustment, Automation and Control, Robotic Total Stations. 


\section{INTRODUÇÃO}

Este capítulo descreve as motivações que geraram esta pesquisa e caracteriza o problema a ser tratado. São apresentados também os objetivos, as justificativas e a estrutura da dissertação.

\subsection{Caracterização do problema}

Pode-se dizer que qualquer objeto, natural ou sintético, está sujeito a variações, em sua dimensão, forma e posição, no espaço e no tempo. E essa variabilidade pode ser analisada por meio de medições de deformações e de estudos sobre o comportamento dos corpos deformáveis. Por estas razões, qualquer estrutura deve ser supervisionada durante toda sua existência, para permitir a detecção precoce de possíveis danos. Mesmo uma pequena alteração da forma do objeto ou mínimas alterações nas áreas circundantes devem ser levadas em consideração, por mais insignificantes que pareçam, pois podem comprometer a integridade de toda a estrutura observada. (CHEN, 1983)

Os estudos científicos sobre o comportamento dos corpos deformáveis estão cada vez mais frequentes em projetos de engenharia, buscando evoluir suas técnicas, metodologias e observações. Destaca-se neste contexto o monitoramento geodésico, que vem se consagrando como uma técnica eficiente para ser aplicada na auscultação estrutural, principalmente nos últimos anos, com o advento de equipamentos geodésicos robóticos - ou mais especificamente - das Estações Totais Robótica (RTS - Robotic Total Station), as quais têm a capacidade de mover a luneta automaticamente, por meio de servomotores, e de reconhecer alvos refletores a partir de tratamento de imagens. Tais equipamentos permitem desenvolver rotinas de automação de busca e de medição dos alvos sem a interferência do operador e de maneira contínua, o que elimina erros grosseiros e reduz o tempo de coleta dos dados. Tais estações têm também recursos e 
programas aplicativos que potencializam o desenvolvimento e gerenciamento de suas operações, proporcionando maior confiabilidade nos resultados obtidos.

A primeira aplicação evidente de uma Estação Total Robótica é o seu uso como equipamento convencional de mensuração. Existe, porém, outra aplicação menos evidente, mas de grande utilidade, que é o seu uso para o controle preciso de pequenos movimentos de objetos no espaço. Trata-se, neste caso, de uma nova oportunidade tecnológica com aplicação direta no monitoramento de estruturas.

Além dos equipamentos geodésicos, outro elemento importante a ser considerado no monitoramento de estruturas é o modelo matemático empregado na determinação dos deslocamentos das mesmas. Neste contexto, para o monitoramento geodésico, existem duas metodologias de medição, que são empregadas distintamente ou em conjunto e que permitem alcançar resultados consistentes. A primeira baseia-se no uso de estações totais e a segunda no uso da tecnologia do Sistema Global de Navegação por Satélite (GNSS - Global Navigation Satellite System). No caso da metodologia baseada no uso de estações totais, os modelos matemáticos disponíveis foram desenvolvidos considerando dois processos de medição:

a) Medição de ângulos e distâncias;

b) Medição de ângulos;

O modelo matemático desenvolvido com base nos valores angulares e nas distâncias medidas é aplicado a partir de um método de medição denominado Método Polar. O modelo matemático desenvolvido apenas com base nos valores angulares é aplicado a partir de métodos de medição denominados Métodos de Interseção Espacial, descritos a seguir:

a) Método de interseção espacial trigonométrica;

b) Método de interseção espacial analítico;

c) Método das distâncias mínimas;

Os modelos matemáticos de cada um desses métodos estão apresentados nos capítulos 3 e 4. 
No caso da metodologia baseada no uso da tecnologia GNSS, os modelos matemáticos também foram desenvolvidos considerando dois processos de posicionamento GNSS:

d) Posicionamento por meio do método cinemático em tempo real (RTK Real Time Kinematic), que se baseia no estabelecimento de uma rede de estações de referência GNSS de alta precisão, gerenciadas por um programa de computador, que calcula os deslocamentos de pontos específicos continuamente e em tempo real;

e) Posicionamento pós-processado, que se baseia no estabelecimento de uma rede de estações de referência GNSS coletando dados apenas durante os períodos críticos de deslocamentos da estrutura. Neste caso, em vez de uma monitoração contínua, os resultados são obtidos após pós-processamento dos dados relativos a períodos específicos de tempo.

Nesta dissertação, serão tratadas apenas as metodologias baseadas nas medições com estações totais. São apresentados e discutidos os resultados referentes à utilização de Estações Totais Robóticas, empregadas como instrumentos de medição geodésica, na aplicação dos modelos matemáticos referentes aos dois métodos das distâncias mínimas, comparados com o Método Polar. Não foram testados os resultados referentes ao Método de Interseção Espacial Trigonométrica e nem ao Método de Interseção Espacial Analítica.

Escolheu-se comparar os resultados do Método Polar e do Método das Distâncias Mínimas devido ao fato de o primeiro ser o método mais simples de ser aplicado com garantia de resultados consistentes e, o segundo, por ser o método desenvolvido no Laboratório de Mensuração do Departamento de Engenharia de Transportes da Escola de Engenharia de São Carlos e que possibilita obter resultados altamente acurados.

Segundo Moreira (1998), a determinação de coordenadas espaciais por meio do método das distâncias mínimas, realizado com equipamentos mecânicos, mostraram valores mais acurados e precisos do que os seus precedentes. Com o 
desenvolvimento dessa dissertação, espera-se aumentar ainda mais a qualidade dos resultados a partir do uso de equipamentos robóticos.

\subsection{Objetivos}

O objetivo geral desta pesquisa é estudar métodos para a determinação de coordenadas espaciais disponíveis na literatura, a partir do uso de Estações Totais Robóticas, e propor procedimentos automáticos para a coleta dos dados das medições obtidas durante a aplicação desses métodos. Como exemplo aplicativo, foram comparados os resultados relativos à aplicação do Método das Distâncias Mínimas com e sem superdeterminação de medidas e do Método Polar.

O objetivo global é mostrar que os métodos de medição, os modelos matemáticos e os equipamentos robóticos testados podem ser empregados com eficiência na determinação de coordenadas espaciais com a finalidade de monitorar, detectar, analisar e tomar decisões rápidas perante possíveis deslocamentos e deformações estruturais.

\subsection{Objetivos específicos}

Os objetivos específicos desta dissertação são os seguintes:

- Estudar e entender os principais métodos de determinação de coordenadas espaciais disponíveis na literatura;

- Estudar e compreender as funcionalidades e os diversos aplicativos de uma estação total robótica;

- Estabelecer rotinas operacionais de campo para a automação e controle de todos os procedimentos de medições, utilizando as estações robóticas aplicadas ao monitoramento;

- Desenvolver rotinas para o estabelecimento de uma rede topográfica absoluta externa ao corpo estrutural, para ser usada como estrutura de referência para a medição dos deslocamentos do corpo estrutural em análise; 
- Verificar a estabilidade da rede topográfica durante o processo de monitoramento e verificar a sensibilidade da mesma para o monitoramento de pontos externos à rede a partir de descolamentos controlados dos mesmos;

- Desenvolver rotinas computacionais, utilizando a plataforma MATLAB (MATrix $L A B o r a t o r y)$ com a finalidade de organização, armazenamento, processamento e análise dos dados de observações realizadas;

- Analisar e comparar as coordenadas espaciais e suas respectivas precisões obtidas com os três métodos validados, utilizando-se diferentes tipos de alvos e as rotinas desenvolvidas para o uso das estações totais robóticas.

\subsection{Justificativa}

São inúmeras as justificativas que motivam o desenvolvimento de pesquisas relacionadas à auscultação estrutural, mas, deve-se, principalmente, à extrema relevância das consequências que podem resultar da falência de uma estrutura civil de grande porte. As fatalidades decorrentes dessas falências, além de comprometer a segurança pública e ambiental, geram perdas econômicas significativas, tornando o conhecimento preciso do comportamento dessas estruturas indispensáveis para o planejamento de manutenções e realização de melhorias das mesmas, prevenindo ou até mesmo evitando grandes desastres. (GAIRNS, 2008)

Grandes tragédias abalaram o mundo no último século e foram inúmeros os acidentes ocorridos que ceifaram milhares de vidas. No Brasil, acontecimentos recentes em obras de engenharia repercutiram e expuseram a real necessidade de monitorá-las. Dentre tais acontecimentos, podem-se citar:

- Deslizamento de terra devido ao rompimento de muros de arrimos e paredes de ancoragem no canteiro de obras da Estação Pinheiros, da linha 4 do metrô da cidade de São Paulo, onde foi aberta uma cratera de 80 metros de diâmetro por 30 metros de profundidade. Estima-se que o prejuízo para a seguradora da obra pode ter passado de $\mathrm{R} \$ 1$ bilhão; (FOLHA DE SÃO PAULO, 2007) 
- Rompimento da Barragem de Algodões I, localizada na cidade de Cocal - PI, sendo que a enxurrada provocada pelo rompimento afetou a região urbana, onde houve mortes, 120 casas foram destruídas e por volta de 3.000 pessoas foram afetadas diretamente, além de causar um dano incalculável oriundo do desastre ambiental ocorrido; (ESTADO DE SÃO PAULO, 2009)

- Queda da ponte na região central do Rio Grande do Sul, onde a estrutura foi rompida pela força da correnteza do rio Jacuí, provocando mortes e interdições na rodovia estadual RSC-287. (ESTADO DE SÃO PAULO, 2010)

Por outro lado, vale a pena ressaltar o fato de os levantamentos topográficos serem, tradicionalmente, uma tarefa de trabalho intensivo e altamente dependente da habilidade do operador. Fatos esses que destacam a necessidade do desenvolvimento de técnicas e métodos de medição que minimizem a ação do operador e automatizem a coleta de dados.

Ao longo do tempo, houve inúmeros avanços tecnológicos na construção de equipamentos topográficos. Como exemplo, pode-se citar o aparecimento das estações totais que, além de medirem direções angulares horizontais e ângulos verticais, passaram a incorporar a medição de distâncias coaxialmente com a luneta. O próximo passo foi a busca da automação, ou seja, isentar o operador de realizar o apontamento do centro do retículo do telescópio do instrumento até o centro do alvo, de forma precisa e acurada. Os desenvolvimentos recentes nesse setor solucionaram esse problema, agregando aos equipamentos, dispositivos servomotores e compensadores precisos que, combinados ao recurso de Reconhecimento Automático de Alvos (ATR - Automatic Target Recognition), possibilitaram alcançar um elevado nível de automatização. Dessa maneira, criou-se uma nova geração de estações totais, as Estações Totais Robóticas. (CHRZANOWSKI, 1992)

Nestes termos, a presente pesquisa pretende testar as vantagens das estações totais robóticas, quando utilizadas no monitoramento de estruturas. 


\subsection{Estrutura da dissertação}

Esta dissertação desenvolve-se ao longo de seis capítulos. No capítulo introdutório, caracteriza-se a relevância da pesquisa, o objetivo principal e os específicos, a justificativa e a estruturação do trabalho por completo. No segundo capítulo, são descritos os instrumentos utilizados, os níveis de automação e os principais erros inerentes ao uso desses equipamentos de mensuração. $O$ terceiro capítulo traz o embasamento teórico desta pesquisa, enfatizando-se os principais sistemas de monitoramento de estruturas, os métodos e técnicas de mensuração aplicados à auscultação estrutural, seguidos dos principais métodos de determinação de coordenadas espaciais. No quarto capítulo, apresenta-se a metodologia e, em seguida, os procedimentos de campo desenvolvidos para a implantação da rede de referência e para a determinação das coordenadas espaciais pelo Método das Distâncias Mínimas e pelo Método Polar. No quinto capítulo, apresentam-se as análises comparativas finais considerando os resultados obtidos na aplicação de cada método validado. No sexto e último capítulo, são mostradas as conclusões desta pesquisa e as recomendações para trabalhos futuros, finalizando com as referências bibliográficas seguidas dos Apêndices e Anexos. 


\section{INSTRUMENTOS DE MENSURAÇÃO}

Apresentam-se, neste capítulo, todas as características e funcionalidades dos equipamentos utilizados nesta pesquisa e ressalta-se a importância dessa instrumentação, com destaque para os fatores que influenciam na qualidade da coleta de dados e para os níveis operacionais de automação e controle. São abordados também os principais erros instrumentais, especificamente, aqueles inerentes às funções automáticas e robóticas.

\subsection{Introdução}

Está cada vez mais frequente em realizações práticas de projetos topográficos o uso de estações totais e de seus respectivos acessórios, tais como, tripés, bases nivelantes, trenas, prismas e adesivos refletores, além de equipamentos auxiliares que complementam a operacionalidade do levantamento, a exemplo de instrumentos metereológicos, os quais fornecem dados de condições ambientais no momento das observações, com intuito de corrigir efeitos sobre as medidas.

A qualidade das observações realizadas por esses instrumentos estão diretamente relacionadas à utilização dos equipamentos de um modo técnico correto e eficiente, à acurácia e ao respectivo desvio padrão ${ }^{1}$ do equipamento. Normalmente, o fabricante fornece os dados em suas especificações técnicas, informando também a norma seguida, a exemplo do Instituto Alemão para Normatização (DIN - Deutsche Institut für Normung) ou da Organização Padrão

\footnotetext{
${ }^{1}$ Desvio padrão é a medida mais comum da dispersão estatística (representado pelo símbolo sigma, $\sigma$ ).
} Ele mostra o quanto de variação ou "dispersão" existe em relação à média (ou valor esperado). Um baixo desvio padrão indica que os dados tendem a estar próximos da média; um desvio padrão alto indica que os dados estão espalhados por uma gama de valores. GEMAEL (1994) 
Internacional (ISO - International Organization for Standardization) utilizada para tal determinação.

Segundo a norma NBR13133/94, a qual regulamenta a execução de levantamento topográfico no Brasil, a classificação das estações totais, segundo suas precisões, é dada de acordo com a Tabela 1.

Tabela 1 - Classificação de estações totais

\begin{tabular}{ccc}
\hline Classes & Precisão angular & Precisão linear \\
\hline 1 - Precisão baixa & $\leq \pm 30 "$ & $\pm(5 \mathrm{~mm}+10 \mathrm{ppm} \times \mathrm{D})$ \\
2 - Precisão média & $\leq \pm 7 ”$ & $\pm(5 \mathrm{~mm}+5 \mathrm{ppm} \times \mathrm{D})$ \\
3 - Precisão alta & $\leq \pm 2 ”$ & $\pm(3 \mathrm{~mm}+3 \mathrm{ppm} \times \mathrm{D})$ \\
\hline
\end{tabular}

Fonte: ABNT - NBR 13133/94

Sendo:

$\mathrm{D}$ = Distância medida em quilômetro $(\mathrm{Km})$;

ppm = Parte por milhão.

Ainda em conformidade com a NBR13133/94, as revisões e aferições devem ocorrer de forma constante nestes instrumentos. Dessa forma, todos medidores eletrônicos de ângulos e distâncias devem ser retificados e/ou calibrados, no máximo, a cada dois anos, em instituições oficiais e/ou universidades, com expedição de certificado de calibração, buscando-se assim, garantir a integridade operacional destes instrumentos, o que gera confiabilidade nas observações realizadas em todos os procedimentos.

Obedecendo aos requisitos dessa norma, para a execução desta pesquisa, os dois instrumentos robóticos envolvidos passaram por verificações e ajustes. Como pode ser visto no certificado de serviço efetuado em outubro de 2011 na Estação Total TCRA 1201+ pela LEICA Geosystems AG em Heerbrugg na Suíça, o qual se encontra no Anexo A. Além dos demais certificados realizados em outubro de 2012 
nas duas estações TCA 1201+ e TCRA 1021+ pela Comercial e Importadora Wild Ltda., os quais constam respectivamente nos Anexos B e C. É importante ressaltar que tal empresa é qualificada como Centro de Serviço Autorizado de Fábrica, e segue um sistema de gerenciamento em conformidade com os padrões da ISO 9001: 2008 / ISO 14001: 1996 (Reg. № 10471-8).

\subsection{Instrumentos e softwares utilizados}

Para o desenvolvimento desta pesquisa, foram disponibilizados pelo Laboratório de Mensuração do Departamento de Engenharia de Transportes da Escola de Engenharia de São Carlos os seguintes instrumentos e softwares:

- Estação Total Robótica (LEICA Geosystems), da série profissional TPS1200+ (Total Station Positioning System), modelo TCA (Theomat Coaxial Automated Total Station), do tipo 1201+, que possui precisão angular de 1", precisão linear de $2 \mathrm{~mm}+2 \mathrm{ppm}$, dispositivos de automação e servomotores (LEICA, 2007). Vide Figura 1.

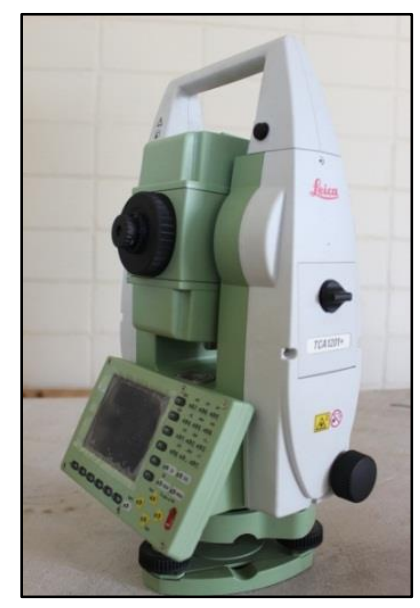

Figura 1 - Estação Total TCA 1201+

- Estação Total Robótica (LEICA Geosystems), da série profissional TPS1200+, modelo Theomat Coaxial Automated Reflectorless Total Station (TCRA), tipo $1201+\mathrm{R} 400$, que possui precisão angular de 1", precisão linear de 
$2 \mathrm{~mm}+2 \mathrm{ppm}$, dispositivos de medições sem alvos refletores, dispositivos de automação e servomotores (LEICA, 2007). Vide Figura 2.

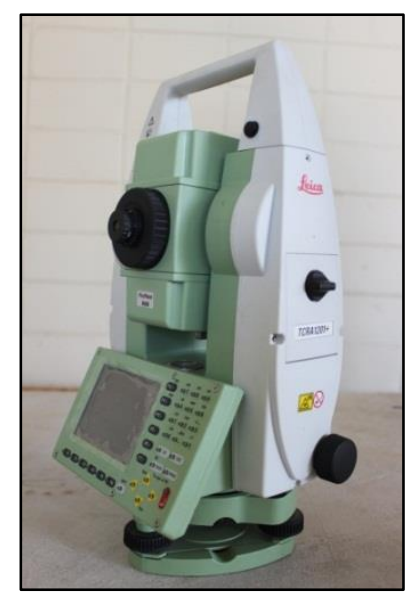

Figura 2 - Estação Total TCRA 1201+

- Dois Tripés Industriais de centragem forçada para o suporte das estações totais. Vide Figura 3.

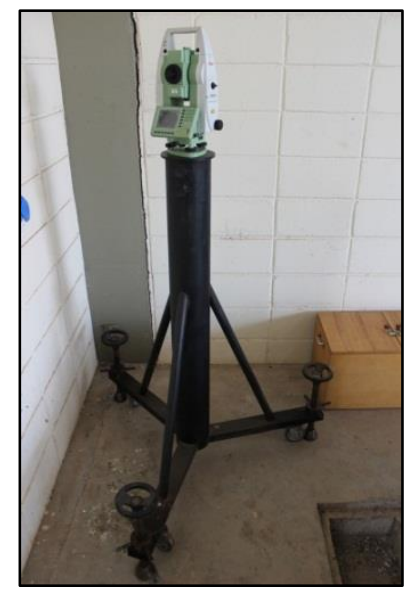

Figura 3 - Tripé Industrial

- Acessórios gerais para o suporte dos prismas e das estações totais. Ilustrado pela Figura 4, sendo então:

- Seis bases nivelantes de alta precisão sem prumo óptico, adequado para altos requisitos de precisão angular - GDF121. 
- Seis conectores entre prismas com suporte e bases nivelantes, denominado Carrier - GRT144.

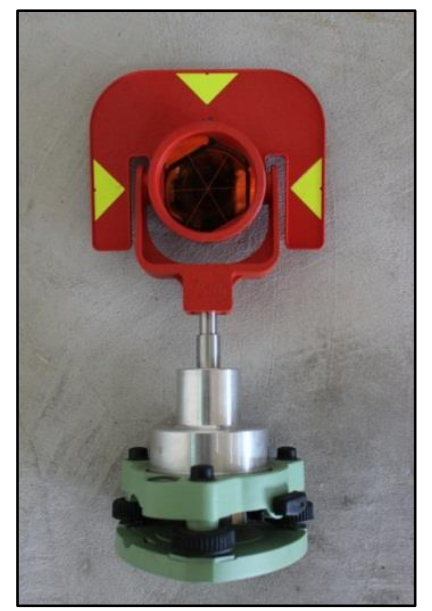

Figura 4 - Jogo composto por base nivelante, Carrier e prisma GPR-111

- Três bases de ferro estrutural para compor a rede absoluta e, posteriormente, serem utilizadas como pontos de controle e verificação de estabilidade dos dois tripés industriais, conforme ilustra a Figura 5.

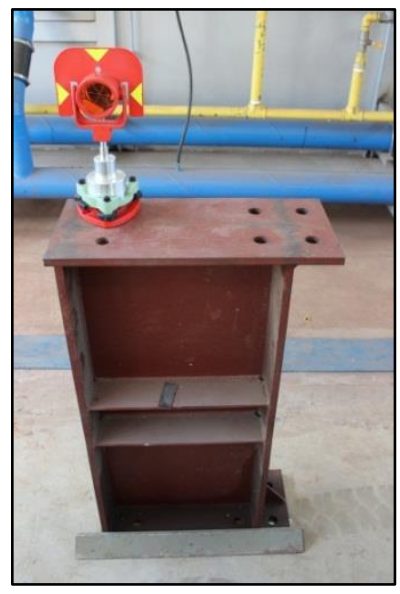

Figura 5 - Base de ferro estrutural

- Seis modelos diferentes de alvos refletores da série profissional Leica, conforme indicado na Tabela 2. 
Sendo:

- Sete prismas circulares de plástico com placa-alvo e suporte para Carrier integrado - GPR111;

- Um miniprisma montado em suporte de plástico incluindo nível de bolha circular (fixação com rosca de 1/4") - GMP111-0;

- Um miniprisma $360^{\circ}$, adequado para aplicações de curto alcance e multidirecionais, que devido ao seu pequeno tamanho, proporciona facilidades na montagem em espaços reduzidos (fixação com rosca de 1/4") - GRZ101;

- Um miniprisma de metal para monitoramento de estruturas com esquadro em "L" para fixação em estruturas - GMP104;

- Um prisma de monitoramento de grande diâmetro para medições de longo alcance, o qual contém ação contra condensação no filtro da superfície refletora (fixação com parafuso de rosca 5/8") - GPR112;

- Uma fita refletiva e autoadesiva com dimensão de $60 \times 60 \mathrm{~mm}$, para medições inferiores a 250 m - GZM31.

Tabela 2 - Modelos de alvos usados na Pesquisa

\begin{tabular}{lllllll}
\hline Modelos & GPR111 & GMP111-0 & GRZ101 & GMP104 & GPR112 & GZM31 \\
Imagens & & & & & & \\
\hline Constantes & $0,0 \mathrm{~mm}$ & $0,0 \mathrm{~mm}$ & $30,0 \mathrm{~mm}$ & $8,9 \mathrm{~mm}$ & $-7.1 \mathrm{~mm}$ & $34,4 \mathrm{~mm}$ \\
\hline
\end{tabular}

Fonte: Leica (2010) 
- Conjunto de montagem para fixação dos prismas (GRZ101, GMP104, GMP111-0 e GPR112) com adaptadores de rosca interna 5/8" e ajuste multidirecional para alvos - GHT112. Vide Figura 6.

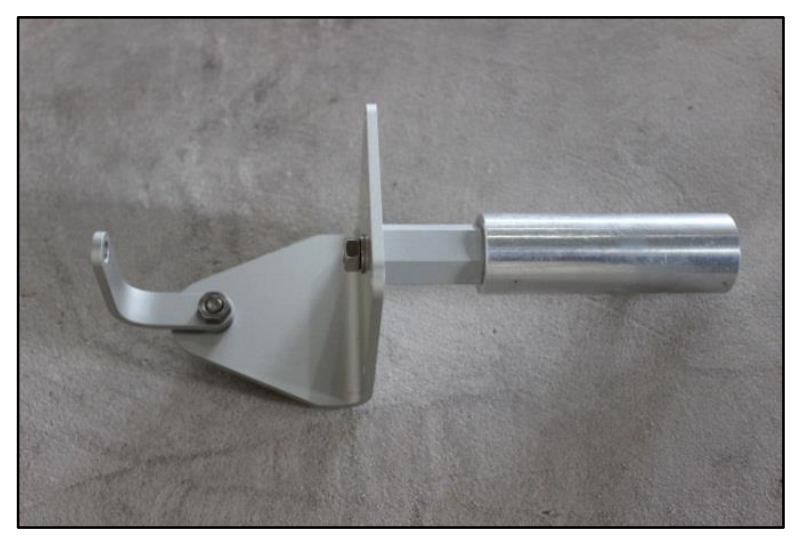

Figura 6 - Adaptador para diferentes tipos de alvos

Também foram projetados e desenvolvidos no Laboratório de Mensuração, os seguintes equipamentos:

- Um suporte com dispositivo ajustável para fixação e deslocamento controlado de alvos com escala milimétrica, conforme ilustrado na Figura 7 . Ver projeto completo no Anexo D.

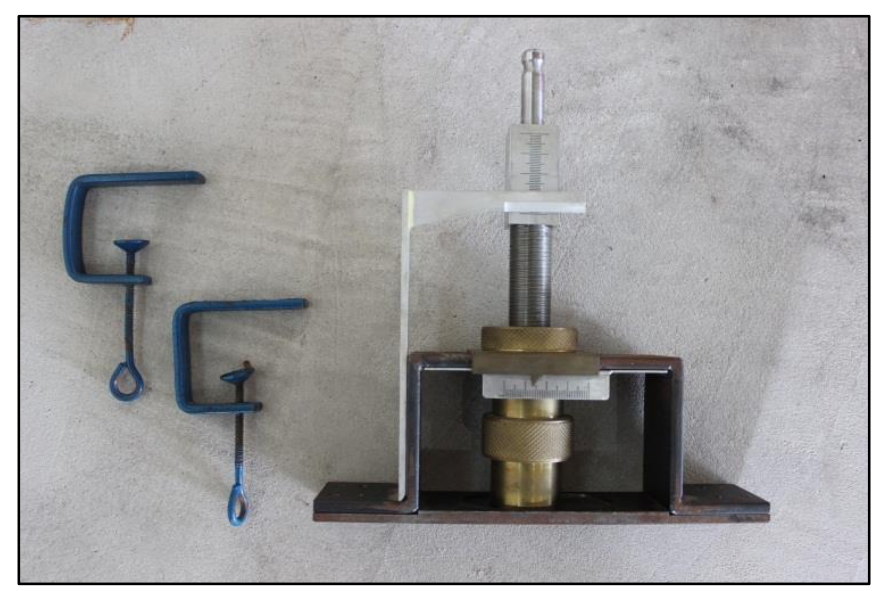

Figura 7 - Suporte para alvos com dispositivo de controle milimétrico

- Adaptador para Carrier e colagem de fitas refletoras. Vide Figura 8. Ver projeto completo no Anexo E. 


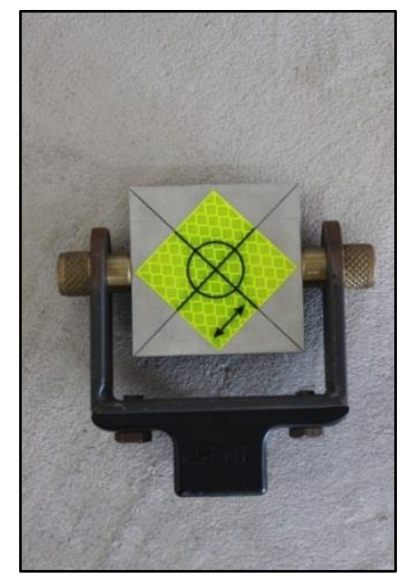

Figura 8 - Adaptador para Carrier e colagem de fitas refletivas

O laboratório disponibilizou ainda os seguintes instrumentos:

- Psicrômetro giratório com enchimento de mercúrio e escala interna, para coleta da umidade relativa do ar e temperatura local. Vide Figura 9. Barômetro para a medição da pressão atmosférica. Vide Figura 10.

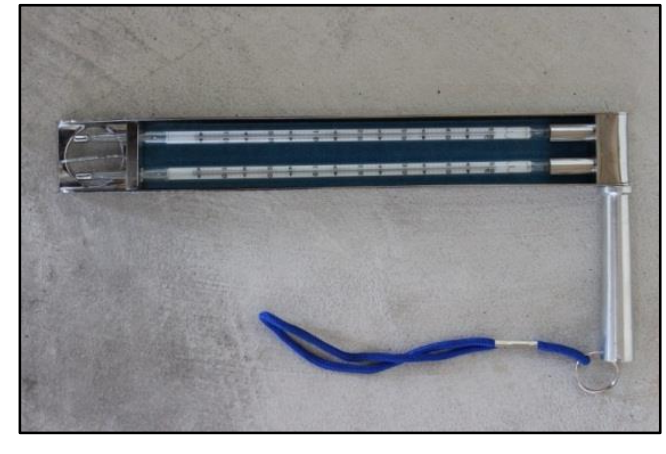

Figura 9 - Psicrômetro giratório

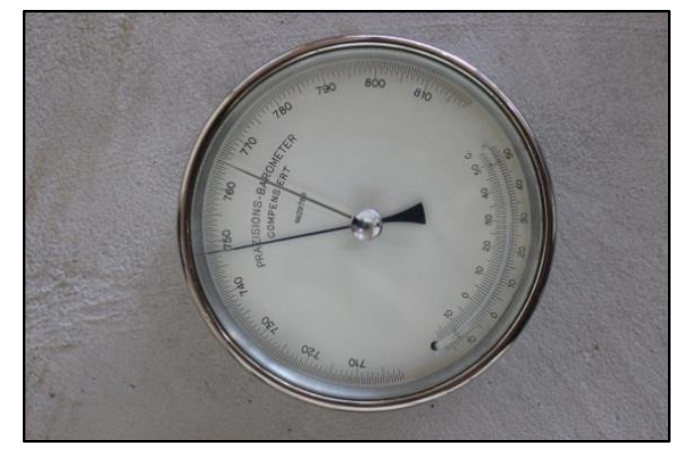

Figura 10 - Barômetro 
- Dois cartões compact flash para armazenamento dos dados coletados em campo e um leitor de cartões com saída para Universal Serial Bus (USB), como mostra a Figura 11.

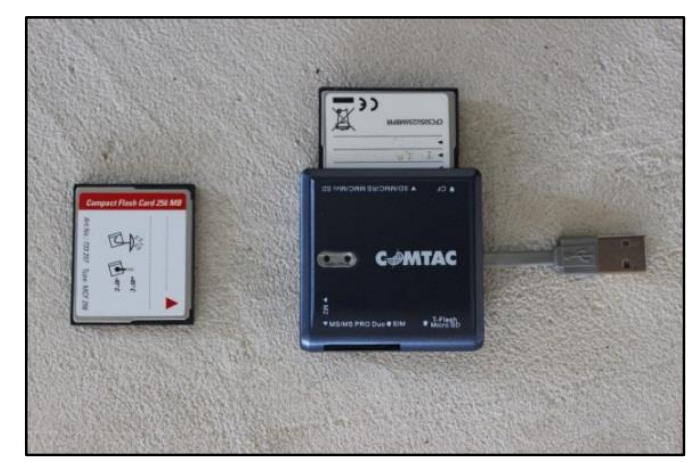

Figura 11 - Cartões compact flash e seu leitor

- Um software MATLAB (MATrix LABoratory) versão 7.6.0.324 (R2008a) elaborado pela The MathWorks Incorporation para a implementação de soluções por meio do desenvolvimento de rotinas computacionais neste ambiente que, segundo Matsumoto (2008) integra:

- Biblioteca de funções matemáticas extremamente eficientes em processamento numérico baseado em matrizes;

- Recursos de geração, visualização e análise dos dados;

- Linguagem de programação de alto nível;

- Interface de troca de dados com sistemas externos (Ex.: Excel).

- Um software LEICA Geo Office (LGO) versão 5.0 desenvolvido por LEICA Geosystems AG para descarga dos dados observados em campo pelas estações totais robóticas. 


\subsubsection{Estação Total Robotizada Leica Theomat Coaxial Automated Total Station (TCA) 1201+}

Conforme o estabelecido pela NBR13133/94, esse equipamento é classificado como de alta precisão, e por suas numerosas funcionalidades e tecnologias disponíveis, podemos considerá-la de alto desempenho, fator crucial para a realização de monitoramentos estruturais, os quais necessitam de posicionamentos com elevado nível de precisão.

As funcionalidades disponíveis nesse equipamento incluem: intercâmbio de dados entre o computador e o instrumento, gestão de dados, incluindo visualização e edição, criação e gestão de listas de códigos, formatação e conversão de dados, carregamento de softwares opcionais de sistema e programas de aplicações específicas que necessitam ser adquiridos do fabricante e podem ser ativados por meio de senhas.

Os componentes e as funções padronizadas de seu sistema estão descritas a seguir:

- Motores internos que permitem a rotação do equipamento no plano vertical e horizontal, qualificando-o como um instrumento motorizado e robótico;

- Reconhecimento Automático de Prisma (ATR) que diz respeito ao sensor interno do instrumento, o qual permite que o mesmo reconheça e desloque a luneta com precisão para um alvo devidamente posicionado. O equipamento realiza essa busca de alvos a partir de um processo de varredura controlado por uma janela de limitação angular vertical e horizontal. Devido à disponibilidade do recurso ATR, esse tipo de equipamento é considerado como sendo um equipamento automático. 
Segundo o Manual de Referência Técnica (LEICA, 2007):

O sensor ATR emite um feixe de laser invisível até o alvo e não são necessários alvos ativos emitindo sinais especiais. Este sinal é refletido pelo alvo e recebido por um sensor de imagem interna, um chip conhecido como Dispositivo de Carga Acoplada (CCD - Charge-Coupled Device) de alta resolução que realiza o processamento digital de imagens (feixe de laser de infravermelhos), ou seja, a intensidade do ponto e as características da luz refletida são calculadas com referência ao centro do sensor $C C D$, e as componentes de afastamento nos planos vertical e horizontal são calculadas em relação a este ponto de referência. Assim, os afastamentos são utilizados para controlar os motores dos eixos telescópicos, que imediatamente posiciona o retículo do equipamento muito próximo do centro do alvo. Para acelerar este processo, o posicionamento é realizado com uma tolerância angular de 16 " do verdadeiro centro do alvo.

Por fim, os mínimos afastamentos restantes são aplicados matematicamente aos ângulos horizontal e vertical, reforçando assim que esses são medidos para o centro do prisma, mesmo que a mira não se destine precisamente ao centro desse alvo. Vide Figura 12.

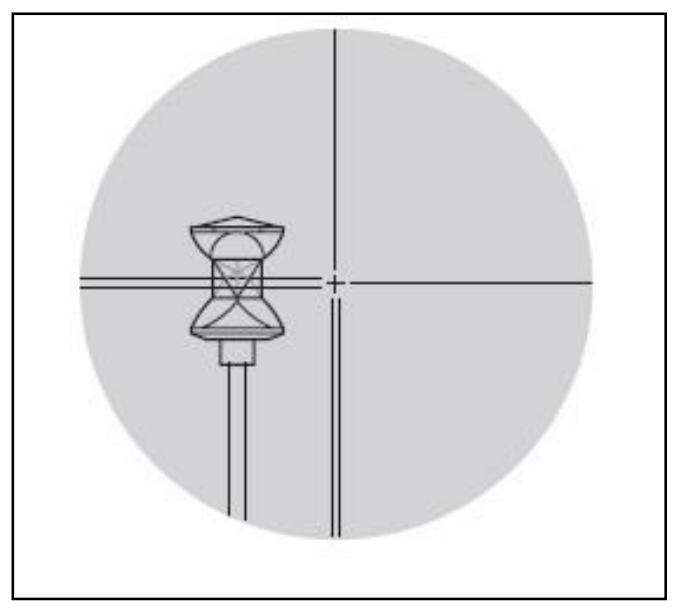

Figura 12 - Posicionamento automático do alvo ATR Fonte: Leica (2007, p.615)

- Outra ferramenta operacional importante do equipamento é a função ATR no modo Lock. A partir dessa função o equipamento mantém a sua luneta fixa na direção do alvo mesmo que este esteja em deslocamento. Após realizar a busca e encontrar o alvo, o instrumento é travado neste alvo e passa a rastreá-lo. 
Além das funções indicadas acima, foram disponibilizados pelo Laboratório de Geomática do STT, os seguintes programas aplicativos:

- Programa Série de Ângulos (Set of Angles), que realiza medições de direções e distâncias para alvos em série. Neste programa, ainda pode-se incluir o módulo de monitoramento como uma opção e, assim, também é usado para medir múltiplos conjuntos de ângulos e distâncias em relação aos pontos a serem observados. Sua operação é limitada por no minímo dois alvos e dois conjuntos de séries de ângulos.

- Monitoramento (Monitoring) destina-se à repetição automática de medições para alvos definidos, em intervalos de medições previamente definidos. Sua utilização é ideal para aplicações de monitoramento em pequena escala, sem a necessidade de um computador fixo no ponto de referência. Este módulo, quando integrado ao programa série de ângulos, torna possível usar um timer para permitir leituras repetidas e automatizadas de observações de direções e distâncias a alvos predefinidos em intervalos definidos. Vide Figura 13.

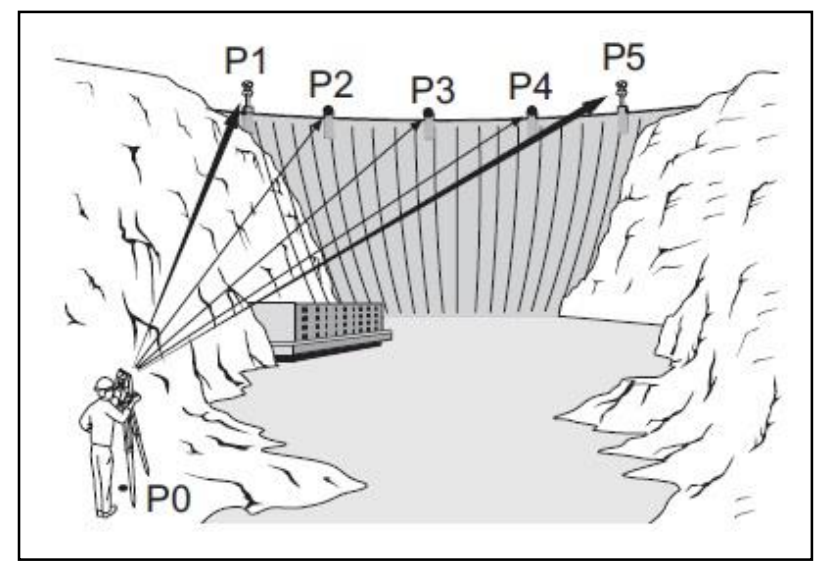

Figura 13 - Série de ângulos e monitoramento estrutural Fonte: Leica (2007, p. 1053) 


\subsubsection{Estação Total Robotizada Leica Theomat Coaxial Reflectorless Automated Total Station (TCRA) 1201+}

As características técnicas deste equipamento são praticamente idênticas ao modelo (TCA 1201+), apresentado no item 2.2.2. A única diferença entre os dois equipamentos é que, neste caso, o equipamento permite realizar medições sem alvo refletor. Daí o atributo Reflectorless.

Para efetuar a medição sem prisma o equipamento possui a função PinPoint $R 400$, a qual emite um feixe de raio laser infra-vermelho visível e coaxial com a objetiva da luneta, proporcionando uma colimação rigorosa sobre o alvo. A distância é medida através de uma técnica de analisador de sistema, que utiliza frequências moduladas na gama de $100 \mathrm{MHz}$. As propriedades do sistema analisador são definidas para cada uma das medições individuais para ambos os feixes do medidor eletrônico de distâncias e as características do alvo.

Com o resultado do sistema de análise, os parâmetros para cada medição individual são conhecidos e a distância, enfim é calculada no processamento de sinal, com base no princípio da máxima probabilidade de ocorrência e/ou estimativas de máxima verossimilhança, o Maximum Likelihood Estimators (MLE). E, segundo Myers et al. (2002), a ideia por trás desta estimativa de máxima verossimilhança é fundamento para determinar os parâmetros que maximizam a probabilidade dos dados da amostra, além disso, aplicam-se métodos estatísticos eficientes para quantificar a incerteza através de limites de confiança. (LEICA, 2008)

A Tabela 3 apresenta algumas das características técnicas mais relevantes dos instrumentos: 
Tabela 3 - Principais características da RTS da série TPS do tipo 1201+

\begin{tabular}{ccc}
\hline Ângulos & Resolução do visor & $0.1 "$ \\
\hline Compensador Biaxial & Exatidão de estabilização & $0.5^{\prime \prime}$ \\
\hline Distâncias & Desvio-padrão (ISO 17123-4) & $2 \mathrm{~mm}+2 \mathrm{ppm}$ \\
\hline Mira Telescópica & Ampliação & $30 \mathrm{x}$ \\
\hline Nível & Resolução do nível eletrônico & $2 "$ \\
\hline Servomotor & Velocidade de rotação & $45 \% / \mathrm{s}$ \\
\hline ATR & Alcance máximo & $1.000 \mathrm{~m}$ \\
& Alcance mínimo & $1.5 \mathrm{~m}$ \\
& Velocidade máxima (modo LOCK) & $5 \mathrm{~m} / \mathrm{s} \mathrm{a} \mathrm{20} \mathrm{m}$ \\
& & $25 \mathrm{~m} / \mathrm{s}$ a $100 \mathrm{~m}$ \\
\hline
\end{tabular}

\subsection{Automação e controle das observações}

De acordo com Natale (1995), a palavra automação está diretamente ligada ao controle automático, ou seja, ações que não dependem da intervenção humana. Este conceito é discutível, porque a atuação do homem sempre será necessária, pois, sem ela, não seria possível a construção e implementação dos processos automáticos. Entretanto, não é o objetivo desta pesquisa este tipo de abordagem filosófica ou sociológica.

Existem, ainda, os níveis de automação e controle, ou seja, fazer com que um procedimento manual torne-se semiautomático ou totalmente automático. E a automação somente é considerada completa, quando toda uma linha de produção ou processo produtivo funcione do começo ao fim sem a intervenção humana, agindo apenas pelo controle das próprias máquinas e por seus controladores (softwares). (ROSÁRIO 2005) 
Rosário (2005) ainda expõe que os sistemas automatizados podem ser aplicados a um simples equipamento ou em todo o processo produtivo. A diferença está no número de elementos monitorados e controlados. Estes podem ser simples válvulas ou servomotores, cuja eletrônica de controle é bem complexa. De uma forma geral, um processo a ser controlado, seja o sistema de pequeno, médio ou grande porte, tem o diagrama semelhante ao mostrado na Figura 14:

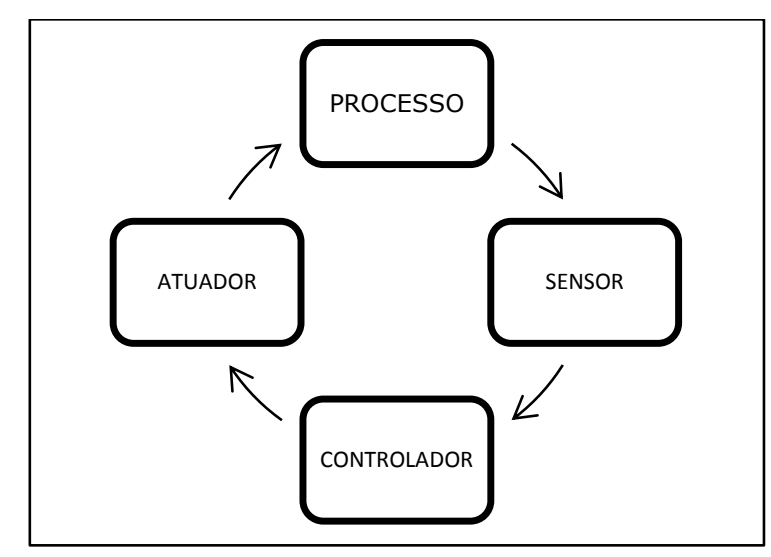

Figura 14 - Diagrama simplificado de um sistema de controle automático Fonte: Adaptado de Rosário (2005)

De acordo com o diagrama acima, os sensores são os elementos que fornecem informações sobre o sistema, correspondendo às entradas do controlador, e esses podem indicar variáveis físicas, como o apontamento com precisão para um alvo. Os atuadores são os dispositivos responsáveis pela realização do trabalho no processo ao qual está se aplicando a automação, podendo ser magnéticos, hidráulicos, pneumáticos, elétricos, servomotores ou de acionamento misto. Já o controlador, é o elemento responsável pelo acionamento dos atuadores, levando em conta o estado das entradas (sensores) e as instruções do programa inserido em sua memória, este elemento é denominado de Controlador Lógico Programável (CLP).

A automação e controle, em geral, são vastamente aplicados nas mais variadas áreas do conhecimento, objetivando melhoras na produtividade e qualidade nos processos considerados repetitivos. E são esses diferenciais que a presente pesquisa busca com a automação e controle do processo de monitorização de estruturas, utilizando-se das estações totais robóticas, que dispõem das respectivas 
vantagens funcionais e operacionais, como o ATR, o monitoramento e a série de ângulos, que oferecem aumento na velocidade das medições repetitivas, além de uma precisão de medição que independe do observador. (MORAES, 2001)

Considera-se, ainda, que na mensuração, a automação e controle estão presentes em diferentes estágios do trabalho, porém, o grau de automação de cada estágio pode ser variável. Dessa maneira, Veiga (2006) conclui: "Independente do grau de automatização, o objetivo final é comum: que a intervenção do operador seja a mínima possível, da coleta dos dados brutos até a representação final da área levantada".

\subsection{Principais erros instrumentais}

Conforme visto no item 2.1, para todo trabalho de mensuração, em especial os que buscam resultados com alta precisão, como é o caso de levantamentos destinados à auscultação estrutural, exigem que os instrumentos de medição estejam devidamente retificados e calibrados, pois existem alguns erros instrumentais que podem afetar a acurácia e a precisão das observações, podendo vir a comprometer o trabalho como um todo.

Dentre estes erros, destacam-se:

- Erro de eixos:

- Erro de horizontalidade do eixo secundário ou erro de basculamento;

- Erro de colimação horizontal ou erro da linha de visada;

- Erro de verticalidade do eixo principal.

- Erro de excentricidade dos círculos;

- Erro de índice do círculo vertical ou erro de colimação vertical;

- Erro de desvio e índice do compensador; 
- Erro devido à refração;

- Erro de colimação do ponto zero ATR.

Os referidos erros podem ser corrigidos, minimizados e compensados de diferentes maneiras, realizando-se verificações e ajustes por meio de modelagens matemáticas, de ajustamento eletrônico e de ajustamento mecânico. O primeiro está disponível em toda série TPS, e é denominado ajustamento combinado, por determinar os erros do instrumento em um só procedimento. Já, o segundo, compete às componentes mecânicas do instrumento, como o nível de bolha e o prumo laser. Entretanto, para a presente pesquisa, será apresentado em detalhe somente o erro relacionado à função automática ATR, conforme segue.

O erro de colimação do ponto zero ATR, corresponde a não coincidência da pontaria até o alvo com o centro do mesmo, em outras palavras, este erro é a divergência angular entre a linha de visada, o que significa a direção em que se efetua a mira dos pontos, e o eixo do sensor CCD, o qual detecta o centro do prisma.

Deve-se considerar, entretanto, que mesmo após um correto ajustamento do ATR, os fios reticulados podem não ficar posicionados exatamente no centro do prisma, após a realização de uma medição em modo ATR, como pode ser visto na Figura 15. Trata-se de uma ocorrência normal para acelerar as medições no modo ATR e, como visto anteriormente no item 2.2.1, os ângulos são corrigidos duas vezes, sendo primeiramente determinados os erros ATR para os planos e, depois, os pequenos desvios individuais de pontaria. (LEICA, 2009)

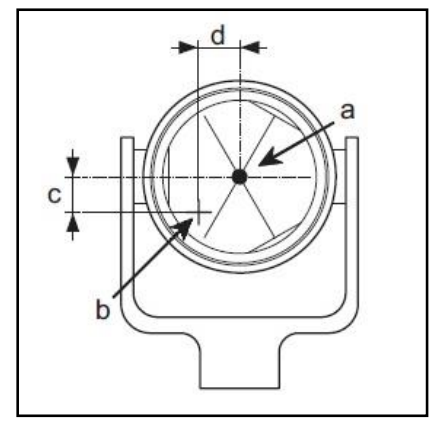

Figura 15 - Erros de colimação da função automática ATR Fonte: Leica (2007, p. 537) 
Sendo:
a) Centro do prisma
b) Fio reticulado
c) Erro de colimação da componente vertical do ATR
d) Erro de colimação da componente horizontal do ATR 


\section{REVISÃO BIBLIOGRÁFICA}

Neste capítulo expõem-se os conceitos relevantes de toda a fundamentação teórica utilizada para a realização desta pesquisa. Inicialmente, são mostrados os sistemas mais usuais para monitorar estruturas. Em seguida, são abordados métodos clássicos de levantamentos topográficos, contendo alguns conceitos e definições. $E$, ao final, são apresentados os principais métodos e técnicas de cálculo para a determinação de coordenadas espaciais.

\subsection{SISTEMAS DE MONITORAMENTO DE ESTRUTURAS}

\subsubsection{Introdução}

O monitoramento de estruturas pode fornecer dados que possibilitam refinar modelos e normas existentes para a construção e manutenção de obras de engenharia, além da geração de novos modelos para auxiliar a compreensão de problemas ocorridos e antecipação de ocorrências futuras.

Tais fatos impulsionam e motivam diversos ramos do conhecimento e de pesquisa. Dessa maneira, o interesse e a preocupação em monitoramento de estruturas têm aumentado significativamente ao longo das últimas décadas e isto pode ser confirmado ao se verificar o crescente número de publicações relacionadas a este assunto. Nesse sentido, têm-se como exemplos, Chen (1983), Chranowski (1992), Chaves (1994), Chaves (2001), Larocca (2004), Granemann (2005), Gairns (2008), dentre outros.

Em conformidade com Chen e Chrzanowski (1986), as análises das variações estruturais podem ser realizadas, aplicando-se variados métodos, sendo que os mais utilizados são:

- Monitoramento físico;

- Monitoramento utilizando técnicas de mensuração. 
Para cada método de monitoramento estrutural apresentado, existem vantagens e desvantagens, assim, serão abordados a seguir aspectos relativos a cada um destes métodos.

\subsubsection{Monitoramento físico}

São técnicas de monitoramento de estrutura que estabelecem a implantação de diversos tipos de sensores ao longo do objeto estrutural; normalmente, esses sensores são engastados na estrutura durante a fase de construção, podendo também ser instalados após o término da obra e têm por finalidade detectar eventuais deformações oriundas de acomodações de tensões internas da estrutura, quanto de forças externas à mesma. (CHRZANOWSKI, 1992)

O Department Of The Army (2002) preconiza que as medições físicas realizadas no local da deformação são feitas utilizando-se dos seguintes equipamentos: inclinômetros, piezômetros, medidor triortogonal de junta, pêndulos, extensômetros, termômetros, fios de prumo, dentre outros. E afirma ainda que os instrumentos de monitoramento físico são de fácil adaptação para fins de monitoramento contínuo. Mas, um fator importante a ser lembrado neste tipo de monitoramento é o fato de as medições serem pontuais e relativas ao longo do tempo. Mesmo que os instrumentos encontrem-se fixados em pontos definidos e suas leituras verifiquem variações em diferentes épocas, essas leituras não são referenciadas a um sistema local de coordenadas ou qualquer outro sistema de referência, ou seja, proporcionam informações de deslocamentos pontuais, localizados e sem referência, dessa maneira, podem somente ser comparadas com outras medidas realizadas de forma independente.

Por exemplo, se considerarmos a instalação de um extensômetro na junção de dois blocos, será possível determinar um deslocamento relativo entre eles, mas não é possível determinar individualmente qual bloco deslocou. (DEPARTAMENT OF ARMY, 2002) 


\subsubsection{Monitoramento com técnicas de mensuração}

A realização de monitoramento de estruturas com técnicas de mensuração baseia-se no estabelecimento de uma rede de pontos interconectados por medições de ângulos e/ou distâncias. Esses pontos são considerados como referências absolutas e estáveis para a determinação das coordenadas espaciais de pontos selecionados sobre a superfície de qualquer corpo ou objeto e, assim, oferecem satisfatórias redundâncias de observações, permitindo o controle de qualidade por meio da detecção de erros e análises estatísticas. Tais resultados obtidos pelas técnicas de mensuração indicam se os alvos instalados em blocos distintos sofreram individualmente variações em suas coordenadas espaciais, o que caracteriza deformações ou deslocamentos da estrutura como um todo. (DEPARTMENT OF THE ARMY, 1994)

Da mesma forma, Chaves (1994, p.53) enfatiza que o método de monitoramento com técnicas de mensuração fornece o estado global de uma estrutura e contém o esquema próprio de verificar os resultados. Dessa forma, tal método é capaz ainda de avaliar a acurácia da medição globalmente, além de fornecer versatilidade e adequabilidade para qualquer ambiente e situação de operação, porém, é mais trabalhoso e demanda operadores capacitados, o que pode elevar os custos operacionais.

\subsection{MENSURAÇÃO APLICADA À AUSCULTAÇÃO DE ESTRUTURAS}

\subsubsection{Introdução}

A determinação de coordenadas utilizando-se de métodos e técnicas de mensuração, geodésica ou topográfica, segundo Kahmen e Faig (1994), está fundamentada basicamente em medições diretas de grandezas, como ângulos horizontais e verticais, distâncias e desníveis. A partir de tais mensurações é possível a realização de cálculos por meio de modelagens matemáticas. 
Com a finalidade de monitorar estruturas, os métodos e técnicas de mensuração utilizados nesta pesquisa foram: triangulação, trilateração, triangulateração, nivelamento trigonométrico, recessão e rede absoluta de referência.

\subsection{MÉTOdOS E TÉCNICAS DE MENSURAÇÃO APLICADOS}

\subsubsection{Triangulação}

A triangulação, ilustrada pela Figura 16, é um método clássico que permite a obtenção das coordenadas dos pontos que formam os vértices dos triângulos com elevada precisão e são utilizados para os mais variados trabalhos de engenharia. Segundo Anderson e Mikhail (1998), um sistema de triangulação consiste em uma série de triângulos justapostos ou sobrepostos, formados por meio de medições dos ângulos subentendidos para cada vértice dos triângulos; e as direções desse sistema formam uma rede que une todas as estações da triangulação nos vértices dos triângulos.

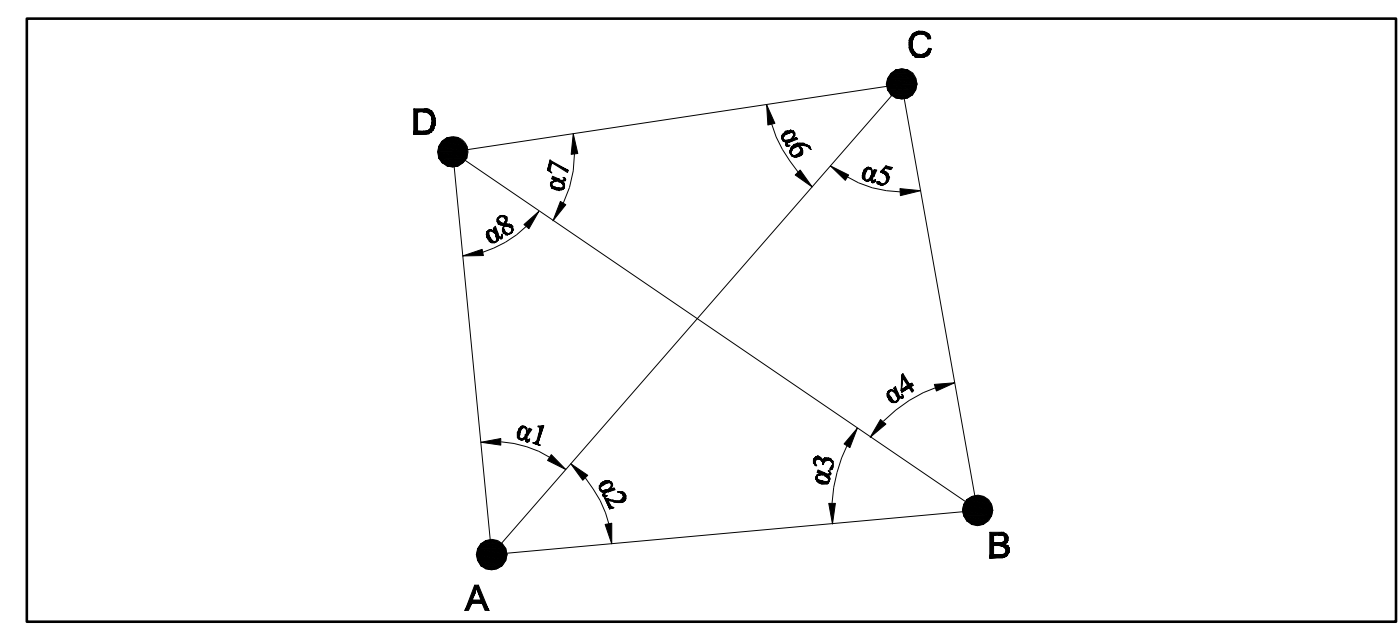

Figura 16 - Triangulação

Fonte: Adaptado de Anderson e Mikhail (1998)

Sendo:

$\alpha_{i}-$ Ângulos horizontais medidos. 


\subsubsection{Trilateração}

Outro método clássico é a trilateração, que também consiste em determinar as coordenadas dos vértices, utilizando-se de modelagens para solução de triângulos, porém, neste método, são as medições de distâncias entre os vértices da figura geométrica que fundamentam os cálculos. Kahmen e Faig (1994) ressaltam que, depois de 1956, com o advento dos medidores eletrônicos de distâncias, o método tornou-se viável devido a possibilidade de medir as distâncias com alto índice de precisão. Vide a Figura 17.

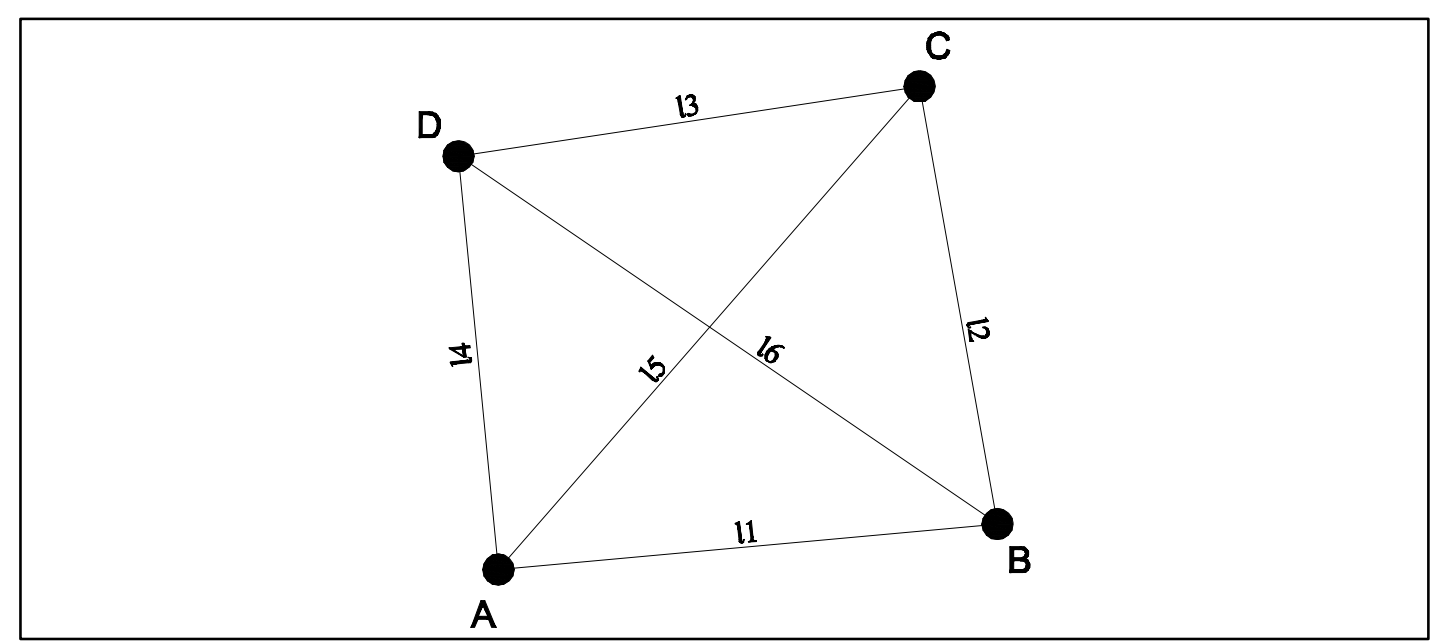

Figura 17 - Trilateração

Fonte: Adaptado de Anderson e Mikhail (1998)

Sendo:

$l_{i}$ - Distância entre os vértices.

\subsubsection{Triangulateração}

Tal método consiste na possibilidade de combinar a triangulação com a trilateração, para produzir um sistema de controle, no qual todos os ângulos e distâncias são observados, como ilustra a Figura18. Trata-se de um sistema mais completo que os mencionados anteriormente, por apresentar todas as vantagens de 
ambos, dos quais é derivado. Portanto, este fato traz significativas vantagens, como o aumento de parâmetros, de observações e, consequentemente mais redundância, o que facilita estimativas e detecção de possíveis erros, tornando o método mais acurado e preciso. (SCHOFIELD, 2001)

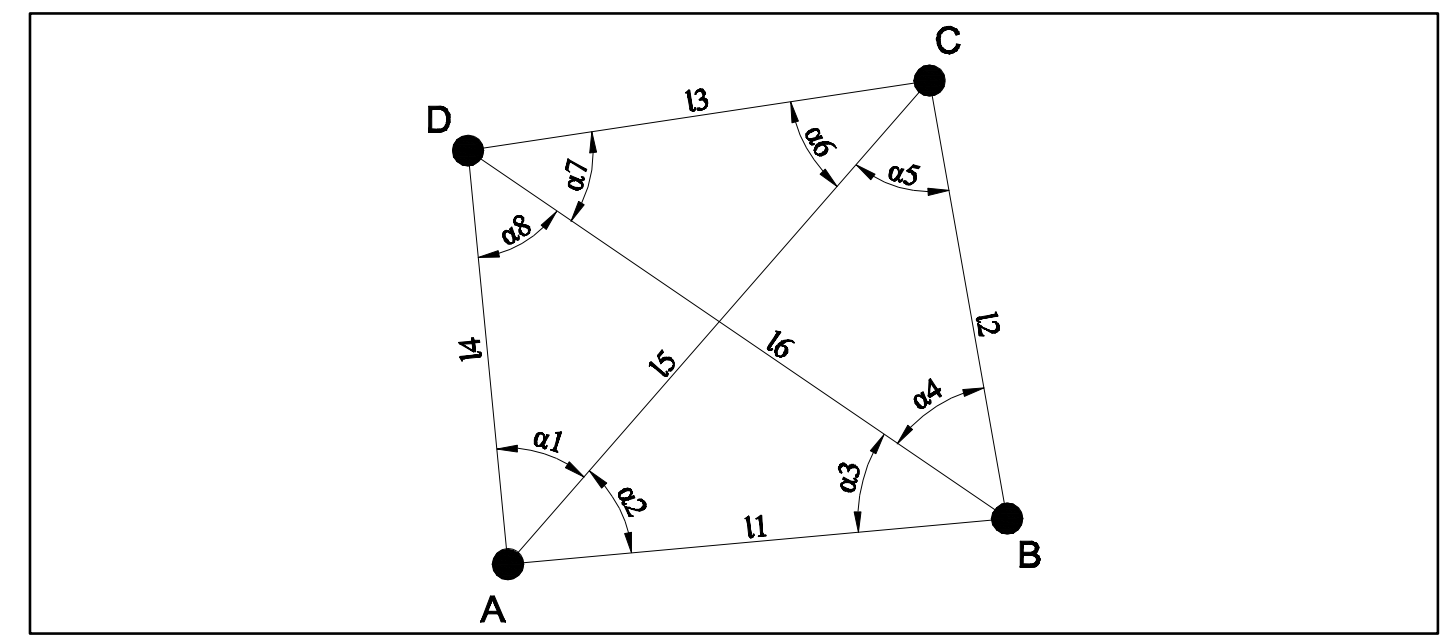

Figura 18 - Triangulateração

Fonte: Adaptado de Schofield (2001)

Sendo:

$\alpha_{i}-$ Ângulos horizontais medidos;

$l_{i}$ - Distância entre os vértices.

De acordo com Anderson e Mikhail (1998), esta metodologia vem sendo empregada extensivamente para estabelecer controle em levantamentos de mensuração. Nesse sentido, Kahmen e Faig (1994), recomendam sua utilização para o estabelecimento de estações bases de observações de referência para a realização de monitoramentos estruturais a partir de técnicas de mensuração.

\subsubsection{Nivelamento trigonométrico}

O nivelamento trigonométrico, como se pode ver na Figura 19, envolve medições de ângulos verticais zenitais ou de altura e distâncias horizontais ou inclinadas entre dois pontos. Essa operação visa à determinação da diferença de 
nível entre eles, por meio de consagrados modelos matemáticos da trigonometria. Sucintamente, a diferença de altura entre os pontos é obtida por meio da resolução de triângulos e, devido a isso, a elevação é determinada indiretamente. (SCHOFIELD, 2001)

De acordo com Kahmen e Faig (1994), com o advento das estações totais, o nivelamento trigonométrico tornou-se um método ágil, com precisão comparável àquela obtida por nivelamentos geométricos, nos quais se determinam as elevações diretamente. Mas, devem-se considerar influências de alguns fatores na propagação dos erros, como a obtenção da altura do instrumento, os efeitos atmosféricos, o posicionamento e altura dos alvos, a precisão dos equipamentos e as distâncias de visadas. Também, Moreira (2003), fundamenta que o nivelamento trigonométrico é uma técnica que tem crescido nos trabalhos de mensuração, pois este nivelamento é de precisão compatível com as tolerâncias estabelecidas pela NBR 13.133/94 para o nivelamento geométrico.

O nivelamento trigonométrico é, portanto, aceito para o estabelecimento de redes de controle vertical para trabalhos fotogramétricos, topográficos e pode ser utilizado como referência para a determinação de coordenadas altimétricas de pontos engastados em pontes, edifícios, barragens e outras grandes estruturas, com a finalidade de analisar as deformações estruturais em três dimensões. (ANDERSON e MIKHAIL, 1998)

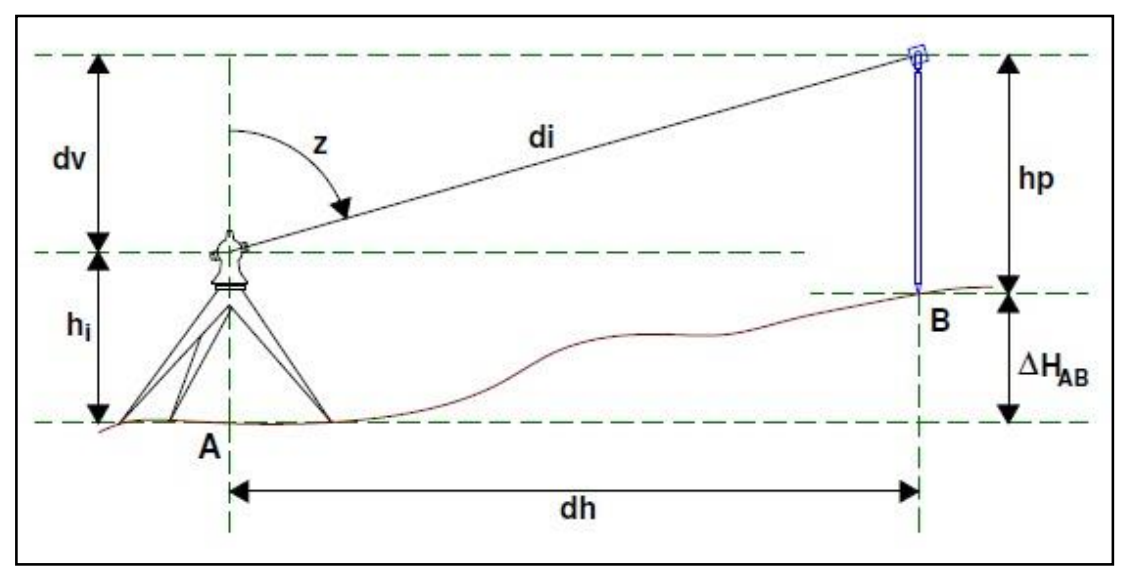

Figura 19 - Nivelamento trigonométrico Fonte: Kahmen e Faig (1994) 
Sendo:

di - Distância inclinada;

$d h$ - Distância horizontal;

$d v$ - Distância vertical entre o centro óptico do equipamento e o centro do alvo;

$Z$ - Ângulo vertical zenital;

$h i$ - Altura do instrumento;

$h p$ - Altura do alvo;

$\Delta H_{A B}$ - Desnível entre os pontos A e B.

\subsubsection{Recessão}

No método da recessão, o equipamento é instalado sobre um ponto, no qual as coordenadas devem ser determinadas e verificadas e, assim, são realizadas observações visando-se os pontos de referência. Para isso, é necessário que se efetue, no mínimo, a observação de três pontos de referência para a obtenção da solução matemática do problema, conforme ilustra a Figura 20. (KAHMEN e FAIG, 1994)

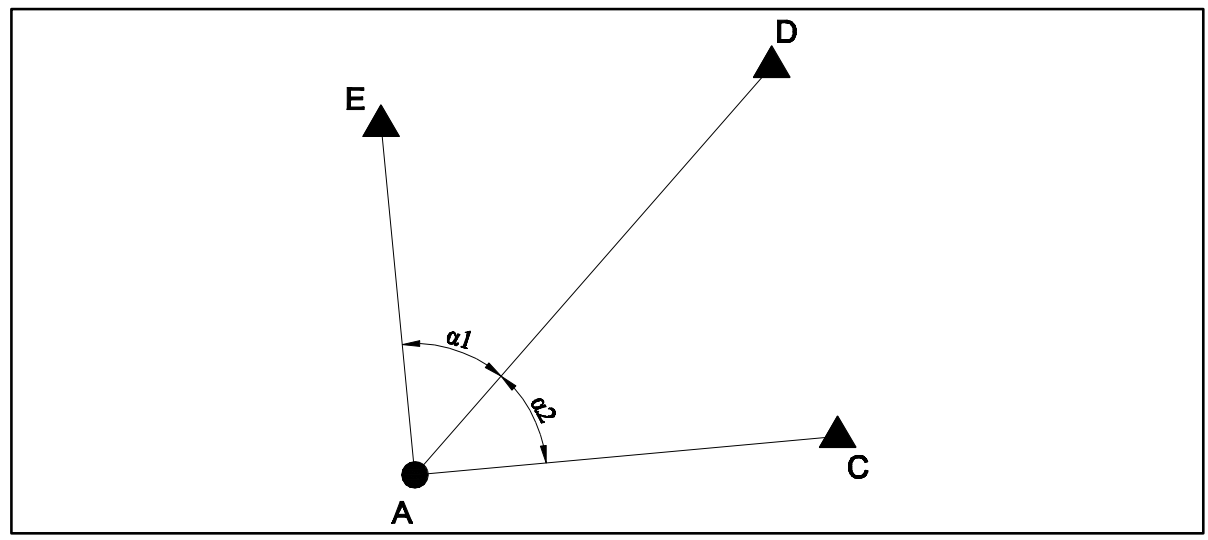

Figura 20 - Recessão

Fonte: Adaptado de Wolf e Ghilani (2006) 
Sendo:

$\alpha i$ - Ângulos horizontais internos;

$A$ - Ponto a ser determinado e verificado;

$C, D$ e $E$ - Pontos de controle e referência.

Para a realização dos cálculos deste método, os instrumentos utilizados nesta dissertação foram configurados com um de seus aplicativos padrão, o Resection. Este aplicativo utiliza um algoritmo embasado pela lei dos senos, cossenos e princípios do M.M.Q. para calcular o ajustamento das observações entre as medidas e as coordenadas dos pontos de controle. Esta modelagem define as coordenadas espaciais dos pontos medidos com suas respectivas precisões e antes de armazenar o resultado da operação, para posterior descarga, é possível analisar em campo os resíduos das medições para tais pontos, a fim de controlar a recessão e, consequentemente, a estabilidade das bases. (LEICA, 2007)

\subsubsection{Rede de referência absoluta de apoio ao monitoramento}

De acordo com o Department Of Army (1994, p.9-2), para monitorar a deformação de um corpo estrutural por meio das técnicas de mensuração, necessita-se de medições de deslocamentos espaciais de pontos selecionados nas estruturas, a partir de pontos de referência localizados externamente às estruturas, como se pode ver na Figura 21. Tais pontos definem uma rede de referência absoluta de referência e têm sido utilizados principalmente como base para a determinação de deslocamentos de alvos predefinidos sobre a superfície de uma estrutura. 


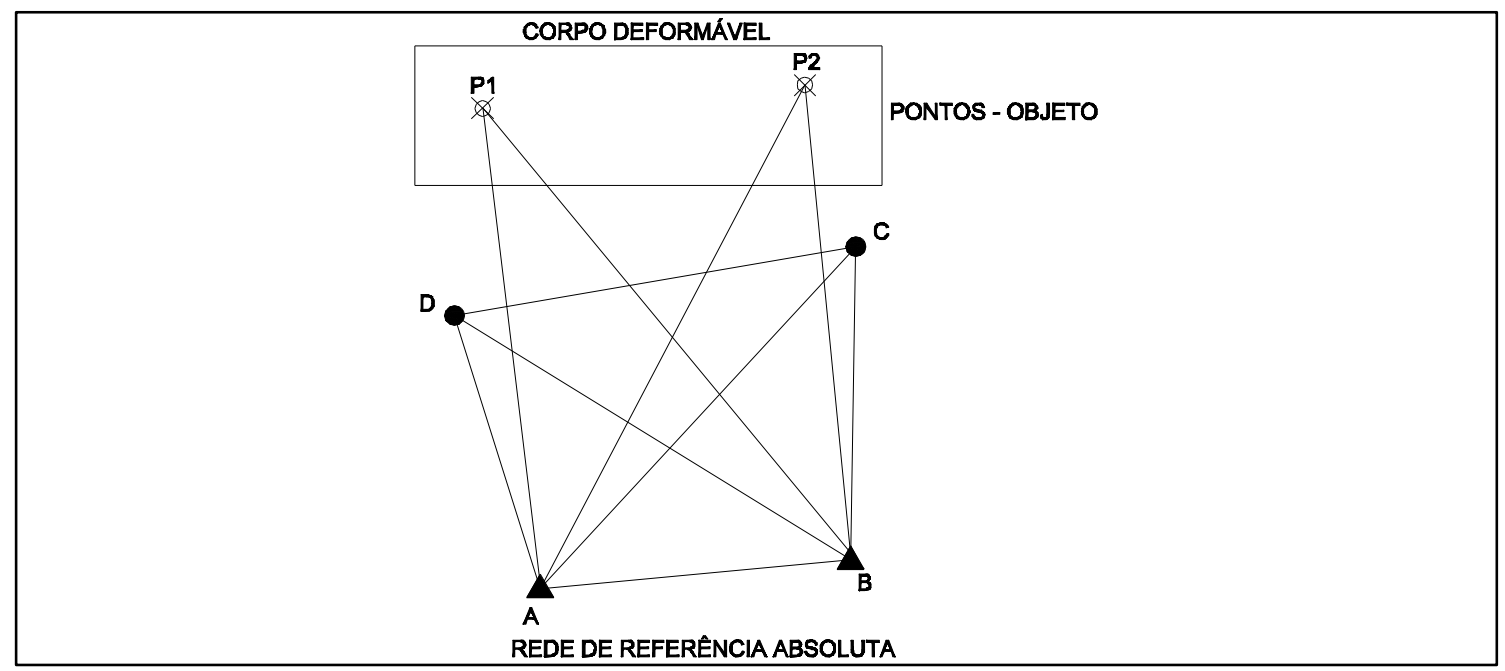

Figura 21 - Rede de referência absoluta Fonte: Adaptado de Chrzanowsky (1981)

Chen et al. (1990) consideram que qualquer ponto da rede de referência que não esteja estável, deve ser identificado antes do cálculo dos deslocamentos dos pontos engastados na estrutura, caso contrário, a análise e interpretação desses deslocamentos podem ser distorcidas, como mostra a Figura 22.

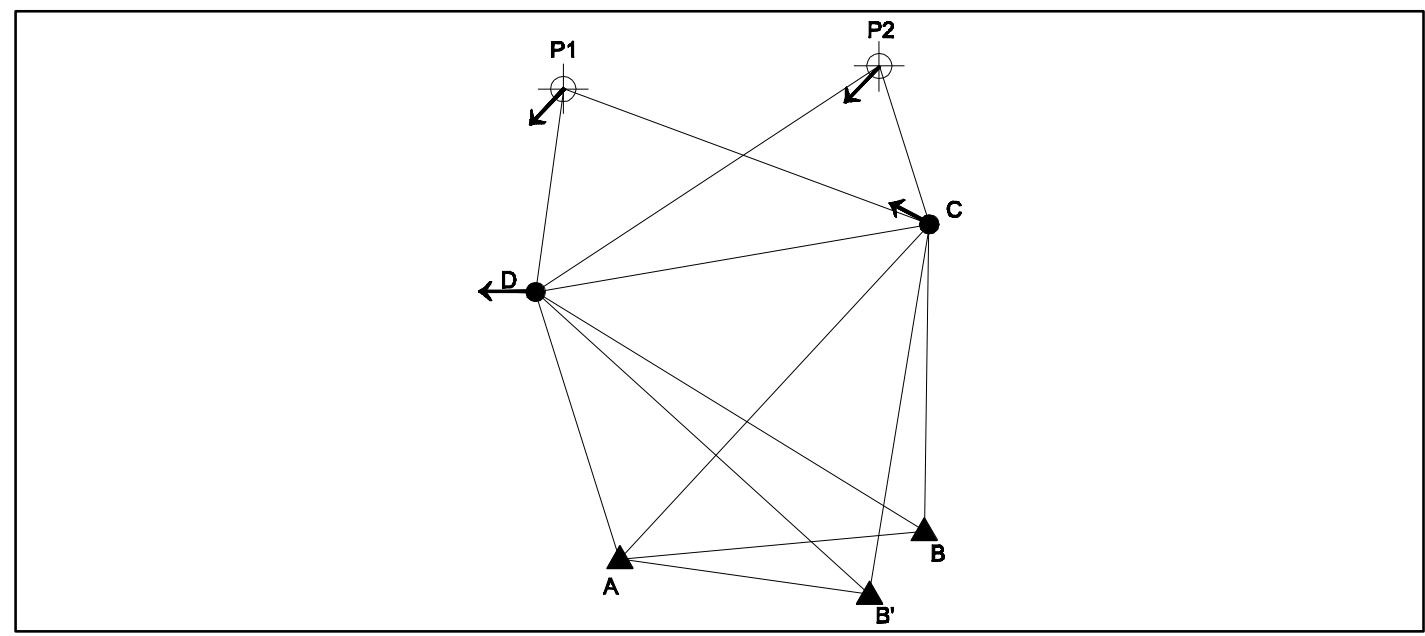

Figura 22 - Influência de um ponto de referência que não seja estável Fonte: Adaptado de Chen et al. (1990)

Em contrapartida, para exemplificar, a Figura 23 ilustra um caso contrário ao até então apresentado, a realização de uma rede de referência relativa, em que alguns pontos da rede estão localizados no corpo deformável. Dessa maneira, os valores obtidos não representam deslocamentos absolutos com referência em 
pontos estáveis e, sim, valores de deslocamentos relativos com referência em pontos com instabilidade, que fazem parte da estrutura a ser monitorada.

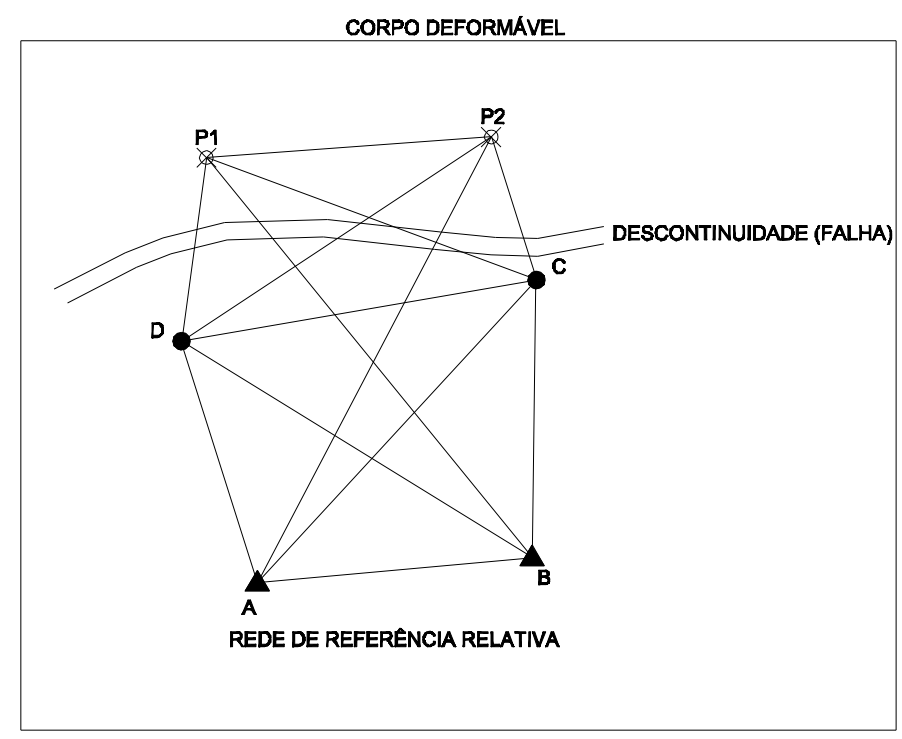

Figura 23 - Rede de referência relativa Fonte: Adaptado de Chrzanowsky (1981)

\subsubsection{Deslocamento e deformação}

As mudanças geométricas de uma estrutura podem ocorrer na geometria externa, caracterizando um deslocamento da estrutura como um todo, ou na geometria interna, caracterizando uma deformação.

O termo deformação, ilustrado pela Figura 24, pode ser definido como a mudança na forma inicial de um corpo sólido, sem sofrer ações de carga ou submetido às tensões ou cargas particulares. Dessa maneira, a deformação pode ser caracterizada por deslocamentos desiguais em pontos distintos definidos no corpo estrutural. (CHAVES, 1994 p.3) 


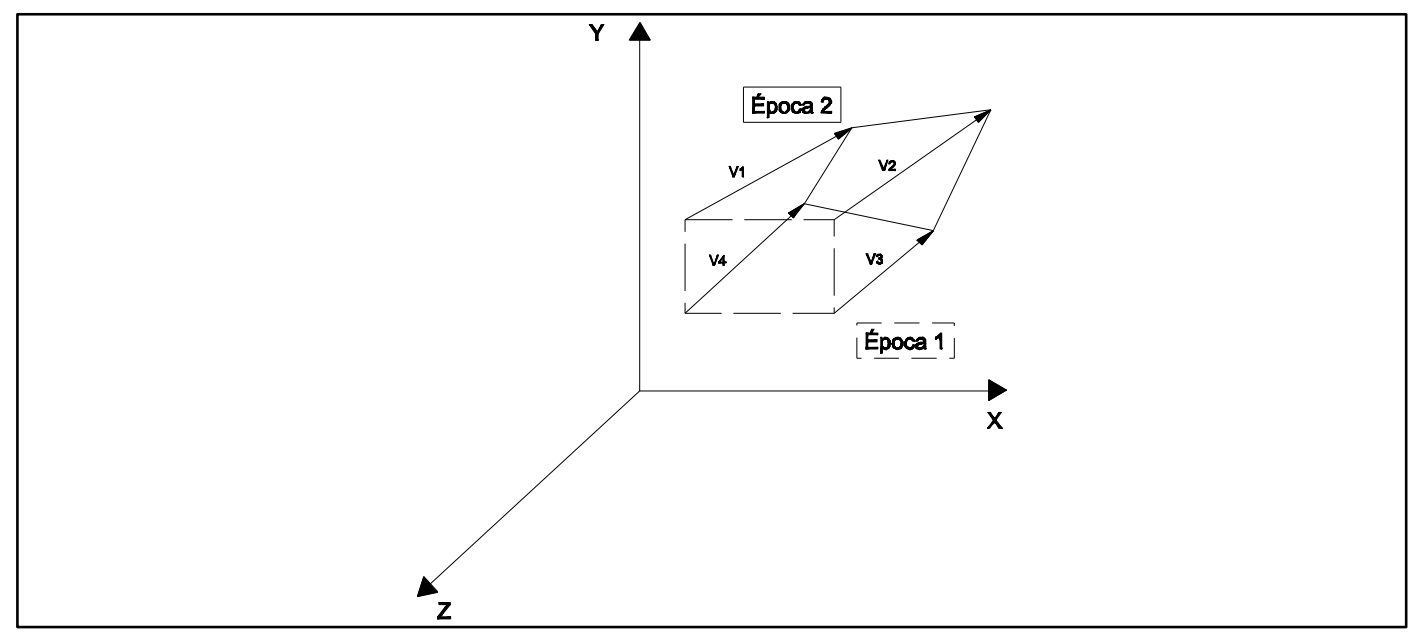

Figura 24 - Deformação de um objeto entre duas épocas Fonte: Adaptado de Chaves (1994)

Sendo:

$V 1 \neq V 2 \neq V 3 \neq V 4-$ Vetores de deformação.

Já o termo deslocamento, segundo Bueno (2007), pode ser definido como a translação e/ou rotação de um ponto ou um corpo rígido que podem ser determinadas em relação a um referencial fixo e estável, como mostra a Figura 25. O autor ainda descreve as ações que podem causar deslocamentos em uma estrutura, como peso próprio, variação de temperatura, cargas ativas, excitação de suporte (sismos), dentre outros.

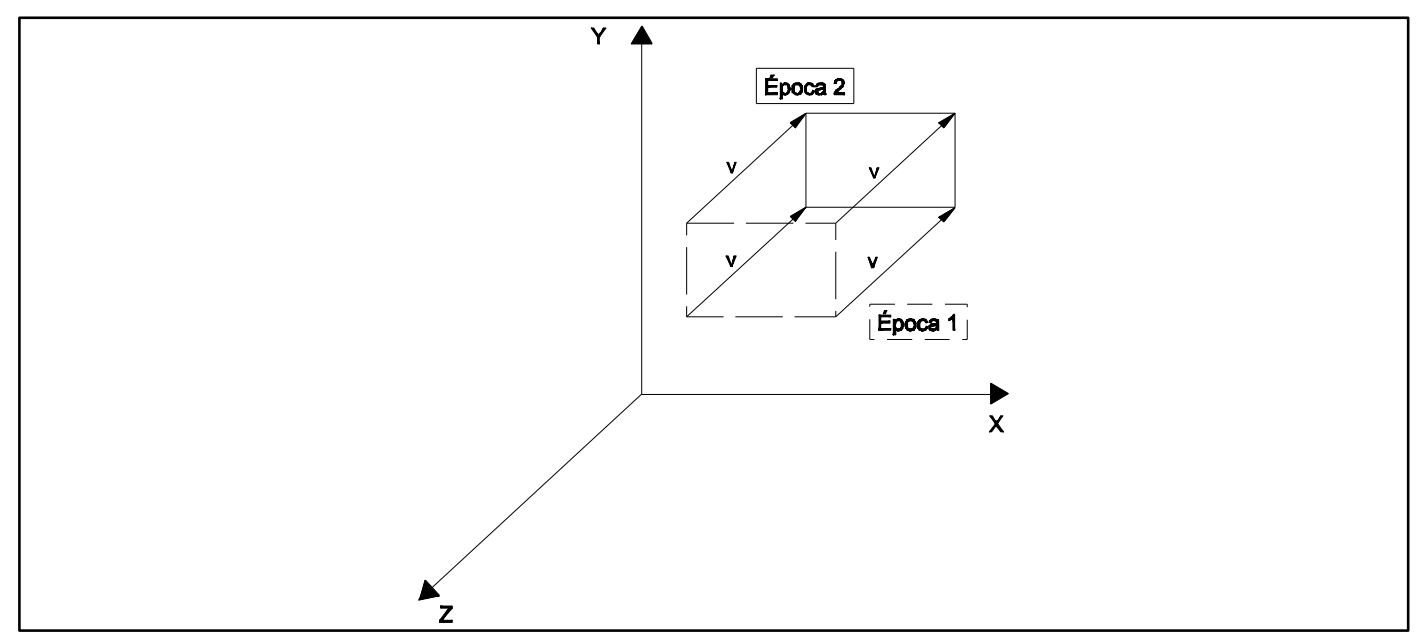

Figura 25 - Deslocamento de um objeto entre duas épocas Fonte: Adaptado de Chaves (1994) 
Sendo:

$V$ - Vetor de deslocamento.

É importante salientar que os termos deslocamento e deformação não podem ser considerados sinônimos.

Para a presente pesquisa simularam-se o deslocamento e a deformação de uma estrutura por meio de manipulações e intervenções milimetricamente controladas, utilizando o suporte com dispositivo ajustável para alvos, como pode ser visto na Figura 7.

\subsubsection{Controle de qualidade das observações e ajustamento da rede absoluta de referência - Teste Bilateral do Qui- Quadrado $\left(\chi^{2}\right)$}

Ao se tratar de controle de qualidade das observações e ajustamento, automaticamente, depara-se com modelos e testes estatísticos, mais especificamente com o Teste Global do Ajustamento, ou somente, Modelo Global. E, quando este se baseia na distribuição $\left(\chi^{2}\right)$, o mesmo é conhecido por Teste QuiQuadrado.

Este teste faz a comparação entre a variância "a priori” $\left(\sigma_{0}^{2}\right)$ e a variância "a posteriori" $\left(\hat{\sigma}_{0}^{2}\right)$ e, obviamente, esse teste somente tem significado quando a variância “a priori” é conhecida. Porém, segundo Gemael (1994, p.121) pode ser arbitrada pelo calculista, pois, a escolha da $\left(\sigma_{0}^{2}\right)$ não influencia no vetor das incógnitas. Dessa maneira, o mesmo sugere adotar $\left(\sigma_{0}^{2}=1\right)$. Já a $\left(\hat{\sigma}_{0}^{2}\right)$ é uma estimativa imparcial da $\left(\sigma_{0}^{2}\right)$ e é obtida, após o ajustamento das observações, a partir da matriz dos resíduos $(V)$. A variância "a posteriori” é dada pela equação (3.1):

$$
\hat{\sigma}_{0}^{2}=\frac{V^{T} P V}{r}
$$


Sendo:

$V$ - Matriz dos resíduos;

$P$ - Matriz peso das observações;

$r$ - Grau de liberdade, obtido pela diferença entre o número de equações $n$ e o número de incógnitas $u$ a ser determinado, sendo: $r=n-u$.

Assim, ao considerar a distribuição $\left(\chi^{2}\right)$, o teste bilateral preconiza como nula a hipótese básica, como se pode ver na equação (3.2):

$$
H_{0}: \hat{\sigma}_{0}^{2}=\sigma_{0}^{2} \text {, ou seja, } E\left\{\hat{\sigma}_{0}^{2} \mid H_{0}\right\}=\sigma_{0}^{2}
$$

Contra a hipótese alternativa, dada pela equação (3.3):

$$
H_{1}: \hat{\sigma}_{0}^{2} \neq \sigma_{0}^{2}
$$

A estatística de comparação é dada pela equação (3.4):

$$
\chi^{* 2}(r)=\frac{\widehat{\sigma}_{0}^{2}}{\sigma_{0}^{2}} \cdot r=\frac{V^{T} P V}{\sigma_{0}^{2}}
$$

Com os valores teóricos, dados pela equação (3.5):

$$
\chi_{r, \frac{\alpha}{2}}^{2} \text { e } \chi_{r, 1-\frac{\alpha}{2}}^{2}
$$

A hipótese básica não é rejeitada, ao nível de significância $(\alpha)$, se atender à condição imposta pela condição (3.6):

$$
\chi^{* 2}<\chi_{r, 1-\frac{\alpha}{2}}^{2} \text { ou } \chi^{* 2}>\chi_{r, \frac{\alpha}{2}}^{2}
$$

Sendo:

$\chi^{* 2}-$ Valor calculado para o teste qui-qudrado, equação (3.4);

$\chi^{2}$ - Valor obtido da tabela de distribuição qui-quadrado;

$\alpha$ - Nível de significância multidimensional. 
Caso contrário, em conformidade com Gemael (1994, p.123), deve-se proceder a uma análise cuidadosa do ajustamento, uma vez que pode haver erro na MVC dos valores observados, ou os resíduos podem estar excessivamente grandes em decorrência de um erro grosseiro ou de erros sistemáticos. Além disso, o modelo matemático pode não ser consistente com as observações ou o sistema como um todo pode também estar mal condicionado.

\subsubsection{Elipse de erros}

Após realizar o ajustamento das observações, obtém-se a matriz variânciacovariância dos parâmetros ajustados, sendo que em sua diagonal principal, encontram-se as variâncias das coordenadas ajustadas. As raízes dessas variâncias fornecem o erro médio ou precisão $\left(\sigma_{X}, \sigma_{Y}, \sigma_{Z}\right)$ das coordenadas ajustadas. Uma análise de precisão da posição é fornecida pela teoria da elipse de erros.

A determinação da elipse de erro consiste, basicamente, em calcular o valor dos seus semieixos principais e a direção do semieixo maior. Esses valores são obtidos por meio da aplicação da teoria de propagação de erros à matriz variânciacovariância das coordenadas ajustadas e à equação de rotação de eixos. A matriz variância-covariância, que é representada por $\left(\Sigma_{X X}\right)$, é obtida pela equação (3.7):

$$
\Sigma_{X X}=\hat{\sigma}_{0}^{2} \cdot Q_{X X}=\hat{\sigma}_{0}^{2} \cdot\left(A^{T} P A\right)^{-1}=\left[\begin{array}{cc}
\sigma_{X}^{2} & \sigma_{X Y} \\
\sigma_{Y X} & \sigma_{Y}^{2}
\end{array}\right]
$$

Sendo:

$\Sigma_{X X}-$ MVC das coordenadas ajustadas;

$\hat{\sigma}_{0}^{2}$ - Variância "a posteriorr";

$A$ - Matriz dos coeficientes das equações de observação;

$P$ - Matriz dos pesos das observações; 
$Q_{X X}$ - Matriz co-fatores da matriz variância-covariância das coordenadas ajustadas;

$$
\begin{aligned}
& \sigma_{X}^{2}-\text { Variância das coordenadas ajustadas } X ; \\
& \sigma_{Y}^{2}-\text { Variância das coordenadas ajustadas } Y \text {; } \\
& \sigma_{X Y} \text { - Covariância }(X, Y) .
\end{aligned}
$$

Aplicando-se a teoria de propagação dos erros à matriz variância-covariância, através dos coeficientes da função de rotação dos eixos coordenados $(X, Y)$, obtémse a matriz variância-covariância correspondente a uma direção qualquer $(\varphi)$, como observado na equação (3.8):

$$
\Sigma_{X X_{\varphi}}=\left[\begin{array}{cc}
\sigma_{X \varphi}^{2} & \sigma_{X Y} \\
\sigma_{Y X_{\varphi}} & \sigma_{Y \varphi}^{2}
\end{array}\right]
$$

Os valores dos elementos da matriz $\Sigma_{X X_{\varphi}}$ podem ser calculados pelas equações (3.9), (3.10) e (3.11):

$$
\begin{gathered}
\sigma_{X}^{2}=\sigma_{X}^{2} \cdot \cos _{\varphi}^{2}+\sigma_{Y}^{2} \cdot \operatorname{sen}_{\varphi}^{2}+2 \cdot \sigma_{X Y} \cdot \operatorname{sen}_{\varphi} \cdot \cos _{\varphi} \\
\sigma_{Y}^{2}=\sigma_{X}^{2} \cdot \operatorname{sen}_{\varphi}^{2}+\sigma_{Y}^{2} \cdot \cos _{\varphi}^{2}-2 \cdot \sigma_{X Y} \cdot \operatorname{sen}_{\varphi} \cdot \cos _{\varphi} \\
\sigma_{X Y_{\varphi}}=-\left(\sigma_{X}^{2}-\sigma_{Y}^{2}\right) \cdot \operatorname{sen}_{\varphi} \cdot \cos _{\varphi}+\sigma_{X Y} \cdot\left(\cos _{\varphi}^{2}-\operatorname{sen}_{\varphi}^{2}\right)
\end{gathered}
$$

A equação (3.9), segundo Gemael (1994), é a expressão de uma curva conhecida como podária e, desta, obtém-se o valor da variância para qualquer direção $(\varphi)$ desejada. Derivando essa equação e igualando-a a zero, temos a equação (3.12), a qual fornece o ângulo correspondente à direção da maior ou menor variância da curva podária. A raiz quadrada da variância calculada com esse ângulo corresponde a um dos semieixos principais da elipse de erro. $O$ outro eixo principal da elipse é perpendicular a esse primeiro eixo principal.

$$
\operatorname{tg}(2 \psi)=\frac{2 \cdot \sigma_{X Y}}{\sigma_{X}^{2}-\sigma_{Y}^{2}}
$$


A fim de diferenciar do ângulo $(\varphi)$, correspondente a uma direção qualquer da podária, o ângulo do eixo principal determinado pela equação (3.12) será representado por $(\psi)$. E, em função deste ângulo, podem-se determinar os valores dos semieixos principais da elipse de erro $\left(\sigma_{\operatorname{máx}} e \sigma_{\min }\right)$, a partir das equações (3.13) e (3.14):

$$
\begin{aligned}
& \sigma_{\text {máx }}^{2}=\sigma_{X}^{2} \cdot \cos ^{2} \psi+\sigma_{Y}^{2} \cdot \operatorname{sen}^{2} \psi+\sigma_{X Y} \cdot \operatorname{sen}(2 \psi) \\
& \sigma_{\text {min }}^{2}=\sigma_{X}^{2} \cdot \operatorname{sen}^{2} \psi+\sigma_{Y}^{2} \cdot \cos ^{2} \psi-\sigma_{X Y} \cdot \operatorname{sen}(2 \psi)
\end{aligned}
$$

Tais equações podem ser reescritas por meio do uso de identidades trigonométricas para substituir as funções quadráticas $\left(\operatorname{sen}^{2} \psi e \cos ^{2} \psi\right)$ por outra mais simples. Então, têm-se as equações (3.15) e (3.16):

$$
\begin{aligned}
& \sigma_{\text {máx }}^{2}=\left(\frac{\sigma_{X}^{2}+\sigma_{Y}^{2}}{2}\right)+\left(\frac{\sigma_{X}^{2}-\sigma_{Y}^{2}}{2}\right) \cdot \cos (2 \psi)+\sigma_{X Y} \cdot \operatorname{sen}(2 \psi) \\
& \sigma_{\text {min }}^{2}=\left(\frac{\sigma_{X}^{2}+\sigma_{Y}^{2}}{2}\right)-\left(\frac{\sigma_{X}^{2}-\sigma_{Y}^{2}}{2}\right) \cdot \cos (2 \psi)-\sigma_{X Y} \cdot \operatorname{sen}(2 \psi)
\end{aligned}
$$

Os valores máximos e mínimos da variância também podem ser expressos de forma mais compacta pelas equações (3.17) e (3.18):

$$
\begin{aligned}
& \sigma_{\text {máx }}^{2}=\sigma_{Y}^{2}+\sigma_{X Y} \cdot \operatorname{cotg}(\psi) \\
& \sigma_{\text {min }}^{2}=\sigma_{X}^{2}-\sigma_{X Y} \cdot \operatorname{cotg}(\psi)
\end{aligned}
$$

\subsection{APRESENTAÇÃO DOS PRINCIPAIS MÉTODOS DE CÁLCULO DE COORDENADAS ESPACIAIS}

\subsubsection{Introdução}

Existem na literatura cinco métodos para a determinação de coordenadas espaciais $(X, Y, Z)$ de pontos fixos, os quais realizam os cálculos de coordenadas espaciais, variando basicamente, apenas as modelagens matemáticas. Os referidos 
métodos foram estudados e revisados, porém, será validado nesta dissertação somente o método polar.

- Método polar;

- Método de interseção espacial trigonométrico;

- Método de interseção espacial analítico;

- Método de interseção espacial analítico com superdeterminação de medidas.

\subsubsection{Método polar}

O Método polar é simples de ser aplicado e consiste em medir ângulos verticais, horizontais e distâncias inclinadas entre o aparelho e o alvo, conforme exibido na Figura 26. O método necessita de um único aparelho devidamente estacionado e orientado. Para o processo de medição, a estação total é instalada sobre uma estrutura estável para garantir que as coordenadas determinadas sejam coerentes com a rede de referência absoluta. Para tanto, é necessária a existência de, pelo menos, um ponto de referência para orientação e verificação de possíveis variações da base.

De acordo com Wolf e Ghilani (2007), o método polar, como o próprio nome sugere, é oriundo dos sistemas polares e as coordenadas tridimensionais são calculadas em função do centro óptico do aparelho, por meio de equações trigonométricas, as quais envolvem todas as observações citadas acima. 


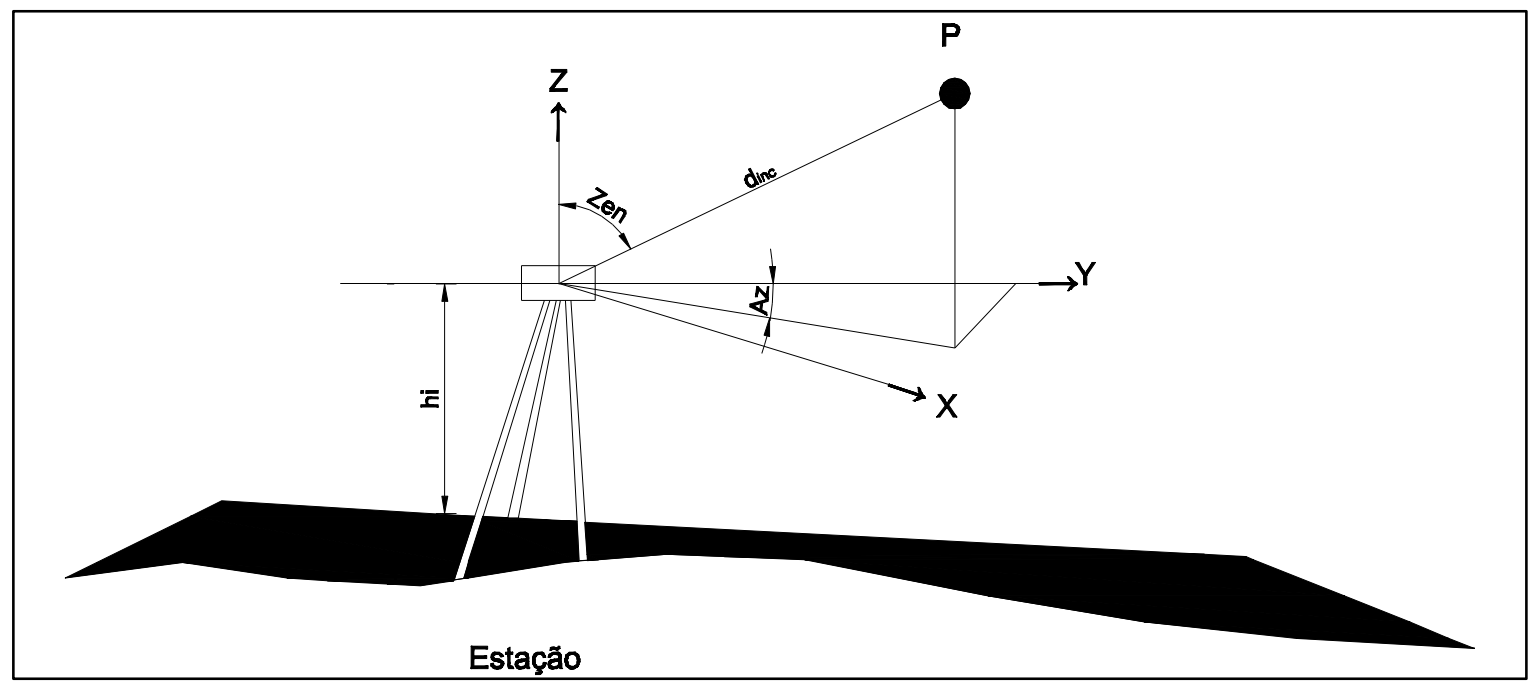

Figura 26 - Esquema representativo do método polar Fonte: Adaptado de Moreira (1998)

As coordenadas do alvo são calculadas pelas seguintes equações:

$$
\begin{aligned}
& X P=X_{0}+d_{i n c} \cdot \operatorname{sen}(Z e n) \cdot \operatorname{sen}(A z) \\
& Y P=Y_{0}+d_{i n c} \cdot \operatorname{sen}(Z e n) \cdot \cos (A z) \\
& Z P=Z_{0}+h_{i}+d_{i n c} \cdot \cos (Z e n)
\end{aligned}
$$

Onde:

$X P, Y P$ e $Z P$ - Coordenadas do alvo fixo;

$X_{0}, Y_{0}$ e $Z_{0}$ - Coordenadas da estação de referência;

$h_{i}$ - Altura do instrumento na estação de referência;

$d_{i n c}$ - Distância inclinada;

$A z$ - Azimute;

Zen - Ângulo vertical zenital. 


\subsubsection{Método de interseção espacial trigonométrico}

A interseção espacial trigonométrica foi o primeiro método desenvolvido para a determinação de pontos no espaço, a partir de medições angulares sem a intervenção da medição de distâncias, como mostra a Figura 27.

O método é dividido em duas etapas: na primeira, determinam-se as coordenadas planas do alvo a partir do cálculo de uma interseção plana e, na segunda, determina-se a altura do alvo a partir das fórmulas do nivelamento trigonométrico. A coordenada plana do alvo é calculada a partir da medição dos ângulos horizontais entre duas estações de referência e o alvo, ressaltando-se que não é utilizada nenhuma medição de distância. A partir da determinação das coordenadas planas e da medição do ângulo vertical zenital, calcula-se a coordenada altimétrica do alvo.

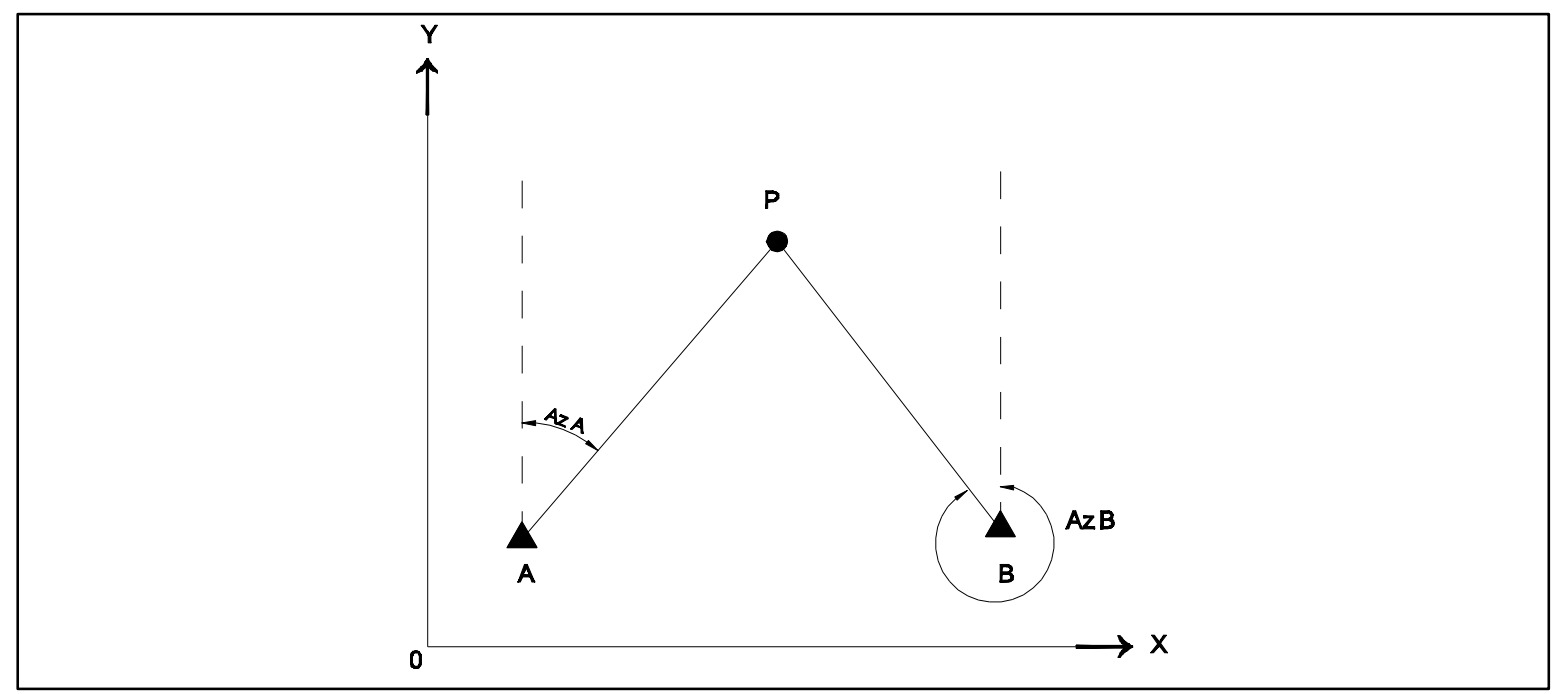

Figura 27 - Representação gráfica do método de interseção plana Fonte: Adaptado de Howald (1989) apud Moreira (1998)

É importante salientar que, neste método, um erro cometido na leitura do ângulo vertical não influencia no resultado das coordenadas planas e, um erro cometido na leitura de um ângulo horizontal, não altera o valor da coordenada altimétrica. Este fato torna o método inconsistente para a determinação de coordenadas espaciais, uma vez que um erro de leitura em qualquer um dos 
ângulos implica, necessariamente, um erro no cálculo da posição do ponto, conforme é mostrado na Figura 28. Esta possibilidade de ocorrência da discrepância no posicionamento do ponto, calculado pelo presente método, é uma desvantagem em relação aos demais métodos citados a seguir. Mesmo assim, de acordo com Moreira (1998), o método de interseção espacial trigonométrico é utilizado em trabalhos de mensuração que dispensam uma precisão apurada.

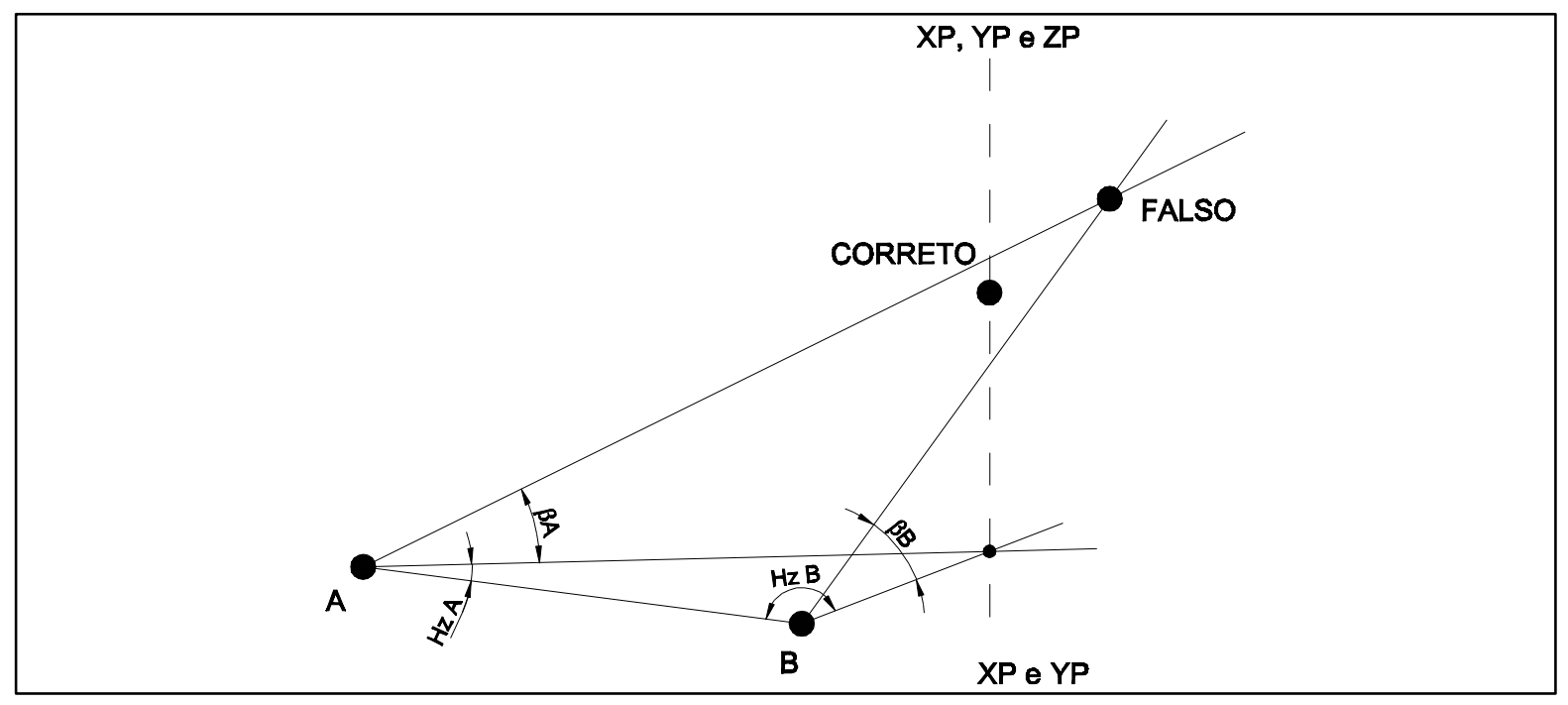

Figura 28 - Representação da discrepância no posicionamento do ponto calculado pelo método de interseção espacial trigonométrico Fonte: Adaptado de Moreira (1998) apud WILD/TMS (1992)

Para determinar as coordenadas de um ponto por interseção espacial trigonométrico, é necessário conhecer as coordenadas de duas estações de referência. A partir destas, são medidas direções, para a obtenção dos azimutes das visadas realizadas. Portanto, as estações são exteriores ao ponto alvo a ser determinado, e cada combinação de duas visadas possibilita o cálculo de uma interseção. Seguem abaixo a operacionalidade e as modelagens matemáticas desta metodologia para a determinação das coordenadas do alvo $\mathrm{P}$.

Moreira (1998) apresenta o procedimento de campo para obtenção dos azimutes $\left(A z_{A}\right)$ e $\left(A z_{B}\right)$, porém, a presente pesquisa utiliza outra maneira para obter os respectivos azimutes, daí, a necessidade de adaptação deste método, conforme será recomendado para projetos futuros: 
- Estação de referência A:

1. Calcula-se o azimute entre $A$ e $B$, pelas coordenadas de $A$ e $B$, conhecidas;

2. Registra-se no equipamento instalado na estação de referência $A \circ$ azimute $A B$ e visa-se a estação de referência $B$ e fixa-se o círculo;

3. Gira-se o aparelho até o alvo $P$ e o ângulo lido é o azimute de $A \rightarrow P$ $\left(A z_{A}\right)$;

4. Deve-se ler ainda o ângulo zenital $\left(Z e n_{A}\right)$ em relação ao alvo.

- Estação de referência B:

1. Calcula-se o azimute entre $B$ e $A$, pelas coordenadas de $B$ e $A$, conhecidas;

2. Registra-se no equipamento instalado na estação de referência $B$ o azimute BA e visa-se a estação de referência A e fixa-se o círculo;

3. Gira-se o aparelho até o alvo $P$ e o ângulo lido é o azimute de $B \rightarrow A$ $\left(A z_{B}\right)$;

4. Deve-se ler ainda o ângulo zenital $\left(Z e n_{B}\right)$ em relação ao alvo.

Dados conhecidos:

$X A, Y A$ e $Z A$ - Coordenadas da estação de referência A;

$X B, Y B$ e $Z B$ - Coordenadas da estação de referência $B$.

A calcular:

$X P, Y P$ e $Z P$ - Coordenadas a calcular do alvo $\mathrm{P}$.

Sendo:

$A z_{A}$ e $A z_{B}-$ Azimutes das direções $\mathrm{A} \rightarrow \mathrm{P}$ e $\mathrm{B} \rightarrow \mathrm{P}$, respectivamente.

As coordenadas planimétricas $(\mathrm{X}, \mathrm{Y})$ do ponto alvo $\mathrm{P}$ são calculadas pelas seguintes equações: 
Se:

$$
\left|\operatorname{tg} A z_{A}\right|>\left|\operatorname{tg} A z_{B}\right|
$$

Então:

$$
\begin{aligned}
& X P=X B+(Y P-Y B) \cdot \operatorname{tg} A z_{B} \\
& Y P=Y A+\left(\frac{(X B-X A)-(Y B-Y A) \cdot \operatorname{tg} A z_{B}}{\operatorname{tg} A z_{A}-\operatorname{tg} A z_{B}}\right)
\end{aligned}
$$

E se:

$$
\begin{gathered}
\left|t g A z_{A}\right|<\left|t g A z_{B}\right| \\
X P=X A+(Y P-Y A) \cdot \operatorname{tg} A z_{A} \\
Y P=Y B+\left(\frac{(X A-X B)-(Y A-Y B) \cdot \operatorname{tg} A z_{A}}{\operatorname{tg} A z_{B}-\operatorname{tgAz_{A}}}\right)
\end{gathered}
$$

Segundo Howald (1989) apud Moreira (1998), as duas expressões acima oferecem os mesmos resultados e ambas podem ser aplicadas para obter controle perante os resultados. No entanto, nos casos em que os ângulos $A z_{A}$ e $A z_{B}$ forem muito próximos a $90^{\circ}$ ou $270^{\circ}$, a tangente torna-se muito grande e tende ao infinito, resultando em cálculos imprecisos. Para esses casos específicos, deve-se priorizar a formulação apresentada em função dos valores absolutos das respectivas tangentes.

A coordenada altimétrica $(Z)$ do alvo $P$ é dada por:

$$
Z P=\frac{Z P A+Z P B}{2}
$$

Sendo:

$$
\begin{aligned}
& Z P A=Z A+\operatorname{cotg} Z e n_{A} \cdot \sqrt{(X P-X A)^{2}+(Y P-Y A)^{2}} \\
& Z P B=Z B+\operatorname{cotg} Z e n_{B} \cdot \sqrt{(X P-X B)^{2}+(Y P-Y B)^{2}}
\end{aligned}
$$


E:

$Z e n_{A} e Z e n_{B}$ - Ângulos zenitais medidos a partir das estações A e B, respectivamente, em direção ao alvo $P$.

\subsubsection{Método de interseção espacial analítico}

No método de interseção espacial analítico, as coordenadas espaciais do alvo são calculadas, concomitantemente, em função dos ângulos horizontais e verticais medidos. Na prática, um erro cometido na leitura de um ângulo vertical influencia no valor das coordenadas planas do alvo e, um erro cometido na leitura de um ângulo horizontal, influencia também no valor da coordenada altimétrica.

Como pode ser visto graficamente na Figura 29, as linhas de visadas são consideradas vetores espaciais que partem das estações de referência, em direção ao alvo a ser calculado. A partir de, pelo menos, dois equipamentos topográficos colimados reciprocamente, pode-se visar o alvo correspondente, e a determinação das coordenadas espaciais faz-se por meio da solução de um sistema de equações estabelecidas em função dos cossenos diretores, determinados pelas linhas de visadas. No caso de haver mais de dois instrumentos de medição, a solução das equações envolvidas pode ser alcançada aplicando-se o M.M.Q. e, a solução para as coordenadas espaciais do alvo, neste caso, é obtida considerando-se que os valores compensados das mesmas são iguais à média aritmética dos resultados obtidos pela combinação de $n$ estações, duas a duas. Nenhuma distância é medida neste método. 


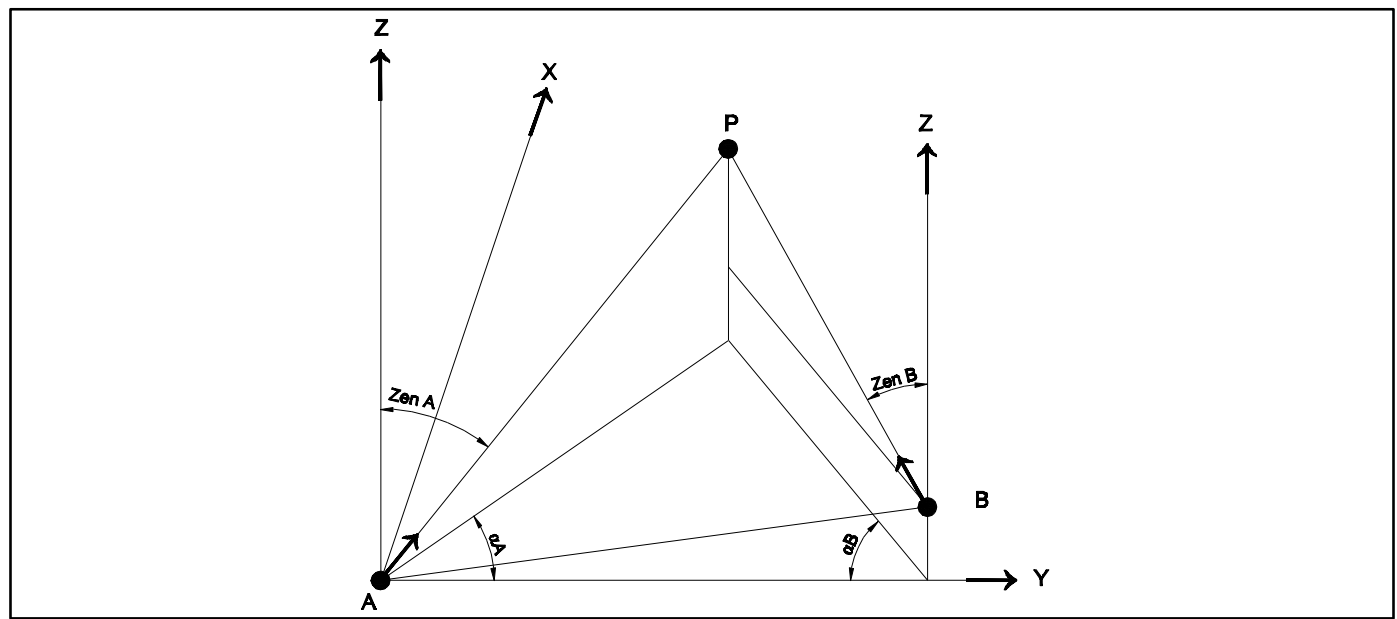

Figura 29 - Representação gráfica do método de interseção espacial analítica Fonte: Adaptado de Moreira (1998)

Analisando apenas um vetor, de acordo com a Figura 30, tem-se:

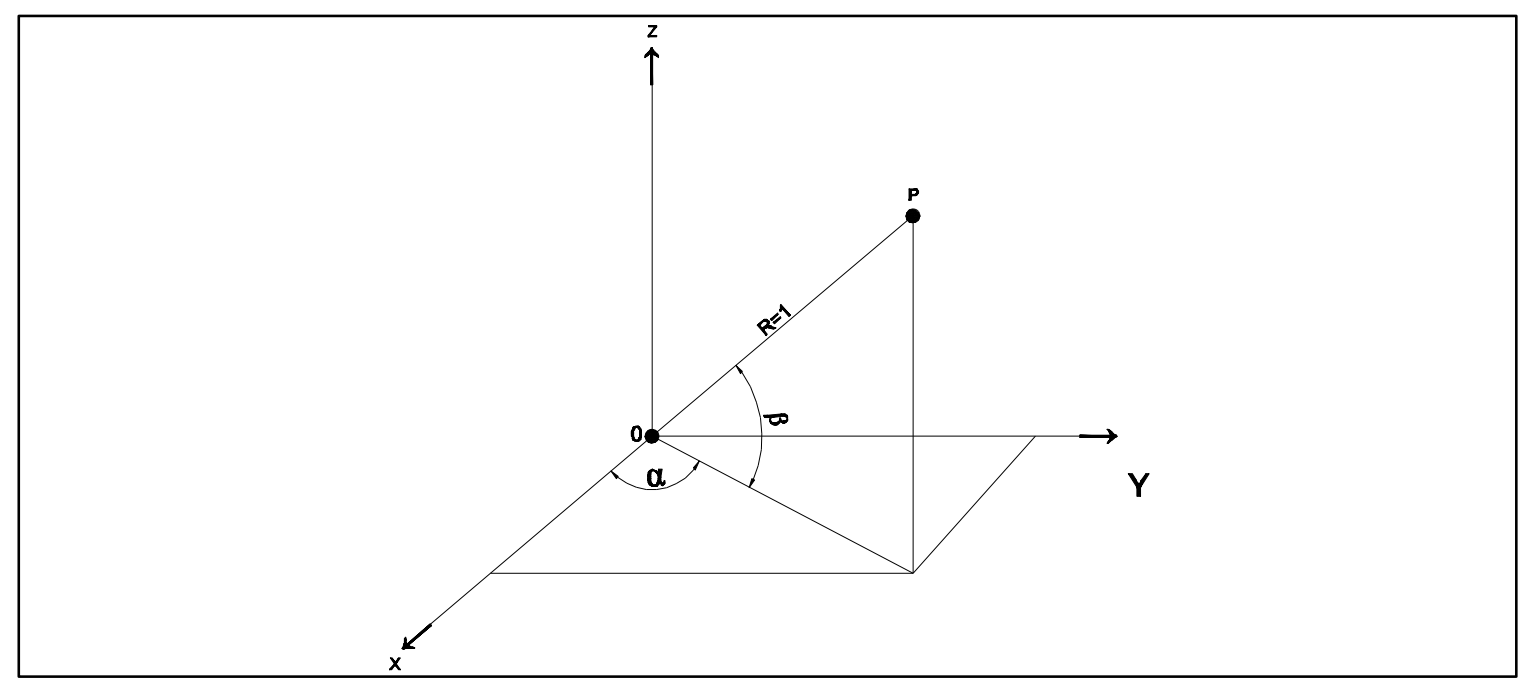

Figura 30 - Coordenadas espaciais do alvo $\mathrm{P}$, utilizando-se vetores Fonte: Adaptado de Carneiro \& Brandão (1992) apud Ibiapina (1993)

A solução do problema de interseção espacial de visadas, utilizando vetores, de acordo com Carneiro e Brandão (1992) apud Ibiapina (1993) pode ser realizada, como mostra a Figura 30 , e as coordenadas espaciais do ponto $\mathrm{P}$ podem ser expressas, matematicamente, da seguinte forma:

$$
X P=r \cdot \cos (\beta) \cdot \cos (\alpha)
$$




$$
\begin{aligned}
& Y P=r \cdot \cos (\beta) \cdot \operatorname{sen}(\alpha) \\
& Z P=r \cdot \operatorname{sen}(\beta)
\end{aligned}
$$

Sendo:

$r$ - Distância da origem até o alvo P;

$\beta$ - Ângulo vertical de altura medido;

$\alpha$ - Ângulo horizontal medido.

Podem-se calcular os cossenos diretores, conforme a Figura 31, admitindo-se que $r=1$.

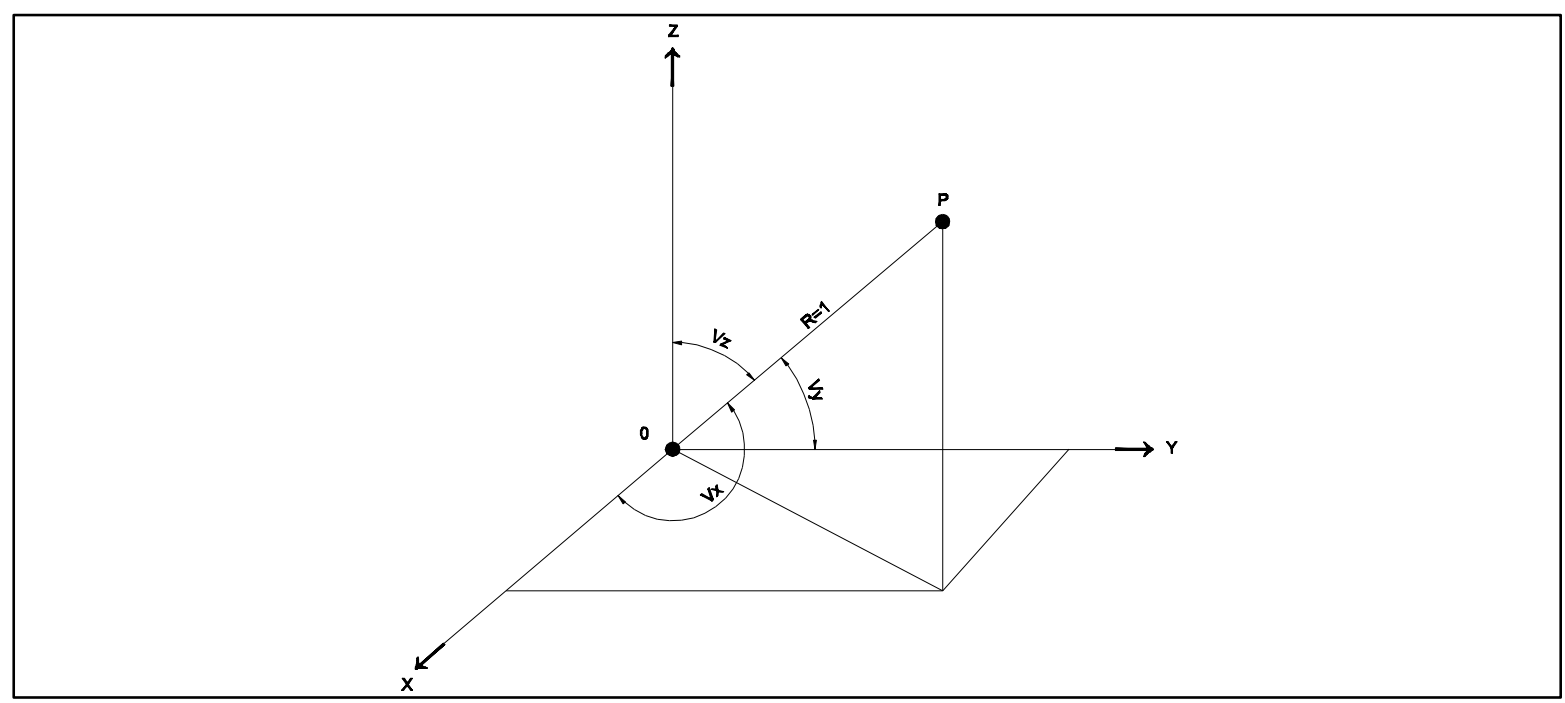

Figura 31 - Representação dos ângulos de referência entre $O P$ e os semieixos positivos Fonte: Adaptado de Carneiro \& Brandão (1992) apud Ibiapina (1993)

Os cossenos diretores da direção $O P$, são dados por:

$$
\begin{aligned}
& \frac{X P}{r}=\cos (\beta) \cdot \cos (\alpha)=k=\cos \left(V_{x}\right) \\
& \frac{Y P}{r}=\cos (\beta) \cdot \operatorname{sen}(\alpha)=m=\cos \left(V_{y}\right)
\end{aligned}
$$




$$
\frac{Z P}{r}=\operatorname{sen}(\beta)=n=\cos \left(V_{z}\right)
$$

Sendo:

$V_{x}, V_{y}$ e $V_{z}$ - Ângulos de $O P$ com os eixos positivos $x, y, z$, respectivamente.

Como pode ser visto na Figura 32, os dois equipamentos estacionados nas estações de referência A e B são colimados reciprocamente e, em seguida, efetuamse as visadas do alvo $P$.

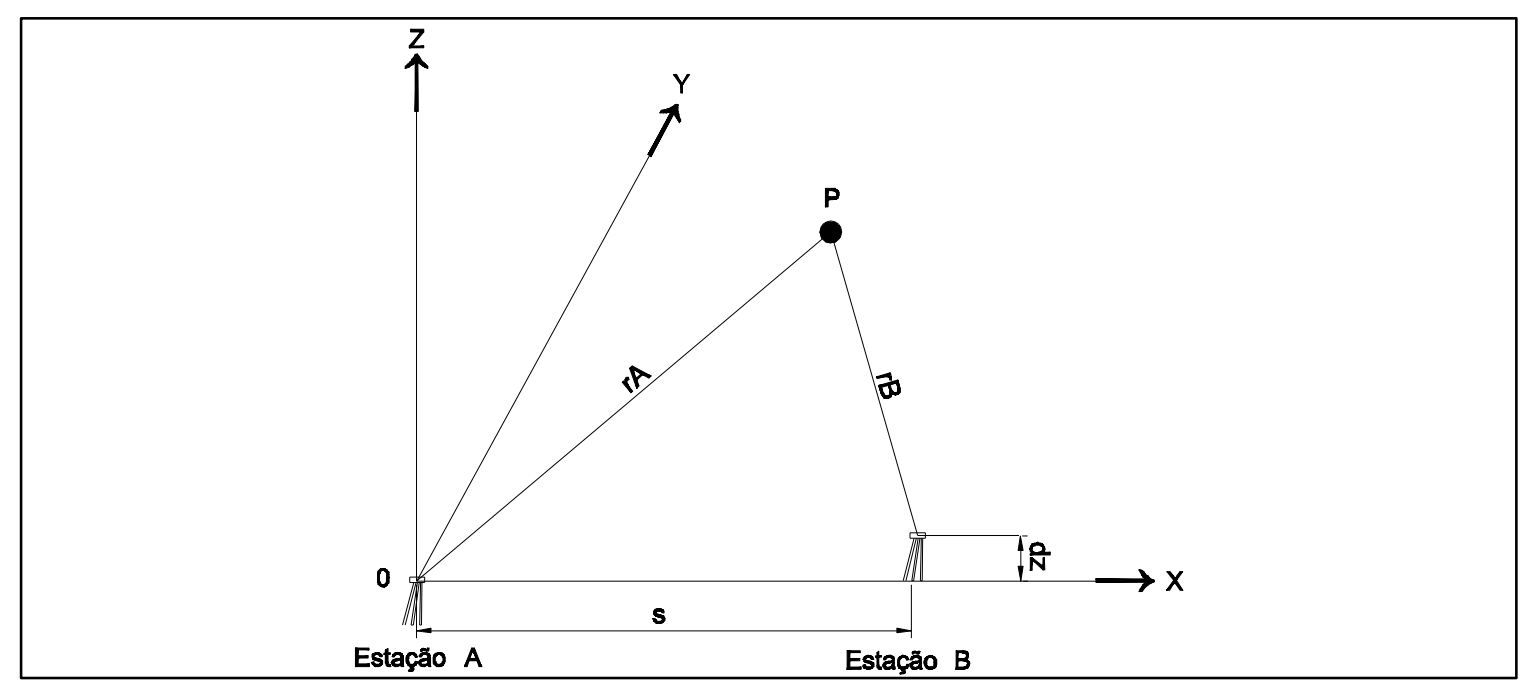

Figura 32 - Posicionamento dos equipamentos nas estações de referência Fonte: Adaptado de Ibiapina (1993) apud Carneiro \& Brandão (1992)

$O$ equipamento instalado na estação $A$ é considerado origem do sistema de referência e a direção $A B$ é visada com um ângulo horizontal predeterminado em 000'00”.

As equações para o cálculo das coordenadas do alvo $\mathrm{P}$, a partir da estação de referência A são:

$$
\begin{aligned}
& X P_{A}=k_{A} \cdot r_{A} \\
& Y P_{A}=m_{A} \cdot r_{A} \\
& Z P_{A}=n_{A} \cdot r_{A}
\end{aligned}
$$


$\mathrm{E}$, as equações para o cálculo das coordenadas do alvo $\mathrm{P}$, a partir da estação de referência $B$ são:

$$
\begin{aligned}
& X P_{B}=k_{B} \cdot r_{B} \\
& Y P_{B}=m_{B} \cdot r_{B} \\
& Z P_{B}=n_{B} \cdot r_{B}
\end{aligned}
$$

Sendo:

$r_{A}$ e $r_{B}$ - Distâncias inclinadas entre as estações de referência $A$ e $B$ e alvo $P$, respectivamente.

Aplicando-se um processo de ajustamento pelo método paramétrico, podemse obter as seguintes equações de erros para realizar o cálculo de $r_{A}$ e $r_{B}$ :

$$
\begin{aligned}
& v 1=r_{A} \cdot k_{A}-\left(s-r_{B} \cdot k_{B}\right) \\
& v 2=r_{A} \cdot m_{A}-r_{B} \cdot m_{B} \\
& v 3=r_{A} \cdot n_{A}-\left(d z+r_{B} \cdot n_{B}\right)
\end{aligned}
$$

Sendo:

$s$ - Distância entre os dois equipamentos;

$d z$ - Diferença de nível entre os dois equipamentos;

$v 1, v 2$ e $v 3$ - Erros residuais.

Matricialmente, tem-se:

$$
V=A X-L
$$

Sendo:

$$
V\left[\begin{array}{l}
v 1 \\
v 2 \\
v 3
\end{array}\right]=A\left[\begin{array}{cc}
k_{A} & k_{B} \\
m_{A} & -m_{B} \\
n_{A} & -n_{B}
\end{array}\right] \cdot X\left[\begin{array}{l}
r_{A} \\
r_{B}
\end{array}\right]-L\left[\begin{array}{c}
S \\
0 \\
d z
\end{array}\right]
$$


Aplicando-se o princípio dos mínimos quadrados (M.M.Q.) ao sistema estabelecido pelas equações (3.42), (3.43) e (3.44), obtém-se os seguintes sistemas de equações normais:

$$
A^{T} \cdot A \cdot X-A^{T} \cdot L=0
$$

De onde se obtém o vetor $X$, ou seja, os valores das incógnitas $r_{A} e r_{B}$. Com os valores calculados de $r_{A}$ e $r_{B}$, podemos substituí-los nas equações (3.36), (3.37), (3.38), (3.39), (3.40) e (3.41) para calcular o par de coordenadas para o ponto P. Assim, as coordenadas finais são obtidas, calculando-se a média aritmética dos valores parciais:

$$
\begin{aligned}
& X P=\frac{X P_{A}+X P_{B}}{2} \\
& Y P=\frac{Y P_{A}+Y P_{B}}{2} \\
& X P=\frac{Z P_{A}+Z P_{B}}{2}
\end{aligned}
$$

Este método permite verificar as medidas realizadas analisando-se os valores dos erros residuais $v 1, v 2$ e $v 3$ obtidos no processo de ajustamento. Esses fatos tornam o método mais confiável em relação à interseção espacial trigonométrica.

Trata-se, porém, de um método inconsistente para o procedimento adotado por esta pesquisa, na qual se realiza a orientação do azimute de cada instrumento por meio da recessão, considerando-se três bases de referência, tanto para as operações em campo, quanto para o cálculo das rotinas computacionais. Tal inconsistência ocorre, porque o método exige a visada recíproca dos instrumentos entre si, após cada um deles ter registrado o azimute em relação ao outro.

\subsubsection{Método de interseção espacial analítico com superdeterminação de medidas}

Tal método fundamenta-se na interseção espacial analítica, como mostra a Figura 33. A proposta desta metodologia foi apresentada por Ibiapina (1993) e, 
basicamente, consiste em associar a cada ponto da rede com coordenadas conhecidas, versores que definem a direção destes pontos ao alvo.

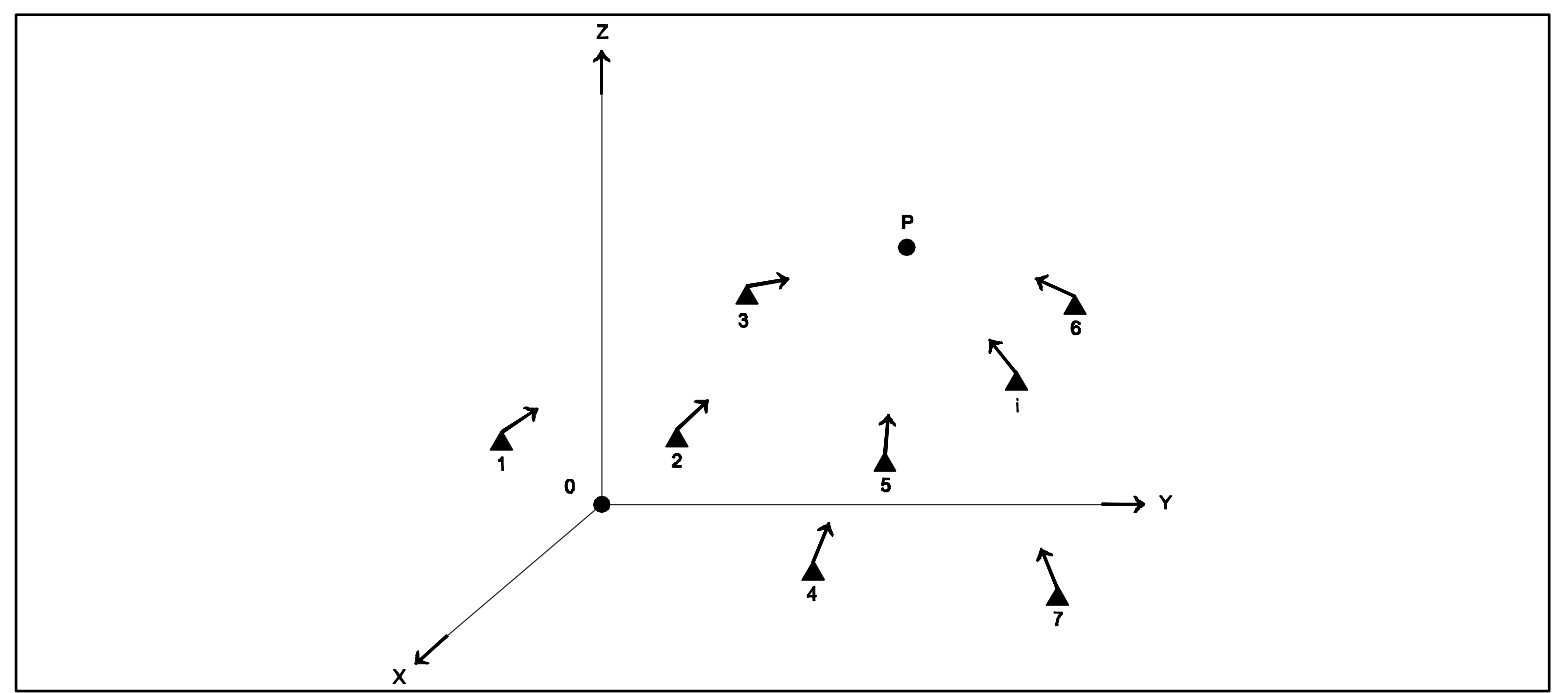

Figura 33 - Esquema representativo do método de interseção espacial analítica com superdeterminação de medidas

Fonte: Adaptado de Ibiapina (1993)

Os pontos $i$ e $j$ e os versores correspondentes $w_{i} e w_{j}$, definem as retas $r_{i}$ e $r_{j}$. As projeções dos versores no sistema de referência adotado são estabelecidas pelos ângulos horizontais $\alpha_{i} e \alpha_{j}$ e zenitais $Z e n_{i} e Z e n_{j}$, como mostra a Figura 34 .

Ainda, segundo esta, as coordenadas de $w_{i} e w_{j}$ são respectivamente:

$$
\begin{aligned}
& w_{i}=\left(\operatorname{sen}\left(Z e n_{i}\right) \cdot \operatorname{sen}\left(\alpha_{i}\right) ; \operatorname{sen}\left(Z e n_{i}\right) \cdot \cos \left(\alpha_{i}\right) ; \cos \left(Z e n_{i}\right)\right) \\
& w_{j}=\left(\operatorname{sen}\left(Z e n_{j}\right) \cdot \operatorname{sen}\left(\alpha_{j}\right) ; \operatorname{sen}\left(Z e n_{j}\right) \cdot \cos \left(\alpha_{j}\right) ; \cos \left(Z e n_{j}\right)\right)
\end{aligned}
$$

Sendo:

$w_{i}$ e $w_{j}$ - Versores em direção ao alvo P;

$Z e n_{i}$ e $Z e n_{j}$ - Ângulos zenitais medidos de cada ponto;

$\alpha_{i}$ e $\alpha_{j}$ - Ângulos horizontais medidos de cada ponto;

$i-1,2,3, \ldots, n-1$ 
$j-2,3,4, \ldots, n$;

$n$ - Número de estações de referência.

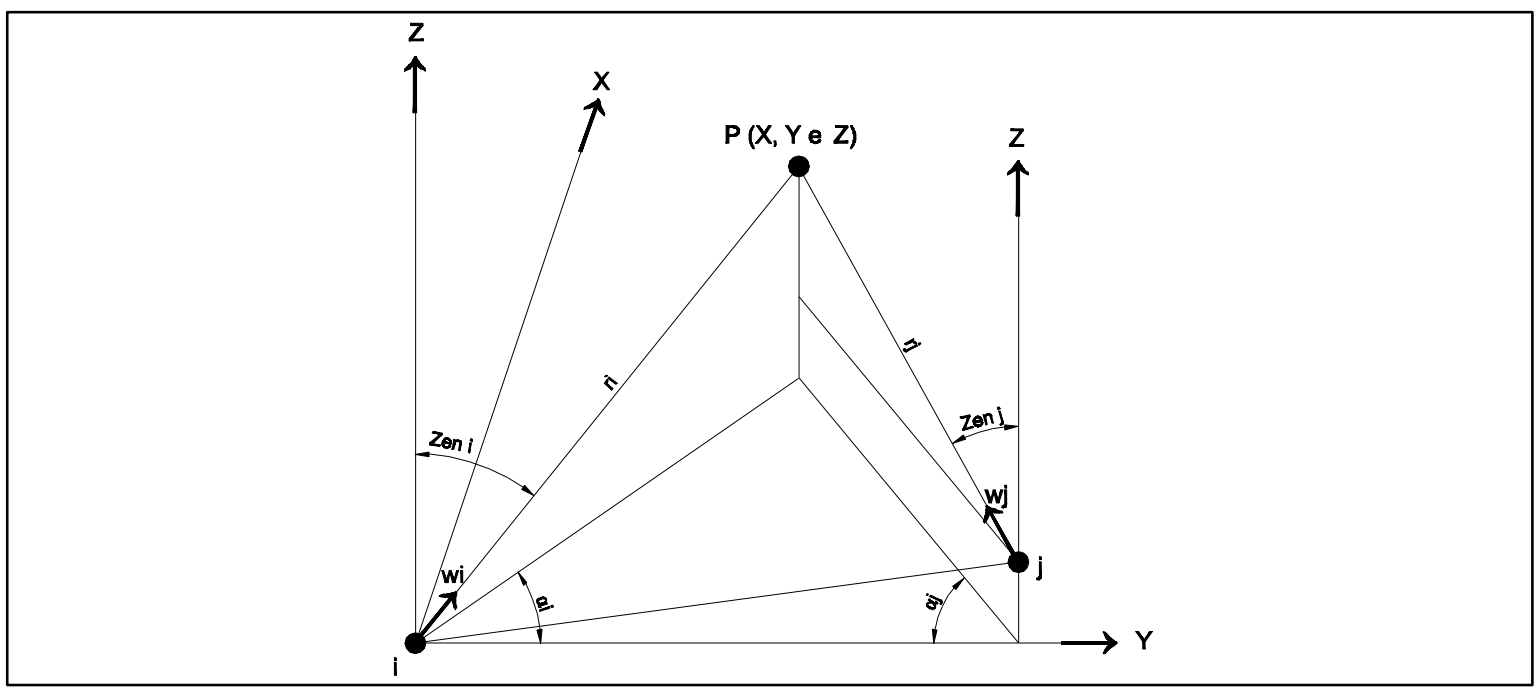

Figura 34 - Representação gráfica do método de interseção espacial analítica Fonte: Adaptado de WILD/TMS (1992) apud Ibiapina (1993)

A interseção espacial analítica com superdeterminação de medidas exige a resolução de uma perpendicular comum entre duas retas reversas no espaço, conforme ilustra a Figura 35.

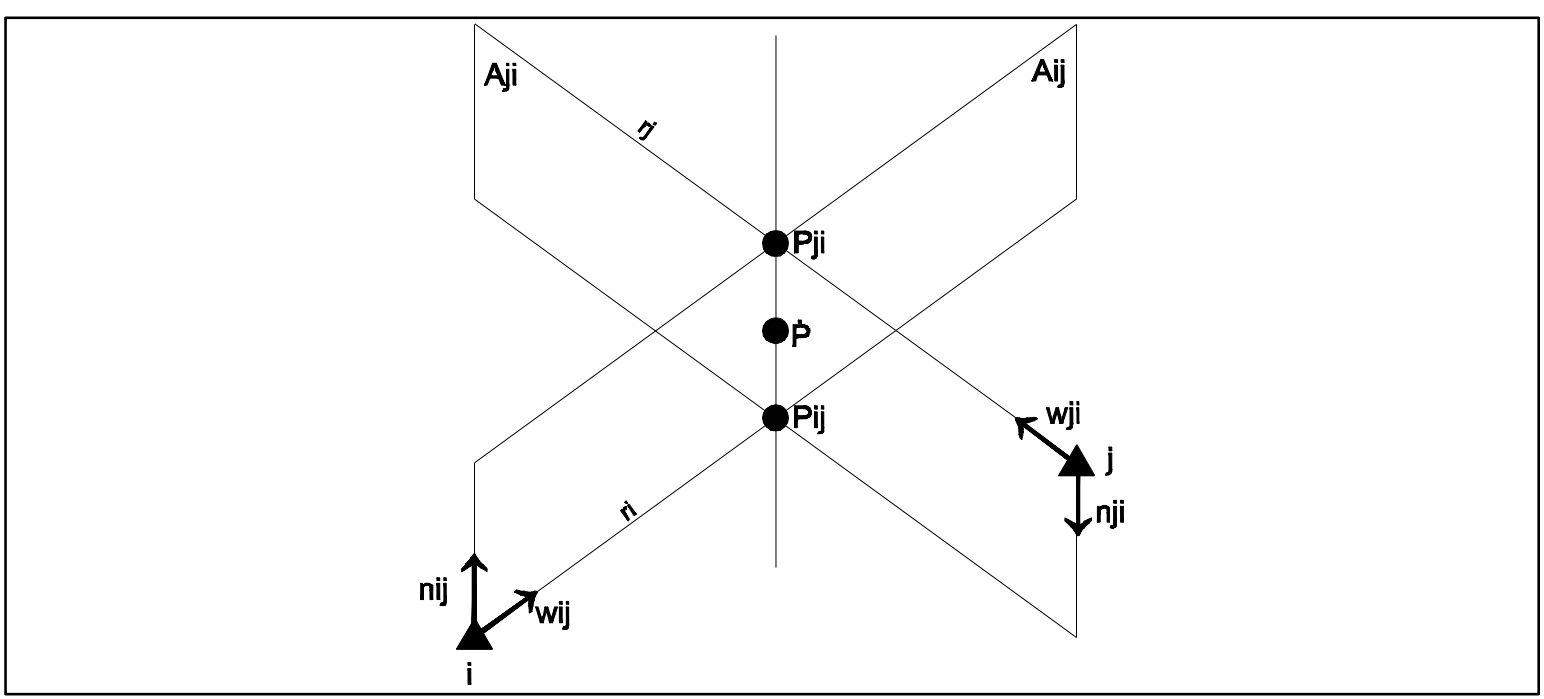

Figura 35 - Representação da reta perpendicular comum pertencente aos planos $A_{i j}$ e $A_{j i}$ Fonte: Adaptado de Ibiapina (1993) 
Para este procedimento, deve-se seguir a sequência:

1. Calcular o vetor perpendicular comum $n_{i j}$ a $w_{i} e w_{j}$ localizado no ponto $i$;

2. Conhecer o plano $A_{i j}$ que contém $w_{i}$ e $n_{i j}$ localizado em $i$;

3. Conhecer a reta de interseção $r_{j}$ localizada no ponto $j$;

4. Determinar o ponto $P_{j i}$ onde a reta $r_{j}$ o plano $A_{i j}$;

5. Calcular o vetor perpendicular comum $n_{i j}$ a $w_{i}$ e $w_{j}$ localizado em $j$;

6. Conhecer o plano $A_{i j}$ que contém $w_{i}$ e $n_{j i}$ localizado em $j$;

7. Conhecer a reta de interseção $r_{i}$ localizada no ponto $i$;

8. Determinar o ponto $P_{i j}$ onde a reta $r_{i}$ intercepta o plano $A_{j i}$;

9. E, por fim, calcular o ponto médio $\bar{P}$ entre $P_{j i}$ e $P_{i j}$.

Para determinar o versor que estabelece a perpendicular, comum entre as retas de interseção, com base nesses referenciais analíticos, calcula-se o produto vetorial de $w_{i} e w_{j}$.

Portanto:

$$
n_{i j}=w_{i} \wedge w_{j}
$$

Sendo:

$n_{i j}-$ Versor perpendicular comum aos versores $w_{i}$ e $w_{j}$;

$w_{i}$ e $w_{j}$-Versores localizados nos pontos $i$ e $j$, respectivamente.

Os versores $n_{i j}$ e $w_{i}$ e $w_{j}$ localizados no ponto $i$, aqui denominado de ponto de origem, definem um plano $A_{i j}$, conforme mostra a Figura 36. 


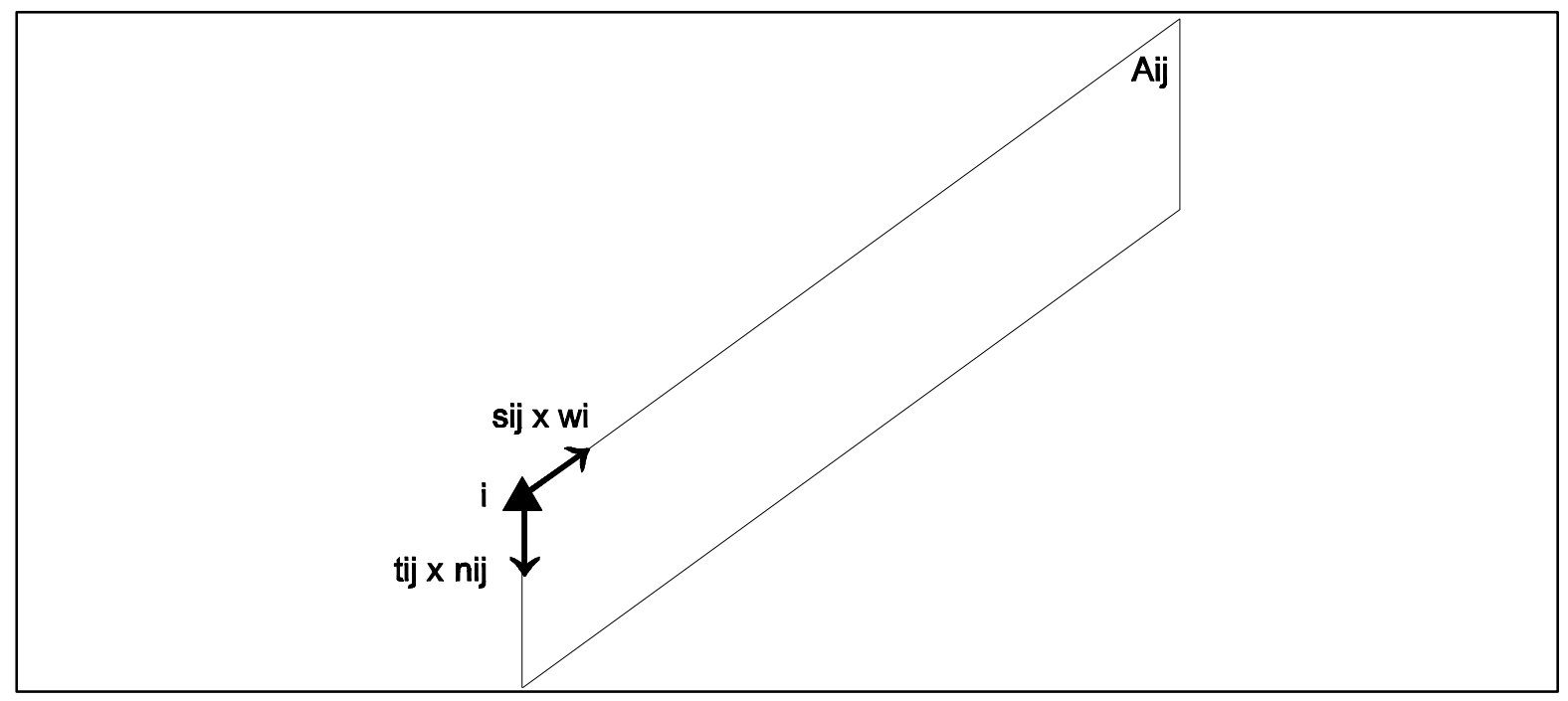

Figura 36 - Representação do plano $A_{i j}$ formado pelo versor $w_{i}$ e pelo versor perpendicular comum $n_{i j}$ com origens no ponto $i$

Fonte: Adaptado de Ibiapina (1993)

Como se pode ver, as coordenadas de um ponto qualquer $P_{A_{i j}}$, pertencem ao plano e são dadas pela equação (3.53):

$$
\left(X_{A_{i j}}, Y_{A_{i j}}, Z_{A_{i j}}\right)=\left(X_{i}, Y_{i}, Z_{i}+h_{i}\right)+s_{i j}\left(X_{w_{i}}, Y_{w_{i}}, Z_{w_{i}}\right)+t_{i j}\left(X_{n_{i j}}, Y_{n_{i j}}, Z_{n_{i j}}\right)
$$

Sendo:

$$
\begin{aligned}
& X_{i}, Y_{i} \text { e } Z_{i} \text { - Coordenadas espaciais do ponto de origem } i \\
& h_{i} \text { - Altura do instrumento no ponto } i \\
& X_{w_{i}}, Y_{w_{i}} \text { e } Z_{w_{i}}-\text { Coordenadas do versor } w_{i} \\
& X_{n_{i j}}, Y_{n_{i j}} \text { e } Z_{n_{i j}}-\text { Coordenadas do versor } n_{i j} \\
& s_{i j} \text { e } t_{i j} \text { - Parâmetros do plano } A_{i j}
\end{aligned}
$$

As coordenadas de $P_{A_{i j}}$ são funções dos parâmetros determinantes do plano $A_{i j}$, daí:

$$
X_{A_{i j}}=X\left(s_{i j}, t_{i j}\right)
$$




$$
\begin{aligned}
& Y_{A_{i j}}=Y\left(s_{i j}, t_{i j}\right) \\
& Z_{A_{i j}}=Z\left(s_{i j}, t_{i j}\right)
\end{aligned}
$$

A equação paramétrica do plano $A_{i j}$, conforme a figura 36 , é a seguinte:

$$
A_{i j}\left(s_{i j}, t_{i j}\right)=\left(X_{i}, Y_{i}, Z_{i}+h_{i}\right)+s_{i j}\left(X_{w_{i}}, Y_{w_{i}}, Z_{w_{i}}\right)+t_{i j}\left(X_{n_{i j}}, Y_{n_{i j}}, Z_{n_{i j}}\right)
$$

Sendo:

$X_{i}, Y_{i}$ e $Z_{i}$ - Coordenadas espaciais do ponto de origem $i$;

$h_{i}$ - Altura do instrumento no ponto $i$

$X_{w_{i}}, Y_{w_{i}}$ e $Z_{w_{i}}$ - Coordenadas do versor $w_{i}$;

$X_{n_{i j}}, Y_{n_{i j}}$ e $Z_{n_{i j}}$ - Coordenadas do versor $n_{i j}$;

$s_{i j}$ e $t_{i j}$ - Parâmetros do plano $A_{i j}$.

As coordenadas de um ponto $P_{r j}$, pertencente à reta de interseção $r_{j}$, com origem no ponto $j$ e estabelecida pelo vetor $w_{j}$, são dadas por:

$$
\left(X_{r_{j}}, Y_{r_{j}}, Z_{r_{j}}\right)=\left(X_{j}, Y_{j}, Z_{j}\right)+m_{j i}\left(X_{w_{j}}, Y_{w_{j}}, Z_{w_{j}}\right)
$$

Sendo:

$X_{j}, Y_{j}$ e $Z_{j}$ - Coordenadas espaciais do ponto de origem $j$;

$h_{j}$ - Altura do instrumento no ponto $j$;

$X_{w_{j}}, Y_{w_{j}}$ e $Z_{w_{j}}-$ Coordenadas do versor $w_{j}$

$m_{j i}$ - Parâmetros da reta de interseção $r_{j}$. 
As coordenadas de $P_{r j}$ são funções dos parâmetros determinantes da reta $r_{j}$, dessa forma:

$$
\begin{aligned}
& X_{r j}=X\left(m_{j i}\right) \\
& Y_{r j}=Y\left(m_{j i}\right) \\
& Z_{r j}=Z\left(m_{j i}\right)
\end{aligned}
$$

A equação paramétrica da reta de interseção $r_{j}$, conforme ilustrado pela Figura 37, é a seguinte:

\section{rj}

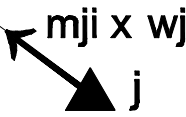

Figura 37 - Representação da reta de interseção $r_{j}$ com origem no ponto $j$ Fonte: Adaptado de Ibiapina (1993)

$$
r_{j}\left(m_{j i}\right)=\left(X_{j}, Y_{j}, Z_{j}+h_{j}\right)+m_{j i}\left(X_{w_{j}}, Y_{w_{j}}, Z_{w_{j}}\right)
$$

Sendo:

$X_{j}, Y_{j}$ e $Z_{j}$ - Coordenadas espaciais do ponto de origem $j$;

$h_{j}-$ Altura do instrumento no ponto $j$;

$X_{w_{j}}, Y_{w_{j}}$ e $Z_{w_{j}}$ - Coordenadas do versor $w_{j}$

$m_{j i}$ - Parâmetros da reta de interseção $r_{j}$. 
O cálculo do ponto de interseção $P_{j i}$ é feito, determinando-se o ponto onde a reta $r_{j}$ intercepta o plano $A_{i j}$, conforme a Figura 38 .

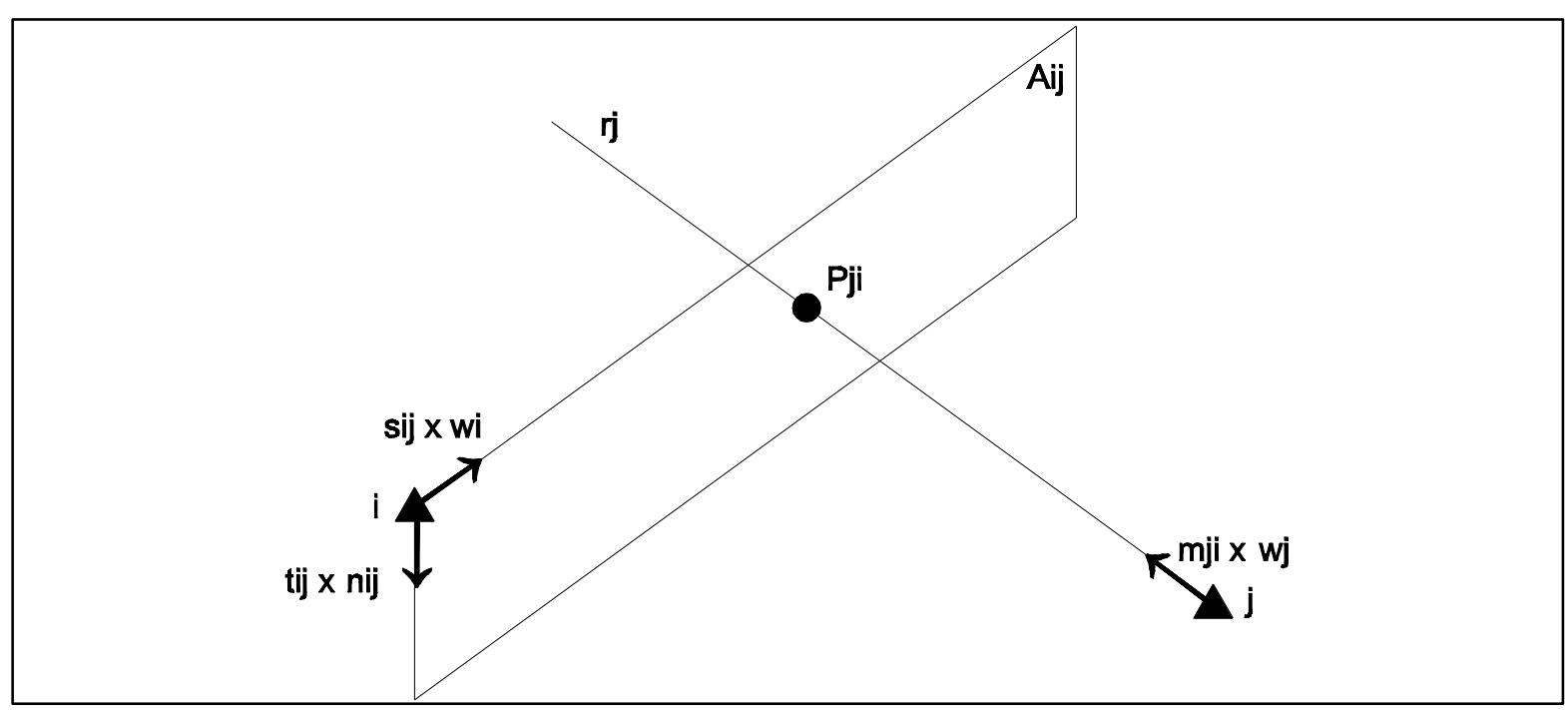

Figura 38 - Representação do posicionamento do ponto de interseção $P_{j i}$, onde $\left(P_{j i}=A_{i j} \cap r_{j}\right)$

Fonte: Adaptado de Ibiapina (1993)

Portanto:

$$
P_{A_{i j}}\left(s_{i j}, t_{i j}\right)=P_{r j}\left(m_{j i}\right)
$$

Da equação (3.53), obtêm-se as coordenadas do ponto $P_{A_{i j}}$, as quais são dadas pelas seguintes equações:

$$
\begin{aligned}
& X_{A_{i j}}\left(s_{i j}, t_{i j}\right)=X_{i}+s_{i j} \cdot X_{w_{i}}+t_{i j} \cdot X_{n_{i j}} \\
& Y_{A_{i j}}\left(s_{i j}, t_{i j}\right)=Y_{i}+s_{i j} \cdot Y_{w_{i}}+t_{i j} \cdot Y_{n_{i j}} \\
& Z_{A_{i j}}\left(s_{i j}, t_{i j}\right)=Z_{i}+h_{i}+s_{i j} \cdot Z_{w_{i}}+t_{i j} \cdot Z_{n_{i j}}
\end{aligned}
$$

E, da equação (3.58), obtêm-se as coordenadas do ponto $P_{r j}$, que são dadas pelas seguintes equações:

$$
X_{r_{j}}\left(m_{j i}\right)=X_{j}+m_{j i} \cdot X_{w_{j}}
$$




$$
\begin{aligned}
& Y_{r_{j}}\left(m_{j i}\right)=Y_{j}+m_{j i} \cdot Y_{w_{j}} \\
& Z_{r_{j}}\left(m_{j i}\right)=Z_{j}+h_{j}+m_{j i} \cdot Z_{w_{j}}
\end{aligned}
$$

No ponto $P_{j i}$, onde a reta de interseção $r_{j}$ intercepta o plano $A_{i j}$, as coordenadas do ponto $P_{A_{i j}}$ são iguais às coordenadas do ponto $P_{r j}$.

Logo:

$$
\begin{aligned}
& X_{A_{i j}}\left(s_{i j}, t_{i j}\right)=X_{r j}\left(m_{j i}\right) \\
& Y_{A_{i j}}\left(s_{i j}, t_{i j}\right)=Y_{r j}\left(m_{j i}\right) \\
& Z_{A_{i j}}\left(s_{i j}, t_{i j}\right)=Z_{r j}\left(m_{j i}\right)
\end{aligned}
$$

Ou ainda:

$$
\begin{aligned}
& X_{A_{i j}}\left(s_{i j}, t_{i j}\right)-X_{r j}\left(m_{j i}\right)=0 \\
& Y_{A_{i j}}\left(s_{i j}, t_{i j}\right)-Y_{r j}\left(m_{j i}\right)=0 \\
& Z_{A_{i j}}\left(s_{i j}, t_{i j}\right)-Z_{r j}\left(m_{j i}\right)=0
\end{aligned}
$$

Os conjuntos de equações (3.64 a 3.66) e (3.67 a 3.69) estabelecem o seguinte sistema de equações:

$$
\begin{aligned}
& s_{i j} \cdot X_{w_{i}}+t_{i j} \cdot X_{n_{i j}}-m_{j i} \cdot X_{w_{j}}=X_{j}-X_{i} \\
& s_{i j} \cdot Y_{w_{i}}+t_{i j} \cdot Y_{n_{i j}}-m_{j i} \cdot Y_{w_{j}}=Y_{j}-Y_{i} \\
& s_{i j} \cdot Z_{w_{i}}+t_{i j} \cdot Z_{n_{i j}}-m_{j i} \cdot Z_{w_{j}}=\left(Z_{j}+h_{j}\right)-\left(Z_{i}+h_{i}\right)
\end{aligned}
$$

As incógnitas do sistema estabelecido pelas equações paramétricas do plano $A_{i j}$ e da reta $r_{j}$ são os parâmetros $s_{i j}, t_{i j}$ e $m_{i j}$. Após o cálculo das incógnitas, determinam-se as coordenadas espaciais do ponto de interseção $P_{j i}$, substituindo os 
valores de $s_{i j}$ e $t_{i j}$ na equação paramétrica do plano $A_{i j}$, ou substituindo o valor de $m_{i j}$ na equação paramétrica da reta $r_{j}$.

Já, substituindo o parâmetro $m_{i j}$ da reta de interseção $r_{j}$, obtém-se que:

$$
P_{j i}=\left(X_{j}, Y_{j}, Z_{j}+h_{j}\right)+m_{j i}\left(X_{w_{j}}, Y_{w_{j}}, Z_{w_{j}}\right)
$$

Assim, as coordenadas espaciais do ponto de interseção $P_{j i}$ são:

$$
\begin{aligned}
& X_{P_{j i}}=X_{j}+m_{j i} \cdot X_{w_{j}} \\
& Y_{P_{j i}}=Y_{j}+m_{j i} \cdot Y_{w_{j}} \\
& Z_{P_{j i}}=Z_{j}+h_{j}+m_{j i} \cdot X_{w_{j}}
\end{aligned}
$$

Ou ainda:

$$
\begin{aligned}
& X_{P_{j i}}=X_{j}+m_{j i} \cdot \operatorname{sen}\left(\alpha_{j}\right) \cdot \operatorname{sen}\left(Z_{e n_{j}}\right) \\
& Y_{P_{j i}}=Y_{j}+m_{j i} \cdot \cos \left(\alpha_{j}\right) \cdot \operatorname{sen}\left(Z e n_{j}\right) \\
& Z_{P_{j i}}=Z_{j}+h_{j}+m_{j i} \cdot \cos \left(Z_{e n_{j}}\right)
\end{aligned}
$$

Os procedimentos de cálculo para determinar as coordenadas espaciais do ponto de interseção $P_{i j}$ seguem a mesma linha de raciocínio dos procedimentos para o cálculo do ponto de interseção $P_{j i}$.

Os dois pontos calculados $P_{i j}$ e $P_{j i}$ são os aqueles lançados pela interseção $i j$, pertencentes à reta perpendicular comum, conforme mostrado na Figura 39.

Com a hipótese de que as leituras angulares realizadas possuem pesos iguais, o posicionamento do ponto lançado é a média entre os pontos de interseção $P_{i j}$ e $P_{j i}$, como mostra a Figura 39. 


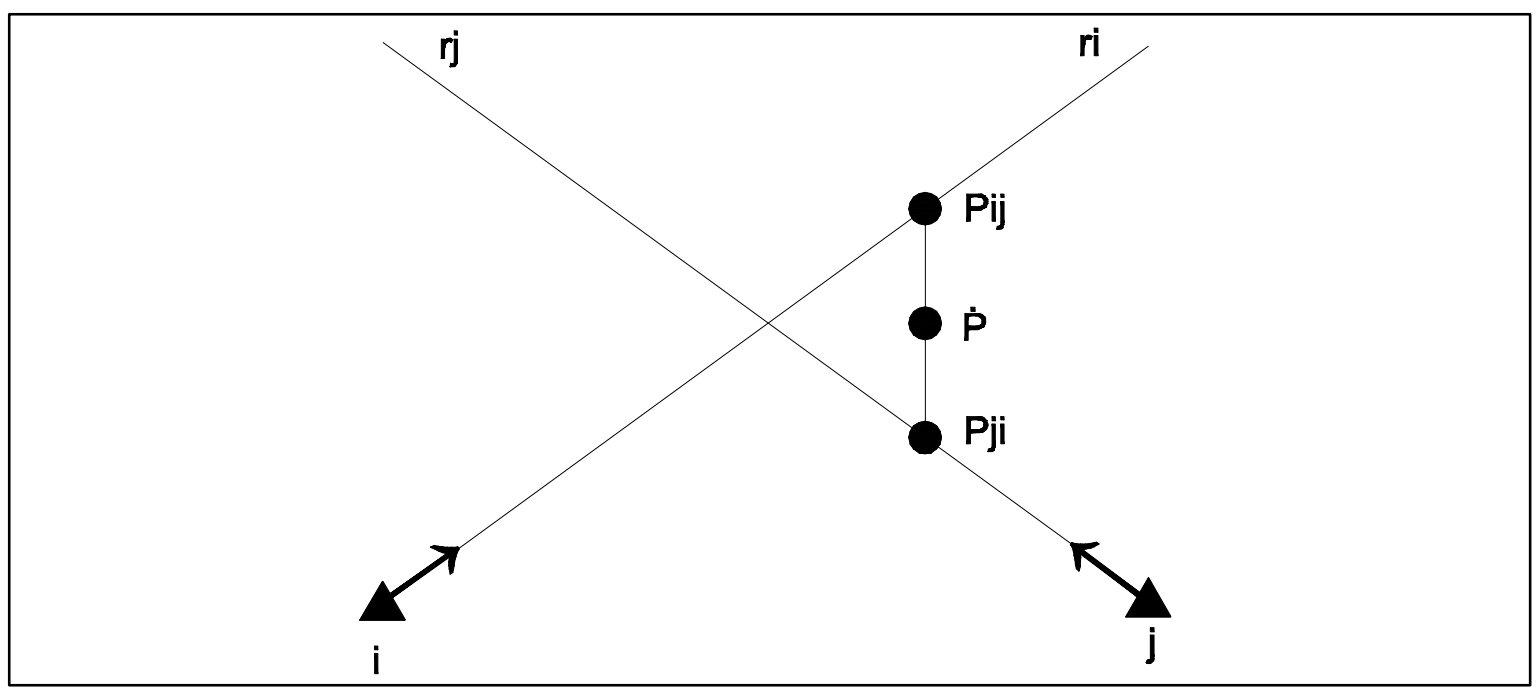

Figura 39 - Esquema de posicionamento dos pontos de interseção $P_{i j}$ e $P_{j i}$ e o ponto médio $\bar{P}$ utilizando o método de interseção espacial analítica Fonte: Adaptado de Ibiapina (1993)

Assim:

$$
\bar{P}=\frac{P_{i j}+P_{j i}}{2}
$$

As coordenadas do ponto $\bar{P}$ são dadas por:

$$
\begin{gathered}
\bar{X}=\frac{X_{P_{i j}}+X_{P_{j i}}}{2} \\
\bar{Y}=\frac{Y_{P_{i j}}+Y_{P_{j i}}}{2} \\
\bar{Z}=\frac{Z_{P_{i j}}+Z_{P_{j i}}}{2}
\end{gathered}
$$

Quando há superdeterminação de medidas, a solução ótima para as coordenadas espaciais do alvo são calculadas considerando-se que os valores compensados destas coordenadas são iguais à média aritmética das $m$ soluções obtidas pela combinação das $n$ estações de referência, duas a duas.

Portanto:

$$
\bar{P}=\frac{\bar{P}_{1}+\bar{P}_{2}+\bar{P}_{3}+\cdots+\bar{P}_{n}}{m}
$$


Sendo:

$n$ - Número de estações;

$m$ - Número total de combinações das $n$ estações;

$\bar{P}_{i}$ - Ponto médio, determinado em cada combinação;

$\bar{P}$ - Média das $m$ combinações.

As coordenadas espaciais do ponto lançado P são dadas por:

$$
\begin{aligned}
& \overline{X P}=\frac{\overline{X P}_{12}+\overline{X P}_{13}+\overline{X P}_{14}+\cdots+\overline{X P}_{i j}+\cdots}{m} \\
& \overline{Y P}=\frac{\overline{Y P}_{12}+\overline{Y P}_{13}+\overline{Y P}_{14}+\cdots+\overline{Y P}_{i j}+\cdots}{m} \\
& \overline{Z P}=\frac{\overline{Z P}_{12}+\overline{Z P}_{13}+\overline{Z P}_{14}+\cdots+\overline{Z P}_{i j}+\cdots}{m}
\end{aligned}
$$

Sendo:

$\bar{X}, \bar{Y}$ e $\bar{Z}$ - Coordenadas espaciais compensadas do alvo;

$\overline{X P_{\imath \jmath}}, \overline{Y P_{\imath \jmath}} e \overline{Z P_{\imath \jmath}}$ - Coordenadas espaciais do alvo obtidas em cada interseção;

$i$ - Índice com variação de $(1 a n-1)$;

$j$ - Índice com variação de (2a n);

n - Número de estações;

$m$ - Número total de interseções. 


\section{METODOLOGIA E DESENVOLVIMENTO}

Neste capítulo, apresenta-se, inicialmente, o local utilizado para o desenvolvimento desta pesquisa e, em seguida, a realização e a implantação da rede absoluta de referência. Por fim, mostra-se a validação do método polar, e, posteriormente, o desenvolvimento dos métodos das distâncias mínimas.

\subsection{DESCRIÇÃO DO LOCAL DE ESTUDO}

\subsubsection{Localização}

A necessidade de um local amplo e com estruturas que possibilitassem elaborar simulações, milimetricamente controladas, de alvos, foi um fator crucial para a escolha e solicitação do espaço laboratorial do Departamento de Engenharia de Estruturas da Escola de Engenharia de São Carlos (SET/EESC/USP). A Figura 40 mostra uma parte do laboratório onde foram realizados os experimentos.

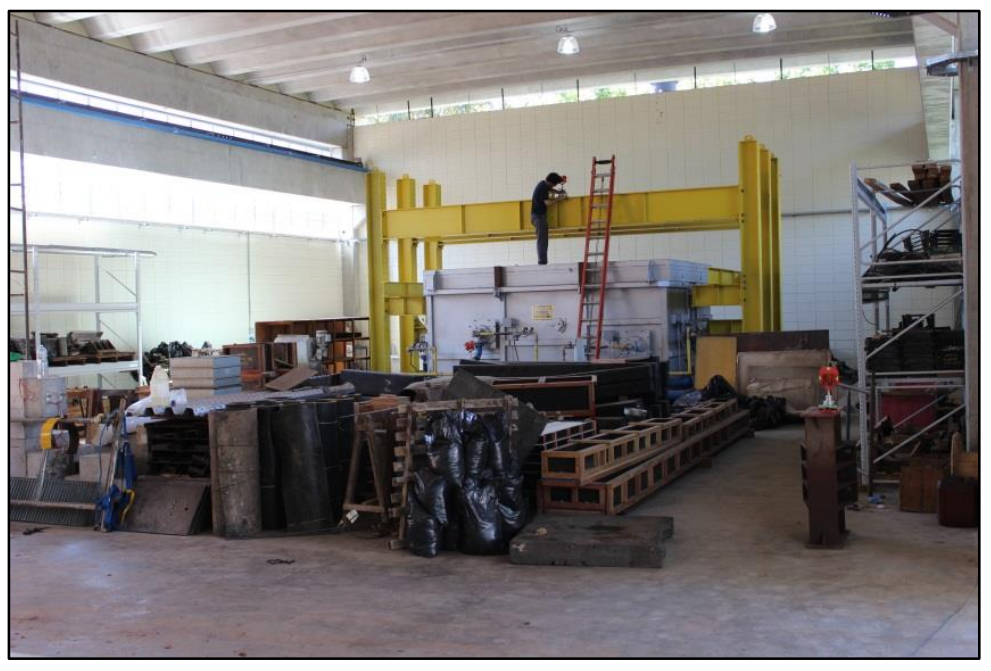

Figura 40 - Laboratório de Estruturas (SET/EESC/USP) 
A Figura 41 mostra todo instrumental utilizado para a realização de coletas de dados, descarga e processamento das observações neste laboratório:

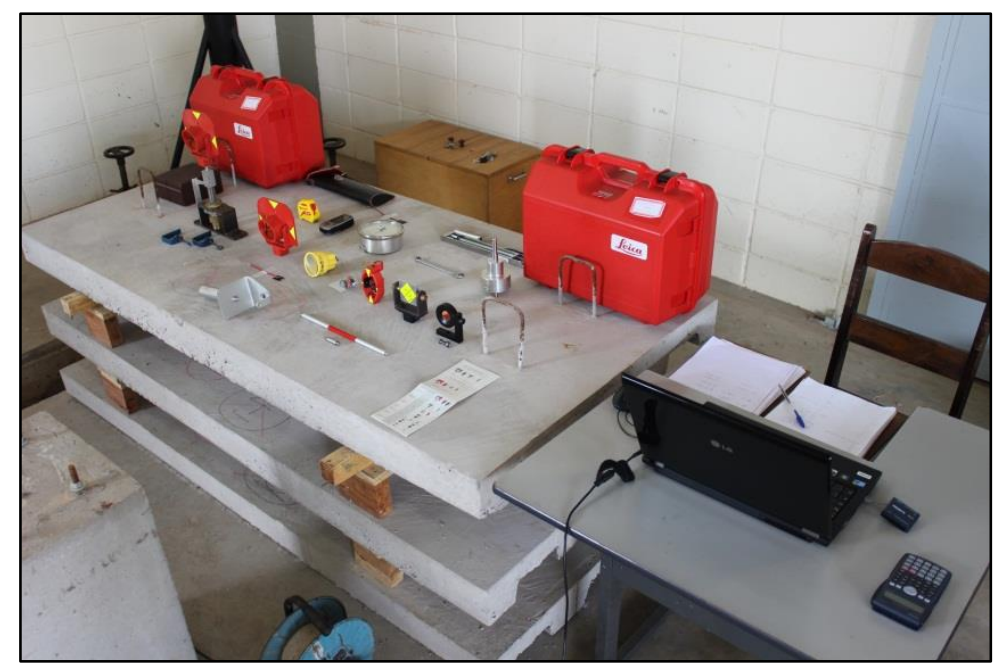

Figura 41 - Organização do instrumental no laboratório

\subsection{IMPLANTAÇÃO DA REDE ABSOLUTA DE REFERÊNCIA}

\subsubsection{Introdução}

Como citado anteriormente, o objetivo final de realizar medições utilizando técnicas de mensuração no monitoramento de estruturas, é determinar as coordenadas espaciais dos pontos na superfície da estrutura com deslocamento em relação a um referencial fixo e estável. Assim, é possível, depois de observações periódicas, determinar as diferenças de coordenadas em épocas ou posições distintas e, consequentemente, os deslocamentos absolutos dos pontos.

Necessariamente, os valores previstos das grandezas a serem monitoradas, ou seja, os controles milimétricos na variação dos pontos têm que ser detectados pelas metodologias e instrumentos empregados, isto é, não somente a precisão dos instrumentos, como também dos resultados obtidos, deverão estar adequadas aos deslocamentos milimétricos previstos para o estudo em questão.

Ainda, em relação ao padrão das precisões das observações, um aspecto importante está relacionado à escolha das técnicas e dos instrumentos utilizados. 
Nesse sentido, considerou-se como sendo zero, a altura de todos os instrumentos posicionados em cada base para todos os procedimentos. Tal fato eliminou um erro inerente à determinação dos centros ópticos dos instrumentos, pois, sua altura sendo zero, automaticamente, todo o sistema está referenciado no próprio centro óptico do instrumento; mantendo, portanto, o mesmo referencial.

Os pontos da rede de referência e os alvos fixados no corpo estrutural podem ter suas posições controladas, a partir de séries de observações predeterminadas, utilizando o ajustamento de observações, no qual se emprega o M.M.Q. com a aplicação do método paramétrico.

Segundo Dalmolin (2004), o ajustamento das observações e análises estatísticas são indispensáveis para trabalhos envolvendo mensuração, por fornecerem resultados confiáveis sobre as medidas obtidas em campo e sua modelagem em geral, o que expressa uma realidade física com a melhor aproximação possível.

\subsubsection{Determinação das coordenadas espaciais das estações base que compõem a rede absoluta de referência para a monitoração de estruturas}

A rede absoluta de referência é composta por cinco estações base localizadas externamente à estrutura, na qual os alvos foram engastados, sendo estas bases denominadas por Base 1, 2, 3, 4 e 5, as quais estão dispostas na forma de um pentágono. As Bases 1 e 2 são materializadas por tripés industriais de centragem forçada e utilizadas para efetuar as medições junto aos alvos fixados na estrutura. Já as Bases 3, 4 e 5 são materializadas por uma base de ferro estrutural e foram utilizadas para referência e verificação da estabilidade das Bases 1 e 2 por meio de medições pelo Método de Recessão.

Após materializar essa rede no Laboratório de Estruturas, adotou-se um procedimento, descrito a seguir, para realizar as medições, o ajustamento e o teste estatístico, com a finalidade de determinar as coordenadas espaciais de todas as 
estações base envolvidas na rede absoluta. Assim, foi estabelecido um sistema tridimensional de referência local, com origem na Base 1, conforme Tabela 4.

Tabela 4 - Coordenadas arbitradas para Base 1

\begin{tabular}{cccc}
\hline \multicolumn{4}{c}{ COORDENADAS ARBITRADAS } \\
\hline & $\mathrm{X}(\mathrm{m})$ & $\mathrm{Y}(\mathrm{m})$ & $\mathrm{Z}(\mathrm{m})$ \\
\hline Base 1 & $1.000,0000$ & $5.000,0000$ & 100,0000 \\
\hline
\end{tabular}

O procedimento adotado foi o seguinte:

1. Definiu-se a sequência de ocupação das bases, respectivamente como (B1, B5, B4, B3 e B2);

2. Para a realização deste procedimento, adotou-se a estação total robótica (TCRA 1201+), escolhida pelo fato de apresentar duas certificações em duas oficinas distintas;

3. Fez-se a padronização do nivelamento de todas as bases da rede, antes de posicionar os alvos e direcioná-los para a base ocupada pela estação total robótica. Para isso, adotou-se o nível de bolha digital da referida estação, seguindo a sequência citada no item 1;

4. Posicionou-se a estação total robótica na primeira base (B1), aguardaram-se quinze minutos para adaptação do instrumento e, em seguida, coletaram-se os dados metereológicos, temperatura, pressão e umidade relativa do ar, para inseri-los no instrumento, o qual efetua a devida correção atmosférica;

5. Iniciaram-se as observações da base (B1) para a (B5), zerando o azimute da estação total robótica nesta base, obtendo-se direções zenitais e azimutais no sentido horário de ângulos internos e externos da rede. Todas as observações foram iniciadas na posição direta da luneta (Face I);

6. Realizaram-se sete séries completas de leituras conjugadas (Face I e II) para cada medição angular e de distância para todas as bases da rede, utilizando o modo ATR. E, conforme o manual de referência Leica (2007, p.1099), desta série de leitura, é 
armazenado o valor médio das medidas, cálculo efetuado internamente pela estação total robótica;

7. Ao encerrar as medições a partir da base (B1), iniciou-se o caminhamento entre as bases da rede respeitando o item 1;

8. Exemplificando, a estação total robótica ocupou a base (B5) e visou, primeiramente, a base (B4), porém, o azimute de origem do sistema já estava zerado e orientado na (B5). Assim, todas as bases da rede foram conhecidas "a priori" devido a realização do item 6. Dessa forma, a função Known BackSight Point foi utilizada e então a estação total robótica orientou o azimute para a direção (B4);

9. Todos os procedimentos do item 6 foram adotados para cada ocupação das bases da rede absoluta de referência.

Após realizar esses procedimentos para todas as bases que compõem a rede absoluta, iniciou-se outra etapa: a descarga e o processamento dos dados coletados. Ao descarregar as observações no software LGO, pôde-se visualizar e conhecer os dados planimétricos observados, como mostra a Tabela 5. 
Tabela 5 - Dados planimétricos observados

\begin{tabular}{|c|c|c|c|}
\hline Direções & Azimutes & Direções & Distância Hz (m) \\
\hline $1-4$ & $15^{\circ} 46^{\prime} 45,6244^{\prime \prime}$ & $1-5$ & 12,6384 \\
\hline $1-3$ & $43^{\circ} 11^{\prime} 34,1270 "$ & $1-3$ & 17,6233 \\
\hline $1-2$ & $86^{\circ} 43^{\prime} 12,2767^{\prime \prime}$ & $1-4$ & 20,9296 \\
\hline $1-5$ & $359^{\circ} 59^{\prime} 41,4987^{\prime \prime}$ & $5-4$ & 9,4173 \\
\hline $5-4$ & $37^{\circ} 11^{\prime} 03,6029 "$ & $4-3$ & 9,6836 \\
\hline $4-3$ & $138^{\circ} 51^{\prime} 34,9109^{\prime \prime}$ & $3-2$ & 12,1416 \\
\hline $3-2$ & $175^{\circ} 03^{\prime} 00,8453^{\prime \prime}$ & $2-1$ & 13,1312 \\
\hline $2-1$ & $266^{\circ} 42^{\prime} 54,1984^{\prime \prime}$ & $5-2$ & 17,6964 \\
\hline $5-3$ & $89^{\circ} 00^{\prime} 05,9442^{\prime \prime}$ & $5-3$ & 12,0648 \\
\hline $5-2$ & $132^{\circ} 11^{\prime} 41,4536 "$ & $4-2$ & 20,7595 \\
\hline $5-1$ & $179^{\circ} 59^{\prime} 39,3791^{\prime \prime}$ & & \\
\hline $4-2$ & $159^{\circ} 03^{\prime} 38,6507^{\prime \prime}$ & & \\
\hline $4-1$ & $195^{\circ} 46^{\prime} 34,6940 "$ & & \\
\hline $4-5$ & $217^{\circ} 11^{\prime} 08,9459^{\prime \prime}$ & & \\
\hline $3-1$ & $223^{\circ} 11^{\prime} 09,3329 "$ & & \\
\hline $3-5$ & $269^{\circ} 00^{\prime} 06,9735^{\prime \prime}$ & & \\
\hline $3-4$ & $318^{\circ} 51^{\prime} 23,4568^{\prime \prime}$ & & \\
\hline $2-5$ & $312^{\circ} 11^{\prime} 55,5357^{\prime \prime}$ & & \\
\hline $2-4$ & $339^{\circ} 03^{\prime} 36,4434^{\prime \prime}$ & & \\
\hline $2-3$ & $355^{\circ} 03^{\prime} 12,4945^{\prime \prime}$ & & \\
\hline
\end{tabular}


E os dados altimétricos observados como ilustra a Tabela 6:

Tabela 6 - Dados altimétricos observados

\begin{tabular}{cccc}
\hline Direções & AElev $(\mathbf{m})$ & Direções & Distâncias $\mathrm{Hz}(\mathbf{m})$ \\
\hline $1-2$ & $-0,0533$ & $1-2$ & 13,1312 \\
$2-3$ & $-0,4449$ & $2-3$ & 12,1416 \\
$3-4$ & $-0,0048$ & $3-4$ & 9,6836 \\
$4-5$ & 0,0175 & $4-5$ & 9,4173 \\
$5-1$ & 0,4900 & $5-1$ & 12,6384 \\
$2-5$ & $-0,4330$ & $2-5$ & 17,6964 \\
$2-4$ & $-0,4501$ & $2-4$ & 20,7595 \\
$3-5$ & 0,0121 & $3-5$ & 12,0648 \\
$1-4$ & $-0,5025$ & $1-4$ & 20,9296 \\
$1-3$ & $-0,4980$ & $1-3$ & 17,6233 \\
\hline
\end{tabular}

As coordenadas aproximadas das Bases (2, 3, 4 e 5), calculadas internamente pela estação total robótica e ilustrada pela Tabela 7 , foram utilizadas para o processamento e ajustamento da rede planimétrica por meio da rotina computacional elaborada no software MATLAB, conforme consta no Apêndice A. Elas foram utilizadas também para processar e ajustar a rede altimétrica, constante no Apêndice B.

Tabela 7 - Coordenadas aproximadas

\begin{tabular}{cccc}
\hline \multicolumn{4}{c}{ COORDENADAS APROXIMADAS } \\
\hline & $\mathrm{X}(\mathrm{m})$ & $\mathrm{Y}(\mathrm{m})$ & $\mathrm{Z}(\mathrm{m})$ \\
\hline Base 2 & $1.013,1098$ & $5.000,7513$ & 99,9482 \\
Base 3 & $1.012,0622$ & $5.012,8485$ & 99,5043 \\
Base 4 & $1.005,6913$ & $5.020,1410$ & 99,4992 \\
Base 5 & 999,9989 & $5.012,6383$ & 99,5137 \\
\hline
\end{tabular}


A Figura 42 ilustra a rede absoluta e as respectivas elipses de erros.

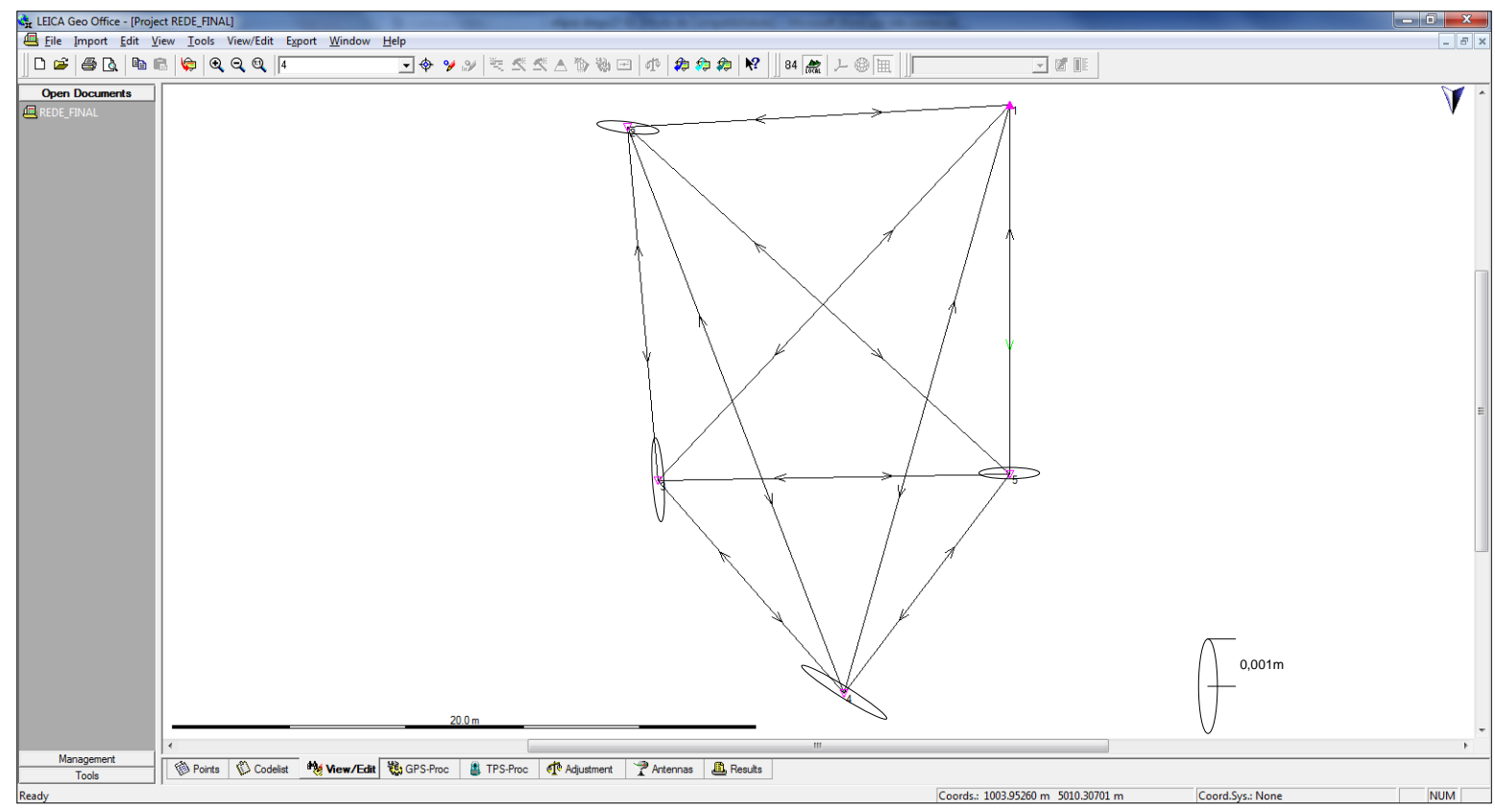

Figura 42 - Rede absoluta de referência e respectivas elipses de erros

A Tabela 8 mostra as coordenadas planialtimétricas processadas e ajustadas, seguidas de suas respectivas precisões.

Tabela 8 - Coordenadas e precisões planialtimétricas ajustadas

\begin{tabular}{ccccccc}
\hline \multicolumn{6}{c}{ COORDENADAS E PRECISÕES AJUSTADAS } \\
\hline & $\mathrm{X}(\mathrm{m})$ & $\sigma_{\mathrm{X}}(\mathrm{mm})$ & $\mathrm{Y}(\mathrm{m})$ & $\sigma_{\mathrm{Y}}(\mathrm{mm})$ & $\mathrm{Z}(\mathrm{m})$ & $\sigma_{\mathrm{Z}}(\mathrm{mm})$ \\
\hline Base 2 & $1.013,1095$ & $4,4319 \mathrm{E}-04$ & $5.000,7513$ & $1,4555 \mathrm{E}-06$ & 99,9462 & $7,6214 \mathrm{E}-04$ \\
Base 3 & $1.012,0619$ & $3,7519 \mathrm{E}-04$ & $5.012,8482$ & $4,2570 \mathrm{E}-04$ & 99,5012 & $7,6214 \mathrm{E}-04$ \\
Base 4 & $1.005,6912$ & $8,3526 \mathrm{E}-05$ & $5.020,1406$ & $1,0461 \mathrm{E}-03$ & 99,4963 & $7,6214 \mathrm{E}-04$ \\
Base 5 & 999,9989 & $3,1203 \mathrm{E}-12$ & $5.012,6380$ & $4,1189 \mathrm{E}-04$ & 99,5126 & $7,6213 \mathrm{E}-04$ \\
\hline
\end{tabular}

Já as precisões espaciais das coordenadas das Bases processadas e ajustadas, constam da Tabela 9. 
Tabela 9 - Precisões espaciais das Bases

\section{PRECISÕES ESPACIAIS DAS BASES}

\begin{tabular}{lc}
\hline & $\sigma_{X Y Z}(\mathrm{~mm})$ \\
\hline Base 2 & $4,4319 \mathrm{E}-04$ \\
Base 3 & $3,7519 \mathrm{E}-04$ \\
Base 4 & $8,3528 \mathrm{E}-05$ \\
Base 5 & $7,5362 \mathrm{E}-10$ \\
\hline
\end{tabular}

Com o intuito de detectar inconsistências do ajustamento, verificar prováveis causas da falha da suposição básica e analisar as diferenças encontradas nas coordenadas ajustadas da rede absoluta, realizou-se uma análise aplicando o Teste Bilateral do Qui-Quadrado $\left(\chi^{2}\right)$, com nível de significância $\alpha=5 \%$, variância "a priori" $\left(\sigma_{0}^{2}\right)=1$ e a variância "a posteriori" $\left(\hat{\sigma}_{0}^{2}\right)$ calculada, conforme ilustra a Tabela 10. As rotinas computacionais para a realização deste teste podem ser vistas nos Apêndices A e B.

Tabela 10 - Teste do $\left(\chi^{2}\right)$ para o ajustamento das redes plana e altimétrica

\begin{tabular}{lccccc}
\hline & $\widehat{\boldsymbol{\sigma}}_{\mathbf{0}}^{2}$ & $\chi_{\boldsymbol{r}, \frac{\boldsymbol{\alpha}}{2}}^{2}$ & $\chi_{\boldsymbol{r}, \mathbf{1}-\frac{\boldsymbol{\alpha}}{2}}^{2}$ & $\chi^{* \mathbf{2}}$ & Hipótese \\
\hline Rede Planimétrica & 1,3941 & 12,3380 & 33,9244 & 30,6713 & Aceita \\
Rede Altimétrica & 0,6902 & 1,6354 & 12,5916 & 2,8579 & Aceita \\
\hline
\end{tabular}

Sendo:

$\chi^{* 2}-$ Valores calculados para o teste do qui-quadrado $\left(\chi^{2}\right)$;

$\chi_{r, \frac{\alpha}{2}}^{2}$ e $\chi_{r, 1-\frac{\alpha}{2}}^{2}-$ Valores obtidos da tabela de distribuição do qui-quadrado $\left(\chi^{2}\right)$;

$\alpha$ - Nível de significância multidimensional.

$r$ - Grau de liberdade, obtido pela diferença entre o número de equações $n$ e o número de incógnitas $u$ a ser determinado, sendo: $r=30-8$, para a planimétrica; e $r=10-4$, para a altimétrica. 
Os valores calculados para $\left(\chi^{* 2}\right)$, tanto para a rede planimétrica, quanto para a rede altimétrica, encontraram-se entre aqueles tabelados $\chi_{r, \frac{\alpha}{2}}^{2}$ e $\chi_{r, 1-\frac{\alpha}{2}}^{2}$, ou seja, $\chi_{r, \frac{\alpha}{2}}^{2}<\chi^{* 2}>\chi_{r, 1-\frac{\alpha}{2}}^{2}$. Dessa maneira, pode-se assumir que a hipótese básica foi aceita e o ajustamento mostrou-se consistente e bem condicionado ao nível de significância de $5 \%$.

\subsection{PLANEJAMENTO PARA AUSCULTAÇÃO ESTRUTURAL}

\subsubsection{Critérios adotados para a execução das observações}

Para a realização das observações efetuadas no Laboratório de Estruturas, com o objetivo de analisar a variação controlada dos alvos, primeiramente, planejouse uma maneira de verificar a estabilidade da Base 1, ocupada pela (TCRA 1201+) e da Base 2 ocupada pela (TCA1201+), as quais foram as origens das medições de cada instrumento posicionado em sua respectiva base. Assim, antes de se realizar qualquer medição dirigida ao alvo engastado na estrutura, verificou-se a estabilidade das Bases 1 e 2 em relação às bases 3, 4 e 5 e esta coordenada espacial foi utilizada nos cálculos para essa medida. Por exemplo, para realizar uma observação na posição inicial, efetuou-se uma série de ângulos, sendo a recessão em relação às (B3, B4 e B5) e, em seguida, ao alvo (P).

Para que $\mathrm{O}$ alvo $(\mathrm{P})$ fosse monitorado, utilizou-se o timer do aplicativo monitoring. Para isso, as duas estações totais robóticas foram configuradas igualmente, respeitando a data e hora do observatório nacional, pois o início e o fim de um monitoramento são programados em relação à data e hora das estações. Assim, adotou-se o tempo de cinco minutos, com intervalo de um minuto para o monitoramento de cada posição do alvo. Dessa maneira, obtiveram-se, no mínimo, cinco séries de leituras, sendo que, cada série de leitura coletou os quatro pontos em questão, três para recessão (B3, B4 e B5) e um para o alvo (P). Por exemplo, ao observar um dos alvos, em sua posição inicial, configuraram-se as estações totais 
robóticas para iniciar o monitoramento às $10 \mathrm{~h}$ do dia 11/12/12 e finalizar o mesmo às 10h 05min do dia 11/12/12. Em seguida, efetuou-se a variação milimétrica desse alvo.

Em relação à variação milimetricamente controlada pelo suporte com dispositivo ajustável engastado na estrutura, ilustrado pela Figura 43, adotou-se um critério com o qual se pretendeu obter dados suficientes para análise. Com tal critério, pôde-se realizar oito medições com cada alvo envolvido no processo, sendo seis variações de $1 \mathrm{~mm}$, uma de $5 \mathrm{~mm}$ e outra de $10 \mathrm{~mm}$, partindo da posição inicial (00) em direção à posição (07), conforme ilustrado na Figura 44. Tal procedimento permitiu detectar a diferença entre as coordenadas espaciais dos alvos em diferentes posições. Comprovando, então, o poder de detecção das metodologias e procedimentos empregados nesta pesquisa.

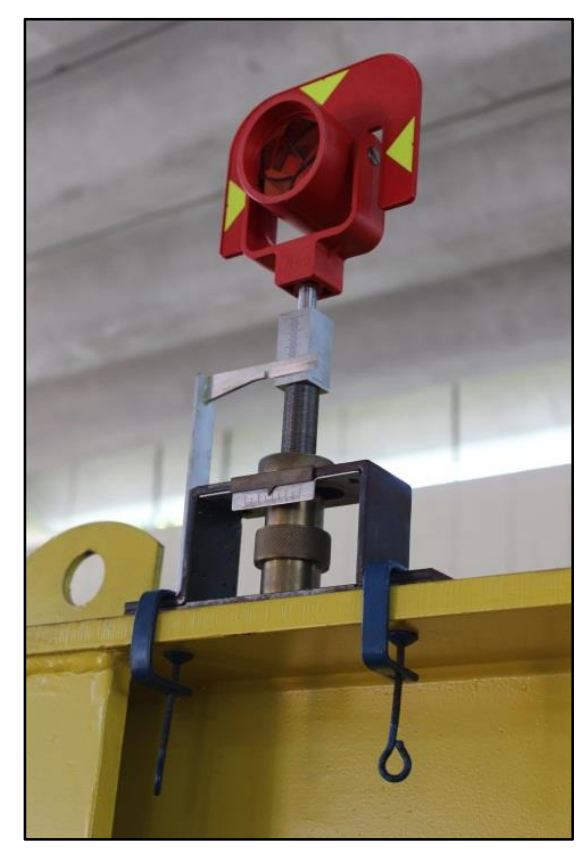

Figura 43 - Suporte com dispositivo ajustável engastado na estrutura

O suporte foi projetado para variações nos eixos $(X, Z)$, mas os métodos aplicados determinam posições espaciais, isso pode ser notado nos resultados, pois, quando há uma mínima trepidação da peça no eixo $(Y)$, esta variação também é detectada, mas não é controlada. 
A Figura 44 ilustra o critério de variação efetuada igual e simultaneamente nos eixos $(X, Z)$.

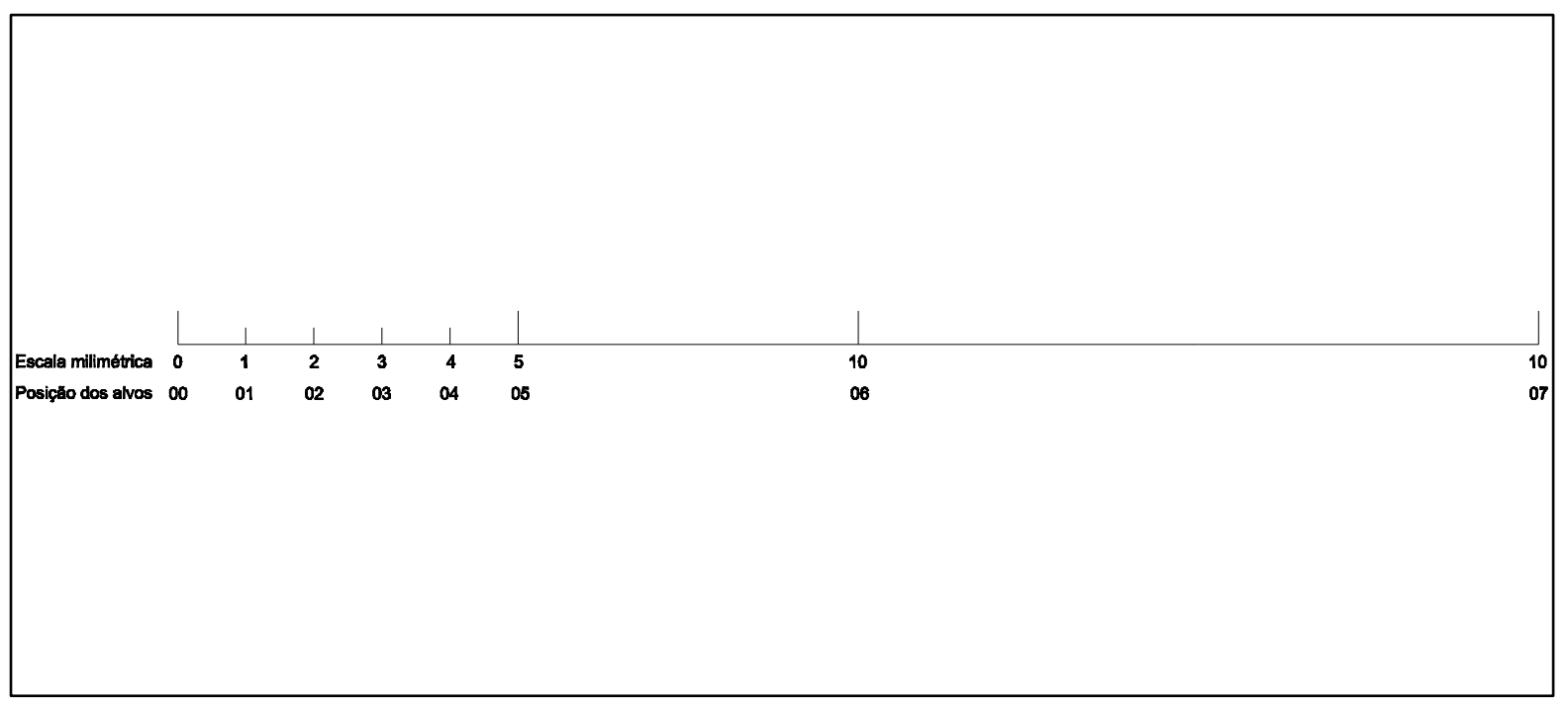

Figura 44 - Critério para variação controlada nos eixos $(X, Z)$ dos alvos

Para efeito de organização e harmonia entre os dados coletados em campo, descarga, processamento e apresentação dos resultados, cada alvo recebeu um código seguido de sua posição e todos eles seguiram a mesma variação:

- O prisma GPR111 recebeu os seguintes códigos:

- GPRC00, GPRC01, GPRC02, GPRC03, GPRC04, GPRC05, GPRC06 e GPRC07.

- O miniprisma GMP111-0:

- GMP00, GMP01, GMP02, GMP03, GMP04, GMP05, GMP06 e GMP07.

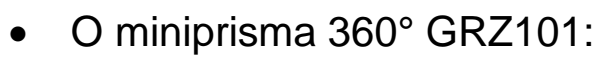

- GRZ00, GRZ01, GRZ02, GRZ03, GRZ04, GRZ05, GRZ06 e GRZ07.

- O miniprisma com esquadro em "L" GMP104: 
- GMPL00, GMPL01, GMPL02, GMPL03, GMPL04, GMPL05, GMPL06 e GMPL07.

- O prisma de monitoramento GPR112:

- GPRM00, GPRM01, GPRM02, GPRM03, GPRM04, GPRM05, GPRM06 e GPRM07.

- A fita refletiva GZM31:

○ FR00, FR01, FR02, FR03, FR04, FR05, FR06 e FR07.

A Figura 45 ilustra as observações realizadas em campo para o alvo GPR111 em sua posição inicial (00), denominado por GPRC00.

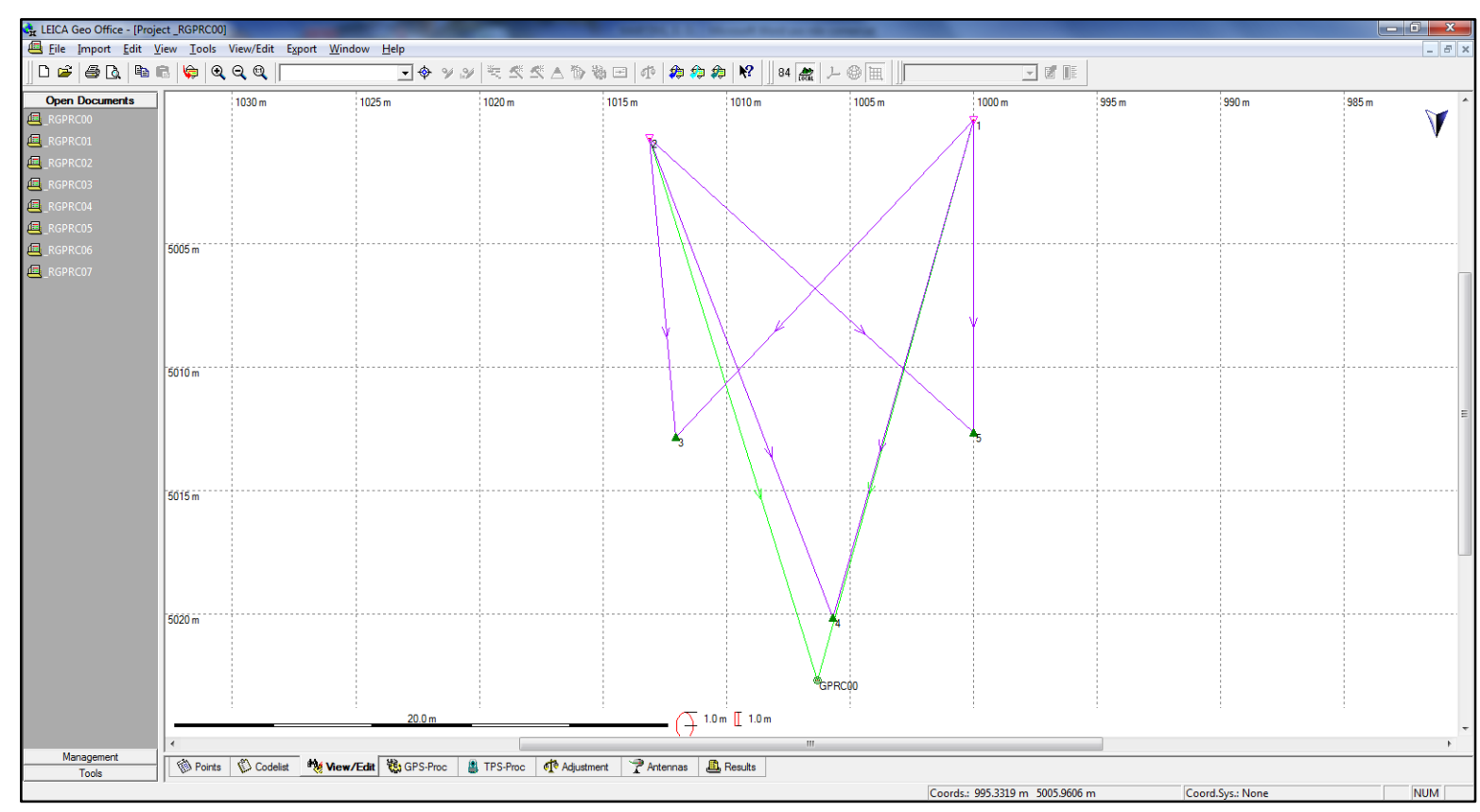

Figura 45 - Observações obtidas em campo para o alvo GPRC00.

Já a Figura 46, mostra e exemplifica as observações realizadas para o alvo GPRC com todas as variações predeterminadas (00-07), que, consequentemente, efetuou-se para os demais tipos de alvos, dispostos separadamente, devido ao fato de sempre verificar a estabilidade das bases antes das observações. 


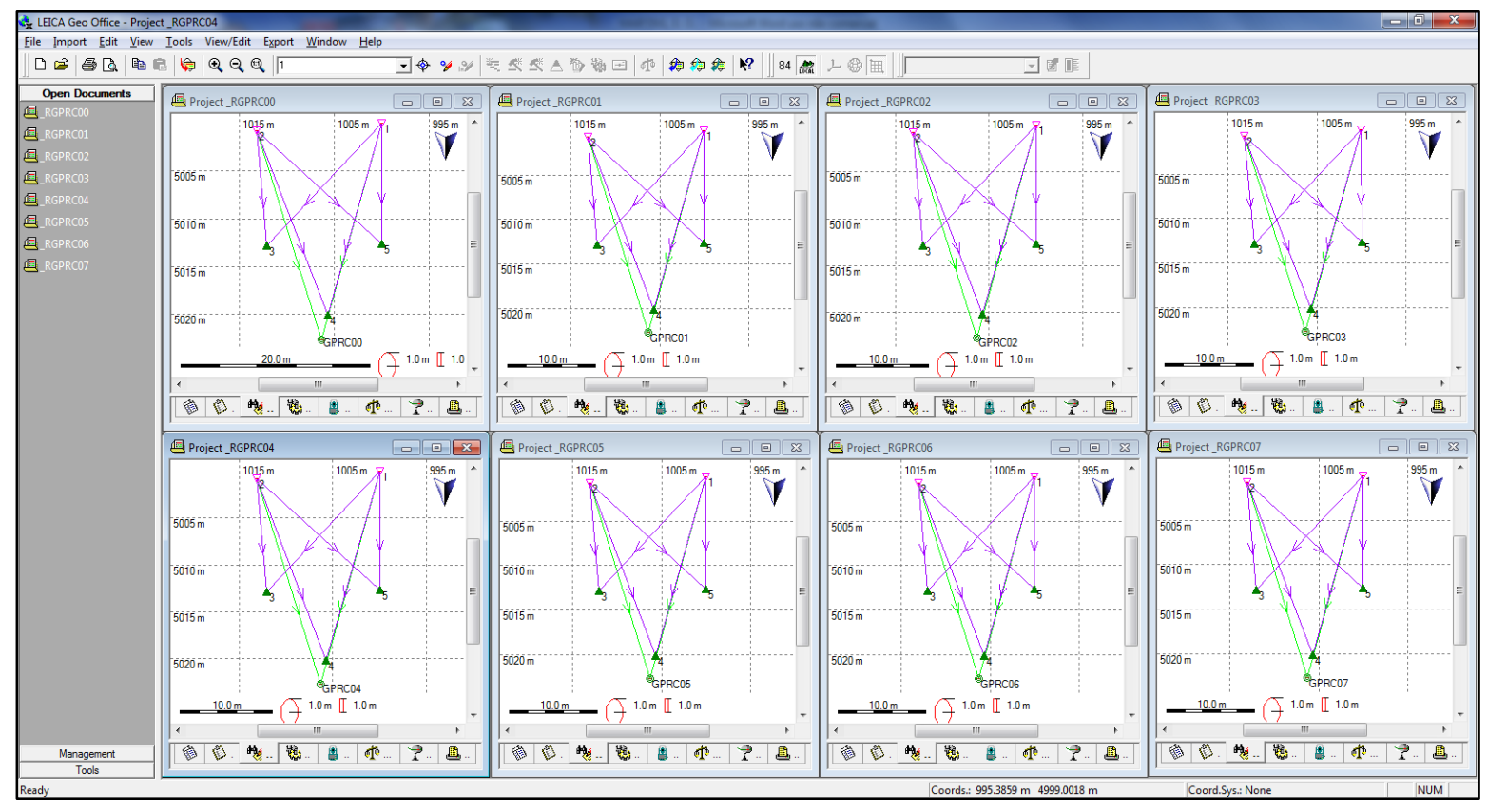

Figura 46 - Observações obtidas em campo para o alvo GPRC com todas as variações

Os dados destas observações compuseram igualmente os dados de entrada para o processamento de todos os métodos validados, para efeito de posterior análise entre tais métodos. Ressalta-se ainda que, para o método polar, utilizaramse somente os dados oriundos da Base1, devido à sua metodologia.

Finalmente, foi escolhido o critério adotado para a saída dos dados e dos valores que foram obtidos ao realizar-se a compilação e o processamento das rotinas computacionais desenvolvidas: utilizou-se o comando format long, porque, segundo Matsumoto (2008), neste consideram-se quatorze casas decimais nos dados de saída. Porém, ainda efetuaram-se arredondamentos que foram executados durante a organização e elaboração de tabelas e planilhas eletrônicas do EXCEL, com quatro casas decimais, o que satisfez as análises, uma vez que este nível de significância permitiu uma excelente comparação entre os métodos validados. 


\subsection{MÉTODO A SER COMPARADO}

\subsubsection{Método Polar}

Como apresentado no item 3.4.2, o método polar foi validado com uma rotina computacional na plataforma MATLAB, a qual é apresentada no Apêndice C. Dessa maneira, serão apresentados os resultados obtidos após o processamento e ajustamento dos dados observados em campo.

Os resultados inerentes à validação do método para o prisma GPR111 serão ilustrados nas próximas páginas pelas Tabelas 11, 12 e 13. Já, a variação das coordenadas espaciais medidas será ilustrada pela Figura 47. No Apêndice D, constam os mesmos dados apresentados por essas tabelas e figura, porém, com os outros tipos de alvos envolvidos nesta pesquisa. 
Tabela 11 - Dados observados e verificação da estabilidade da Base 1 (Método Polar)

\begin{tabular}{|c|c|c|c|c|c|c|c|c|c|}
\hline \multicolumn{10}{|c|}{ MÉTODO POLAR - GPR111 (0.0mm) } \\
\hline \multicolumn{10}{|c|}{ BASE 1} \\
\hline \multicolumn{4}{|c|}{ DADOS OBSERVADOS } & \multicolumn{6}{|c|}{ ESTABILIDADE DA BASE "RECESSÃO" } \\
\hline PONTOS & Azimute & Zenital & $\mathrm{Di}(\mathrm{m})$ & $X(m)$ & $\sigma_{x}(m m)$ & $Y(m)$ & $\sigma_{Y}(\mathrm{~mm})$ & $Z(m)$ & $\sigma_{z}(\mathrm{~mm})$ \\
\hline GPRC00 & $15^{\circ} 34^{\prime} 48,1685^{\prime \prime}$ & $84^{\circ} 25^{\prime} 48,6111^{\prime \prime}$ & 23,6692 & $1.000,0044$ & 2,1 & $4.999,9975$ & 0,4 & 100,0000 & 1,2 \\
\hline GPRC01 & $15^{\circ} 35^{\prime} 00,3475^{\prime \prime}$ & $84^{\circ} 25^{\prime} 59,2228^{\prime \prime}$ & 23,6697 & $1.000,0042$ & 2,0 & $4.999,9975$ & 0,5 & 100,0000 & 1,3 \\
\hline GPRC02 & $15^{\circ} 35^{\prime} 05,4400^{\prime \prime}$ & $84^{\circ} 26^{\prime} 08,1627^{\prime \prime}$ & 23,6698 & $1.000,0043$ & 1,7 & $4.999,9975$ & 0,4 & 99,9996 & 0,7 \\
\hline GPRC03 & $15^{\circ} 35^{\prime} 06,7493^{\prime \prime}$ & $84^{\circ} 26^{\prime} 17,2567^{\prime \prime}$ & 23,6701 & $1.000,0047$ & 2,0 & $4.999,9974$ & 0,3 & 99,9997 & 0,7 \\
\hline GPRC04 & $15^{\circ} 35^{\prime} 13,1560^{\prime \prime}$ & $84^{\circ} 26^{\prime} 26,6696^{\prime \prime}$ & 23,6702 & $1.000,0047$ & 2,1 & $4.999,9975$ & 0,3 & 99,9997 & 0,7 \\
\hline GPRC05 & $15^{\circ} 35^{\prime} 21,4801 "$ & $84^{\circ} 26^{\prime} 33,7920^{\prime \prime}$ & 23,6701 & $1.000,0046$ & 2,3 & $4.999,9977$ & 0,4 & 99,9997 & 0,8 \\
\hline GPRC06 & $15^{\circ} 35^{\prime} 58,9549^{\prime \prime}$ & $84^{\circ} 27^{\prime} 20,5565^{\prime \prime}$ & 23,6718 & $1.000,0047$ & 2,1 & $4.999,9976$ & 0,4 & 99,9997 & 0,7 \\
\hline GPRC07 & $15^{\circ} 37^{\prime} 18,7227^{\prime \prime}$ & $84^{\circ} 28^{\prime} 49,1844 "$ & 23,6739 & $1.000,0047$ & 1,9 & $4.999,9975$ & 0,4 & 99,9997 & 0,8 \\
\hline
\end{tabular}


Tabela 12 - Coordenadas e precisões ajustadas dos alvos (Método Polar)

\begin{tabular}{cccccccc}
\hline \multicolumn{7}{c}{ COORDENADAS E PRECISÕES AJUSTADAS } \\
\hline PONTOS & $X(\mathrm{~m})$ & $\sigma_{X}(\mathrm{~mm})$ & $Y(\mathrm{~m})$ & $\sigma_{Y}(\mathrm{~mm})$ & $\mathrm{Z}(\mathrm{m})$ & $\sigma_{Z}(\mathrm{~mm})$ & $\sigma_{X Y Z}(\mathrm{~mm})$ \\
\hline GPRC00 & $1.006,3316$ & 1,9721 & $5.022,6894$ & 0,5498 & 102,2973 & $3,8933 \mathrm{E}-05$ & 2,0473 \\
GPRC01 & $1.006,3329$ & 1,9721 & $5.022,6896$ & 0,5500 & 102,2961 & $3,8891 \mathrm{E}-05$ & 2,0473 \\
GPRC02 & $1.006,3336$ & 1,9721 & $5.022,6896$ & 0,5500 & 102,2947 & $3,8856 \mathrm{E}-05$ & 2,0473 \\
GPRC03 & $1.006,3342$ & 1,9721 & $5.022,6899$ & 0,5500 & 102,2938 & $3,8821 \mathrm{E}-05$ & 2,0473 \\
GPRC04 & $1.006,3350$ & 1,9720 & $5.022,6900$ & 0,5501 & 102,2928 & $3,8784 \mathrm{E}-05$ & 2,0473 \\
GPRC05 & $1.006,3358$ & 1,9720 & $5.022,6899$ & 0,5502 & 102,2919 & $3,8756 \mathrm{E}-05$ & 2,0473 \\
GPRC06 & $1.006,3406$ & 1,9719 & $5.022,6908$ & 0,5505 & 102,2868 & $3,8573 \mathrm{E}-05$ & 2,0473 \\
GPRC07 & $1.006,3502$ & 1,9717 & $5.022,6912$ & 0,5513 & 102,2768 & $3,8227 \mathrm{E}-05$ & 2,0473 \\
\hline
\end{tabular}


Tabela 13 - Variação controlada, variação das coordenadas e diferença entre ambas (Método Polar)

\begin{tabular}{cccccccc}
\hline \multicolumn{2}{c}{ CONTROLE } & \multicolumn{3}{c}{ VARIAÇÃO DAS COORDENADAS } & \multicolumn{3}{c}{$\begin{array}{c}\text { DIFERENÇA ENTRE } \\
\text { CONTROLE EARIAÇÃo }\end{array}$} \\
\hline Pontual (mm) & Intervalo $(\mathrm{mm})$ & \multicolumn{1}{c}{$\Delta \mathrm{X}(\mathrm{mm})$} & $\Delta \mathrm{Y}(\mathrm{mm})$ & $\Delta \mathrm{Z}(\mathrm{mm})$ & $\mathrm{X}(\mathrm{mm})$ & $\mathrm{Y}(\mathrm{mm})$ & $\mathrm{Z}(\mathrm{mm})$ \\
\hline 1,0 & $0,0-1,0$ & 1,3 & 0,2 & $-1,2$ & $-0,3$ & 0,8 & 0,2 \\
1,0 & $1,0-2,0$ & 0,7 & 0,0 & $-1,4$ & 0,3 & 1,0 & 0,4 \\
1,0 & $2,0-3,0$ & 0,7 & 0,2 & $-0,9$ & 0,3 & 0,8 & 0,1 \\
1,0 & $3,0-4,0$ & 0,8 & 0,1 & $-1,1$ & 0,2 & 0,9 & $-0,1$ \\
1,0 & $4,0-5,0$ & 0,8 & $-0,1$ & $-0,8$ & 0,2 & 1.1 & 0,2 \\
5,0 & $5,0-10,0$ & 4,8 & 0,9 & $-5,2$ & 0,2 & $-0,9$ & $-0,2$ \\
10,0 & $10,0-20,0$ & 9,6 & 0,4 & $-9,9$ & 0,4 & $-0,4$ & 0,1 \\
\hline
\end{tabular}




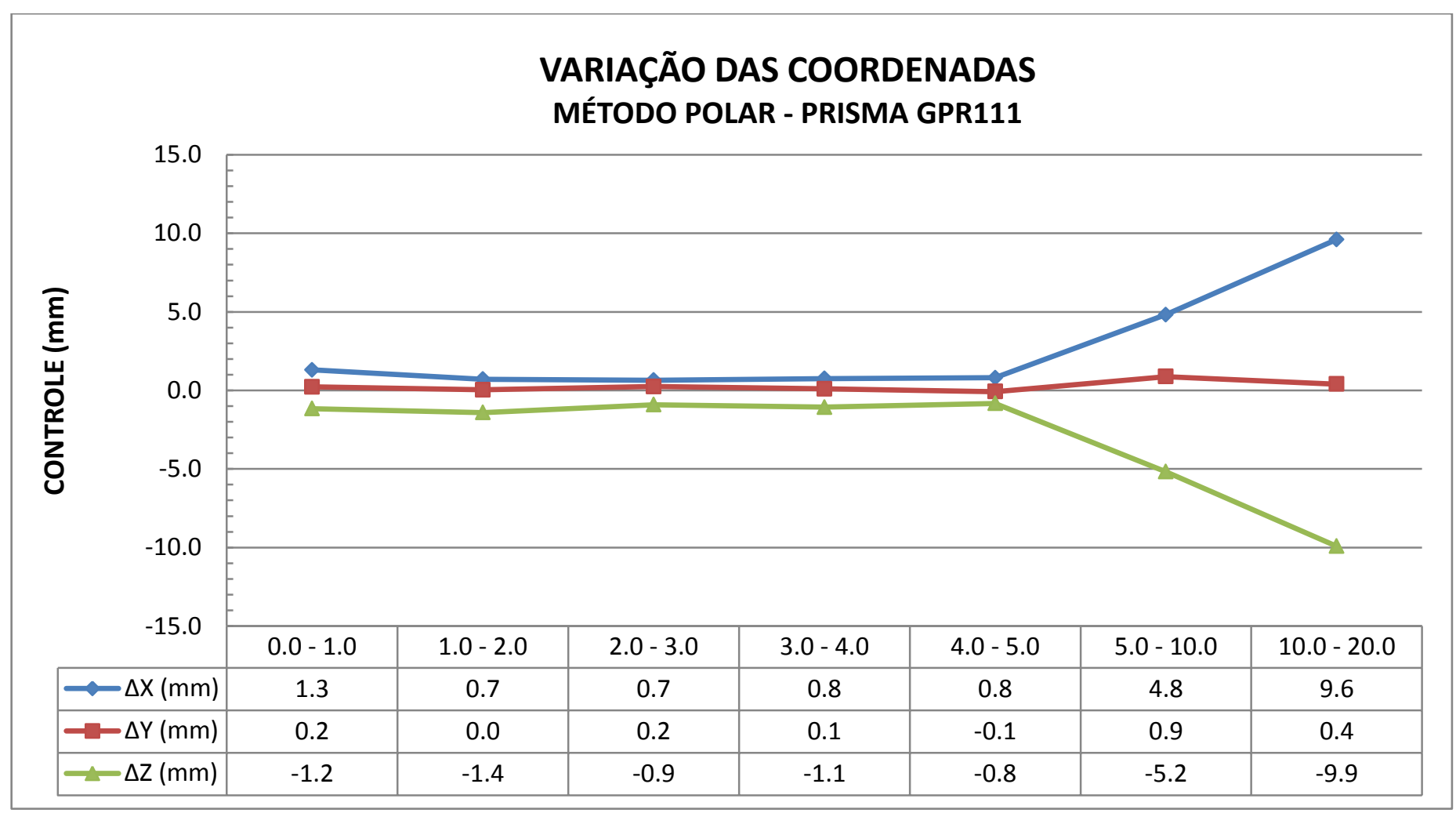

Figura 47 - Variação das coordenadas para o prisma GPR111 (Método Polar) 
De posse destes resultados obtidos por meio do método polar, observou-se que as precisões das determinações e a precisão do posicionamento espacial do alvo em deslocamento foram de ordem milimétrica, conforme Tabela 12. Então, é possível assegurar que este método convencional e considerado clássico, obedece às restrições técnicas das estações totais robóticas utilizadas e apresenta resultados compatíveis com a precisão nominal dos referidos aparelhos e, portanto, pode ser considerado preciso.

Ao se comparar os valores obtidos com a variação controlada, avaliou-se que este método, juntamente com os procedimentos estudados, apresenta uma precisão espacial dentro de milímetros e, ao realizar as diferenças entre o controle e a variação das coordenadas espaciais, verificaram-se resíduos baixos, também da ordem de milímetros.

Considerando-se, portanto, os índices de variação em relação ao controle, pode-se afirmar que o método polar juntamente com as estações totais robóticas, apresenta precisões aceitáveis para trabalhos de mensuração de precisão ou para controle de grandes estruturas de obras civis. Este, porém, não irá satisfazer monitoramentos de fissuras, fadigas, deslocamento ou deformações que exijam precisões da ordem de décimos e centésimos de milímetros.

\subsection{PROPOSTA PARA O CÁLCULO DE COORDENADAS ESPACIAIS PELO MÉTODO DAS DISTÂNCIAS MÍNIMAS}

\subsubsection{Introdução}

O método proposto fundamenta-se na minimização de uma função matemática, definida pelo somatório das distâncias entre as linhas de visadas de duas estações de medições e o lugar geométrico, supostamente ocupado, por um alvo refletor. As distâncias, neste caso, são determinadas a partir de cálculos em função de uma interseção espacial considerando os azimutes e os ângulos zenitais medidos com as estações totais robóticas. 
Sabe-se que as linhas de visadas concomitantes não são concorrentes no mesmo lugar geométrico, devido aos erros intrínsecos das medições e das variáveis do modelo físico. Nestas condições, se as retas das linhas de visadas não são concorrentes no mesmo ponto geométrico, elas devem passar muito próximas a ele. Sendo assim, quando o alvo é visado por vários instrumentos de medição angulares e de distâncias, simultaneamente, para que os valores das coordenadas sejam corretos e ajustados, o somatório das distâncias medidas e calculadas deve ser mínimo. Dessa premissa, resulta a designação de Método de Determinação de Coordenadas Espaciais por Distâncias Mínimas.

Para a realização deste método, deve-se empregar um número mínimo de duas estações fixas para satisfazer as condições exigidas por sua modelagem matemática e operacionalidade em campo. Outra condição necessária para seu desenvolvimento é a visibilidade de ambas as estações aos pontos de referência, para a devida verificação de estabilidade das bases e orientação das observações.

Os procedimentos para o cálculo das coordenadas espaciais utilizando o método em questão, estão detalhados em suas formulações matemáticas, apresentadas a seguir e implementadas em uma rotina na plataforma MATLAB, que consta no Apêndice E.

\subsubsection{Modelo matemático proposto}

O desenvolvimento matemático generalizado do método apresentado por Moreira (1998) consiste no princípio de que as retas definidas pelas linhas de visada realizadas simultaneamente, que vão do centro óptico de cada instrumento ao alvo, não são concorrentes no mesmo lugar geométrico ocupado pelo alvo no espaço, porém, são consideradas retas reversas. $E$ isto ocorre devido a erros relacionados a diversos fatores e, dentre eles, ressalta-se a dificuldade de executar a pontaria do equipamento até o alvo com exatidão, restrições técnicas dos instrumentos e manuseio do operador. Devido a esses motivos, é que se optou pelo uso de equipamentos automáticos, pois, assim, espera-se atenuar tais erros. 
O método consiste, basicamente, na determinação das coordenadas tridimensionais do alvo em função das coordenadas do centro óptico dos instrumentos de medição, das leituras angulares referentes ao alvo: ângulo horizontal e zenital, medidos em cada estação e da orientação das retas definidas pelas linhas de visadas. Dessa maneira, os principais elementos que compõem esquematicamente o método são representados pela Figura 48.

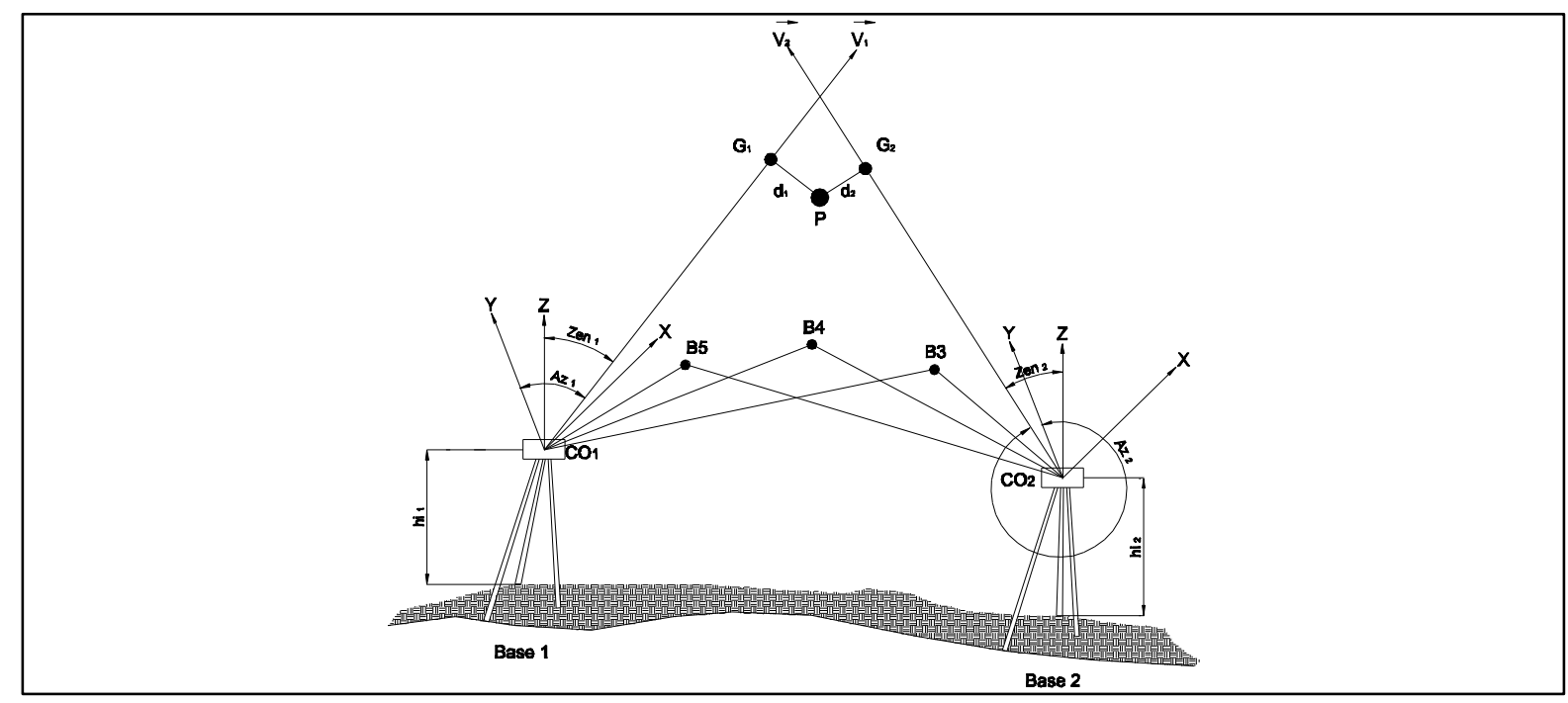

Figura 48 - Representação genérica dos elementos que compõem o método Fonte: Adaptado de Moreira (1998)

Sendo:

$P$ - Alvo de coordenadas espaciais desconhecidas $(X P, Y P, Z P)$;

$B 3, B 4$ e $B 5$ - Pontos de referência e orientação das bases 1 e 2;

Bases 1 e 2 - Tripés industriais alocados nas bases 1 e 2 ;

$\mathrm{CO}_{1,2}$ - Coordenadas do centro óptico de cada instrumento instalado em sua respectiva base;

$h_{1,2}$ - Altura dos instrumentos, sendo: $h_{1,2}=0$;

$Z_{e n_{1,2}}$ - Ângulos zenitais lidos nas estações, em relação ao alvo;

$A z_{1,2}$ - Azimutes das direções entre os instrumentos e 0 alvo $P$, obtidos por meio do método da recessão, considerando $(B 3, B 4$ e $B 5)$; 
$\vec{V}_{1,2}$ - Vetor direção da linha de visada do centro óptico de cada instrumento;

$d_{1,2}$ - Distâncias entre a reta $\vec{V}_{1,2}$ e o alvo $P$;

$G_{1,2}-$ Pontos genéricos em função do parâmetro da reta genérica $t_{i}$;

$X, Y$ e Z - Eixos do sistema ortogonal de referência.

\subsubsection{Determinação das equações das retas definidas pelas linhas de visadas dos dois instrumentos até 0 alvo $\mathbf{P}$}

As linhas de visada dos aparelhos que são direcionadas a um alvo $P$, não são concorrentes nesse ponto, devido a diversos fatores e erros que induzem estas linhas a não se interceptarem no alvo, porém estas passam muito próximas a ele.

Quando o somatório de todas as distâncias do alvo às retas for mínimo, os dados angulares coletados fornecem o melhor resultado para a coordenada do alvo requerido. Mas, para que estas distâncias sejam determinadas e o seu somatório minimizado, primeiramente, deve-se estabelecer as equações das retas definidas pelas linhas de visada de cada instrumento dirigido a cada alvo P. Estas retas têm como origem o centro óptico de cada aparelho, dados por suas coordenadas $X \mathrm{CO}_{i}, \mathrm{YCO}_{i}, Z \mathrm{ZO}_{i}$.

A direção de cada reta é dada pelo versor $\bar{v}_{i}$, definido em função dos cossenos diretores destas retas, em relação ao sistema de referência, tomando-se o azimute e o ângulo zenital do alvo, conforme segue:

$$
\bar{v}_{i}=\left(a_{i}, b_{i}, c_{i}\right)
$$

Sendo:

$$
\begin{aligned}
& a_{i}=\operatorname{sen}\left(Z e n_{i}\right) \cdot \operatorname{sen}\left(A z_{i}\right) \\
& b_{i}=\operatorname{sen}\left(Z e n_{i}\right) \cdot \cos \left(A z_{i}\right)
\end{aligned}
$$




$$
c_{i}=\cos \left(Z_{e n}\right)
$$

Sendo:

$$
\begin{aligned}
& \bar{v}_{i}-\text { Versor diretor da reta } i \\
& a_{i}-\text { Coordenada do versor, na direção do eixo } x ; \\
& b_{i}-\text { Coordenada do versor, na direção do eixo } y ; \\
& c_{i}-\text { Coordenada do versor, na direção do eixo } z .
\end{aligned}
$$

A reta genérica $r_{i}$ tem como origem o centro óptico de cada aparelho e a direção do versor $\bar{v}_{i}$, logo:

$$
r_{i}=\mathrm{CO}_{i}+t_{i} \cdot \bar{v}_{i}
$$

Sendo:

$\mathrm{CO}_{i}$ - centro óptico do instrumento, de coordenadas $\mathrm{XCO}_{i}, \mathrm{YCO}_{i}, \mathrm{ZCO}_{i}$;

$t_{i}$ - parâmetro da reta genérica;

$\bar{v}_{i}-$ versor, da reta $r_{i}$.

\subsubsection{Determinação de um ponto genérico $G_{i}\left(t_{i}\right)$ sobre a reta $r_{i}$}

Os pontos genéricos $G_{i}\left(t_{i}\right)$ são os pontos sobre as retas genéricas $r_{i}$, nas quais uma perpendicular com origem no alvo $P$ intercepta as referidas retas. Ressaltando que é único o ponto da reta definida pela linha de visada, em que a distância ao alvo $\mathrm{P}$ é mínima. E este ponto genérico $G_{i}\left(t_{i}\right)$ é definido a partir das coordenadas do centro óptico de cada instrumento $\mathrm{CO}_{i}$ e do versor diretor da reta 
determinada pelos cossenos diretores dos azimutes e ângulos zenitais, lidos em cada instrumento, em direção a cada alvo.

As coordenadas do ponto genérico $G_{i}\left(t_{i}\right)$ são dadas por:

$$
\begin{aligned}
& X G_{i}=X C O_{i}+t_{i} \cdot a_{i} \\
& Y G_{i}=Y C O_{i}+t_{i} \cdot b_{i} \\
& Z G_{i}=Z C O_{i}+t_{i} \cdot c_{i}
\end{aligned}
$$

Sendo:

$G_{i}\left(t_{i}\right)$ - Ponto genérico em função do parâmetro $t_{i}$;

$X G_{i}, Y G_{i}, Z G_{i}$ - Coordenadas do ponto genérico $G_{i}$, sobre a reta $r_{i}$.

\subsubsection{Determinação da distância entre os pontos genéricos e $O$ alvo $P$}

Essa distância a cada reta definida pela linha de visada deve ser mínima para que os valores obtidos para as coordenadas do alvo $P$, em função de todas as visadas angulares, sejam considerados como os mais exatos possíveis. A referida distância é determinada em função das coordenadas do ponto genérico $G_{i}$ e do alvo $P$, pela equação da distância entre dois pontos, logo:

$$
d_{i}=\sqrt{\left(X P-\left(X C O_{i}+t_{i} \cdot a_{i}\right)\right)^{2}+\left(Y P-\left(Y C O_{i}+t_{i} \cdot b_{i}\right)\right)^{2}+\left(Z P-\left(Z C O_{i}+t_{i} \cdot c_{i}\right)\right)^{2}}(4.9)
$$




\subsubsection{Determinação da distância entre os pontos genéricos e $O$ alvo $P$}

O somatório das distâncias entre as retas definidas pelas linhas de visadas dos instrumentos e o alvo, deve ser definido matematicamente, sendo, em seguida, minimizado. Então:

$$
\begin{gathered}
\sum_{1}^{n} d_{i}^{2}=\left(\left(X P-\left(X C O_{i}+t_{i} \cdot a_{i}\right)\right)^{2}+\left(Y P-\left(Y C O_{i}+t_{i} \cdot b_{i}\right)\right)^{2}+\right. \\
\left.+\left(Z P-\left(Z C O_{i}+t_{i} \cdot c_{i}\right)\right)^{2}\right)
\end{gathered}
$$

Sendo:

$n$ - Número de estações envolvidas no processo.

Elevando ao quadrado ambos os membros na equação (4.10), elimina-se a raiz do segundo membro, conforme segue:

$$
\begin{gathered}
\left(\sum_{1}^{n} d_{i}\right)^{2}=\left(\left(X P-\left(X C O_{i}+t_{i} \cdot a_{i}\right)\right)^{2}+\left(Y P-\left(Y C O_{i}+t_{i} \cdot b_{i}\right)\right)^{2}+\right. \\
\left.+\left(Z P-\left(Z C O_{i}+t_{i} \cdot c_{i}\right)\right)^{2}\right)
\end{gathered}
$$

Efetuando-se as operações indicadas em cada parcela do segundo membro da equação (4.11), e denominando-se o primeiro termo de $M X$, o segundo de $M Y$ e o terceiro de $M Z$, temos:

$$
\begin{gathered}
\begin{array}{r}
M X=(X P)^{2}-2 \cdot(X P) \cdot\left(X C O_{i}\right)-2 \cdot(X P) \cdot a_{i} \cdot t_{i}+\left(X C O_{i}\right)^{2}+ \\
+2 \cdot\left(X C O_{i}\right) \cdot a_{i} \cdot t_{i}+\left(a_{i}\right)^{2} \cdot\left(t_{i}\right)^{2}
\end{array} \\
\begin{array}{r}
M Y=(Y P)^{2}-2 \cdot(Y P) \cdot\left(Y C O_{i}\right)-2 \cdot(Y P) \cdot b_{i} \cdot t_{i}+\left(Y C O_{i}\right)^{2}+ \\
+2 \cdot\left(Y C O_{i}\right) \cdot b_{i} \cdot t_{i}+\left(b_{i}\right)^{2} \cdot\left(t_{i}\right)^{2}
\end{array} \\
M Z=(Z P)^{2}-2 \cdot(Z P) \cdot\left(Z C O_{i}\right)-2 \cdot(Z P) \cdot c_{i} \cdot t_{i}+\left(Z C O_{i}\right)^{2}+
\end{gathered}
$$




$$
+2 \cdot\left(Z C O_{i}\right) \cdot c_{i} \cdot t_{i}+\left(c_{i}\right)^{2} \cdot\left(t_{i}\right)^{2}
$$

Então:

$$
\sum_{1}^{n}\left(d_{i}\right)^{2}=M X+M Y+M Z
$$

Onde, os elementos conhecidos das equações (4.12), (4.13) e (4.14) são:

$X C O_{i}, Y C O_{i}, Z C O_{i}-$ Coordenadas do centro óptico dos instrumentos;

$a_{i}, b_{i}, c_{i}$-Coordenadas dos versores diretores das linhas de visada;

E as incógnitas são:

$X P, Y P, Z P-$ Coordenadas do alvo $\mathrm{P}$;

$t_{i}$ - Parâmetros das retas definidas pelas linhas de visada, com $i=$ $1,2,3, \ldots, n$.

\subsubsection{Determinação das derivadas parciais em função das incógnitas}

As derivadas parciais são determinadas para que se possa minimizar a função que representa o somatório das distâncias entre as linhas de visada e o lugar geométrico supostamente ocupado pelo alvo $\mathrm{P}$.

Se escrevermos a equação (4.15) em função de suas incógnitas, teremos:

$$
F=F\left(X P, Y P, Z P, t_{1}, t_{2}, t_{3}, \ldots, t_{n}\right)
$$

Sendo:

F - Equação escrita em função das incógnitas.

Ao derivar a equação (4.16) em função de $X P$, tem-se:

$$
\frac{\partial F}{\partial(X P)}=2 \cdot n \cdot(X P)-2 \cdot \sum_{1}^{n}\left(X C O_{i}\right)-2 \cdot \sum_{1}^{n}\left(a_{i} \cdot t_{i}\right)
$$


Ao desenvolver os somatórios:

$$
\begin{gathered}
\frac{\partial F}{\partial(X P)}=2 . n \cdot(X P)-2 \cdot\left(\left(X C O_{1}\right)+\left(X C O_{2}\right)+\cdots+\left(X C O_{n}\right)\right)- \\
-2 \cdot\left(a_{1} \cdot t_{1}+a_{2} \cdot t_{2}+\cdots+a_{n} \cdot t_{n}\right)
\end{gathered}
$$

Igualando-se a zero:

$$
\begin{gathered}
\text { 2.n. }(X P)-2 \cdot\left(\left(X \mathrm{CO}_{1}\right)+\left(X \mathrm{CO}_{2}\right)+\cdots+\left(X C O_{n}\right)\right)- \\
-2 \cdot\left(a_{1} \cdot t_{1}+a_{2} \cdot t_{2}+\cdots+a_{n} \cdot t_{n}\right)=0
\end{gathered}
$$

Derivando-se a equação (4.16) em função de $Y P$, tem-se:

$$
\frac{\partial F}{\partial(Y P)}=2 \cdot n \cdot(Y P)-2 \cdot \sum_{1}^{n}\left(Y C O_{i}\right)-2 \cdot \sum_{1}^{n}\left(b_{i} \cdot t_{i}\right)
$$

Desenvolvendo-se os somatórios:

$$
\begin{gathered}
\frac{\partial F}{\partial(Y P)}=2 . n \cdot(Y P)-2 \cdot\left(\left(Y C O_{1}\right)+\left(Y C O_{2}\right)+\cdots+\left(Y C O_{n}\right)\right)- \\
-2 \cdot\left(b_{1} \cdot t_{1}+b \cdot t_{2}+\cdots+b_{n} \cdot t_{n}\right)
\end{gathered}
$$

Igualando-se a zero:

$$
\begin{gathered}
\text { 2.n. }(Y P)-2 \cdot\left(\left(Y C O_{1}\right)+\left(Y C O_{2}\right)+\cdots+\left(Y C O_{n}\right)\right)- \\
-2 \cdot\left(b_{1} \cdot t_{1}+b_{2} \cdot t_{2}+\cdots+b_{n} \cdot t_{n}\right)=0
\end{gathered}
$$

Derivando-se a equação (4.16) em função de $Z P$, tem-se:

$$
\frac{\partial F}{\partial(Z P)}=2 \cdot n \cdot(Z P)-2 \cdot \sum_{1}^{n}\left(Z C O_{i}\right)-2 \cdot \sum_{1}^{n}\left(c_{i} \cdot t_{i}\right)
$$

Desenvolvendo-se os somatórios:

$$
\begin{gathered}
\frac{\partial F}{\partial(Z P)}=2 \cdot n \cdot(Z P)-2 \cdot\left(\left(Z C O_{1}\right)+\left(Z C O_{2}\right)+\cdots+\left(Z C O_{n}\right)\right)- \\
-2 \cdot\left(c_{1} \cdot t_{1}+c_{2} \cdot t_{2}+\cdots+c_{n} \cdot t_{n}\right)
\end{gathered}
$$


Igualando-se a zero:

$$
\begin{gathered}
2 \cdot n \cdot(Z P)-2 \cdot\left(\left(Z C O_{1}\right)+\left(Z C O_{2}\right)+\cdots+\left(Z C O_{n}\right)\right)- \\
-2 \cdot\left(c_{1} \cdot t_{1}+c_{2} \cdot t_{2}+\cdots+c_{n} \cdot t_{n}\right)=0
\end{gathered}
$$

Derivando-se a equação (4.16) em função de $t_{1}$, tem-se:

$$
\begin{aligned}
\frac{\partial F}{\partial\left(t_{1}\right)}=-2 \cdot a_{1} \cdot(X P)-2 \cdot b_{1} \cdot(Y P)-2 \cdot c_{1} \cdot(Z P)+2 \cdot a_{1} \cdot\left(X C O_{1}\right)+2 \cdot b_{1} \cdot\left(Y C O_{1}\right)+ \\
+2 \cdot c_{1} \cdot\left(Z C O_{1}\right)+2 \cdot\left(a_{1}\right)^{2} \cdot t_{1}+2 \cdot\left(b_{1}\right)^{2} \cdot t_{1}+2 \cdot\left(c_{1}\right)^{2} \cdot t_{1}
\end{aligned}
$$

Igualando-se a zero:

$$
\begin{aligned}
& -2 \cdot a_{1} \cdot(X P)-b_{1} \cdot(Y P)-2 \cdot c_{1} \cdot(Z P)+2 \cdot a_{1} \cdot\left(X C O_{1}\right)+2 \cdot b_{1} \cdot\left(Y C O_{1}\right)+ \\
& \quad+2 \cdot c_{1} \cdot\left(Z C O_{1}\right)++2 \cdot\left(a_{1}\right)^{2} \cdot t_{1}+2 \cdot\left(b_{1}\right)^{2} \cdot t_{1}+2 \cdot\left(c_{1}\right)^{2} \cdot t_{1}=0
\end{aligned}
$$

Derivando-se a equação (4.16) em função de $t_{2}$, tem-se:

$$
\begin{aligned}
\frac{\partial F}{\partial\left(t_{2}\right)}=-2 \cdot a_{2} \cdot & (X P)-2 \cdot b_{2} \cdot(Y P)-2 \cdot c_{2} \cdot(Z P)+2 \cdot a_{2} \cdot\left(X C O_{2}\right)+2 \cdot b_{2} \cdot\left(Y C O_{2}\right)+ \\
& +2 \cdot c_{2} \cdot\left(Z_{C O}\right)+2 \cdot\left(a_{2}\right)^{2} \cdot t_{2}+2 \cdot\left(b_{2}\right)^{2} \cdot t_{2}+2 \cdot\left(c_{2}\right)^{2} \cdot t_{2}
\end{aligned}
$$

Igualando-se a zero:

$$
\begin{aligned}
& -2 \cdot a_{2} \cdot(X P)-b_{2} \cdot(Y P)-2 \cdot c_{2} \cdot(Z P)+2 \cdot a_{2} \cdot\left(X \mathrm{CO}_{2}\right)+2 \cdot b_{2} \cdot\left(Y_{C O}\right)+ \\
& \quad+2 \cdot c_{2} \cdot\left(\mathrm{ZCO}_{2}\right)+2 \cdot\left(a_{2}\right)^{2} \cdot t_{2}+2 \cdot\left(b_{2}\right)^{2} \cdot t_{2}+2 \cdot\left(c_{2}\right)^{2} \cdot t_{2}=0
\end{aligned}
$$

Derivando-se a equação (4.16) em função de $t_{n}$, tem-se:

$$
\begin{aligned}
\frac{\partial F}{\partial\left(t_{n}\right)}=-2 \cdot a_{n \cdot}(X P)-2 \cdot b_{n} \cdot(Y P)-2 \cdot c_{n} \cdot(Z P)+2 \cdot a_{n \cdot}\left(X C O_{n}\right)+2 \cdot b_{n} \cdot\left(Y C O_{n}\right)+ \\
+2 \cdot c_{n \cdot}\left(Z C O_{n}\right)+2 \cdot\left(a_{n}\right)^{2} \cdot t_{n}+2 \cdot\left(b_{n}\right)^{2} \cdot t_{n}+2 \cdot\left(c_{n}\right)^{2} \cdot t_{n}
\end{aligned}
$$


Igualando-se a zero:

$$
\begin{aligned}
& -2 . a_{n \cdot}(X P)-b_{n} \cdot(Y P)-2 \cdot c_{n} \cdot(Z P)+2 \cdot a_{n \cdot}\left(X C O_{n}\right)+2 \cdot b_{n} \cdot\left(Y_{C O}\right)+ \\
& \quad+2 \cdot c_{n} \cdot\left(Z C O_{n}\right)+2 \cdot\left(a_{n}\right)^{2} \cdot t_{n}+2 \cdot\left(b_{n}\right)^{2} \cdot t_{n}+2 \cdot\left(c_{n}\right)^{2} \cdot t_{n}=0
\end{aligned}
$$

\subsubsection{Formulação matricial}

A matriz dos coeficientes das incógnitas será sempre uma matriz quadrada, devido ao fato de as incógnitas serem as coordenadas do alvo $(X P, Y P, Z P)$ e os parâmetros das retas definidas pelas linhas de visada. Dessa maneira, o número de equações é sempre igual ao número de estações envolvidas no processo, acrescido de três unidades, ou seja, as coordenadas espaciais do alvo.

Para a presente pesquisa, foram utilizados dois instrumentos, sendo, portanto, sua equação matricial elaborada em função desta quantidade, a qual é dada por:

$$
M_{C O E F} \cdot M_{I N C}=M_{I N D}
$$

Sendo:

$M_{C O E F}-$ Matriz dos coeficientes das incógnitas;

$M_{I N C}$ - Matriz das incógnitas;

$M_{I N D}$ - Matriz dos termos independentes;

Sabendo-se que a matriz dos coeficientes, pela formulação proposta, será sempre uma matriz quadrada, logo, se esta for invertida, teremos:

$$
M_{I N C}=\left(M_{C O E F}\right)^{-1} \cdot M_{I N D}
$$

O resultado deste processo é a solução matricial da equação (4.33). E como a matriz das incógnitas é uma matriz coluna, cada elemento já é o valor requerido para as respectivas incógnitas, de acordo com a disposição apresentada na coluna. 
A matriz dos coeficientes para esta pesquisa foram da ordem $(5 \times 5)$, devido ao número das incógnitas. Sendo três para as coordenadas do alvo $\mathrm{P}(X P, Y P, Z P)$, e mais duas para os parâmetros das linhas de visada realizadas pelos dois instrumentos $\left(t_{1} e t_{2}\right)$.

$$
M_{\text {COEF }}=\left[\begin{array}{ccccc}
n & 0 & 0 & -a_{1} & -a_{2} \\
0 & n & 0 & -b_{1} & -b_{2} \\
0 & 0 & n & -c_{1} & -c_{2} \\
-a_{1} & -b_{1} & -c_{1} & 1 & 0 \\
-a_{2} & -b_{2} & -c_{2} & 0 & 1
\end{array}\right]
$$

Sendo:

$n$ - Número de estações $n=2$;

$M_{I N C}$ - Matriz das incógnitas;

A matriz das incógnitas para este caso é da ordem (5x1), e é dada por:

$$
M_{I N C}=\left[\begin{array}{c}
X P \\
Y P \\
Z P \\
t_{1} \\
t_{2}
\end{array}\right]
$$

Consequentemente, a matriz dos termos independentes também é da ordem (5x1), dada por:

$$
M_{I N D}=\left[\begin{array}{c}
\sum_{1}^{2}\left(X C O_{i=1,2}\right) \\
\sum_{1}^{2}\left(Y C O_{i=1,2}\right) \\
\sum_{1}^{2}\left(Z C O_{i=1,2}\right) \\
-\left(a_{1} \cdot X C O_{1}+b_{1} \cdot Y C O_{1}+c_{1} \cdot Z C O_{1}\right) \\
-\left(a_{2} \cdot X C O_{2}+b_{2} \cdot Y C O_{2}+c_{2} \cdot Z C O_{2}\right)
\end{array}\right]
$$




\subsubsection{Determinação das coordenadas dos pontos de distância mínima $\left(G_{i}\right)$, entre as linhas de visada e o alvo $\mathbf{P}$}

O ponto genérico de distância mínima $\left(G_{i}\right)$ sobre a reta definida pela linha de visada de cada instrumento, em relação ao alvo $\mathrm{P}$, é o lugar geométrico definido pela perpendicularidade que vai da referida reta ao alvo $P$.

A representação genérica da posição dos pontos de distância mínima entre as retas, definidas pelas linhas de visadas dos instrumentos e o alvo, é ilustrada pela Figura 49.

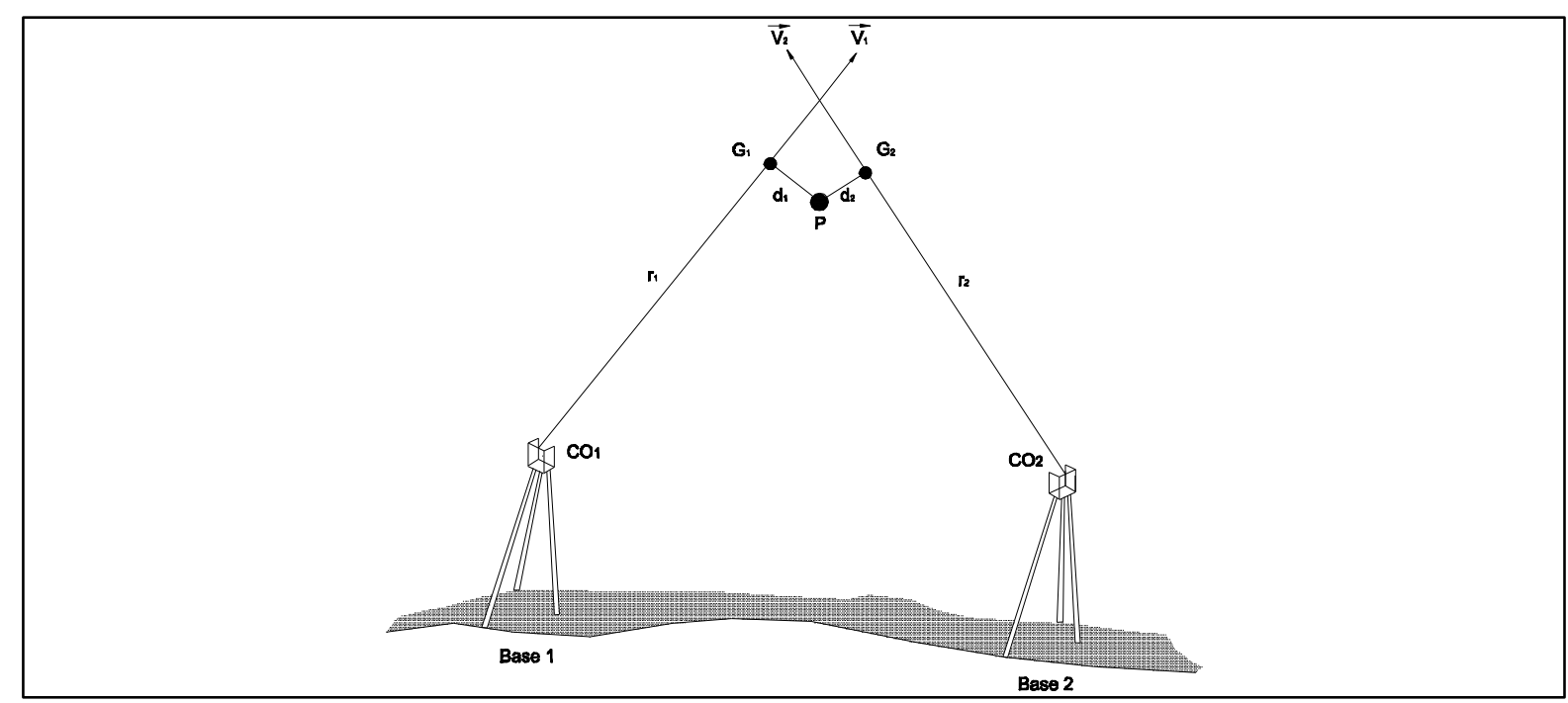

Figura 49 - Pontos de distância mínima entre as linhas de visadas e o alvo Fonte: Adaptado de Moreira (1998)

Sendo:

$\mathrm{CO}_{i=1,2}$ - Centro óptico das estações totais robóticas;

$\bar{V}_{i=1,2}-$ Vetores direção das linhas de visada;

$G_{i=1,2}$ - Pontos de distância mínima entre o alvo e a linha de visada;

$r_{i=1,2}$ - Retas definidas pelas linhas de visada; 
$d_{i=1,2}$ - Distâncias entre o alvo $\mathrm{P}$ e os pontos $G_{i=1,2}$, respectivamente.

As retas $r_{i}$ têm como origem o centro óptico dos instrumentos e como direção o vetor $\bar{v}_{i}$, definido por suas coordenadas $\left(a_{i}, b_{i}, c_{i}\right)$. O ponto $\left(G_{i}\right)$ é definido pela equação (4.37). Sendo $i=1,2$ :

$$
G_{i}=C O_{i}+t_{i} \cdot \bar{v}_{i}
$$

As equações paramétricas são dadas por:

$$
\begin{aligned}
& X G_{i}=X C O_{i}+t_{i} \cdot a_{i} \\
& Y G_{i}=Y C O_{i}+t_{i} \cdot b_{i} \\
& Z G_{i}=Z C O_{i}+t_{i} \cdot c_{i}
\end{aligned}
$$

Estas são as coordenadas dos pontos de distância mínima, localizados sobre as retas, definidas pelas linhas de visadas entre os instrumentos e os alvos, em função dos cossenos diretores das mesmas. Os valores de $t_{i}$ são obtidos após a minimização da função, que é definida pela equação (4.15).

\subsubsection{Determinação das distâncias entre os pontos $\left(G_{i}\right)$ e 0 alvo $P$}

Esses pontos genéricos de distância mínima $\left(G_{i}\right)$, que estão sobre as retas definidas pelas linhas de visadas de todos os instrumentos, em relação ao alvo, são respectivamente, o lugar geométrico definido pela perpendicularidade que vai de cada reta, individualmente, ao alvo $P$.

As distâncias entre os pontos $\left(G_{i}\right)$ e o alvo $\mathrm{P}$ são dadas pela equação (4.41).

$$
d_{i}=\sqrt{\left(X P-X G_{i}\right)^{2}+\left(Y P-Y G_{i}\right)^{2}+\left(Z P-Z G_{i}\right)^{2}}
$$

Sendo:

$d_{i}$ - Distância entre os pontos $\left(G_{i}\right)$ e o alvo P; 
$X P, Y P, Z P$ - Coordenadas do alvo, calculadas pela equação (4.33);

$X G_{i}, Y G_{i}, Z G_{i}$ - Coordenadas dos pontos sobre as retas diretoras das linhas de visadas.

\subsubsection{Determinação das distâncias mínima, média e máxima entre os pontos $\left(G_{i}\right)$ e o alvo $P$}

As referidas distâncias são determinadas para que se tenha uma noção exata da amplitude de variação destas grandezas. No entanto, a média deve ser considerada o melhor valor. Sendo:

$$
\begin{aligned}
& d_{\text {min }}=\left(d_{i}\right)_{\text {min }} \\
& d_{\text {med }}=\frac{\sum_{1}^{n}\left(d_{i}\right)}{n} \\
& d_{\text {max }}=\left(d_{i}\right)_{\max }
\end{aligned}
$$

Sendo:

$$
\begin{aligned}
& d_{\text {min }} \text { - Menor distância entre os pontos }\left(G_{i}\right) \text { e o alvo } \mathrm{P} ; \\
& d_{m e d} \text { - Média das distâncias entre os pontos }\left(G_{i}\right) \text { e o alvo } \mathrm{P} ; \\
& d_{\text {max }} \text { - Maior distância entre os pontos }\left(G_{i}\right) \text { e o alvo } \mathrm{P} ; \\
& n \text { - Número de estações ou instrumentos envolvidos no processo } n=2 .
\end{aligned}
$$




\subsubsection{Determinação da precisão aparente das coordenadas dos pontos $\left(G_{i}\right)$, sobre as retas definidas pelas linhas de visada}

A precisão aparente das coordenadas dos pontos genéricos $\left(G_{i}\right)$ é definida como o desvio padrão da média destas determinações. Como a média das coordenadas dos pontos genéricos $\left(G_{i}\right)$ é igual ao valor das coordenadas do alvo $\mathrm{P}$, os valores obtidos para a precisão aparente das determinações são absolutamente iguais.

A precisão aparente das coordenadas dos pontos $\left(G_{i}\right)$ é dada por:

$$
\begin{gathered}
\sigma_{X G}=\sqrt{\frac{\sum\left(X P-X G_{i}\right)^{2}}{n-1}} \\
\sigma_{Y G}=\sqrt{\frac{\sum\left(Y P-Y G_{i}\right)^{2}}{n-1}} \\
\sigma_{Z G}=\sqrt{\frac{\sum\left(Z P-Z G_{i}\right)^{2}}{n-1}}
\end{gathered}
$$

Sendo:

$$
\begin{aligned}
& X P, Y P, Z P-\text { Coordenadas do alvo; } \\
& X G_{i}, Y G_{i}, Z G_{i}-\text { Coordenadas dos pontos sobre as linhas de visada; } \\
& n \text { - Número de estações ou instrumentos envolvidos no processo } n=2 .
\end{aligned}
$$

\subsubsection{Determinação da precisão aparente das coordenadas finais do alvo $P$}

A precisão aparente ou desvio padrão das coordenadas finais de cada alvo $P$ são definidos em função da precisão aparente das determinações dos valores das coordenadas dos pontos genéricos $\left(G_{i}\right)$, considerando-se os $n$ instrumentos ou 
estações envolvidos no processo. Então, a precisão aparente é calculada em função do desvio padrão da média das coordenadas $X G_{i}, Y G_{i}, Z G_{i}$. Logo:

$$
\begin{aligned}
& \sigma_{\overline{X P}}=\frac{\sigma_{X G}}{\sqrt{n}} \\
& \sigma_{\overline{Y P}}=\frac{\sigma_{Y G}}{\sqrt{n}} \\
& \sigma_{\overline{Z P}}=\frac{\sigma_{Z G}}{\sqrt{n}}
\end{aligned}
$$

Sendo:

$$
\begin{aligned}
& \sigma_{\overline{X P}}, \sigma_{\overline{Y P}}, \sigma_{\overline{Z P}}-\text { Precisão aparente das coordenadas finais de P; } \\
& \sigma_{X G_{i}}, \sigma_{Y G_{i}}, \sigma_{Z G_{i}}-\text { Precisão aparente das coordenadas dos pontos }\left(G_{i}\right) ; \\
& n \text { - Número de estações ou instrumentos envolvidos no processo } n=2 .
\end{aligned}
$$

\subsubsection{Determinação da precisão do posicionamento espacial do alvo $P$}

Determinadas as coordenadas do alvo $\mathrm{P}$ e suas respectivas precisões aparentes, pode-se estimar um valor médio em torno do qual, provavelmente, fique localizado espacialmente o ponto que define a posição do alvo P. Neste caso, define-se a precisão do posicionamento espacial do alvo $\left(\sigma_{p}\right)$, como sendo o escalar obtido pela raiz quadrada da soma dos quadrados das precisões aparentes das coordenadas espaciais do alvo $P$.

A precisão espacial do posicionamento do alvo $\mathrm{P}$ é calculada por:

$$
\sigma_{p}=\sqrt{\left(\sigma_{\overline{X P}}\right)^{2}+\left(\sigma_{\overline{Y P}}\right)^{2}+\left(\sigma_{\overline{Z P}}\right)^{2}}
$$

Sendo:

$\sigma_{p}$ - Precisão do posicionamento espacial do alvo P; 
$\sigma_{\overline{X P}}, \sigma_{\overline{Y P}}, \sigma_{\overline{Z P}}-$ Precisão aparente das coordenadas finais de $\mathrm{P}$.

\subsubsection{Validação do modelo matemático}

O método proposto e sua modelagem matemática foram validados considerando as informações coletadas em campo, sendo estas, dados de entrada para uma rotina de programação computacional elaborada em ambiente MATLAB, constante no Apêndice E.

Para os dados de saída, os valores das coordenadas espaciais e suas precisões, foram atribuídos o format long no prompt de comando da interface do software. Sendo que este comando considera em seu formato quatorze casas decimais, porém, para a apresentação dos dados em planilhas eletrônicas do EXCEL, foram truncados neste ambiente, valores com quatro casas decimais, nível de significância que já permite comparações entre os demais métodos.

\subsubsection{Determinação e análise das coordenadas espaciais calculadas para a variação do alvo GPR111}

A determinação das coordenadas espaciais dos alvos, sendo estes deslocados de forma controlada e com seis tipos diferentes de refletores, foi efetuada com o processamento dos dados de entrada de cada refletor.

A Tabela 14 mostra os dados observados e a verificação da estabilidade para a Base 1, com suas respectivas precisões, realizadas por meio do método de recessão, antes da realização de cada medida em direção ao alvo com deslocamento controlado. Já a Tabela 15 apresenta os dados observados juntamente com a verificação da estabilidade da Base 2.

As precisões aparentes das coordenadas dos alvos são calculadas em função das precisões aparentes das médias das coordenadas $\left(G_{i}\right)$, conforme item 4.5.2.10 do desenvolvimento matemático. Os valores das coordenadas espaciais e 
respectivas precisões para o refletor GPR111 e a precisão aparente do posicionamento espacial dos pontos deslocados $\left(\sigma_{X, Y, Z}\right)$ são dados em função da precisão aparente de suas respectivas coordenadas, conforme item 4.5.2.12 do desenvolvimento matemático proposto. Tais valores são apresentados na Tabela 16. $\mathrm{Na}$ Figura 50, pode-se visualizar o comportamento da variação em relação ao controle.

O Apêndice $F$ mostra os dados para a validação deste método em relação aos outros tipos de alvos. 
Tabela 14 - Dados observados e verificação da estabilidade da Base 1 (Distância Mínima)

\begin{tabular}{|c|c|c|c|c|c|c|c|c|}
\hline \multicolumn{9}{|c|}{ MÉTODO DAS DISTÂNCIAS MÍNIMAS - GPR111 (0.0 mm) } \\
\hline \multicolumn{9}{|c|}{ BASE 1} \\
\hline \multicolumn{3}{|c|}{ DADOS OBSERVADOS } & \multicolumn{6}{|c|}{ ESTABILIDADE DA BASE "RECESSÃO" } \\
\hline PONTOS & Azimute & Zenital & $X(m)$ & $\sigma_{X}(m m)$ & $\mathrm{Y}(\mathrm{m})$ & $\sigma_{Y}(\mathrm{~mm})$ & $\mathrm{Z}(\mathrm{m})$ & $\sigma_{\mathrm{z}}(\mathrm{mm})$ \\
\hline GPRC00 & $15^{\circ} 34^{\prime} 48,1685^{\prime \prime}$ & $84^{\circ} 25^{\prime} 48,6111^{\prime \prime}$ & $1.000,0044$ & 2,1 & $4.999,9975$ & 0,4 & 100,0000 & 1,2 \\
\hline GPRC01 & $15^{\circ} 35^{\prime} 00,3475^{\prime \prime}$ & $84^{\circ} 25^{\prime} 59,2228^{\prime \prime}$ & $1.000,0042$ & 2,0 & $4.999,9975$ & 0,5 & 100,0000 & 1,3 \\
\hline GPRC02 & $15^{\circ} 35^{\prime} 05,4400^{\prime \prime}$ & $84^{\circ} 26^{\prime} 08,1627^{\prime \prime}$ & $1.000,0043$ & 1,7 & $4.999,9975$ & 0,4 & 99,9996 & 0,7 \\
\hline GPRC03 & $15^{\circ} 35^{\prime} 06,7493^{\prime \prime}$ & $84^{\circ} 26^{\prime} 17,2567^{\prime \prime}$ & $1.000,0047$ & 2,0 & $4.999,9974$ & 0,3 & 99,9997 & 0,7 \\
\hline GPRC04 & $15^{\circ} 35^{\prime} 13,1560^{\prime \prime}$ & $84^{\circ} 26^{\prime} 26,6696^{\prime \prime}$ & $1.000,0047$ & 2,1 & $4.999,9975$ & 0,3 & 99,9997 & 0,7 \\
\hline GPRC05 & $15^{\circ} 35^{\prime} 21,4801 "$ & $84^{\circ} 26^{\prime} 33,7920^{\prime \prime}$ & $1.000,0046$ & 2,3 & $4.999,9977$ & 0,4 & 99,9997 & 0,8 \\
\hline GPRC06 & $15^{\circ} 35^{\prime} 58,9549 "$ & $84^{\circ} 27^{\prime} 20,5565^{\prime \prime}$ & $1.000,0047$ & 2,1 & $4.999,9976$ & 0,4 & 99,9997 & 0,7 \\
\hline GPRC07 & $15^{\circ} 37^{\prime} 18,7227^{\prime \prime}$ & $84^{\circ} 28^{\prime} 49,1844^{\prime \prime}$ & $1.000,0047$ & 1,9 & $4.999,9975$ & 0,4 & 99,9997 & 0,8 \\
\hline
\end{tabular}


Tabela 15 - Dados observados e verificação da estabilidade da Base 2 (Distância Mínima)

\begin{tabular}{|c|c|c|c|c|c|c|c|c|}
\hline \multicolumn{9}{|c|}{ BASE 2} \\
\hline \multicolumn{3}{|c|}{ DADOS OBSERVADOS } & \multicolumn{6}{|c|}{ ESTABILIDADE DA BASE "RECESSÃO" } \\
\hline PONTOS & Azimute & Zenital & $X(m)$ & $\sigma_{X}(m m)$ & $Y(m)$ & $\sigma_{Y}(\mathrm{~mm})$ & $\mathrm{Z}(\mathrm{m})$ & $\sigma_{Z}(\mathrm{~mm})$ \\
\hline GPRC00 & $342^{\circ} 49^{\prime} 02,9670 "$ & $84^{\circ} 09^{\prime} 14,4809^{\prime \prime}$ & $1.013,1146$ & 2,0 & $5.000,7533$ & 0,6 & 99,9462 & 1,2 \\
\hline GPRC01 & $342^{\circ} 49^{\prime} 17,4631^{\prime \prime}$ & $84^{\circ} 09^{\prime} 24,9417^{\prime \prime}$ & $1.013,1144$ & 2,0 & $5.000,7532$ & 0,3 & 99,9461 & 1,3 \\
\hline GPRC02 & $342^{\circ} 49^{\prime} 24,0562^{\prime \prime}$ & $84^{\circ} 09^{\prime} 34,9946 "$ & $1.013,1145$ & 1,6 & $5.000,7534$ & 0,4 & 99,9459 & 0,7 \\
\hline GPRC03 & $342^{\circ} 49^{\prime} 29,5291^{\prime \prime}$ & $84^{\circ} 09^{\prime} 43,4492^{\prime \prime}$ & $1.013,1144$ & 1,7 & $5.000,7536$ & 0,4 & 99,9461 & 0,7 \\
\hline GPRC04 & $342^{\circ} 49^{\prime} 30,4846^{\prime \prime}$ & $84^{\circ} 09^{\prime} 53,5269^{\prime \prime}$ & $1.013,1150$ & 1,6 & $5.000,7537$ & 0,5 & 99,9460 & 0,6 \\
\hline GPRC05 & $342^{\circ} 49^{\prime} 44,1066^{\prime \prime}$ & $84^{\circ} 09^{\prime} 59,0432 "$ & $1.013,1142$ & 2,0 & $5.000,7533$ & 0,4 & 99,9461 & 0,6 \\
\hline GPRC06 & $342^{\circ} 50^{\prime} 31,9851^{\prime \prime}$ & $84^{\circ} 10^{\prime} 43,7141^{\prime \prime}$ & $1.013,1139$ & 2,0 & $5.000,7533$ & 0,4 & 99,9461 & 0,7 \\
\hline GPRC07 & $342^{\circ} 51^{\prime} 49,2595^{\prime \prime}$ & $84^{\circ} 12^{\prime} 09,3632^{\prime \prime}$ & $1.013,1147$ & 1,9 & $5.000,7534$ & 0,4 & 99,9461 & 0,7 \\
\hline
\end{tabular}


Tabela 16 - Coordenadas dos alvos e precisões aparentes (Distância Mínima)

\section{COORDENADAS E PRECISÕES APARENTES - GPR111}

\begin{tabular}{cccccccc}
\hline PONTOS & $X(\mathrm{~m})$ & $\sigma_{X}(\mathrm{~mm})$ & $Y(\mathrm{~m})$ & $\sigma_{Y}(\mathrm{~mm})$ & $\mathrm{Z}(\mathrm{m})$ & $\sigma_{Z}(\mathrm{~mm})$ & $\sigma_{X Y Z}(\mathrm{~mm})$ \\
\hline GPRC00 & $1.006,3316$ & 0,0010 & $5.022,6894$ & 0,0108 & 102,2972 & 0,1046 & 0,1052 \\
GPRC01 & $1.006,3329$ & 0,0016 & $5.022,6898$ & 0,0175 & 102,2960 & 0,1685 & 0,1695 \\
GPRC02 & $1.006,3337$ & 0,0014 & $5.022,6902$ & 0,0153 & 102,2946 & 0,1479 & 0,1487 \\
GPRC03 & $1.006,3343$ & 0,0007 & $5.022,6902$ & 0,0080 & 102,2938 & 0,0772 & 0,0776 \\
GPRC04 & $1.006,3351$ & 0,0016 & $5.022,6902$ & 0,0168 & 102,2926 & 0,1622 & 0,1631 \\
GPRC05 & $1.006,3358$ & 0,0001 & $5.022,6899$ & 0,0020 & 102,2919 & 0,0196 & 0,0197 \\
GPRC06 & $1.006,3407$ & 0,0002 & $5.022,6911$ & 0,0021 & 102,2868 & 0,0202 & 0,0203 \\
GPRC07 & $1.006,3504$ & 0,0004 & $5.022,6917$ & 0,0048 & 102,2769 & 0,0468 & 0,0471 \\
\hline
\end{tabular}


Tabela 17 - Variação controlada, variação das coordenadas e diferença entre ambas (Distância Mínima)

\begin{tabular}{cccccccc}
\hline \multicolumn{2}{c}{ CONTROLE } & \multicolumn{3}{c}{$\begin{array}{c}\text { DIFERENÇAS ENTRE } \\
\text { COORDENADAS AJUSTADAS }\end{array}$} & \multicolumn{3}{c}{ RESíDUO ENTRE CONTROLE E } \\
COORDENADAS
\end{tabular}




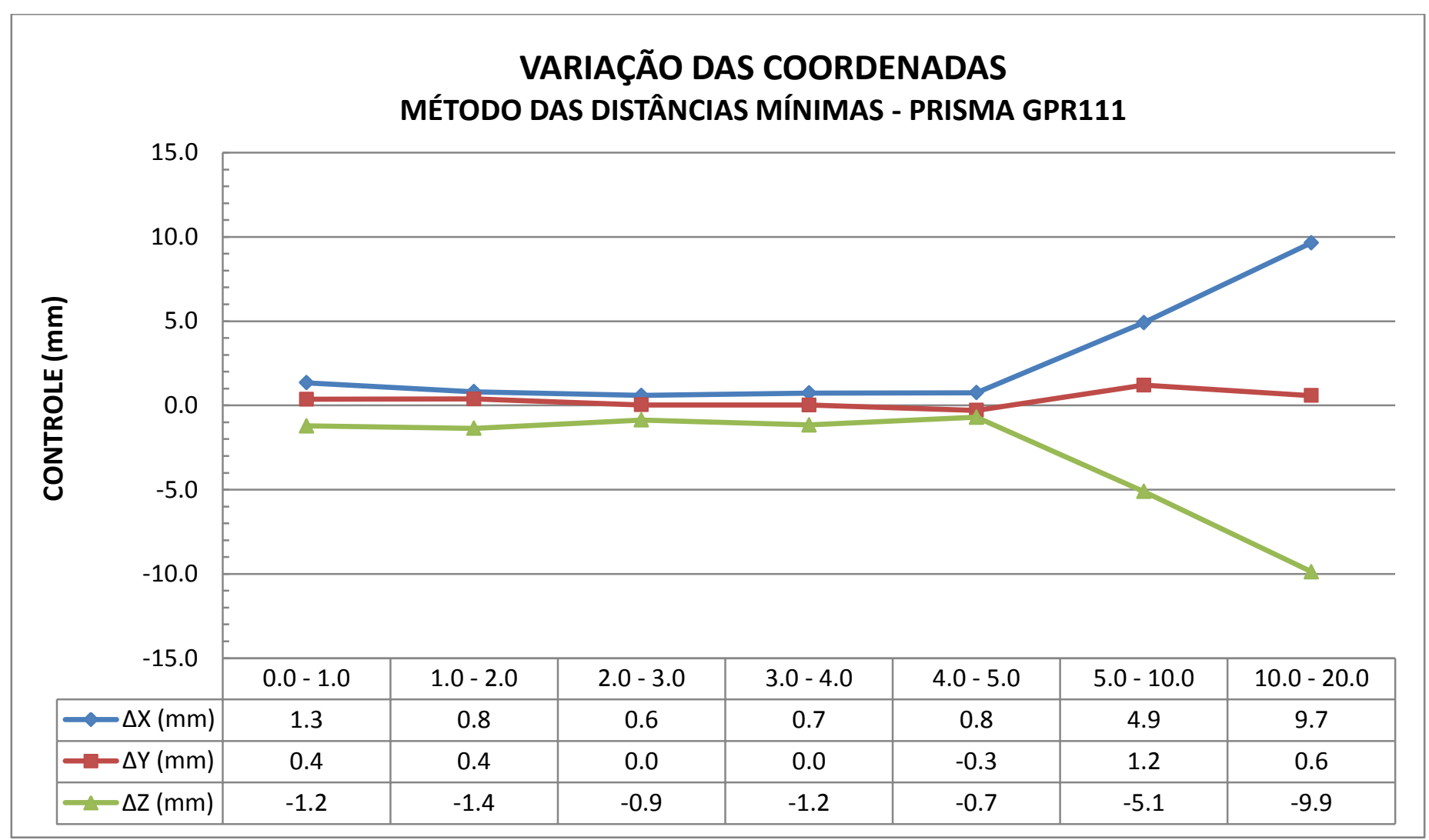

Figura 50 - Variação das coordenadas para o prisma GPR111 (Distância Mínima) 
Com estes resultados, observa-se que as precisões aparentes, calculadas em função das médias das determinações, e a precisão do posicionamento espacial dos alvos em deslocamento são da ordem de décimos e centésimos de milímetros, conforme Tabela 16. Assim, pode-se assegurar que o método proposto, dentro das restrições técnicas das estações totais robóticas utilizadas, também apresenta resultados compatíveis com a precisão nominal dos referidos aparelhos.

Ao comparar os valores obtidos pela diferença entre as coordenadas espaciais com a variação controlada, avalia-se que o método proposto, executado com os procedimentos estudados, apresenta resíduos extremamente baixos, também da ordem de décimos de milímetros.

Dessa forma, considerando-se os índices de variação em relação ao controle, pode-se afirmar que o método proposto, juntamente com as estações totais robóticas, apresenta precisões aceitáveis para trabalhos de mensuração de alta precisão, exigido na monitoração industrial e para controle de grandes estruturas de obras civis.

\subsection{PROPOSTA PARA O CÁLCULO DE COORDENADAS ESPACIAIS PELO MÉTODO DAS DISTÂNCIAS MÍNIMAS COM AJUSTAMENTO DAS OBSERVAÇÕES}

\subsubsection{Introdução}

A proposta deste método, denominado Método das Distâncias Mínimas e Ajuste, efetua cálculos para determinar coordenadas espaciais de alvos ou pontos fixos, fundamentando-se em alguns princípios. As coordenadas espaciais de um alvo são definidas por meio de uma função, sendo variáveis, as coordenadas do centro óptico dos instrumentos envolvidos no processo, os ângulos zenitais e os azimutes das linhas de visada desses instrumentos, em direção ao referido alvo. Desse modo, o presente método executa o cálculo das coordenadas espaciais dos 
alvos, empregando em sua modelagem matemática o ajustamento das observações pelo Método dos Mínimos Quadrados (M.M.Q.).

Cada estação fixa ou instrumento envolvido no processo fornece três equações que, segundo Gemael (1994), são as equações de erros da metodologia apresentada. E, para este método, as incógnitas são as coordenadas espaciais do alvo $\mathrm{P}(X P, Y P, Z P)$ e os parâmetros $\left(t_{i}\right)$ das retas $\left(r_{i}\right)$, definidas pela linha de visada de cada instrumento. Entretanto, o processo deve conter, no mínimo, duas estações fixas empregadas, para que, assim, haja pelo menos um grau de liberdade, isto é, seis equações para as cinco incógnitas possíveis, as coordenadas espaciais do alvo e os dois parâmetros das retas definidas pelas linhas de visada.

Se $(n)$, que representa o número de observações ou equações de erros, e $(u)$, o número de incógnitas, para o método de ajustamento: $(n>u)$, aplica-se o método dos coeficientes, logo, o requisito mínimo exigido são duas estações fixas. Portanto, para a presente pesquisa, foi utilizada a condição descrita acima, duas estações fixas ocupadas por dois instrumentos simultaneamente.

Como este método calcula as coordenadas espaciais dos alvos, em função das coordenadas do centro óptico dos instrumentos e da orientação das retas, definidas pelas linhas de visadas, a orientação destas retas implica a concepção de no mínimo, um ponto de orientação, para obtenção dos azimutes, porém, este trabalho considerou três pontos de orientação, que por meio da recessão permite ajustar este azimute obtido e gerar maior confiabilidade nas medições realizadas.

Em função destes azimutes e dos ângulos zenitais observados de cada estação fixa, em relação ao alvo e a partir de cossenos diretores, são determinados os coeficientes ou parâmetros das equações de erros. Estes parâmetros são denominados por $\left(a_{i}, b_{i}, c_{i}\right)$, que são as coordenadas dos versores unitários que definem as direções das linhas de visadas.

Os valores de $\bar{r}_{i}\left(a_{i}, b_{i}, c_{i}\right)$ são parâmetros escalares das retas e indicam a localização espacial do alvo, tendo como origem as coordenadas do centro óptico dos instrumentos e dos versores diretores destas retas. Então, esta proposta apresentada exige a condição de que os dois instrumentos estacionados em cada 
base, possam visar os pontos de orientação, porém, sem a necessidade de intervisibilidade entre os instrumentos.

Por fim, após a montagem das equações de erros, o desenvolvimento matemático proposto segue o roteiro de cálculo de ajustamento de observações pelo M.M.Q., por meio do Método Paramétrico.

\subsubsection{Modelo matemático proposto}

A modelagem matemática é fundamentada nos princípios básicos da Geometria Analítica Espacial, que é apresentada sob o aspecto vetorial, conforme Boulos e Camargo (2005); e, no ajustamento pelo método paramétrico, com aplicação do modelo para observações mediatas, utilizando técnicas do M.M.Q., em conformidade com Gemael (1994) e Wolf e Ghilani (2006).

Para a obtenção desta modelagem, é necessário determinar as leituras angulares referentes ao alvo, azimutes e ângulos zenitais, medidos em cada estação e as coordenadas espaciais do centro óptico de cada instrumento envolvido no processo. Ressaltando que, para a validação deste método na presente pesquisa, foram utilizados dois instrumentos devidamente posicionados em duas estações fixas, Base 1 e 2, e a orientação de cada base para a coleta de dados é dada pela realização da recessão, apresentada no item 3.3.5, em relação a três pontos de referência previamente definidos pela rede absoluta, ilustrada no item 4.2.2.

\subsubsection{Determinação das coordenadas dos versores das linhas de visadas}

Os versores das linhas de visadas $\bar{r}_{i}\left(a_{i}, b_{i}, c_{i}\right)$, em relação aos eixos coordenados $(x, y, z)$, são definidos por:

$$
\begin{aligned}
& a_{i}=\operatorname{sen}\left(Z e n_{i}\right) \cdot \operatorname{sen}\left(A z_{i}\right) \\
& b_{i}=\operatorname{sen}\left(Z e n_{i}\right) \cdot \cos \left(A z_{i}\right)
\end{aligned}
$$




$$
c_{i}=\cos \left(\operatorname{Zen}_{i}\right)
$$

Sendo:

$$
\begin{aligned}
& \bar{r}_{i} \text { - Versor diretor da reta } i \\
& a_{i} \text { - Coordenada do versor, na direção do eixo } x ; \\
& b_{i} \text { - Coordenada do versor, na direção do eixo } y ; \\
& c_{i} \text { - Coordenada do versor, na direção do eixo } z \text {. } \\
& A z_{i}-\text { Azimute em direção ao alvo } \mathrm{P} \text {, sendo } i=1,2 ; \\
& Z \operatorname{Zen}_{i}-\text { Ângulo zenital em direção ao alvo } \mathrm{P} \text {, sendo } i=1,2 .
\end{aligned}
$$

\subsubsection{Determinação das equações de erros}

Das visadas executadas, em cada estação base, são fornecidas três equações de erros, uma para cada coordenada de $\mathrm{P}(X P, Y P, Z P)$, isto é:

$$
\begin{aligned}
& X P+V 1_{i}=X C O_{i}+a_{i} \cdot \lambda_{i} \\
& Y P+V 2_{i}=Y C O_{i}+b_{i} \cdot \lambda_{i} \\
& Z P+V 3_{i}=Z C O_{i}+c_{i} \cdot \lambda_{i}
\end{aligned}
$$

Sendo:

$\mathrm{XCO}_{i}, \mathrm{YCO}_{i}, \mathrm{ZCO}_{i}$ - Coordenadas do centro óptico dos instrumentos posicionados nas estações fixas;

$i$ - Número de bases envolvidas no processo, sendo $i=1,2$.

Se for generalizado, para as duas estações, ter-se-ão as equações de erros (4.58), (4.59) e (4.60) para a Base 1, e as equações de erros (4.61), (4.62) e (4.63) para a Base 2: 


$$
\begin{aligned}
& V 1_{1}=X P-X C O_{1}-a_{1} \cdot \lambda_{1} \\
& V 2_{1}=Y P-Y C O_{1}-b_{1} \cdot \lambda_{1} \\
& V 3_{1}=Z P-Z C O_{1}-c_{1} \cdot \lambda_{1} \\
& V 1_{2}=X P-X C O_{2}-a_{2} \cdot \lambda_{2} \\
& V 2_{2}=Y P-Y C O_{2}-b_{2} \cdot \lambda_{2} \\
& V 3_{2}=Z P-Z C O_{2}-c_{2} \cdot \lambda_{2}
\end{aligned}
$$

Sendo:

$X \mathrm{XO}_{i}, \mathrm{YCO}_{i}, \mathrm{ZCO}_{i}-$ Coordenadas do centro óptico dos instrumentos;

$X P, Y P, Z P$ - Incógnitas (coordenadas do alvo P);

$V 1_{i}, V 2_{i}, V 3_{i}-$ Resíduos;

$\lambda_{i}-$ Incógnitas (parâmetros das retas definidas pelas linhas de visada);

$i$ - Número de bases envolvidas no processo, sendo $i=1,2$.

A função $3 n\left(V 1_{i}, V 2_{i}, V 3_{i}\right)$, com $(i=1 e 2)$ e sendo $(3+n)$ variáveis $(X P, Y P, Z P)$ e $\left(\lambda_{i}\right)$, com $(i=1 e 2)$, é descrita pelo conjunto de equações (4.58 a 4.63), e foi denominada $(V)$ :

$$
V: \mathfrak{R}^{3+n} \rightarrow \mathfrak{R}^{3 n}
$$

E, para a presente pesquisa:

$$
V: \Re^{3+2} \rightarrow \Re^{3.2}
$$

Isto é, a função (4.66) deve ser minimizada:

$$
V=V\left(X P, Y P, Z P, \lambda_{1}, \lambda_{2}\right)
$$


Para que os resíduos, valores das funções $\left(V 1_{i}, V 2_{i}, V 3_{i}\right)$ tornem-se mínimos, para, as duas estações base, as incógnitas estão relacionadas por uma função $F$, definidas por:

$$
F=F\left(X P, Y P, Z P, \lambda_{1}, \lambda_{2}\right)
$$

\subsubsection{Resolução matricial}

Segundo Wolf e Ghilani (2006), Anderson e Mikhail (1998) e Gemael (1994), pela equação geral do M.M.Q., tem-se:

$$
V=A X-L
$$

Sendo:

$V$ - Vetor dos resíduos;

$A$ - Matriz dos coeficientes das incógnitas;

$X$ - Vetor das incógnitas;

$L-$ Vetor das observações.

A matriz $(A)$ é obtida derivando-se a função na forma canônica de Jordan, definida pela equação (4.67), segundo o conjunto de equações (4.58 a 4.63), em relação às incógnitas.

Sendo assim, tem-se:

$$
A=\left[\begin{array}{lllll}
\frac{\partial F 1_{1}}{\partial X P} & \frac{\partial F 1_{1}}{\partial Y P} & \frac{\partial F 1_{1}}{\partial Z P} & \frac{\partial F 1_{1}}{\partial \lambda_{1}} & \frac{\partial F 1_{1}}{\partial \lambda_{2}} \\
\frac{\partial F 2_{1}}{\partial X P} & \frac{\partial F 2_{1}}{\partial Y P} & \frac{\partial F 2_{1}}{\partial Z P} & \frac{\partial F 2_{1}}{\partial \lambda_{1}} & \frac{\partial F 2_{1}}{\partial \lambda_{2}} \\
\frac{\partial F 3_{1}}{\partial X P} & \frac{\partial F 3_{1}}{\partial Y P} & \frac{\partial F 3_{1}}{\partial Z P} & \frac{\partial F 3_{1}}{\partial \lambda_{1}} & \frac{\partial F 3_{1}}{\partial \lambda_{2}} \\
\frac{\partial F 1_{2}}{\partial X P} & \frac{\partial F 1_{2}}{\partial Y P} & \frac{\partial F 1_{2}}{\partial Z P} & \frac{\partial F 1_{2}}{\partial \lambda_{1}} & \frac{\partial F 1_{2}}{\partial \lambda_{2}} \\
\frac{\partial F 2_{2}}{\partial X P} & \frac{\partial F 2_{2}}{\partial Y P} & \frac{\partial F 2_{2}}{\partial Z P} & \frac{\partial F 2_{2}}{\partial \lambda_{1}} & \frac{\partial F 2_{2}}{\partial \lambda_{2}} \\
\frac{\partial F 3_{2}}{\partial X P} & \frac{\partial F 3_{2}}{\partial Y P} & \frac{\partial F 3_{2}}{\partial Z P} & \frac{\partial F 3_{2}}{\partial \lambda_{1}} & \frac{\partial F 3_{2}}{\partial \lambda_{2}}
\end{array}\right]
$$


Derivando-se, temos:

$$
A=\left[\begin{array}{ccccc}
1 & 0 & 0 & -a_{1} & 0 \\
0 & 1 & 0 & -b_{1} & 0 \\
0 & 0 & 1 & -c_{1} & 0 \\
1 & 0 & 0 & 0 & -a_{2} \\
0 & 1 & 0 & 0 & -b_{2} \\
0 & 0 & 1 & 0 & -c_{2}
\end{array}\right]
$$

O vetor das incógnitas $(X)$ é dado por:

$$
X=\left[\begin{array}{l}
X P \\
Y P \\
Z P \\
\lambda_{1} \\
\lambda_{2}
\end{array}\right]
$$

O vetor dos resíduos $(V)$ é dado por:

$$
V=\left[\begin{array}{l}
V 1_{1} \\
V 2_{1} \\
V 3_{1} \\
V 1_{2} \\
V 2_{2} \\
V 3_{2}
\end{array}\right]
$$

O vetor $(L)$ é composto pelas coordenadas do centro óptico dos dois instrumentos envolvidos neste processo, sendo estes valores considerados como observações, obtidos indiretamente, em função dos valores angulares determinados nas medições realizadas em campo, a partir da rede absoluta e recessão, assim:

$$
L=\left[\begin{array}{l}
X \mathrm{XO}_{1} \\
Y C O_{1} \\
Z C O_{1} \\
X C O_{2} \\
Y C O_{2} \\
Z C O_{2}
\end{array}\right]
$$




\subsubsection{Aplicação do modelo para observações mediatas utilizando o M.M.Q.}

Neste caso, deve-se considerar que as observações não são correlacionadas, pois, observam-se azimutes e ângulos zenitais, independentemente para cada alvo. Consideram-se também os pesos das observações, portanto, a matriz dos pesos $(P)$ será simétrica e seus respectivos pesos será inversamente proporcional às precisões angulares elevadas ao quadrado de cada instrumento utilizado, dispostas na diagonal principal.

Sabendo se que, pelo método empregado, o modelo generalizado é dado pela equação (4.74), sendo a matriz peso $(P)$ simétrica e, ainda, partindo-se do princípio de que o produto resultante da transposta da matriz dos vetores dos resíduos $(V)$, multiplicada pela matriz dos pesos $(P)$ e pela própria matriz dos resíduos $(V)$, deve ser mínimo, isto é:

$$
V^{T} P V=\text { mínimo }
$$

Tem-se:

$$
V^{T} P V=\left(X^{T} A^{T}-L^{T}\right) \cdot P \cdot(A X-L)
$$

Efetuando-se a multiplicação indicada, tem-se;

$$
V^{T} P V=X^{T} . A^{T} . P . A \cdot X-2 \cdot L^{T} . P \cdot A \cdot X+L^{T} . P . L
$$

E derivando-se parcialmente em relação a $(X)$, tem-se:

$$
\frac{\partial V^{T} P V}{\partial X}=2 \cdot X^{T} \cdot A^{T} \cdot P \cdot A-2 \cdot L^{T} \cdot P \cdot A
$$

Igualando-se a zero:

$$
A^{T} . P . A . X-A^{T} . P . L=0
$$

Definindo:

$$
N=A^{T} \cdot P \cdot A
$$




$$
n=A^{T} . P . L
$$

Vem:

$$
N X=n
$$

Daí:

$$
X=N^{-1} \cdot n
$$

Obtendo-se $(X)$, pode-se calcular $(V)$ por meio da equação (4.68). E, ao retornar à equação (4.78), colocando-se em evidência o fator comum, tem-se:

$$
A^{T} . P .(A . X-L)=0
$$

Então:

$$
A^{T} . P . V=0
$$

A equação (4.84) é um controle do M.M.Q. e, durante a aplicação do método, este controle sempre deve ser executado, para que se tenha confiança nos resultados finais.

$E$, finalmente, sabe-se que:

$$
\hat{\sigma}_{0}^{2}=\frac{V^{T} P V}{n-u}
$$

Sendo:

$\hat{\sigma}_{0}^{2}$ - Variância “a posteriori” ou precisão das determinações;

$V^{T} P V$ - Somatório dos quadrados dos resíduos;

$n$ - Número de equações de erros, sendo $n=6$;

$u$ - Número de incógnitas $u=5$. 


\subsubsection{Cálculo dos erros e das matrizes variância-covariância (MVC)}

Após o cálculo da matriz das incógnitas $(X)$, podem-se explorar os resultados de maneira a se obter todas as informações estatísticas do modelo, essencialmente, as contidas nas matrizes de variância-covariância das incógnitas, das observações compensadas e dos erros residuais, sendo:

$$
\begin{aligned}
& Q_{L L}=P^{-1} \\
& Q_{X X}=N^{-1} \\
& Q_{\overline{L L}}=\hat{\sigma}_{0}^{2} \cdot P^{-1} \\
& Q_{V V}=P^{-1}-\bar{K}
\end{aligned}
$$

$\mathrm{E}:$

$$
\bar{Q}=A \cdot N^{-1} \cdot A^{T}
$$

Sendo:

$$
\begin{aligned}
& Q_{L L}-\text { Matriz variância-covariância das observações; } \\
& Q_{X X}-\text { Matriz variância-covariância das incógnitas; } \\
& Q_{\overline{L L}}-\text { Matriz variância-covariância das observações compensadas; } \\
& Q_{V V}-\text { Matriz dos resíduos. }
\end{aligned}
$$

Os cálculos são realizados utilizando-se a lei de propagação dos erros médios aplicada a um vetor de função $(f)$, composto simultaneamente pelos vetores $L, X, \bar{L}$ e V:

$L-$ Vetor das observações;

$X$ - Vetor das incógnitas; 
$\bar{L}$ - Vetor das observações compensadas;

$V-$ Vetor dos erros residuais.

\subsubsection{Validação do modelo matemático proposto}

O modelo matemático proposto foi validado a partir dos dados observados e coletados em campo com o emprego de rotinas computacionais em plataforma MATLAB.

As coordenadas do centro óptico dos instrumentos foram determinadas por meio da recessão, considerando-se a altura do instrumento igual a zero. Portanto, o desenvolvimento desta programação, com base em rotinas computacionais, pode ser visto no Apêndice $G$.

\subsubsection{Determinação e análise das coordenadas espaciais calculadas para o alvo GPR111}

Conforme citado acima, a modelagem matemática foi totalmente codificada e implementada no MATLAB, ambiente em que foram calculadas as coordenadas espaciais dos alvos, as quais se apresentam em uma variação milimetricamente controlada em seu deslocamento, considerando seis diferentes tipos de alvos refletores. Porém, serão apresentados, a seguir, apenas os dados, resultados e análises inerentes ao alvo GPR111, sendo que isto, para os demais alvos, consta no Apêndice $\mathrm{H}$.

As Tabelas 18 e 19 mostram os dados observados em campo, seguidos da verificação da estabilidade das bases. A tabela 20 ilustra as coordenadas e precisões ajustadas dos alvos em deslocamento. Já, a variação controlada, a variação das coordenadas ajustadas e a diferença entre ambas podem ser vistas na Tabela 21. Por fim, na Figura 51 é ilustrada, graficamente, a variação das coordenadas espaciais. 
Tabela 18 - Dados observados e verificação da estabilidade da Base 1 (Distância Mínima e Ajuste)

\begin{tabular}{|c|c|c|c|c|c|c|c|c|}
\hline \multicolumn{9}{|c|}{ MÉTODO DAS DISTÂNCIAS MÍNIMAS E AJUSTE - GPR111 (0.0mm) } \\
\hline \multicolumn{9}{|c|}{ BASE 1} \\
\hline \multicolumn{3}{|c|}{ DADOS OBSERVADOS } & \multicolumn{6}{|c|}{ ESTABILIDADE DA BASE "RECESSÃO" } \\
\hline PONTOS & Azimute & Zenital & $X(m)$ & $\sigma_{\mathrm{x}}(\mathrm{mm})$ & $\mathrm{Y}(\mathrm{m})$ & $\sigma_{Y}(\mathrm{~mm})$ & $\mathrm{Z}(\mathrm{m})$ & $\sigma_{Z}(\mathrm{~mm})$ \\
\hline GPRC00 & $15^{\circ} 34^{\prime} 48,1685^{\prime \prime}$ & $84^{\circ} 25^{\prime} 48,6111 "$ & $1.000,0044$ & 2,1 & $4.999,9975$ & 0,4 & 100,0000 & 1,2 \\
\hline GPRC01 & $15^{\circ} 35^{\prime} 00,3475^{\prime \prime}$ & $84^{\circ} 25^{\prime} 59,2228^{\prime \prime}$ & $1.000,0042$ & 2,0 & $4.999,9975$ & 0,5 & 100,0000 & 1,3 \\
\hline GPRC02 & $15^{\circ} 35^{\prime} 05,4400^{\prime \prime}$ & $84^{\circ} 26^{\prime} 08,1627^{\prime \prime}$ & $1.000,0043$ & 1,7 & $4.999,9975$ & 0,4 & 99,9996 & 0,7 \\
\hline GPRC03 & $15^{\circ} 35^{\prime} 06,7493 "$ & $84^{\circ} 26^{\prime} 17,2567^{\prime \prime}$ & $1.000,0047$ & 2,0 & $4.999,9974$ & 0,3 & 99,9997 & 0,7 \\
\hline GPRC04 & $15^{\circ} 35^{\prime} 13,1560^{\prime \prime}$ & $84^{\circ} 26^{\prime} 26,6696^{\prime \prime}$ & $1.000,0047$ & 2,1 & $4.999,9975$ & 0,3 & 99,9997 & 0,7 \\
\hline GPRC05 & $15^{\circ} 35^{\prime} 21,4801 "$ & $84^{\circ} 26^{\prime} 33,7920^{\prime \prime}$ & $1.000,0046$ & 2,3 & $4.999,9977$ & 0,4 & 99,9997 & 0,8 \\
\hline GPRC06 & $15^{\circ} 35^{\prime} 58,9549^{\prime \prime}$ & $84^{\circ} 27^{\prime} 20,5565^{\prime \prime}$ & $1.000,0047$ & 2,1 & $4.999,9976$ & 0,4 & 99,9997 & 0,7 \\
\hline GPRC07 & $15^{\circ} 37^{\prime} 18,7227^{\prime \prime}$ & $84^{\circ} 28^{\prime} 49,1844^{\prime \prime}$ & $1.000,0047$ & 1,9 & $4.999,9975$ & 0,4 & 99,9997 & 0,8 \\
\hline
\end{tabular}


Tabela 19 - Dados observados e verificação da estabilidade da Base 2 (Distância Mínima e Ajuste)

\begin{tabular}{|c|c|c|c|c|c|c|c|c|}
\hline \multicolumn{9}{|c|}{ BASE 2} \\
\hline \multicolumn{3}{|c|}{ DADOS OBSERVADOS } & \multicolumn{6}{|c|}{ ESTABILIDADE DA BASE "RECESSÃO" } \\
\hline PONTOS & Azimute & Zenital & $X(m)$ & $\sigma_{x}(m m)$ & $Y(m)$ & $\sigma_{Y}(\mathrm{~mm})$ & $\mathrm{Z}(\mathrm{m})$ & $\sigma_{Z}(\mathrm{~mm})$ \\
\hline GPRC00 & $342^{\circ} 49^{\prime} 02,9670^{\prime \prime}$ & $84^{\circ} 09^{\prime} 14,4809^{\prime \prime}$ & $1.013,1146$ & 2,0 & $5.000,7533$ & 0,6 & 99,9462 & 1,2 \\
\hline GPRC01 & $342^{\circ} 49^{\prime} 17,4631^{\prime \prime}$ & $84^{\circ} 09^{\prime} 24,9417^{\prime \prime}$ & $1.013,1144$ & 2,0 & $5.000,7532$ & 0,3 & 99,9461 & 1,3 \\
\hline GPRC02 & $342^{\circ} 49^{\prime} 24,0562^{\prime \prime}$ & $84^{\circ} 09^{\prime} 34,9946 "$ & $1.013,1145$ & 1,6 & $5.000,7534$ & 0,4 & 99,9459 & 0,7 \\
\hline GPRC03 & $342^{\circ} 49^{\prime} 29,5291^{\prime \prime}$ & $84^{\circ} 09^{\prime} 43,4492^{\prime \prime}$ & $1.013,1144$ & 1,7 & $5.000,7536$ & 0,4 & 99,9461 & 0,7 \\
\hline GPRC04 & $342^{\circ} 49^{\prime} 30,4846^{\prime \prime}$ & $84^{\circ} 09^{\prime} 53,5269 "$ & $1.013,1150$ & 1,6 & $5.000,7537$ & 0,5 & 99,9460 & 0,6 \\
\hline GPRC05 & $342^{\circ} 49^{\prime} 44,1066^{\prime \prime}$ & $84^{\circ} 09^{\prime} 59,0432^{\prime \prime}$ & $1.013,1142$ & 2,0 & $5.000,7533$ & 0,4 & 99,9461 & 0,6 \\
\hline GPRC06 & $342^{\circ} 50^{\prime} 31,9851^{\prime \prime}$ & $84^{\circ} 10^{\prime} 43,7141^{\prime \prime}$ & $1.013,1139$ & 2,0 & $5.000,7533$ & 0,4 & 99,9461 & 0,7 \\
\hline GPRC07 & $342^{\circ} 51^{\prime} 49,2595^{\prime \prime}$ & $84^{\circ} 12^{\prime} 09,3632^{\prime \prime}$ & $1.013,1147$ & 1,9 & $5.000,7534$ & 0,4 & 99,9461 & 0,7 \\
\hline
\end{tabular}


Tabela 20 - Coordenadas e precisões ajustadas dos alvos (Distância Mínima e Ajuste)

\begin{tabular}{cccccccc}
\hline \multicolumn{7}{c}{ COORDENADAS E PRECISÕES AJUSTADAS } \\
\hline PONTOS & $X(\mathrm{~m})$ & $\sigma_{X}(\mathrm{~mm})$ & $\mathrm{Y}(\mathrm{m})$ & $\sigma_{\mathrm{Y}}(\mathrm{mm})$ & $\mathrm{Z}(\mathrm{m})$ & $\sigma_{Z}(\mathrm{~mm})$ & $\sigma_{X Y Z}(\mathrm{~mm})$ \\
\hline GPRC00 & $1.006,3316$ & $1,2783 \mathrm{E}-8$ & $5.022,6893$ & $1,4772 \mathrm{E}-7$ & 102,2972 & $1,3228 \mathrm{E}-8$ & $1,4886 \mathrm{E}-7$ \\
GPRC01 & $1.006,3329$ & $1,2783 \mathrm{E}-8$ & $5.022,6898$ & $1,4772 \mathrm{E}-7$ & 102,2960 & $1,3227 \mathrm{E}-8$ & $1,4886 \mathrm{E}-7$ \\
GPRC02 & $1.006,3337$ & $1,2783 \mathrm{E}-8$ & $5.022,6902$ & $1,4773 \mathrm{E}-7$ & 102,2946 & $1,3226 \mathrm{E}-8$ & $1,4887 \mathrm{E}-7$ \\
GPRC03 & $1.006,3343$ & $1,2782 \mathrm{E}-8$ & $5.022,6902$ & $1,4774 \mathrm{E}-7$ & 102,2938 & $1,3224 \mathrm{E}-8$ & $1,4888 \mathrm{E}-7$ \\
GPRC04 & $1.006,3351$ & $1,2782 \mathrm{E}-8$ & $5.022,6902$ & $1,4772 \mathrm{E}-7$ & 102,2926 & $1,3223 \mathrm{E}-8$ & $1,4886 \mathrm{E}-7$ \\
GPRC05 & $1.006,3355$ & $1,2782 \mathrm{E}-8$ & $5.022,6909$ & $1,4774 \mathrm{E}-7$ & 102,2919 & $1,3222 \mathrm{E}-8$ & $1,4888 \mathrm{E}-7$ \\
GPRC06 & $1.006,3407$ & $1,2781 \mathrm{E}-8$ & $5.022,6911$ & $1,4776 \mathrm{E}-7$ & 102,2868 & $1,3216 \mathrm{E}-8$ & $1,4890 \mathrm{E}-7$ \\
GPRC07 & $1.006,3504$ & $1,2780 \mathrm{E}-8$ & $5.022,6917$ & $1,4776 \mathrm{E}-7$ & 102,2769 & $1,3203 \mathrm{E}-8$ & $1,4890 \mathrm{E}-7$ \\
\hline
\end{tabular}


Tabela 21 - Variação controlada, variação das coordenadas ajustadas e diferença entre ambas (Distância Mínima e Ajuste)

\begin{tabular}{cccccccc}
\hline & & \multicolumn{2}{c}{$\begin{array}{c}\text { DIFERENÇAS ENTRE } \\
\text { CONTROLE }\end{array}$} & \multicolumn{2}{c}{$\begin{array}{c}\text { RESÍDUO ENTRE CONTROLE E } \\
\text { COORDENADAS }\end{array}$} \\
\hline Pontual $(\mathrm{mm})$ & Intervalo $(\mathrm{mm})$ & $\Delta \mathrm{X}(\mathrm{mm})$ & $\Delta \mathrm{Y}(\mathrm{mm})$ & $\Delta \mathrm{Z}(\mathrm{mm})$ & $\mathrm{X}(\mathrm{mm})$ & $\mathrm{Y}(\mathrm{mm})$ & $\mathrm{Z}(\mathrm{mm})$ \\
\hline 1,0 & $0,0-1,0$ & 1,3 & 0,5 & $-1,3$ & $-0,3$ & 0,5 & $-0,3$ \\
1,0 & $1,0-2,0$ & 0,8 & 0,4 & $-1,4$ & 0,2 & 0,6 & $-0,4$ \\
1,0 & $2,0-3,0$ & 0,6 & 0,0 & $-0,9$ & 0,4 & 1,0 & 0,1 \\
1,0 & $3,0-4,0$ & 0,7 & 0,0 & $-1,2$ & 0,3 & 1,0 & $-0,2$ \\
1,0 & $4,0-5,0$ & 0,5 & 0,7 & $-0,7$ & 0,5 & 0,3 & 0,3 \\
5,0 & $5,0-10,0$ & 5,2 & 0,3 & $-5,1$ & $-0,2$ & 4,7 & $-0,1$ \\
10,0 & $10,0-20,0$ & 9,7 & 0,6 & $-9,9$ & 0,3 & 0,3 & 0,1 \\
\hline
\end{tabular}




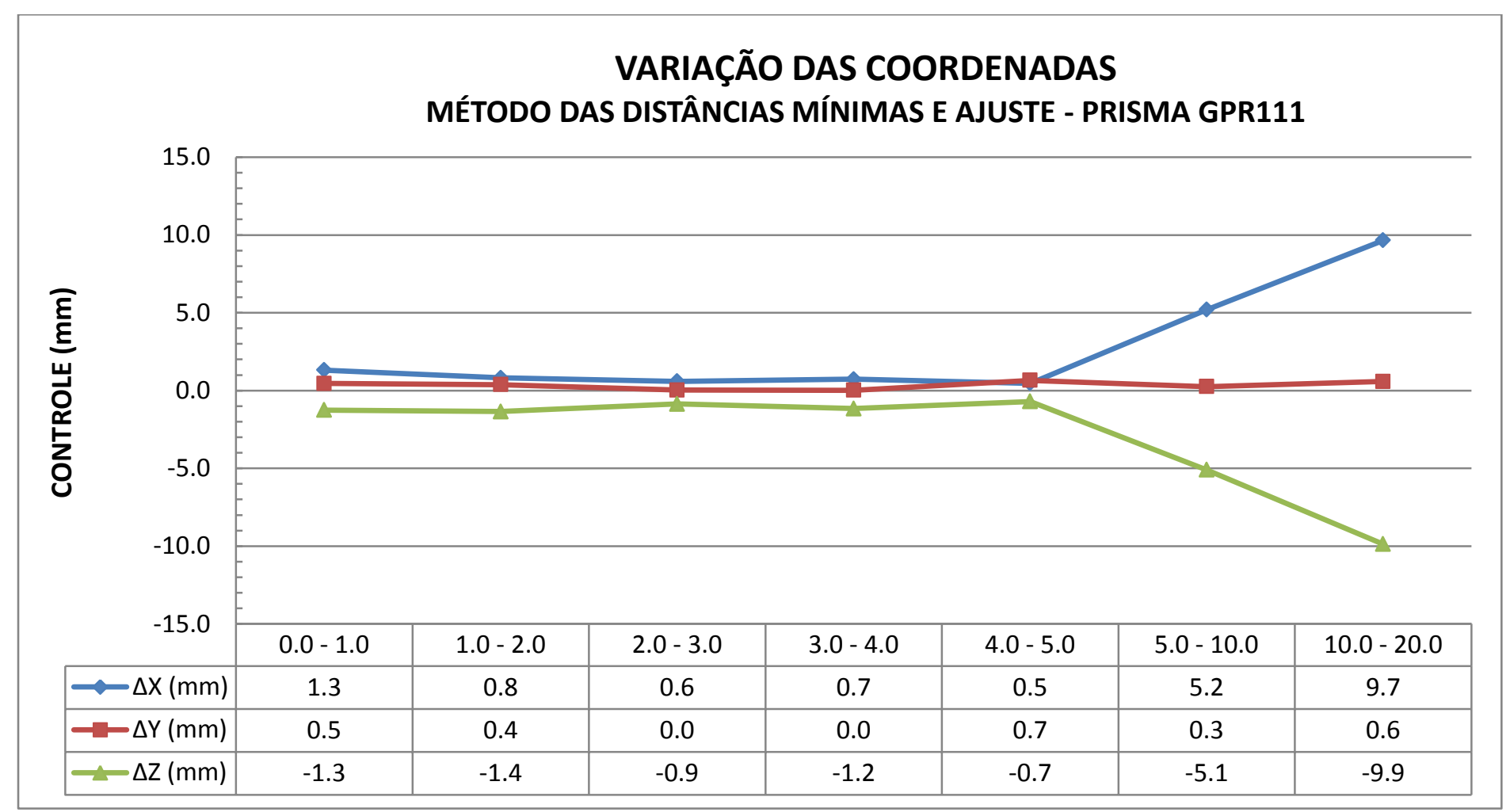

Figura 51 - Variação das coordenadas espaciais para o prisma GPR111 (Distância Mínima e Ajuste) 
Calcularam-se, desse modo, as variações realizadas, por meio da diferença entre as coordenadas espaciais determinadas pelo método proposto e, os valores encontrados foram comparados com o controle adotado para a variação do deslocamento.

Observa-se que as precisões calculadas pelo método de minimização e ajuste e a precisão do posicionamento espacial dos pontos, pelos critérios propostos, são da ordem de milímetros elevados à sétima potência negativa, conforme Tabela 20. Isso pôde assegurar, então, que os procedimentos realizados, dentro das restrições técnicas das estações totais robóticas utilizadas, apresentaram resultados compatíveis com suas precisões nominais.

Os valores para as precisões das coordenadas dos alvos, determinados por este método, permitem assegurar que este pode ser considerado altamente preciso e exato. Comparando os resultados obtidos com os valores de controle, calculados com o nível de significância em conformidade com a Tabela 21, a qual também expõe resíduos da ordem de décimos de milímetros, pode-se avaliar o alto nível de precisão atingido.

Tais resultados, portanto, permitem afirmar que este método, juntamente com a utilização das estações totais robóticas, apresenta um elevado nível de precisão para determinação de coordenadas espaciais e, também, garantem confiabilidade e segurança em trabalhos de mensuração e de engenharia em geral, principalmente, para o objetivo desta pesquisa, que é determinar coordenadas espaciais a partir do método das distâncias mínimas, com o intuito de detectar, verificar, analisar e controlar deformações e deslocamentos estruturais. 


\section{ANÁLISES COMPARATIVAS}

Expõem-se neste capítulo, todas as análises comparativas entre os métodos validados.

\subsection{Considerações iniciais}

Nos itens $4.4,4.5$ e 4.6 os cálculos das coordenadas espaciais foram executados com todas as casas decimais possíveis no ambiente MATLAB e os mesmos tiveram seus dados de saída em format long, composto por quatorze casas decimais, porém, ainda realizaram-se arredondamentos em planilha eletrônica do EXCEL para o nível de significância proposto, com quatro casas decimais depois da vírgula.

Com esse nível de significância, foram determinadas as coordenadas espaciais de todos os tipos de alvos com variação controlada em função da modelagem matemática de cada método validado. Assim, nas metodologias validadas, considerou-se a variação controlada como sendo um referencial, e os valores das variações, obtidos em função das determinações das coordenadas espaciais, como valores aproximados. Dessa maneira, foram feitas as mesmas considerações para todos os métodos validados.

Para a análise comparativa entre os resultados obtidos, foi realizado o confrontamento entre as coordenadas e precisões espaciais, respectivamente, determinadas a partir do método polar, método das distâncias mínimas e método das distâncias mínimas e ajuste. Foi feita também uma comparação entre a diferença do controle, que é um referencial, e a diferença das variações das coordenadas espaciais determinadas pelos métodos validados.

Ressalta-se ainda, a impossibilidade de realizar a comparação, descrita acima, entre os diferentes tipos de alvos, pois, ao efetuar a troca entre os alvos 
envolvidos, as posições ocupadas por eles jamais serão as mesmas, por estarem adaptados em apoios e peças distintas, e por terem variadas formas, dimensões e fixações, além de sofrerem adaptações para serem fixados no suporte com dispositivo ajustável. Porém, podemos analisá-los separadamente e constatar as determinações e precisões obtidas com cada tipo de alvo a partir de cada método utilizado.

\subsection{Análise comparativa entre os métodos}

As coordenadas e precisões espaciais determinadas a partir dos métodos validados podem ser analisadas na Tabela 22. Já, os resíduos gerados por meio das diferenças absolutas entre a variação do controle ou variação referencial e as variações entre as coordenadas espaciais determinadas em cada método, são apresentados na Tabela 23. 
Tabela 22 - Coordenadas e precisões espaciais obtidas pelos métodos de determinações validados

\section{COORDENADAS E PRECISÕES ESPACIAIS OBTIDAS PELOS MÉTODOS VALIDADOS}

\begin{tabular}{|c|c|c|c|c|c|c|c|c|}
\hline \multirow[b]{2}{*}{ Método } & \multicolumn{4}{|c|}{ GPRC00 } & \multicolumn{4}{|c|}{ GPRC01 } \\
\hline & $\mathrm{X}(\mathrm{m})$ & $Y(m)$ & $Z(m)$ & $\sigma_{X Y Z}(\mathrm{~mm})$ & $X(m)$ & $Y(m)$ & $Z(m)$ & $\sigma_{X Y Z}(m m)$ \\
\hline Polar & $1.006,3316$ & $5.022,6894$ & 102,2973 & 2,0473 & $1.006,3329$ & $5.022,6896$ & 102,2961 & 2,0473 \\
\hline Dist. Mín. & $1.006,3316$ & $5.022,6894$ & 102,2972 & 0,1052 & $1.006,3329$ & $5.022,6898$ & 102,2960 & 0,1695 \\
\hline \multirow[t]{2}{*}{ Mín. e Aj. } & $1.006,3316$ & $5.022,6893$ & 102,2972 & $1,4886 \mathrm{E}-7$ & $1.006,3329$ & $5.022,6898$ & 102,2960 & $1,4886 \mathrm{E}-7$ \\
\hline & \multicolumn{4}{|c|}{ GPRC02 } & \multicolumn{4}{|c|}{ GPRC03 } \\
\hline Método & $X(m)$ & $Y(m)$ & $Z(m)$ & $\sigma_{X Y Z}(m m)$ & $X(m)$ & $Y(m)$ & $Z(m)$ & $\sigma_{X Y Z}(m m)$ \\
\hline Polar & $1.006,3336$ & $5.022,6896$ & 102,2947 & 2,0473 & $1.006,3342$ & $5.022,6899$ & 102,2938 & 2,0473 \\
\hline Dist. Mín. & $1.006,3337$ & $5.022,6902$ & 102,2946 & 0,1487 & $1.006,3343$ & $5.022,6902$ & 102,2938 & 0,0776 \\
\hline Mín. e Aj. & $1.006,3337$ & $5.022,6902$ & 102,2946 & $1,4887 \mathrm{E}-7$ & $1.006,3343$ & $5.022,6902$ & 102,2938 & $1,4888 \mathrm{E}-7$ \\
\hline
\end{tabular}


COORDENADAS E PRECISÕES ESPACIAIS OBTIDAS PELOS MÉTODOS VALIDADOS (CONTINUAÇÃO)

\begin{tabular}{|c|c|c|c|c|c|c|c|c|}
\hline \multirow[b]{2}{*}{ Método } & \multicolumn{4}{|c|}{ GPRC04 } & \multicolumn{4}{|c|}{ GPRC05 } \\
\hline & $X(m)$ & $Y(m)$ & $\mathrm{Z}(\mathrm{m})$ & $\sigma_{X Y Z}(m m)$ & $X(m)$ & $Y(m)$ & $\mathrm{Z}(\mathrm{m})$ & $\sigma_{X Y Z}(m m)$ \\
\hline Polar & $1.006,3350$ & $5.022,6900$ & 102,2928 & 2,0473 & $1.006,3358$ & $5.022,6899$ & 102,2919 & 2,0473 \\
\hline Dist. Mín. & $1.006,3351$ & $5.022,6902$ & 102,2926 & 0,1631 & $1.006,3358$ & $5.022,6899$ & 102,2919 & 0,0197 \\
\hline \multirow[t]{2}{*}{ Mín. e Aj. } & $1.006,3351$ & $5.022,6902$ & 102,2926 & $1,4886 \mathrm{E}-7$ & $1.006,3355$ & $5.022,6909$ & 102,2919 & $1,4888 \mathrm{E}-7$ \\
\hline & \multicolumn{4}{|c|}{ GPRC06 } & \multicolumn{4}{|c|}{ GPRC07 } \\
\hline Método & $X(m)$ & $Y(m)$ & $\mathrm{Z}(\mathrm{m})$ & $\sigma_{X Y Z}(m m)$ & $X(m)$ & $\mathrm{Y}(\mathrm{m})$ & $\mathrm{Z}(\mathrm{m})$ & $\sigma_{X Y Z}(m m)$ \\
\hline Polar & $1.006,3406$ & $5.022,6908$ & 102,2868 & 2,0473 & $1.006,3502$ & $5.022,6912$ & 102,2768 & 2,0473 \\
\hline Dist. Mín. & $1.006,3407$ & $5.022,6911$ & 102,2868 & 0,0203 & $1.006,3504$ & $5.022,6917$ & 102,2769 & 0,0471 \\
\hline Mín. e Aj. & $1.006,3407$ & $5.022,6911$ & 102,2868 & $1,4890 \mathrm{E}-7$ & $1.006,3504$ & $5.022,6917$ & 102,2769 & $1,4890 \mathrm{E}-7$ \\
\hline
\end{tabular}


Tabela 23 - Diferença entre o controle e a variação das coordenadas ajustadas em cada método

\begin{tabular}{|c|c|c|c|c|c|c|c|c|c|c|}
\hline & & \multicolumn{9}{|c|}{ RESÍDUOS ENTRE CONTROLE E VARIAÇÃO DAS COORDENADAS - GPR111 } \\
\hline \multicolumn{2}{|c|}{ Controle } & \multicolumn{3}{|c|}{ Polar } & \multicolumn{3}{|c|}{ Distância Mínima } & \multicolumn{3}{|c|}{ Distância Mínima e Ajuste } \\
\hline Pontual (mm) & Intervalo $(\mathrm{mm})$ & $X(\mathrm{~mm})$ & $\mathrm{Y}(\mathrm{mm})$ & $\mathrm{Z}(\mathrm{mm})$ & $X(\mathrm{~mm})$ & $\mathrm{Y}(\mathrm{mm})$ & $\mathrm{Z}(\mathrm{mm})$ & $X(\mathrm{~mm})$ & $\mathrm{Y}(\mathrm{mm})$ & $\mathrm{Z}(\mathrm{mm})$ \\
\hline 1,0 & $0,0-1,0$ & $-0,3$ & $-0,2$ & 0,8 & $-0,3$ & 0,6 & $-0,2$ & $-0,3$ & 0,5 & $-0,3$ \\
\hline 1,0 & $1,0-2,0$ & 0,3 & 0,0 & 1,0 & 0,2 & 0,6 & $-0,4$ & 0,2 & 0,6 & $-0,4$ \\
\hline 1,0 & $2,0-3,0$ & 0,3 & $-0,2$ & 0,8 & 0,4 & 1,0 & 0,1 & 0,4 & 1,0 & 0,1 \\
\hline 1,0 & $3,0-4,0$ & 0,2 & $-0,1$ & 0,9 & 0,3 & 1,0 & $-0,2$ & 0,3 & 1,0 & $-0,2$ \\
\hline 1,0 & $4,0-5,0$ & 0,2 & 0,1 & 1,1 & 0,2 & 1,3 & 0,3 & 0,5 & 0,3 & 0,3 \\
\hline 5,0 & $5,0-10,0$ & 0,2 & $-0,9$ & $-0,2$ & 0,1 & 3,8 & $-0,1$ & $-0,2$ & 4,7 & $-0,1$ \\
\hline 10,0 & $10,0-20,0$ & 0,4 & $-0,4$ & 0,1 & 0,3 & 0,3 & 0,1 & 0,3 & 0,3 & 0,1 \\
\hline
\end{tabular}


A partir das análises comparativas realizadas, considerando as diferenças absolutas encontradas entre a variação das coordenadas ajustadas obtidas por meio dos três métodos validados nesta pesquisa e a variação controlada pelo suporte ajustável, foi possível detectar resíduos dentro do padrão de décimos de milímetros e, dessa maneira, pode-se afirmar que as diferenças são mínimas e conduzem a resultados da mesma ordem de grandeza. Tais resultados são apresentados na Tabela 22.

Quanto às precisões espaciais das coordenadas ajustadas, primeiramente, deve-se considerar que, para o método polar, as precisões espaciais foram calculadas a partir de um ajustamento das observações por meio do M.M.Q., como pode ser visto em sua rotina computacional constante no Apêndice C. Neste caso, o método polar obteve precisões milimétricas.

No método das distâncias mínimas, a precisão espacial foi calculada em função das médias das determinações. No entanto, deve-se considerar que esse método minimiza sua função objetivo, conforme foi apresentado. Dessa forma, as precisões obtidas neste método devem ter maior confiabilidade do que as apresentadas no método polar, pois suas precisões foram de décimos de milímetros.

Já, no método de determinação de coordenadas espaciais a partir das distâncias mínimas com ajustamento das observações, as precisões são calculadas pela minimização e ajustamento, simultaneamente, de todos os parâmetros envolvidos, por meio do M.M.Q. Nesse caso, refletem a precisão e a exatidão das coordenadas espaciais obtidas. Tal método ajusta os valores estimados para essas precisões, dessa forma, justifica-se que tais valores sejam menores do que aqueles obtidos pelos demais métodos, para as coordenadas espaciais dos mesmos pontos. Então, o método das distâncias mínimas e ajuste, além de minimizar, ajusta todas as estimativas. Portanto, os resíduos calculados com as diferenças absolutas entre as variações do controle com as variações dos valores calculados, verifica-se o alto nível de exatidão conquistado com todas as metodologias e procedimentos adotados nesta pesquisa, pois esses resíduos encontram-se na ordem de décimos de milímetros, o que comprova, mais uma vez, que os métodos validados apresentam características semelhantes quanto ao aspecto de determinação de coordenadas 
espaciais. Porém, apresentam características diferentes quanto às precisões obtidas, sendo que ao compará-las, concluímos que o método polar é o menos preciso, o método das distâncias mínimas é intermediário neste aspecto e o método das distâncias mínimas e ajuste é o que se apresenta com o maior nível de precisão. 


\section{CONCLUSÕES E RECOMENDAÇÕES}

Este capítulo apresenta as principais conclusões das etapas ao longo deste trabalho, com destaque para a importância dos métodos desenvolvidos e dos resultados encontrados após suas realizações. Também serão apresentadas as recomendações para trabalhos futuros nesta linha de pesquisa.

\subsection{Conclusões}

Diante dos resultados obtidos e das análises comparativas realizadas entre os métodos validados nesta pesquisa, pode chegar às seguintes conclusões:

A concepção das estações totais robóticas, as quais são classificadas como de alta precisão, primeiramente, possibilita o estabelecimento de sistemas de automação e controle dos procedimentos de medições e cálculos, por meio de suas funções de reconhecimento automático de alvos (ATR) e aplicativos internos que auxiliam e elevam o nível de automação. Como exemplo, o aplicativo recessão, o qual permite verificar a estabilidade das bases em tempo real, pois, ao ser executado, mostra no visor do instrumento as coordenadas espaciais obtidas, seguidas de suas precisões, permitindo ao operador analisar os resultados e tomar as devidas decisões em campo. Outro aplicativo exemplar é o de séries de ângulos com monitoramento, que realiza todas as observações dos alvos a serem medidos em série, inclusive a recessão, de acordo com o tempo e intervalo impostos para as observações requeridas. Portanto, estes instrumentos dispensam a ação do operador para a realização das observações, e este fato elimina erros grosseiros inerentes à operação humana.

Outro erro que foi eliminado está relacionado à determinação dos centros ópticos das estações totais robóticas, pois estes são as origens de todas as observações e cálculos efetuados ao longo desta pesquisa. $O$ erro foi eliminado quando adotou-se que a altura destes instrumentos era igual a zero. Ao deixar a 
altura dos instrumentos zerados, todos os sistemas de referência e de medições estão localizados nos próprios centros ópticos dos instrumentos.

A concepção das três bases de orientação (B3, B4 e B5) possibilitou que as bases (1 e 2), utilizadas para monitoração, efetuassem visadas comuns, evitando-se assim, visadas recíprocas entre os instrumentos, o que eliminou, então, a condição de obrigatoriedade de intervisibilidade entre eles, ampliando o campo de ação de todos os métodos. Este fato também impõe a necessidade de adaptar os outros métodos de determinação de coordenadas espaciais estudados no item 3.4, porém não validados, exceto o método que utiliza satélites artificiais para posicionamento espacial.

A instrumentação utilizada para fixação dos alvos não permitiram comparações entre os diferentes tipos de alvos utilizados, porém, os mesmos puderam ser analisados separadamente, e apresentaram resultados muito similares, quanto às precisões obtidas.

O método utilizado como base comparativa, o polar, apresenta características similares aos outros dois métodos, quanto aos resultados obtidos para as coordenadas espaciais medidas, porém, apresenta resultados distintos, considerando-se suas precisões. Mas, por apresentar uma metodologia simples, necessitar de apenas uma estação total e por apresentar precisões milimétricas, tal método mostra-se aceitável para a determinação de coordenadas espaciais, visando ao controle de obras de engenharia. Podem ser estes os motivos para sua vasta utilização nos procedimentos de mensuração.

O método denominado distância mínima apresenta valores menores para as precisões aparentes, porque as coordenadas dos alvos são calculadas a partir da otimização de uma função, no caso, minimizando-se um somatório de distâncias espaciais. As determinações dessas distâncias, tendo valores minimizados, proporcionam às precisões, também, valores mínimos. Portanto, pelo fato da minimização da função objetivo, apresenta valores mais precisos que o método polar, porém, é mais trabalhoso do que este, por demandar conhecimentos computacionais e de geometria analítica espacial. 
Já, o método denominado distância mínima e ajuste é o mais preciso de todos, porque além de minimizar a função objetivo, fornece todas as estimativas previstas pelo processo de ajustamento por meio do M.M.Q., entretanto, ele é mais trabalhoso, por demandar conhecimentos computacionais, de geometria analítica espacial e ajustamento de observações.

Os métodos de distância mínima e de distância mínima e ajuste são mais precisos, aliados à utilização de estações totais robóticas, que possibilita a realização de procedimentos automáticos, a exemplo da rede absoluta de referência, recessão e série de ângulos com monitoring, aumentam ainda mais este nível de acurácia e precisão.

Conclui-se, então, que os três métodos validados na presente pesquisa, juntamente com os procedimentos automáticos estabelecidos com o uso de estações totais robóticas, podem ser adotados para a determinação de coordenadas espaciais com a finalidade de monitorar e controlar grandes obras de engenharia. Isto porque, as precisões obtidas nas verificações práticas de campo e laboratoriais em todos os métodos, analisados individualmente, indicaram que esses resultados apresentam valores de ordem milimétrica.

\subsection{Recomendações}

No presente trabalho, foram validados os métodos polar, da distância mínima e da distância mínima e ajuste, entretanto, devido a inconsistências, não foi possível validar "a priori" os outros métodos estudados, apresentados no item 3.4. Porém, recomenda-se, para trabalhos futuros, a adaptação dos métodos não validados aos procedimentos empregados nesta pesquisa, para que possam ser determinados, analisados e comparados.

Dessa forma, quanto ao emprego de procedimentos e metodologias para a determinação de coordenadas espaciais, a partir dos métodos estudados, são feitas as seguintes recomendações: 
1. Elaborar, projetar e desenvolver novas peças de suporte para alvos com dispositivos de controle ajustável, com escalas mais refinadas, contendo graduações com décimos e centésimos de milímetros, como é o caso dos paquímetros. Além de elaborar um dispositivo com maior controle de variação, como, por exemplo, travas em suas graduações, o que eliminaria o erro inerente de o operador estimar a variação e o posicionamento do alvo na escala graduada.

2. Planejar, projetar e desenvolver peças e métodos para se que possa utilizar diferentes tipos de alvos refletores, para que seja possível compará-los quanto à determinação das coordenadas espaciais, e não somente quanto às precisões espaciais obtidas.

3. Inserir novos parâmetros dentro dos métodos das distâncias mínimas e distância mínima e ajuste, como, por exemplo, considerar as distâncias observadas pelas estações totais robóticas, lembrando que até o momento, estes métodos utilizam, em suas modelagens matemáticas, somente observações angulares.

4. Recomenda-se, ainda, buscar novos ambientes de programação computacional, objetivando o desenvolvimento de um software intuitivo, contendo todos os métodos estudados, para que este possa ser utilizado também por profissionais que não pertençam à área de mensuração. Tal software serviria, inclusive, para fundamentar novas pesquisas em todas as áreas de abrangência do conhecimento. 


\section{REFERÊNCIAS BIBLIOGRÁFICAS}

ABNT - Associação Brasileira de Normas Técnicas - NBR13133 - Execução de levantamento topográfico. 35 p., 1994.

ANDERSON, J.M.; MIKHAIL E.M. Surveying: Theory and practice. $7^{\text {th }}$ ed. Wcb McGrow-Hill, New York, 1998.

BOULOS, P.; CAMARGO, I. Geometria Analítica: Um tratamento vetorial. $3^{\mathrm{a}}$ ed.: Pearson education. São Paulo, 2005.

BUENO, R. F. Monitoração, por GPS, de deslocamentos em estrutura com carga dinâmica. Tese (Doutorado em Engenharia de Transportes) - Curso de PósGraduação em Engenharia de Transportes, Escola Politécnica da Universidade de São Paulo. 192 p., 2007.

CHAVES, J. C. Uso da tecnologia GPS na monitoração de deformação: Sistemas, etapas e experimento. Tese (Doutorado em Engenharia de Transportes) - Curso de Pós-Graduação em Engenharia de Transportes, EESC/USP, 2001.

CHAVES, J. C. Controle de deformações em barragens: Métodos de monitoramento e viabilidade de utilização do GPS. São Paulo. Dissertação (Mestrado em Engenharia de Transportes) - Curso de Pós-Graduação em Engenharia de Transportes, Escola Politécnica da Universidade de São Paulo. 197 p., 1994.

CHEN, Y.Q. Analysis of deformation surveys - A generalized method. Department of Surveying Engineering, University of New Brunswick. Technical Report no 94, 1983.

CHEN, Y.Q. and CHRZANOWSKI A. An overview of the physical interpretation of deformation measurements. Deformation Measurements Workshop, MIT, Boston, Mass., 31 October - 1 November, Proceedings (MIT), p. 207-220, 1986. 
CHEN, Y. Q., CHRZANOWSKI, A., ROMERO P., and SECORD J. M. Integration of geodetic and geotechnical deformation surveys in the geosciences. Tectonophysics. 130: 369-383, 1986.

CHEN, Y.Q., CHRZANOWSKI A. and SECORD J. M. A strategy for the analysis of the stability of reference points in deformation surveys. CISM Journal ACSGC, Vol. 44 No. 2, p. 141-149, 1990.

CHRZANOWSKI, A. A comparison of different approaches into the analysis of deformation measurements. Proc. of FIG XVI International Congress, Montreaux, Paper no 602.3, 1981.

CHRZANOWSKI, A. Existing resources, standards, and procedures for precise monitoring and analysis of structural deformation. Volume I. Virginia: U.S. Army Corps of Engineers - Topographic Engineering Center, 190 p. (technical Report TEC-0025), 1992.

DALMOLIN, Q. Ajustamento por mínimos quadrados. CPGCG - Curso de Pós Graduação em Ciências Geodésicas da UFPR. Curitiba: Editora UFPR, 2004.

DEPARTMENT OF THE ARMY. Manual 1110-1-1004 deformation monitoring and control surveying. U. S. Army Corps of Engineers Washington, DC, 1994.

DEPARTMENT OF THE ARMY. Structural deformation surveying. US Army Corps of Engineers, Washington, DC, 2002.

GAIRNS, C. Development of a semi-automated system for structural deformation monitoring using a reflectorless total station. M.Sc. thesis, Department of Geodesy and Geomatics Engineering Technical Report no 255, University of New Brunswick, Fredericton, New Brunswick, Canada, 117 p., 2008.

GEMAEL, C. Introdução ao ajustamento de observações: Aplicações geodésicas. $1^{1}$ ed. Curitiba: Editora UFPR, 1994.

GRANEMANN, D. Estabelecimento de uma Rede Geodésica para o Monitoramento de estruturas: estudo de caso na Usina Hidrelétrica Salto Caxias. Dissertação de Mestrado - Curso de Pós-Graduação em Ciências Geodésicas. Universidade Federal do Paraná - Curitiba, 2005. 
IBIAPINA, D. S. Método de cálculo das coordenadas espaciais de um ponto com superdeterminação de medidas. Dissertação de mestrado em transportes (EESC-USP). São Carlos - SP. 72 p., 1993.

KAHMEN, H.; FAIG, W. S. Surveying. Berlim; New York: Walter de Gruyter, 1994.

LAROCCA, A. P. C. O uso do GPS como instrumento de controle de deslocamentos dinâmicos de obras civis - Aplicação na área de transportes. Tese (Doutorado em Engenharia de Transportes - EESC/USP), 2004.

LEICA. Manual de operação da série TPS1200+. Versão 7.0 em Português. Leica Geosystems AG. Heerbrugg, Suiça, 2008.

LEICA. Original Accessories, material matters. Leica Geosystems AG. Heerbrugg, Suiça, 2010.

LEICA. Technical data. Leica Geosystems AG. Heerbrugg, Suiça, 2009.

LEICA. Technical reference manual. Version 5.5 in English. Leica Geosystems AG. Heerbrugg, Suiça, 2007.

MATSUMOTO, E. Y. MATLAB 7: Fundamentos. $2^{\mathrm{a}}$ edição. São Paulo, Editora Érica Ltda., 2008.

MORAES, C. C. Engenharia de automação industrial. $1^{a}$ edição. Rio de Janeiro RJ: LTC-Livros Técnicos e científicos, 2001.

MOREIRA, A. P. Métodos de cálculo de coordenadas tridimensionais para o controle de obras de engenharia. Tese (Doutorado em Engenharia de Transportes). Escola de Engenharia de São Carlos, Universidade de São Paulo, São Carlos, 206 p., 1998.

MOREIRA, A. S. B. Nivelamento trigonométrico e nivelamento geométrico classe IIN da NBR 13.133/94: Limites e condições de compatibilidade. Dissertação (Mestrado em Engenharia de Transportes) - Curso de Pós-Graduação em Engenharia de Transportes, Escola de Engenharia de São Carlos, Universidade de São Paulo, São Carlos, 103 p., 2003. 
MYERS, R. H., MONTGOMERY, D. C., VINING, G. G. Generalized linear models: with applications in engineering and the sciences. Wiley series in probability and statistics. New York: John Wiley \& Sons, 2002.

NATALE, F. Automação industrial. Editora Érica, São Paulo, 1995.

ROSÁRIO, J. M. Princípios de mecatrônica. Editora Pearson prentice hall, São Paulo, 2005.

SCHOFIELD, W. Engineering surveying: theory and examination problems for students. $5^{\text {th }}$ ed. London: Elsevier, 2001.

WOLF, P. R., GHILANI, C. D. Adjustment computations: statistics and least squares in surveying and GIS. New York: John Wiley \& Sons, 1997.

WOLF, P. R., GHILANI, C. D. Elementary surveying: an introduction to geomatics. $12^{\text {th }}$ ed. New Jersey: Pearson prentice hall, 2007.

WOLF, P. R., GHILANI, C. D. Adjustment: Spatial data analysis. $4^{\text {th }}$ ed. New York: John Wiley \& Sons, 2006.

VEIGA, L. A. K. Topografia Automatizada. Curso de especialização em geotecnologias - Universidade Federal do Paraná (UFPR). Curitiba, 61p., 2006. 


\title{
APÊNDICE A - Rotina computacional para determinação das coordenadas planimétricas da rede absoluta de referência
}

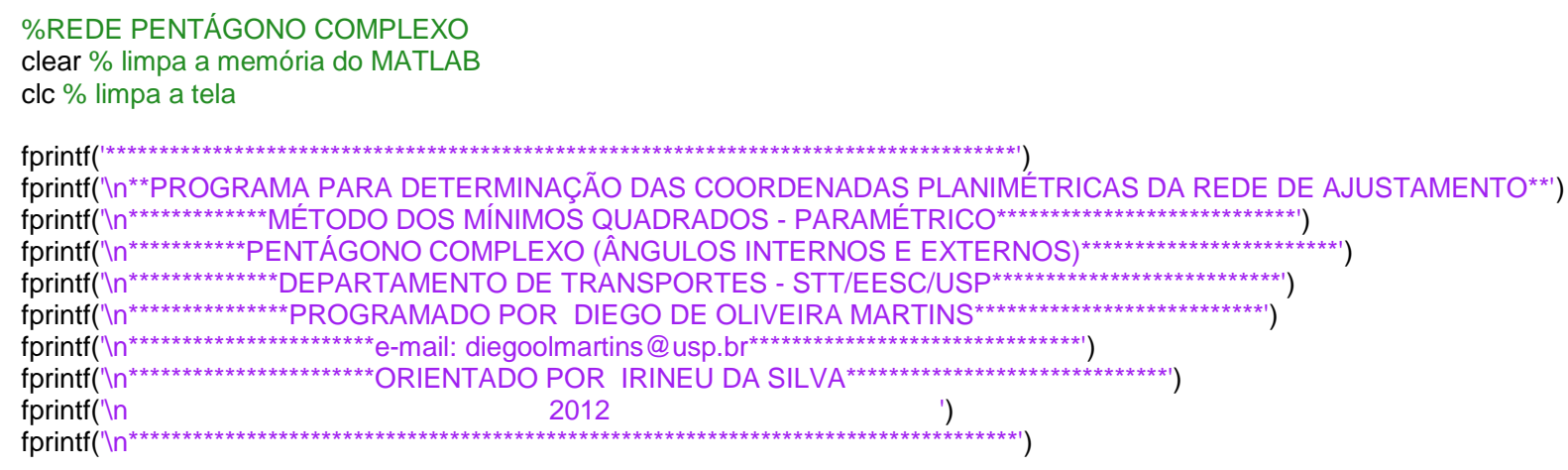

\author{
format long \\ \%DADOS DE ENTRADA (OBSERVAÇÃO) \\ \%COORDENADAS DA ESTAÇÃO DE REFERÊNCIA (CONTROLE) \\ fprintf('InEntre com as coordenadas planas da estação de referência:'); \\ $X A=$ input('InDigite a coordenada $X$ da estação de referência $(A)(m): ')$; \\ $Y A=$ input('InDigite a coordenada $Y$ da estação de referência $(A)(m): ')$;
}

\section{\%COORDENADAS APROXIMADAS DAS ESTAÇÕES}

fprintf('InEntre com as coordenadas planas aproximadas das estações:');

$X B=$ input('InDigite a coordenada aproximada $X$ da estação $(B)(m): ')$;

YB = input('InDigite a coordenada aproximada Y da estação (B)(m):');

$X C=$ input('InDigite a coordenada aproximada $X$ da estação $(C)(m): ')$;

$Y C=$ input('InDigite a coordenada aproximada $Y$ da estação $(\mathrm{C})(\mathrm{m}):$ :');

$X D=$ input('InDigite a coordenada aproximada $X$ da estação $(D)(m): ')$;

YD = input('InDigite a coordenada aproximada $Y$ da estação (D)(m):');

$X E=$ input('InDigite a coordenada aproximada $X$ da estação (E)(m):');

YE = input('InDigite a coordenada aproximada $Y$ da estação $(E)(m): ')$;

\section{\%OBSERVAÇÃO DE DISTÂNCIAS HORIZONTAIS (do)}

fprintf('InEntre com as distâncias observadas entre as estações:');

doAE = input('InDigite a distância horizontal observada entre a estação ocupada (A) e a estação visada (E) (m):'); doAC = input('InDigite a distância horizontal observada entre a estação ocupada (A) e a estação visada (C) (m):'); doAD = input('InDigite a distância horizontal observada entre a estação ocupada (A) e a estação visada (D) (m):'); doED = input('InDigite a distância horizontal observada entre a estação ocupada (E) e a estação visada (D) (m):'); doDC = input('InDigite a distância horizontal observada entre a estação ocupada (D) e a estação visada (C) (m):'); doCB = input('InDigite a distância horizontal observada entre a estação ocupada (C) e a estação visada (B) (m):''); doBA = input('InDigite a distância horizontal observada entre a estação ocupada (B) e a estação visada (A) (m):'); doEB = input('InDigite a distância horizontal observada entre a estação ocupada (E) e a estação visada (B) (m):'); doEC = input('InDigite a distância horizontal observada entre a estação ocupada (E) e a estação visada (C) (m):') doDB = input('InDigite a distância horizontal observada entre a estação ocupada (D) e a estação visada (B) (m):');

\%OBSERVAÇÃO DE AZIMUTES (ao Ré Et Vt)

fprintf('InEntre com os azimutes observados:');

\%Ângulo horizontal (EAD)

aoEAD = fprintf('InDigite o ângulo horizontal observado entre a estação ocupada (A), a estação ré (E) e a estação visada (D) em (GMS):');

aoEADG = input('ไnGrau:');

aoEADM = input('InMinuto:'); 


\section{4}

aoEADS = input('InSegundo:');

\%CONVERSÃO DE ÂNGULOS: GMS PARA GRAUS DECIMAIS

format long

aoEADdec $=\operatorname{aoEADG}+(\operatorname{aoEADM} / 60)+(\operatorname{aoEADS} / 3600) \quad$ \%Ângulo horizontal em grau decimal

\%CONVERSÃO DE ÂNGULOS EM GRAUS DECIMAIS PARA RADIANOS

format long

fprintf('InConversão de graus-radianos $\backslash n ')$;

fprintf('InDados de entrada: angulo em graus $\backslash n ')$;

radianos)

aoEADrad $=$ aoEADdec ${ }^{*}(\mathrm{pi} / 180)$

\%Ângulo horizontal em radiano (MATLAB trabalha em

\%Ângulo horizontal (DAC)

aoDAC = fprintf('InDigite o ângulo horizontal observado entre a estação ocupada (A), a estação ré (D) e a estação visada (C) em (GMS):');

aoDACG = input('InGrau:');

aoDACM = input('ไnMinuto:');

aoDACS = input('InSegundo:');

\%CONVERSÃO DE ÂNGULOS: GMS PARA GRAUS DECIMAIS

format long

aoDACdec $=$ aoDACG $+(\operatorname{aoDACM} / 60)+(\operatorname{aoDACS} / 3600) \quad$ \%Ângulo horizontal em grau decimal

\%CONVERSÃO DE ÂNGULOS EM GRAUS DECIMAIS PARA RADIANOS

format long

fprintf('ไnConversão de graus-radianos $\backslash n ')$;

fprintf('\nDados de entrada: angulo em graus $\backslash n ')$;

$\operatorname{aoDACrad}=\operatorname{aoDACdec}(\mathrm{pi} / 180)$

\%Ângulo horizontal (CAB)

aoCAB = fprintf('InDigite o ângulo horizontal observado entre a estação ocupada (A), a estação ré (C) e a estação visada (B) em (GMS):');

aoCABG = input('\nGrau:');

aoCABM = input('InMinuto:');

aoCABS = input('InSegundo:');

\%CONVERSÃO DE ÂNGULOS: GMS PARA GRAUS DECIMAIS

format long

aoCABdec $=\operatorname{aoCABG}+(\operatorname{aoCABM} / 60)+(\operatorname{aoCABS} / 3600) \quad$ \%Ângulo horizontal em grau decimal

\%CONVERSÃO DE ÂNGULOS EM GRAUS DECIMAIS PARA RADIANOS

format long

fprintf('ไnConversão de graus-radianos $\backslash n ')$;

fprintf('\nDados de entrada: angulo em graus $\backslash n ')$;

aoCABrad $=\operatorname{aoCABdec}(p i / 180)$

\%Ângulo horizontal (BAE)

aoBAE = fprintf('ไnDigite o ângulo horizontal observado entre a estação ocupada (A), a estação ré (B) e a estação visada (E) em (GMS):');

aoBAEG = input('InGrau:');

aoBAEM = input('InMinuto:');

aoBAES = input('InSegundo:');

\section{\%CONVERSÃO DE ÂNGULOS: GMS PARA GRAUS DECIMAIS \\ format long}

aoBAEdec $=\operatorname{aoBAEG}+(\operatorname{aoBAEM} / 60)+($ aoBAES/3600) $\quad$ \%Ângulo horizontal em grau decimal

\%CONVERSÃO DE ÂNGULOS EM GRAUS DECIMAIS PARA RADIANOS

format long

fprintf('ไnConversão de graus-radianos $\backslash n$ ');

fprintf('InDados de entrada: angulo em graus $\backslash n ')$;

aoBAErad $=$ aoBAEdec ${ }^{*}(\mathrm{pi} / 180)$

\%Ângulo horizontal em radiano

\%Ângulo horizontal (AED)

aoAED = fprintf('InDigite o ângulo horizontal observado entre a estação ocupada (E), a estação ré (A) e a estação visada (D) em (GMS):');

aoAEDG = input('\nGrau:');

aoAEDM = input('ไnMinuto:');

aoAEDS = input('InSegundo:');

\%CONVERSÃO DE ÂNGULOS: GMS PARA GRAUS DECIMAIS

format long

aoAEDdec $=$ aoAEDG $+($ aoAEDM/60) $+($ aoAEDS/3600)

\%Ângulo horizontal em grau decimal 


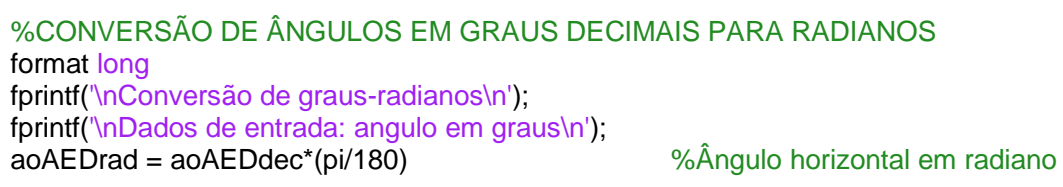

\%Ângulo horizontal (EDC)

aoEDC = fprintf('InDigite o ângulo horizontal observado entre a estação ocupada (D), a estação ré (E) e a estação visada (C) em (GMS):');

aoEDCG = input('InGrau:');

aoEDCM = input('InMinuto:');

aoEDCS = input('InSegundo:');

\section{\%CONVERSÃO DE ÂNGULOS: GMS PARA GRAUS DECIMAIS \\ format long \\ aoEDCdec $=$ aoEDCG $+($ aoEDCM/60) $+($ aoEDCS/3600)}

\%Ângulo horizontal em grau decimal

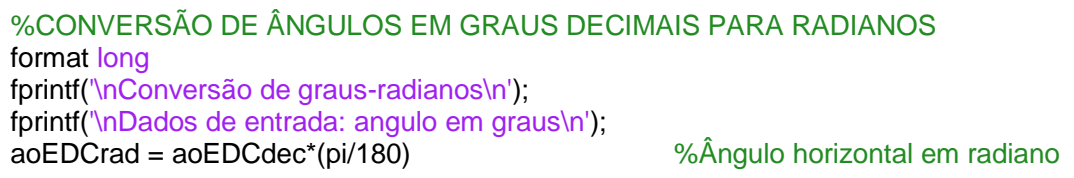

\%Ângulo horizontal (DCB)

aoDCB = fprintf('InDigite o ângulo horizontal observado entre a estação ocupada (C), a estação ré (D) e a estação visada (B) em (GMS):');

aoDCBG = input('InGrau:');

aoDCBM = input('InMinuto:');

aoDCBS = input('InSegundo:');

\%CONVERSÃO DE ÂNGULOS: GMS PARA GRAUS DECIMAIS

format long

aoDCBdec $=\operatorname{aoDCBG}+(\operatorname{aoDCBM} / 60)+(\operatorname{aoDCBS} / 3600) \quad$ \%Ângulo horizontal em grau decimal

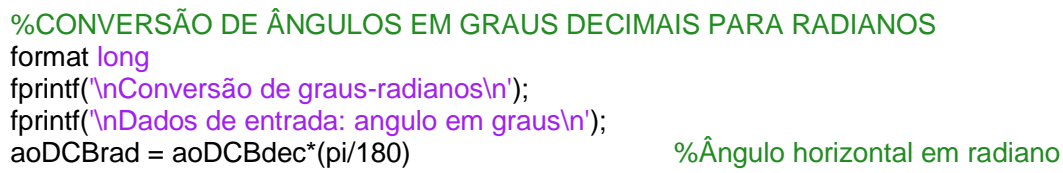

\%Ângulo horizontal (CBA)

aoCBA = fprintf('InDigite o ângulo horizontal observado entre a estação ocupada (B), a estação ré (C) e a estação visada (A) em (GMS):');

aoCBAG = input('\nGrau:');

aoCBAM = input('InMinuto:');

aoCBAS = input('\nSegundo:');

\%CONVERSÃO DE ÂNGULOS: GMS PARA GRAUS DECIMAIS

format long

aoCBAdec $=$ aoCBAG $+($ aoCBAM/60) $+($ aoCBAS/3600 $) \quad$ \%Ângulo horizontal em grau decimal

\section{\%CONVERSÃO DE ÂNGULOS EM GRAUS DECIMAIS PARA RADIANOS \\ format long}

fprintf('\nConversão de graus-radianos $\backslash n ')$;

fprintf('\nDados de entrada: angulo em graus $\backslash n ')$;

aoCBArad $=\operatorname{aoCBAdec}^{*}(\mathrm{pi} / 180) \quad$ \%Ângulo horizontal em radiano

\%Ângulo horizontal (DEC)

aoDEC = fprintf('InDigite o ângulo horizontal observado entre a estação ocupada (E), a estação ré (D) e a estação visada (C) em (GMS):');

aoDECG = input('ไnGrau:');

aoDECM = input('InMinuto:');

aoDECS = input('InSegundo:');

\%CONVERSÃO DE ÂNGULOS: GMS PARA GRAUS DECIMAIS

format long

aoDECdec $=$ aoDECG $+(\operatorname{aoDECM} / 60)+(\operatorname{aoDECS} / 3600)$

\%Ângulo horizontal em grau decimal

\%CONVERSÃO DE ÂNGULOS EM GRAUS DECIMAIS PARA RADIANOS

format long

fprintf('\nConversão de graus-radianos $\backslash n ')$;

fprintf(' 'nDados de entrada: angulo em graus $\backslash n ')$;

$\operatorname{aoDECrad}=\operatorname{aoDECdec}^{\star}(\mathrm{pi} / 180)$

\%Ângulo horizontal em radiano 
\%Ângulo horizontal (CEB)

aoCEB = fprintf('InDigite o ângulo horizontal observado entre a estação ocupada (E), a estação ré (C) e a estação visada (B) em (GMS):');

aoCEBG = input('InGrau:');

aoCEBM = input('InMinuto:');

aoCEBS = input('InSegundo:');

\%CONVERSÃO DE ÂNGULOS: GMS PARA GRAUS DECIMAIS

format long

aoCEBdec $=$ aoCEBG $+($ aoCEBM/60) $+($ aoCEBS/3600) $\quad$ \%Ângulo horizontal em grau decimal

\%CONVERSÃO DE ÂNGULOS EM GRAUS DECIMAIS PARA RADIANOS

format long

fprintf('\nConversão de graus-radianos $\backslash n$ ');

fprintf('\nDados de entrada: angulo em graus $\backslash n ')$;

aoCEBrad $=$ aoCEBdec ${ }^{*}(\mathrm{pi} / 180)$

\%Ângulo horizontal em radiano

\%Ângulo horizontal (BEA)

aoBEA = fprintf('InDigite o ângulo horizontal observado entre a estação ocupada (E), a estação ré (B) e a estação visada (A) em (GMS):');

aoBEAG = input('InGrau:');

aoBEAM = input('InMinuto:');

aoBEAS = input('InSegundo:');

\%CONVERSÃO DE ÂNGULOS: GMS PARA GRAUS DECIMAIS

format long

aoBEAdec $=\operatorname{aoBEAG}+(\operatorname{aoBEAM} / 60)+(\operatorname{aoBEAS} / 3600) \quad$ \%Ângulo horizontal em grau decimal

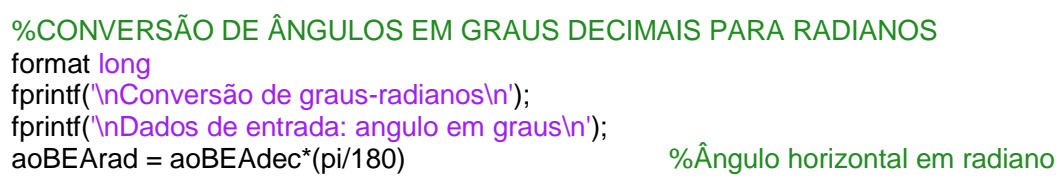

\%Ângulo horizontal (CDB)

aoCDB = fprintf('InDigite o ângulo horizontal observado entre a estação ocupada (D), a estação ré (C) e a estação visada (B) em (GMS):');

aoCDBG = input('InGrau:');

aoCDBM = input('InMinuto:');

aoCDBS = input('InSegundo:');

\%CONVERSÃO DE ÂNGULOS: GMS PARA GRAUS DECIMAIS
format long

aoCDBdec $=$ aoCDBG $+($ aoCDBM/60)+(aoCDBS/3600) \%Ângulo horizontal em grau decimal

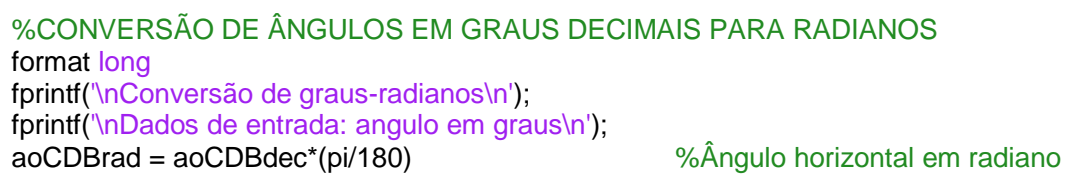

\%Ângulo horizontal (BDA)

aoBDA = fprintf('InDigite o ângulo horizontal observado entre a estação ocupada (D), a estação ré (B) e a estação visada (A) em (GMS):');

aoBDAG = input('ไnGrau:');

aoBDAM = input('InMinuto:');

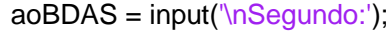

\%CONVERSÃO DE ÂNGULOS: GMS PARA GRAUS DECIMAIS
format long
aoBDAdec $=$ aoBDAG+(aoBDAM/60)+(aoBDAS/3600)
\%Ângulo horizontal em grau decimal

\%CONVERSÃO DE ÂNGULOS EM GRAUS DECIMAIS PARA RADIANOS

format long

fprintf('InConversão de graus-radianos $\backslash n ')$;

fprintf('InDados de entrada: angulo em graus $\backslash n ')$;

aoBDArad $=$ aoBDAdec $*(p i / 180)$

\%Ângulo horizontal em radiano

\%Ângulo horizontal (ADE)

aoADE = fprintf('InDigite o ângulo horizontal observado entre a estação ocupada (D), a estação ré (A) e a estação visada (E) em (GMS):');

aoADEG = input('ไnGrau:');

aoADEM = input('ไnMinuto:'); 
aoADES = input('InSegundo:');

\%CONVERSÃO DE ÂNGULOS: GMS PARA GRAUS DECIMAIS

format long

aoADEdec $=\operatorname{aoADEG}+(\operatorname{aoADEM} / 60)+(\operatorname{aoADES} / 3600) \quad$ \%Ângulo horizontal em grau decimal

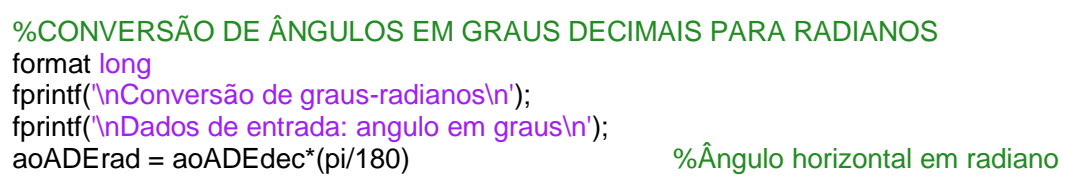

\%Ângulo horizontal em radiano

\%Ângulo horizontal (BCA)

aoBCA = fprintf('InDigite o ângulo horizontal observado entre a estação ocupada (C), a estação ré (B) e a estação visada (A) em (GMS):');

aoBCAG = input('InGrau:');

aoBCAM = input('InMinuto:');

aoBCAS = input('InSegundo:');

\section{\%CONVERSÃO DE ÂNGULOS: GMS PARA GRAUS DECIMAIS \\ format long}

aoBCAdec $=$ aoBCAG $+(\operatorname{aoBCAM} / 60)+($ aoBCAS/3600) $\quad$ \%Ângulo horizontal em grau decimal

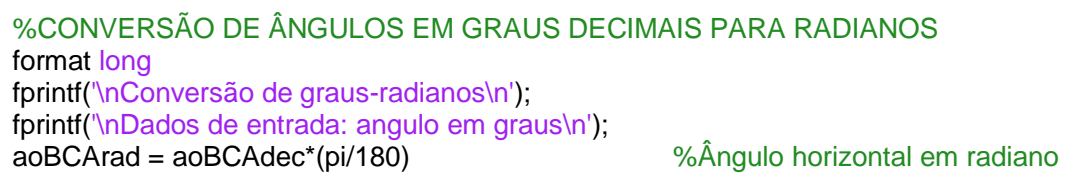

\%Ângulo horizontal (ACE)

aoACE = fprintf('InDigite o ângulo horizontal observado entre a estação ocupada (C), a estação ré (A) e a estação visada (E) em (GMS):');

aoACEG = input('\nGrau:');

aoACEM = input('InMinuto:');

aoACES = input('InSegundo:');

\%CONVERSÃO DE ÂNGULOS: GMS PARA GRAUS DECIMAIS

format long

aoACEdec $=$ aoACEG $+($ aoACEM/60)+(aoACES/3600) \%Ângulo horizontal em grau decimal

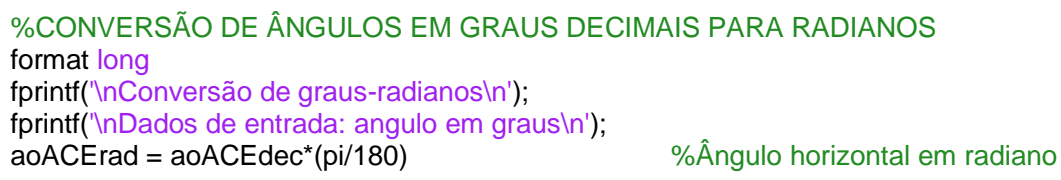

\%Ângulo horizontal (ECD)

aoECD = fprintf('InDigite o ângulo horizontal observado entre a estação ocupada (C), a estação ré (E) e a estação visada (D) em (GMS):');

aoECDG = input('\nGrau:');

aoECDM = input('InMinuto:');

aoECDS = input('InSegundo:');

\%CONVERSÃO DE ÂNGULOS: GMS PARA GRAUS DECIMAIS

format long

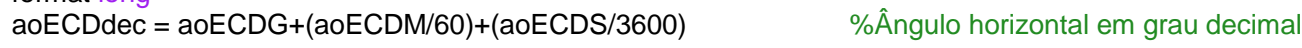

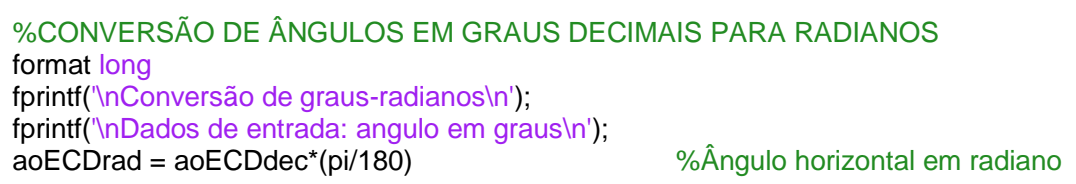

\%Ângulo horizontal (ABE)

aoABE = fprintf('InDigite o ângulo horizontal observado entre a estação ocupada (B), a estação ré (A) e a estação visada (E) em (GMS):');

aoABEG = input('InGrau:');

aoABEM = input('InMinuto:');

aoABES = input('InSegundo:');

\%CONVERSÃO DE ÂNGULOS: GMS PARA GRAUS DECIMAIS

format long

aoABEdec $=\operatorname{aoABEG}+(\mathrm{aoABEM} / 60)+(\mathrm{aoABES} / 3600) \quad$ \%Ângulo horizontal em grau decimal 
\%CONVERSÃO DE ÂNGULOS EM GRAUS DECIMAIS PARA RADIANOS

format long

fprintf('ไnConversão de graus-radianos $\backslash n ')$;

fprintf('\nDados de entrada: angulo em graus $\backslash n ')$;

aoABErad $=$ aoABEdec ${ }^{*}(\mathrm{pi} / 180)$

\%Ângulo horizontal em radiano

\%Ângulo horizontal (EBD)

aoEBD = fprintf('|nDigite o ângulo horizontal observado entre a estação ocupada (B), a estação ré (E) e a estação visada (D) em (GMS):');

aoEBDG = input('InGrau:');

aoEBDM = input('InMinuto:');

aoEBDS = input('ไnSegundo:');

\%CONVERSÃO DE ÂNGULOS: GMS PARA GRAUS DECIMAIS

format long

aoEBDdec $=$ aoEBDG $+($ aoEBDM/60) $+($ aoEBDS/3600 $)$

\%Ângulo horizontal em grau decimal

\%CONVERSÃO DE ÂNGULOS EM GRAUS DECIMAIS PARA RADIANOS

format long

fprintf('\nConversão de graus-radianos $\backslash n ')$;

fprintf('\nDados de entrada: angulo em graus $\backslash n ')$;

aoEBDrad $=\operatorname{aoEBDdec}^{*}(\mathrm{pi} / 180)$

\%Ângulo horizontal em radiano

\%Ângulo horizontal (DBC)

aoDBC = fprintf('InDigite o ângulo horizontal observado entre a estação ocupada (B), a estação ré (D) e a estação visada (C) em (GMS):');

aoDBCG = input('\nGrau:');

aoDBCM = input('InMinuto:');

aoDBCS = input('InSegundo:');

\%CONVERSÃO DE ÂNGULOS: GMS PARA GRAUS DECIMAIS

format long

aoDBCdec $=$ aoDBCG $+($ aoDBCM $/ 60)+(\operatorname{aoDBCS} / 3600)$

\%Ângulo horizontal em grau decimal

\%CONVERSÃO DE ÂNGULOS EM GRAUS DECIMAIS PARA RADIANOS

format long

fprintf('ไnConversão de graus-radianos $\backslash n ')$;

fprintf('\nDados de entrada: angulo em graus $\backslash n ')$;

aoDBCrad $=$ aoDBCdec $*(p i / 180)$

\%Ângulo horizontal em radiano

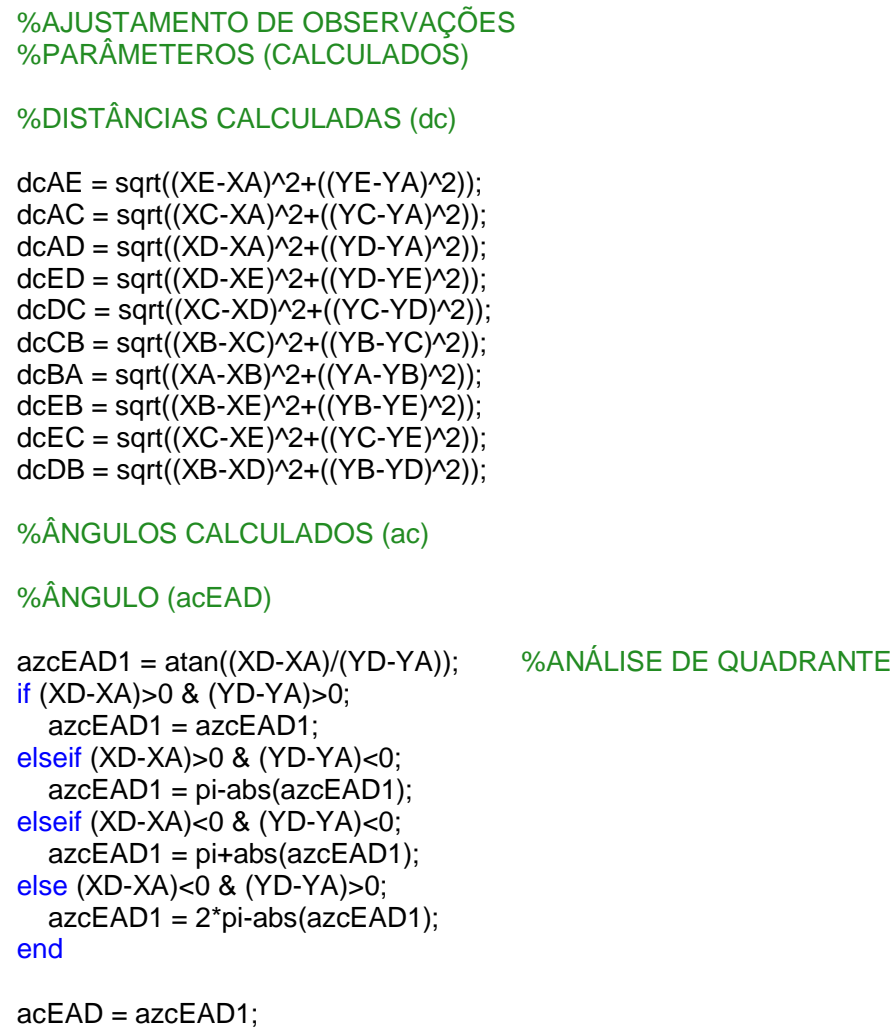


\%ÂNGULO (acDAC)

$\operatorname{azcDAC1}=\operatorname{atan}((X C-X A) /(Y C-Y A))$

if $(X C-X A)>0$ \& (YC-YA $)>0$;

azcDAC1 = azcDAC1;

elseif $(X C-X A)>0$ \& $(Y C-Y A)<0$;

azcDAC1 = pi-abs (azcDAC1);

elseif $(X C-X A)<0 \&(Y C-Y A)<0$;

azcDAC1 = pi+abs(azcDAC1);

else $(X C-X A)<0$ \& $(Y C-Y A)>0$;

$\operatorname{azcDAC1}=2^{*}$ pi-abs (azcDAC1);

end

$\operatorname{acDAC}=\operatorname{azcDAC1} ;$

\%ÂNGULO (acCAB)

$\operatorname{azcCAB1}=\operatorname{atan}((\mathrm{XB}-\mathrm{XA}) /(\mathrm{YB}-\mathrm{YA})) ;$

if $(X B-X A)>0 \&(Y B-Y A)>0$;

azcCAB1 = azcCAB1

elseif $(\mathrm{XB}-\mathrm{XA})>0$ \& $(\mathrm{YB}-\mathrm{YA})<0$;

azcCAB1 = pi-abs (azcCAB1)

elseif $(X B-X A)<0 \&(Y B-Y A)<0$;

azcCAB1 = pi+abs (azcCAB1);

else $(X B-X A)<0$ \& $(Y B-Y A)>0$;

$\operatorname{azcCAB} 1=2^{*} \mathrm{pi}-\mathrm{abs}(\operatorname{azcCAB} 1)$;

end

$\operatorname{acCAB}=\operatorname{azc} C A B 1 ;$

\%ÂNGULO (acBAE)

$\operatorname{azcBAE} 1=\operatorname{atan}((\mathrm{XE}-\mathrm{XA}) /(\mathrm{YE}-\mathrm{YA}))$;

if $(X E-X A)>0$ \& (YE-YA) $>0$;

azcBAE1 = azcBAE1

elseif $(X E-X A)>0$ \& $(Y E-Y A)<0$;

azcBAE1 = pi-abs (azcBAE1);

elseif $(X E-X A)<0$ \& $(Y E-Y A)<0$;

azcBAE1 = pi+abs (azcBAE1);

else $(X E-X A)<0$ \& $(Y E-Y A)>0$;

azcBAE1 $=2 *$ pi-abs(azcBAE1);

end

$\operatorname{acBAE}=\operatorname{azcBAE} 1 ;$

\%ÂNGULO (acAED)

azcAED1 $=\operatorname{atan}((X D-X E) /(Y D-Y E))$;

if $(X D-X E)>0$ \& (YD-YE) $>0$;

azcAED1 = azcAED1

elseif $(X D-X E)>0 \&(Y D-Y E)<0$;

azcAED1 = pi-abs (azcAED1)

elseif $(X D-X E)<0$ \& (YD-YE) $<0$;

azcAED1 = pi+abs(azcAED1);

else $(X D-X E)<0$ \& $(Y D-Y E)>0$;

azcAED1 $=2^{*}$ pi-abs(azcAED1);

end

acAED = azcAED1;

\%ÂNGULO (acEDC)

$\operatorname{azcEDC1}=\operatorname{atan}((X C-X D) /(Y C-Y D)) ;$

if $(X C-X D)>0$ \& (YC-YD) $>0$;

azcEDC1 $=$ azcEDC1

elseif $(X C-X D)>0$ \& $(Y C-Y D)<0$;

azcEDC1 = pi-abs (azcEDC1)

elseif $(X C-X D)<0$ \& $(Y C-Y D)<0$;

azcEDC1 = pi+abs(azcEDC1);

else $(X C-X D)<0$ \& $(Y C-Y D)>0$;

azcEDC1 $=2^{*}$ pi-abs(azcEDC1); end

acEDC $=$ azcEDC1;
\%ANÁLISE DE QUADRANTE

\%ANÁLISE DE QUADRANTE

\%ANÁLISE DE QUADRANTE \%(SEGUNDO MIKHAIL) 


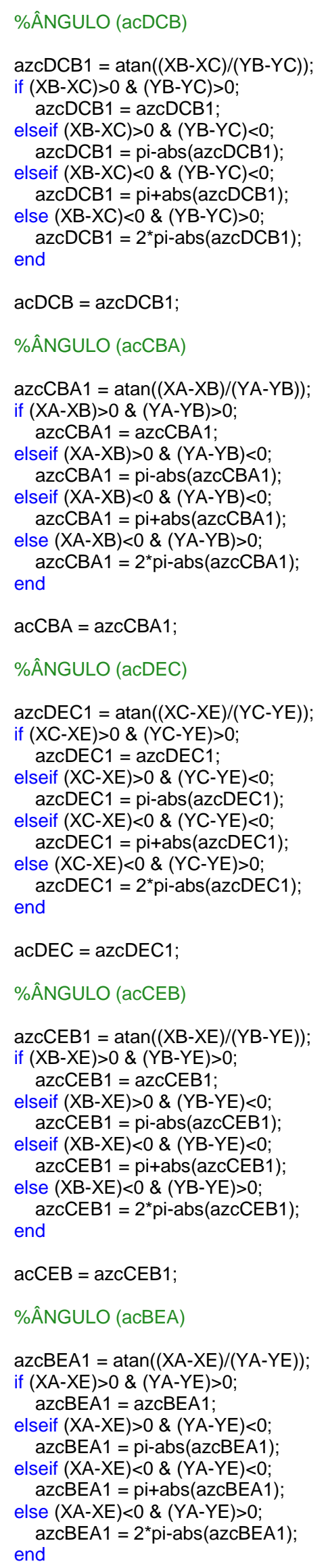


acBEA = azcBEA1;

\%ÂNGULO (acCDB)

$\operatorname{azcCDB} 1=\operatorname{atan}((\mathrm{XB}-\mathrm{XD}) /(\mathrm{YB}-\mathrm{YD}))$;

if $(X B-X D)>0 \&(Y B-Y D)>0$;

azcCDB1 = azcCDB1

elseif $(X B-X D)>0$ \& $(Y B-Y D)<0$;

azcCDB1 = pi-abs (azcCDB1);

elseif $(X B-X D)<0$ \& $(Y B-Y D)<0$;

azcCDB1 = pi+abs (azcCDB1);

else $(X B-X D)<0$ \& $(Y B-Y D)>0$

azcCDB1 $=2^{*}$ pi-abs (azcCDB1);

end

$\operatorname{acCDB}=\operatorname{azcCDB} 1 ;$

\%ÂNGULO (acBDA)

$\operatorname{azcBDA} 1=\operatorname{atan}((\mathrm{XA}-\mathrm{XD}) /(\mathrm{YA}-\mathrm{YD}))$

if $(X A-X D)>0$ \& (YA-YD) $>0$;

azcBDA1 = azcBDA1

elseif $(X A-X D)>0$ \& $(Y A-Y D)<0$;

azcBDA1 = pi-abs (azcBDA1);

elseif $(X A-X D)<0$ \& $(Y A-Y D)<0$;

azcBDA1 = pi+abs(azcBDA1);

else $(X A-X D)<0 \&(Y A-Y D)>0$

azcBDA1 $=2^{*}$ pi-abs (azcBDA1);

end

$\operatorname{acBDA}=\operatorname{azcBDA} 1$

\%ÂNGULO (acADE)

$\operatorname{azcADE} 1=\operatorname{atan}((X E-X D) /(Y E-Y D))$

if $(X E-X D)>0$ \& $(Y E-Y D)>0$;

azcADE1 = azcADE1

elseif $(X E-X D)>0$ \& $(Y E-Y D)<0$; azcADE1 = pi-abs (azcADE1); elseif $(X E-X D)<0$ \& $(Y E-Y D)<0$; azcADE1 = pi+abs(azcADE1); else $(X E-X D)<0 \&(Y E-Y D)>0$ azcADE1 = 2* pi-abs(azcADE1); end

$\operatorname{acADE}=\operatorname{azcADE} 1$

\%ÂNGULO (acBCA)

$\operatorname{azcBCA} 1=\operatorname{atan}((\mathrm{XA}-\mathrm{XC}) /(\mathrm{YA}-\mathrm{YC}))$

if $(X A-X C)>0$ \& $(Y A-Y C)>0$;

azcBCA1 = azcBCA1

elseif $(X A-X C)>0 \&(Y A-Y C)<0$; azcBCA1 = pi-abs $(\operatorname{azcBCA} 1)$; elseif $(X A-X C)<0$ \& $(Y A-Y C)<0$; azcBCA1 = pi+abs (azcBCA1); else $(X A-X C)<0$ \& $(Y A-Y C)>0$; azcBCA1 $=2^{*} \mathrm{pi}-\mathrm{abs}(\operatorname{azcBCA} 1)$; end

$\operatorname{acBCA}=\operatorname{azcBCA} 1$

\%ÂNGULO (acACE)

$\operatorname{azcACE} 1=\operatorname{atan}((\mathrm{XE}-\mathrm{XC}) /(\mathrm{YE}-\mathrm{YC}))$

if $(X E-X C)>0$ \& $(Y E-Y C)>0$;

azcACE1 = azcACE1;

elseif $(X E-X C)>0$ \& $(Y E-Y C)<0$; azcACE1 = pi-abs (azcACE1); elseif $(X E-X C)<0$ \& $(Y E-Y C)<0$; azcACE1 = pi+abs(azcACE1); else $(X E-X C)<0$ \& (YE-YC) $>0$; azcACE1 = 2* pi-abs(azcACE1); end 
$\operatorname{acACE}=\operatorname{azcACE} 1$

\%ÂNGULO (acECD)

azcECD1 = atan $((X D-X C) /(Y D-Y C))$;

if $(X D-X C)>0$ \& (YD-YC) $>0$;

azcECD1 = azcECD1

elseif $(X D-X C)>0$ \& $(Y D-Y C)<0$;

azcECD1 = pi-abs(azcECD1)

elseif $(X D-X C)<0$ \& (YD-YC) $<0$;

azcECD1 = pi+abs (azcECD1)

else $(X D-X C)<0$ \& $(Y D-Y C)>0$;

azcECD1 = 2* pi-abs(azcECD1);

end

acECD = azcECD1;

\%ÂNGULO (acCBA)

azcCBA1 = atan $((\mathrm{XA}-\mathrm{XB}) /(\mathrm{YA}-\mathrm{YB}))$;

if $(\mathrm{XA}-\mathrm{XB})>0$ \& $(\mathrm{YA}-\mathrm{YB})>0$

azcCBA1 = azcCBA1;

elseif $(X A-X B)>0$ \& $(Y A-Y B)<0$;

azcCBA1 = pi-abs (azcCBA1);

elseif $(X A-X B)<0$ \& $(Y A-Y B)<0$;

azcCBA1 $=$ pi+abs (azcCBA1)

else $(X A-X B)<0$ \& $(Y A-Y B)>0$;

azcCBA1 $=2^{*}$ pi-abs (azcCBA1);

end

$\operatorname{acCBA}=\operatorname{azcCBA} 1 ;$

\%ÂNGULO (acABE)

$\operatorname{azcABE} 1=\operatorname{atan}((\mathrm{XE}-\mathrm{XB}) /(\mathrm{YE}-\mathrm{YB}))$;

if $(X E-X B)>0$ \& $(Y E-Y B)>0$;

azcABE1 = azcABE1;

elseif $(X E-X B)>0$ \& $(Y E-Y B)<0$; azcABE1 = pi-abs (azcABE1);

elseif $(X E-X B)<0$ \& $(Y E-Y B)<0$;

azcABE1 $=$ pi+abs (azcABE1) else $(X E-X B)<0$ \& (YE-YB) $>0$;

azcABE1 $=2^{*}$ pi-abs (azcABE1);

end

$\operatorname{acABE}=\operatorname{azcABE} 1 ;$

\%ÂNGULO (acEBD)

azcEBD1 $=\operatorname{atan}((X D-X B) /(Y D-Y B))$

if $(\mathrm{XD}-\mathrm{XB})>0$ \& $(\mathrm{YD}-\mathrm{YB})>0$

azcEBD1 = azcEBD1

elseif $(X D-X B)>0$ \& (YD-YB $)<0$;

azcEBD1 = pi-abs(azcEBD1);

elseif $(X D-X B)<0$ \& (YD-YB $)<0$;

azcEBD1 $=p i+a b s(a z c E B D 1)$

else $(X D-X B)<0$ \& $(Y D-Y B)>0$;

azcEBD1 = 2* pi-abs(azcEBD1);

end

$\mathrm{acEBD}=\mathrm{azcEBD} 1$;

\%ÂNGULO (acDBC)

$\operatorname{azcDBC} 1=\operatorname{atan}((\mathrm{XC}-\mathrm{XB}) /(\mathrm{YC}-\mathrm{YB})) ;$

if $(X C-X B)>0 \&(Y C-Y B)>0$;

$\operatorname{azcDBC} 1=\operatorname{azcDBC1}$

elseif $(X C-X B)>0$ \& $(Y C-Y B)<0$;

azcDBC1 = pi-abs (azcDBC1)

elseif $(X C-X B)<0$ \& $(Y C-Y B)<0$;

azcDBC1 $=p i+a b s(a z c D B C 1)$

else $(\mathrm{XC}-\mathrm{XB})<0$ \& $(\mathrm{YC}-\mathrm{YB})>0$;

$\operatorname{azcDBC1}=2^{*} \operatorname{pi}-\operatorname{abs}(\operatorname{azcDBC} 1)$; 


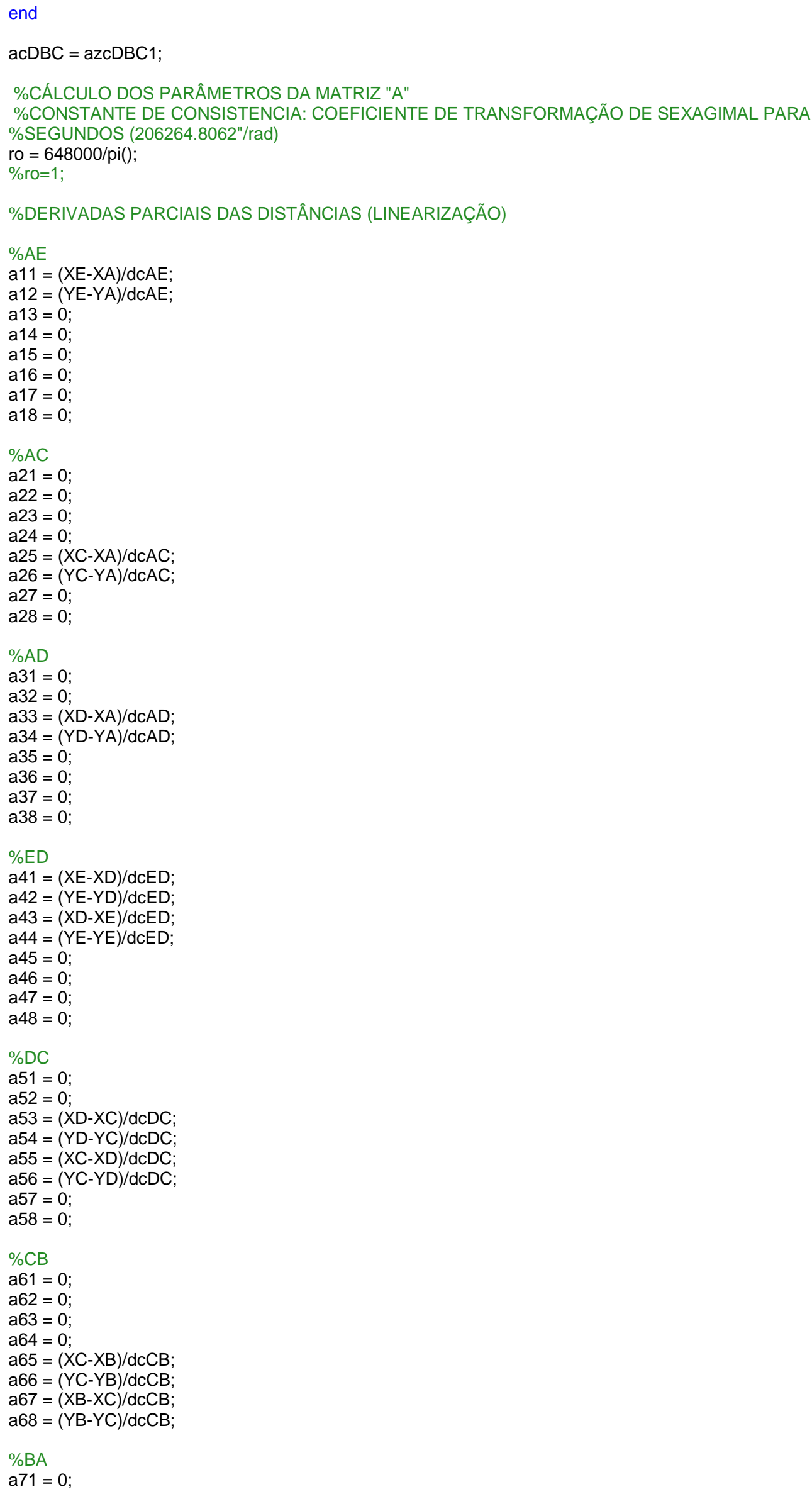


a72 $=0 ;$

a74 $=0$;

a75 $=0$;

a76 $=0$;

a77 $=(\mathrm{XB}-\mathrm{XA}) / \mathrm{dcBA}$;

$\mathrm{a} 78=(\mathrm{YB}-\mathrm{YA}) / \mathrm{dcBA} ;$

$\% E B$

a81 $=(\mathrm{XE}-\mathrm{XB}) / \mathrm{dcEB} ;$

$\mathrm{a} 82=(\mathrm{YE}-\mathrm{YB}) / \mathrm{dcEB} ;$

a83 $=0$;

$\mathrm{a} 84=0$;

a85 $=0 ;$

$\mathrm{a} 86=0$;

$\mathrm{a} 87=(\mathrm{XB}-\mathrm{XE}) / \mathrm{dcEB} ;$

$\mathrm{a} 88=(\mathrm{YB}-\mathrm{YE}) / \mathrm{dcEB} ;$

$\% \mathrm{EC}$

a91 $=(X E-X C) / d c E C ;$

$\mathrm{a} 92=(\mathrm{YE}-\mathrm{YC}) / \mathrm{dcEC} ;$

a93 $=0$

a94 = 0;

a95 $=(X C-X E) / d c E C ;$

a96 $=(Y C-Y E) / d c E C ;$

$\mathrm{a} 97=0$;

a98 $=0$;

$\% \mathrm{DB}$

a101 $=0$;

a102 $=0$;

a103 $=(X D-X B) / d c D B ;$

a104 $=(Y D-Y B) / d c D B ;$

a105 $=0$;

a106 $=0$;

a107 $=(X B-X D) / d c D B ;$

$\mathrm{a} 108=(\mathrm{YB}-\mathrm{YD}) / \mathrm{dcDB} ;$

\%DERIVADAS PARCIAIS DOS AZIMUTES (LINEARIZAÇÃO)

$\%$ EAD

a111 = 0;

a112 =

a113 $=\mathrm{ro}^{*}\left((\mathrm{YD}-\mathrm{YA}) /(\mathrm{dcAD})^{\wedge} 2\right)$

a114 $=\mathrm{ro}^{*}\left((\mathrm{XA}-\mathrm{XD}) /(\mathrm{dcAD})^{\wedge} 2\right)$;

a115 $=0$;

a116 $=0$;

a117 $=0$;

$\mathrm{a} 118=0$;

$\% \mathrm{DAC}$

a121 = 0;

a122 $=0$;

a123 = ;

a124 = 0;

a125 $=\mathrm{ro}^{*}\left((\mathrm{YC}-\mathrm{YA}) /(\mathrm{dcAC})^{\wedge} 2\right)$

a126 $=\mathrm{ro}^{*}\left((\mathrm{XA}-\mathrm{XC}) /(\mathrm{dcAC})^{\wedge} 2\right) ;$

a127 $=0$;

$\mathrm{a} 128=0$;

$\% \mathrm{CAB}$

a131 = 0;

a132 = 0 ;

a133 = ;

a134 =

a135 $=0$;

a136 $=0$;

a137 $=\mathrm{ro}^{*}\left((\mathrm{YB}-\mathrm{YA}) /(\mathrm{dcBA})^{\wedge} 2\right)$;

$\mathrm{a} 138=\mathrm{ro}^{*}\left((\mathrm{XA}-\mathrm{XB}) /(\mathrm{dcBA})^{\wedge} 2\right)$

$\% \mathrm{BAE}$

a141 $=\mathrm{ro}^{*}\left((\mathrm{YE}-\mathrm{YA}) /(\mathrm{dcAE})^{\wedge} 2\right)$

a142 $=\mathrm{ro}^{*}\left((\mathrm{XA}-\mathrm{XE}) /(\mathrm{dcAE})^{\wedge} 2\right) ;$

a143 $=0$; 
a144 = 0;

a145 =

a146 =0;

a147 = 0;

a148 = ;

$\% A E D$

a151 $=\mathrm{ro}^{*}\left((\mathrm{YE}-\mathrm{YD}) /(\mathrm{dcED})^{\wedge} 2\right) ;$

a152 $=\mathrm{ro}^{*}\left((\mathrm{XD}-\mathrm{XE}) /(\mathrm{dcED})^{\wedge} 2\right)$;

a153 $=\mathrm{ro}^{*}\left((\mathrm{YD}-\mathrm{YE}) /(\mathrm{dcED})^{\wedge} 2\right) ;$

a154 $=\mathrm{ro}^{*}\left((X E-X D) /(\mathrm{dcED})^{\wedge} 2\right)$;

a155 $=0$;

a156 $=0$;

a157 $=0$;

a158 $=0$;

$\%$ EDC

a161 = 0;

a162 $=0 ;$

a163 $=\mathrm{ro}^{*}\left((\mathrm{YD}-\mathrm{YC}) /(\mathrm{dcDC})^{\wedge} 2\right)$

a164 $=\mathrm{ro}^{*}\left((X C-X D) /(\mathrm{dcDC})^{\wedge} 2\right)$;

a165 $=\mathrm{ro}^{*}\left((\mathrm{YC}-\mathrm{YD}) /(\mathrm{dcDC})^{\wedge} 2\right) ;$

a166 $=\mathrm{ro}^{*}\left((\mathrm{XD}-\mathrm{XC}) /(\mathrm{dcDC})^{\wedge} 2\right) ;$

a167 $=0$;

a168 $=0$;

\%DCB

a $171=0$;

a172 $=0 ;$

a173 $=0$;

a174 = 0;

a175 $=\mathrm{ro}^{*}\left((\mathrm{YC}-\mathrm{YB}) /(\mathrm{dcCB})^{\wedge} 2\right)$

a176 $=\mathrm{ro}^{*}\left((\mathrm{XB}-\mathrm{XC}) /(\mathrm{dcCB})^{\wedge} 2\right) ;$

a177 $=\mathrm{ro}^{*}\left((\mathrm{YB}-\mathrm{YC}) /(\mathrm{dcCB})^{\wedge} 2\right)$;

a178 $=\mathrm{ro}^{*}\left((\mathrm{XC}-\mathrm{XB}) /(\mathrm{dcCB})^{\wedge} 2\right)$;

$\%$ CBA

a181 = 0 ;

a182 $=0$

a183 $=0$;

a184 $=0$

a185 = 0;

a186 $=0$

a187 $=\mathrm{ro}^{*}\left((\mathrm{YA}-\mathrm{YB}) /(\mathrm{dcBA})^{\wedge} 2\right)$; a188 $=\mathrm{ro}^{*}\left((\mathrm{XB}-\mathrm{XA}) /(\mathrm{dcBA})^{\wedge} 2\right)$;

\%DEC

a191 $=\mathrm{ro}^{*}\left((\mathrm{YE}-\mathrm{YC}) /(\mathrm{dcEC})^{\wedge} 2\right) ;$

a192 $=\mathrm{ro}^{*}\left((\mathrm{XC}-\mathrm{XE}) /(\mathrm{dcEC})^{\wedge} 2\right)$;

a193 $=0$;

a194 $=0$;

a195 $=\mathrm{ro}^{*}\left((\mathrm{YC}-\mathrm{YE}) /(\mathrm{dcEC})^{\wedge} 2\right)$

a196 $=\mathrm{ro}^{\star}\left((\mathrm{XE}-\mathrm{XC}) /(\mathrm{dcEC})^{\wedge} 2\right) ;$

a197 $=0$;

a198 = 0 ;

$\% \mathrm{CEB}$

a201 $=r^{*}\left((Y E-Y B) /(d c E B)^{\wedge} 2\right) ;$

a202 $=\mathrm{ro}^{*}\left((\mathrm{XB}-\mathrm{XE}) /(\mathrm{dcEB})^{\wedge} 2\right)$;

a203 = 0;

a204 =

a205 $=0 ;$

a206 $=0$

a207 $=\mathrm{ro}^{*}\left((\mathrm{YB}-\mathrm{YE}) /(\mathrm{dcEB})^{\wedge} 2\right)$;

a208 $=\mathrm{ro}^{\star}\left((\mathrm{XE}-\mathrm{XB}) /(\mathrm{dcEB})^{\wedge} 2\right)$;

$\% B E A$

a211 $=r^{*}\left((Y E-Y A) /(d c A E)^{\wedge} 2\right) ;$

a212 $=\mathrm{ro}^{*}\left((X A-X E) /(\mathrm{dcAE})^{\wedge} 2\right)$;

a213 = 0;

a214 =0;

a215 $=0$;

a216 = 0;

a217 = 0; 
a218 = 0;

$\% \mathrm{CDB}$

a221 = 0;

a222 = 0 ;

a223 $=\mathrm{ro}^{*}\left((\mathrm{YD}-\mathrm{YB}) /(\mathrm{dcDB})^{\wedge} 2\right)$;

a224 $=\mathrm{ro}^{*}\left((\mathrm{XB}-\mathrm{XD}) /(\mathrm{dcDB})^{\wedge} 2\right)$;

a225 $=0$;

a226 $=0$;

a227 $=\mathrm{ro}^{*}\left((\mathrm{YB}-\mathrm{YD}) /(\mathrm{dcDB})^{\wedge} 2\right)$;

$\mathrm{a} 228=\mathrm{ro}^{*}\left((\mathrm{XD}-\mathrm{XB}) /(\mathrm{dcDB})^{\wedge} 2\right)$;

$\% B D A$

$\mathrm{a} 231=0$;

a232 $=0$;

$\mathrm{a} 233=\mathrm{ro}^{*}\left((\mathrm{YD}-\mathrm{YA}) /(\mathrm{dcAD})^{\wedge} 2\right)$

$\mathrm{a} 234=\mathrm{ro}^{*}\left((\mathrm{XA}-\mathrm{XD}) /(\mathrm{dcAD})^{\wedge} 2\right)$;

a235 $=0$;

a236 = 0 ;

a237 $=0$;

a238 = 0 ;

$\% A D E$

a241 = ro*((YE-YD)/(dcED $\left.)^{\wedge} 2\right)$;

a242 $=\mathrm{ro}^{*}\left((X D-X E) /(\mathrm{dcED})^{\wedge} 2\right)$;

$\mathrm{a} 243=\mathrm{ro}^{*}\left((\mathrm{YD}-\mathrm{YE}) /(\mathrm{dcED})^{\wedge} 2\right)$;

a244 $=\mathrm{ro}^{*}\left((X E-X D) /(\mathrm{dcED})^{\wedge} 2\right)$;

a245 $=0$;

a246 = 0 ;

a247 = 0 ;

a248 $=0$;

$\% \mathrm{BCA}$

a251 = 0;

a252 = 0 ;

a253 $=0$;

a254 = 0;

$\mathrm{a} 255=\mathrm{ro} *\left((Y C-Y A) /(\mathrm{dcAC})^{\wedge} 2\right) ;$

$\mathrm{a} 256=\mathrm{ro}^{*}\left((\mathrm{XA}-\mathrm{XC}) /(\mathrm{dcAC})^{\wedge} 2\right)$;

a257 = 0;

a258 = 0;

$\%$ ACE

a261 $=r^{*}\left((Y E-Y C) /(d c E C)^{\wedge} 2\right)$; a262 $=r^{*}\left((X C-X E) /(d c E C)^{\wedge} 2\right)$;

a263 = 0;

a264 $=0$;

$\mathrm{a} 265=\mathrm{ro}^{*}\left((\mathrm{YC}-\mathrm{YE}) /(\mathrm{dcEC})^{\wedge} 2\right)$;

$\mathrm{a} 266=\mathrm{ro}^{*}\left((\mathrm{XE}-\mathrm{XC}) /(\mathrm{dcEC})^{\wedge} 2\right) ;$

a267 $=0$;

$\mathrm{a} 268=0$;

$\%$ ECD

a271 =0;

a272 = 0;

$\mathrm{a} 273=\mathrm{ro}^{*}\left((\mathrm{YC}-\mathrm{YD}) /(\mathrm{dcDC})^{\wedge} 2\right)$;

$\mathrm{a} 274=\mathrm{ro}^{*}\left((\mathrm{XD}-\mathrm{XC}) /(\mathrm{dcDC})^{\wedge} 2\right)$;

a275 $=\mathrm{ro}^{*}\left((\mathrm{YD}-\mathrm{YC}) /(\mathrm{dcDC})^{\wedge} 2\right) ;$

$\mathrm{a} 276=\mathrm{ro}^{*}\left((\mathrm{XC}-\mathrm{XD}) /(\mathrm{dcDC})^{\wedge} 2\right)$;

a277 = 0 ;

a278 = 0;

$\% \mathrm{ABE}$

a281 $=r^{*}\left((Y E-Y B) /(d c E B)^{\wedge} 2\right) ;$

a282 $=\mathrm{ro}^{\star}\left((\mathrm{XB}-\mathrm{XE}) /(\mathrm{dcEB})^{\wedge} 2\right) ;$

a283 $=0$;

a284 = 0 ;

a285 = 0 ;

a286 = ;

a287 $=\mathrm{ro}^{*}\left((\mathrm{YB}-\mathrm{YE}) /(\mathrm{dcEB})^{\wedge} 2\right)$;

$\mathrm{a} 288=\mathrm{ro}^{*}\left((\mathrm{XE}-\mathrm{XB}) /(\mathrm{dcEB})^{\wedge} 2\right)$;

$\%$ EBD

a291 = 0; 


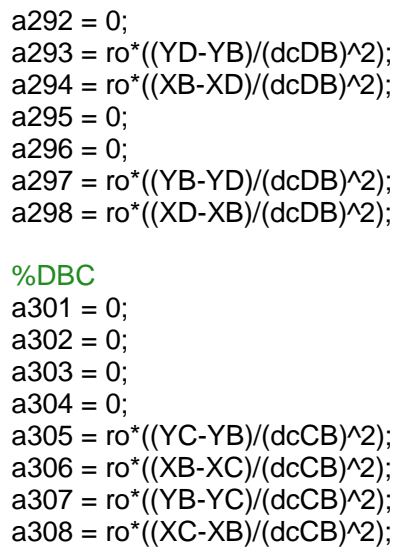

\%MATRIZ "A"

$\mathrm{A}=[\mathrm{a} 11$ a12 a13 a14 a15 a16 a17 a18;

a21 a22 a23 a24 a25 a26 a27 a28;

a31 a32 a33 a34 a35 a36 a37 a38;

a41 a42 a43 a44 a45 a46 a47 a48;

a51 a52 a53 a54 a55 a56 a57 a58;

a61 a62 a63 a64 a65 a66 a67 a68;

a71 a72 a73 a74 a75 a76 a77 a78

a81 a82 a83 a84 a85 a86 a87 a88

a91 a92 a93 a94 a95 a96 a97 a98;

a101 a102 a103 a104 a105 a106 a107 a108;

a111 a112 a113 a114 a115 a116 a117 a118;

a121 a122 a123 a124 a125 a126 a127 a128;

a131 a132 a133 a134 a135 a136 a137 a138;

a141 a142 a143 a144 a145 a146 a147 a148;

a151 a152 a153 a154 a155 a156 a157 a158;

a161 a162 a163 a164 a165 a166 a167 a168;

a171 a172 a173 a174 a175 a176 a177 a178;

a181 a182 a183 a184 a185 a186 a187 a188;

a191 a192 a193 a194 a195 a196 a197 a198;

a201 a202 a203 a204 a205 a206 a207 a208;

a211 a212 a213 a214 a215 a216 a217 a218;

a221 a222 a223 a224 a225 a226 a227 a228;

a231 a232 a233 a234 a235 a236 a237 a238;

a241 a242 a243 a244 a245 a246 a247 a248;

a251 a252 a253 a254 a255 a256 a257 a258;

a261 a262 a263 a264 a265 a266 a267 a268;

a271 a272 a273 a274 a275 a276 a277 a278;

a281 a282 a283 a284 a285 a286 a287 a288;

a291 a292 a293 a294 a295 a296 a297 a298;

a301 a302 a303 a304 a305 a306 a307 a308];

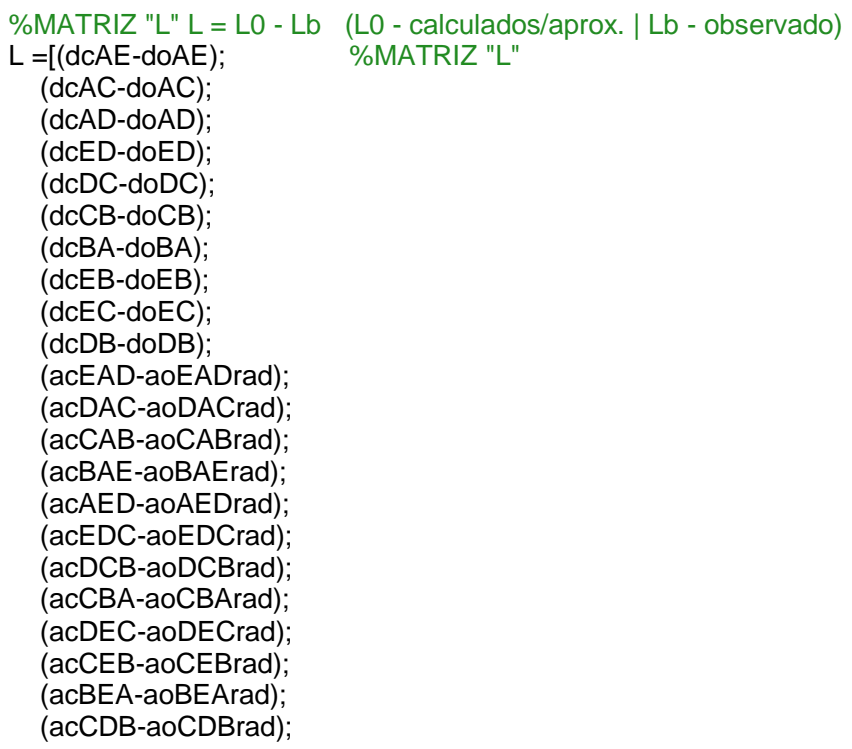




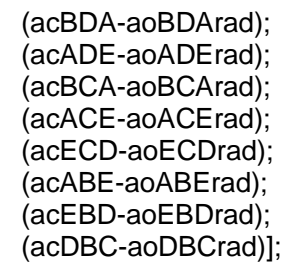

\%MATRIZ PESO "P" (ELb) (mm)

\%CÁLCULO DOS ERROS ESTIMADOS

$\mathrm{dpAE}=0.002+2^{*}(\mathrm{doAE} / 1000000) ; \quad \%$ PRECISÃO LINEAR DA ESTAÇÃO TOTAL $(2 \mathrm{~mm}+2 \mathrm{ppm})$ $\mathrm{dpAC}=0.002+2^{*}(\mathrm{doAC} / 1000000)$ $\mathrm{dpAD}=0.002+2^{*}(\mathrm{doAD} / 1000000)$; $\mathrm{dpED}=0.002+2^{*}(\mathrm{doED} / 1000000)$ $\mathrm{dpDC}=0.002+2^{*}(\mathrm{doDC} / 1000000)$; $\mathrm{dpCB}=0.002+2^{*}(\mathrm{doCB} / 1000000)$; $\mathrm{dpBA}=0.002+2^{*}(\mathrm{doBA} / 1000000)$ $\mathrm{dpEB}=0.002+2 *(\mathrm{doEB} / 1000000)$; $\mathrm{dpEC}=0.002+2^{*}(\mathrm{doEC} / 1000000)$ $\mathrm{dpDB}=0.002+2^{*}(\mathrm{doDB} / 1000000)$; $\mathrm{dpao}=\left(\left((0+0+(1 / 3600))^{*} \mathrm{pi}\right) / 180\right) ;$

\%PRECISÃO ANGULAR DA ESTAÇÃO TOTAL (1")

\%MATRIZ (ELb)

$E L b=\left[(d p A E)^{\wedge} 200000000000000000000000000000\right.$

0 (dpAC)^2 00000000000000000000000000000000 ; 00 (dpAD)^2000000000000000000000000000; 000 (dpED)^200000000000000000000000000; $0000(\mathrm{dpDC})^{\wedge} 20000000000000000000000000$; 00000 (dpCB)^2000000000000000000000000; 000000 (dpBA)^200000000000000000000000000; $0000000(\mathrm{dpEB})^{\wedge} 20000000000000000000000$; $00000000(\mathrm{dpEC})^{\wedge} 2000000000000000000000$; $000000000(\mathrm{dpDB})^{\wedge} 200000000000000000000$;

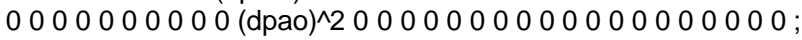
00000000000 (dpao)^2000000000000000000; ; $000000000000(\mathrm{dpao})^{\wedge} 200000000000000000$ 0000000000000 (dpao)^20000000000000000; ; 00000000000000 (dpao)^2000000000000000 000000000000000 (dpao)^200000000000000: 0000000000000000 (dpao)^20000000000000; ; $00000000000000000(\mathrm{dpao})^{\wedge} 2000000000000$; $000000000000000000(\mathrm{dpao})^{\wedge} 200000000000$; 0000000000000000000 (dpao)^20000000000; 00000000000000000000 (dpao)^20000000000 : 000000000000000000000 (dpao)^200000000; ; $0000000000000000000000(\mathrm{dpao})^{\wedge} 20000000$; 00000000000000000000000 (dpao)^2000000; ; $000000000000000000000000(\mathrm{dpao})^{\wedge} 200000$ 0000000000000000000000000 (dpao)^20000; 00000000000000000000000000 (dpao)^2000; ; 000000000000000000000000000 (dpao)^200; 0000000000000000000000000000 (dpao)^20;; 00000000000000000000000000000 (dpao)^2 ];

\%MATRIZ PESO "P"

$P=\operatorname{inv}(E L b) ;$

\%AJUSTAMENTO DE OBSERVAÇÕES

\%COORDENADAS APROXIMADAS

$\mathrm{CA}=[\mathrm{XE} ; \mathrm{YE} ; \mathrm{XD} ; \mathrm{YD} ; \mathrm{XC} ; \mathrm{YC} ; \mathrm{XB} ; \mathrm{YB}]$

\%COORDENADAS DO VETOR INCOGNITA "X"

$X=-\operatorname{inv}\left(A^{\prime *} P^{*} A\right)^{*}\left(A^{\prime *} P^{*} L\right)$;

\%CALCULO DE N E n

$N=\left(A^{\prime *} P^{*} A\right)$; 
$n=A^{* *} P * L$

$\% \mathrm{X}=-\operatorname{inv}(\mathrm{N}){ }^{*} \mathrm{n}$;

\%COORDENADAS FINAIS

format long

$\mathrm{CF}=\mathrm{CA}+\mathrm{X}$

\%VETOR DOS RESÍDUOS

$V=\left(A^{*} X\right)-L ;$

\%CALCULO DA PRECISÃO (sp = sigma ao quadrado)

tol $=\left(\mathrm{V}^{* *} \mathrm{P}^{*} \mathrm{~V}\right)$;

$\mathrm{sp}=\left(\left(\mathrm{V}^{\prime *} \mathrm{P}^{*} \mathrm{~V}\right) /(30-8)\right)$

\% MATRIZ DOS COFATORES

$Q x x=\operatorname{inv}\left(A^{\prime *} P^{\star} A\right)$;

$Q \|=A^{*} \operatorname{inv}\left(A^{\prime *} P^{\star} A\right)^{*} A^{\prime} ;$

\% MATRIZ VARIANCIA-COVARIANCIA DAS OBSERVAÇÕES (KII) e DAS COORDENADAS AJUSTADAS (Kxx):

$\mathrm{KII}=\mathrm{sp}^{\star} \mathrm{QII}$

$\mathrm{Kxx}=\mathrm{sp}^{\star} \mathrm{Qxx}$;

$E x=s p^{*} \operatorname{inv}\left(A^{\prime *} P^{*} A\right)$;

\%TESTE ESTATÍSTICO DO CHI-QUDRADO (X^2)

$\mathrm{n}=30 ; \%$ observacoes

$\mathrm{u}=8 ; \%$ incognitas

$\mathrm{sp}=\mathrm{sp} \%$ varianacia aposteriori $=\mathrm{sp}$

sa $=1 ; \%$ variancia apriori $=1$

$\mathrm{nc}=10 ; \%$ nivel de confiança

$\mathrm{si}=\operatorname{chi} 2 \operatorname{inv}\left(0.5^{*} \mathrm{nc} / 100,(\mathrm{n}-\mathrm{u})\right)$;

ss=chi2inv $\left(1-0.5^{*} n c / 100,(n-u)\right)$;

$\mathrm{st}=(\mathrm{n}-\mathrm{u})^{*} \mathrm{sp} / \mathrm{sa}$;

if $s t<s i \mid s t>s s$

teste_iguais='Hipotese Básica var_apriori = var_posteriori ....Rejeitado'

else

teste_iguais='Hipotese Básica var_apriori = var_posteriori ... Aceito' end 


\section{APÊNDICE B - Rotina computacional para determinação das coordenadas altimétricas da rede absoluta de referência}

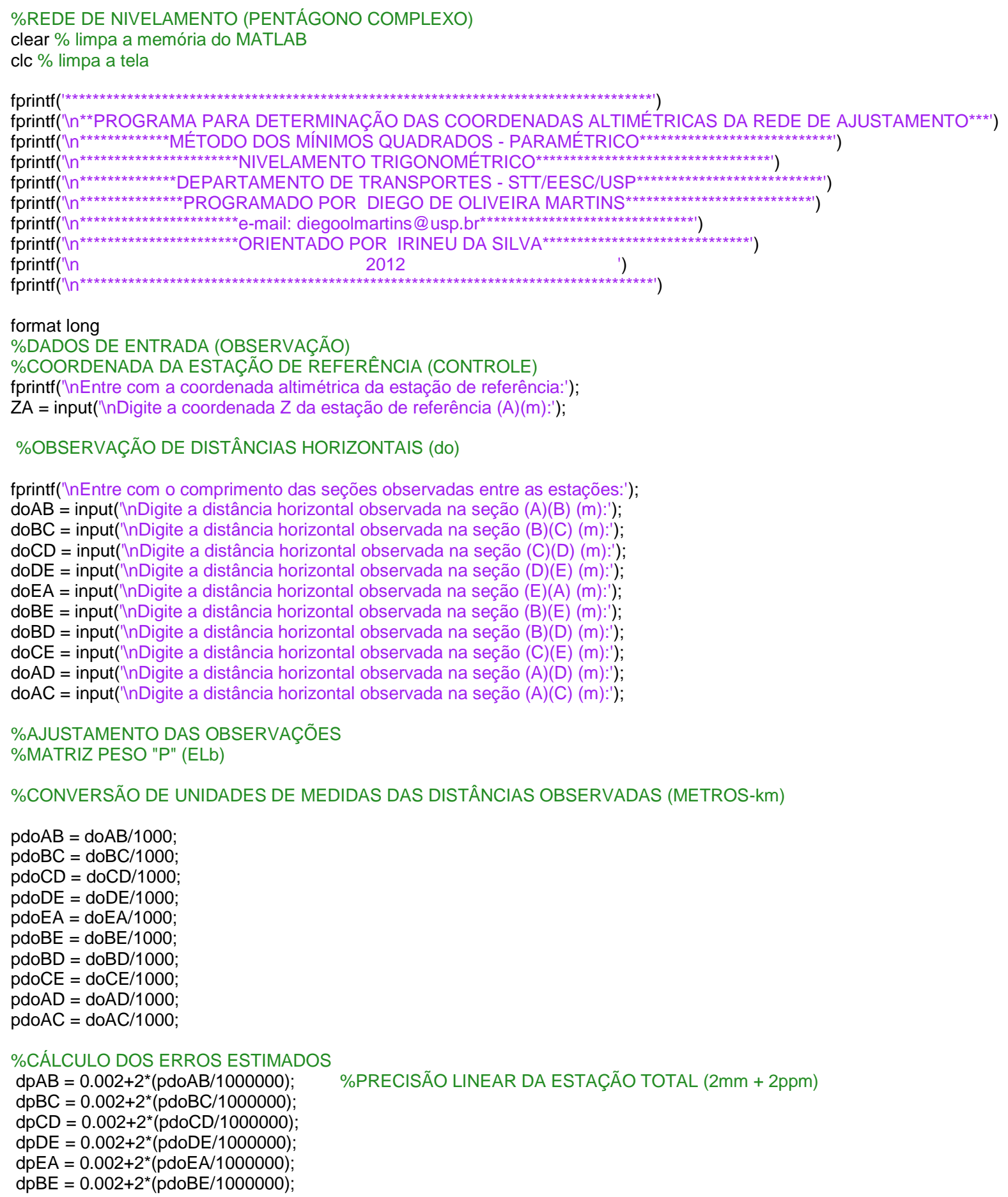




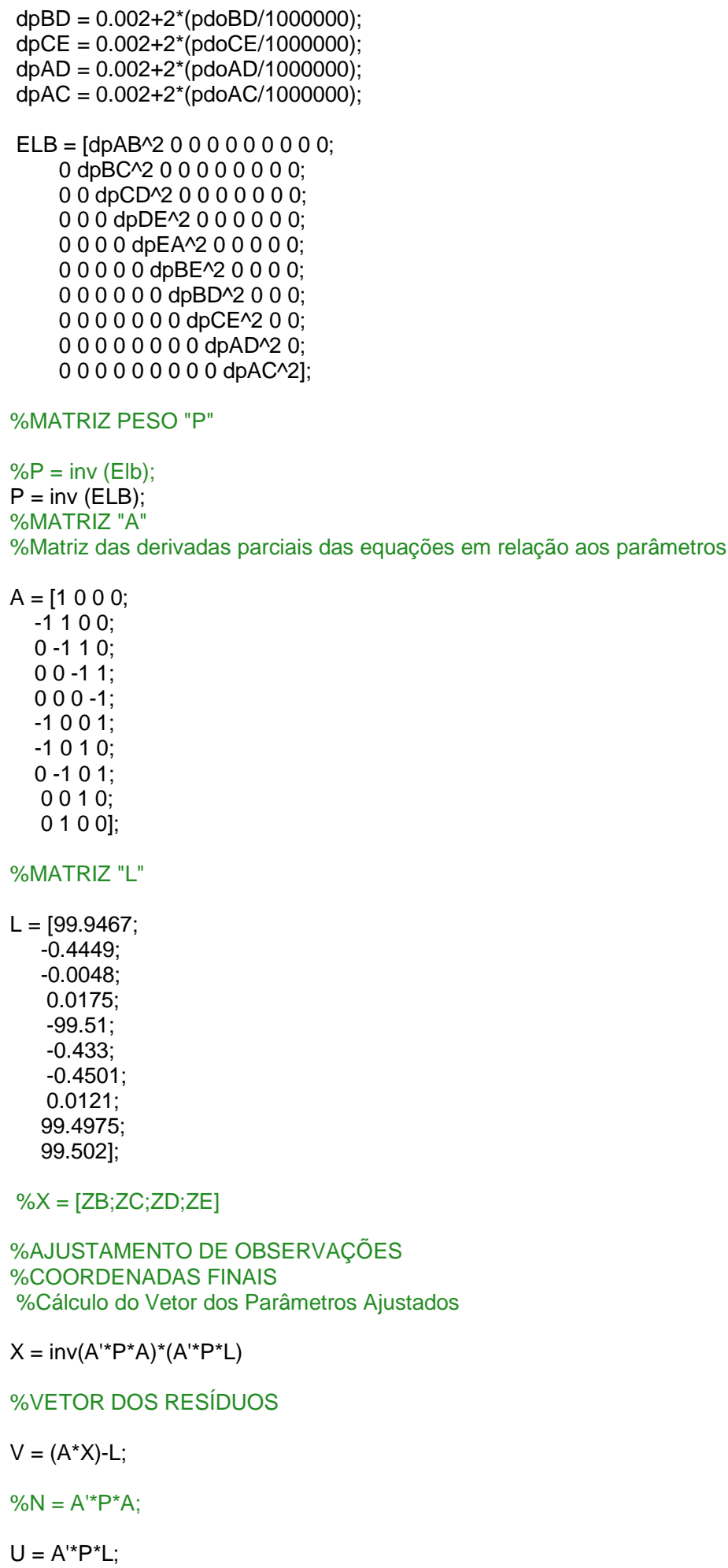




\section{2}

Ex $=\operatorname{sp}^{*} \operatorname{inv}\left(A^{\prime *} P^{*} A\right)$

\%Cálculo da MVC dos Valores Observados Ajustados:

Ela $=\operatorname{sp}^{*}\left(A^{*}\left(\operatorname{inv}\left(A^{\prime *} P^{*} A\right)\right)^{*} A^{\prime}\right)$;

$\% M V C$ DOS RESIDUOS

$E v v=s p^{*}\left(\left(A^{*}\left(\operatorname{inv}\left(A^{\prime *} P^{*} A\right)\right)^{*} A^{\prime}\right)-\operatorname{inv}(P)\right)$

\%AJUSTAMENTO DE OBSERVAÇṌES

\%CALCULO DE N E $n$

$N=A^{\prime *} P * A$

$\mathrm{n}=\mathrm{A}^{\prime *} \mathrm{P}{ }^{*} \mathrm{~L}$;

$\%$ MATRIZ DOS COFATORES

$Q x x=\operatorname{inv}\left(A^{\prime *} P^{*} A\right)$;

QII $=A^{*} \operatorname{inv}\left(A^{\prime *} P^{*} A\right)^{*} A^{\prime} ;$

\%MATRIZ VARIANCIA-COVARIANCIA DAS OBSERVAÇÕES (KII) e DAS COORDENADAS AJUSTADAS (Kxx):

$\mathrm{KII}=\mathrm{sp}^{*} \mathrm{Qll}$;

$\mathrm{Kxx}=\mathrm{sp}^{*} \mathrm{Qxx}$

$E x=s p^{*} \operatorname{inv}\left(A^{\prime *} P^{*} A\right)$;

\%TESTE ESTATÍSTICO DO CHI-QUDRADO (X^2)

$\mathrm{n}=10 ; \%$ observacoes

$\mathrm{u}=4 ; \%$ incognitas

$\mathrm{sp}=\mathrm{sp} \%$ varianacia aposteriori $=\mathrm{sp}$

$\mathrm{sa}=1 ; \%$ variancia apriori $=1$

$\mathrm{nc}=10 ; \%$ nivel de confiança

$\mathrm{si}=\operatorname{chi} 2 \operatorname{inv}\left(0.5^{*} \mathrm{nc} / 100,(\mathrm{n}-\mathrm{u})\right)$;

$\mathrm{ss}=\operatorname{chi} 2 \operatorname{inv}\left(1-0.5^{*} \mathrm{nc} / 100,(\mathrm{n}-\mathrm{u})\right)$;

$\mathrm{st}=(\mathrm{n}-\mathrm{u})^{*} \mathrm{sp} / \mathrm{sa}$;

if $s t<s i \mid s t>s s$

teste_iguais='Hipotese Básica var_apriori = var_posteriori ...Rejeitado'

else

teste_iguais='Hipotese Básica var_apriori = var_posteriori ... Aceito'

end 


\section{APÊNDICE C - Rotina computacional para determinações das coordenadas espaciais dos alvos por meio do método polar}

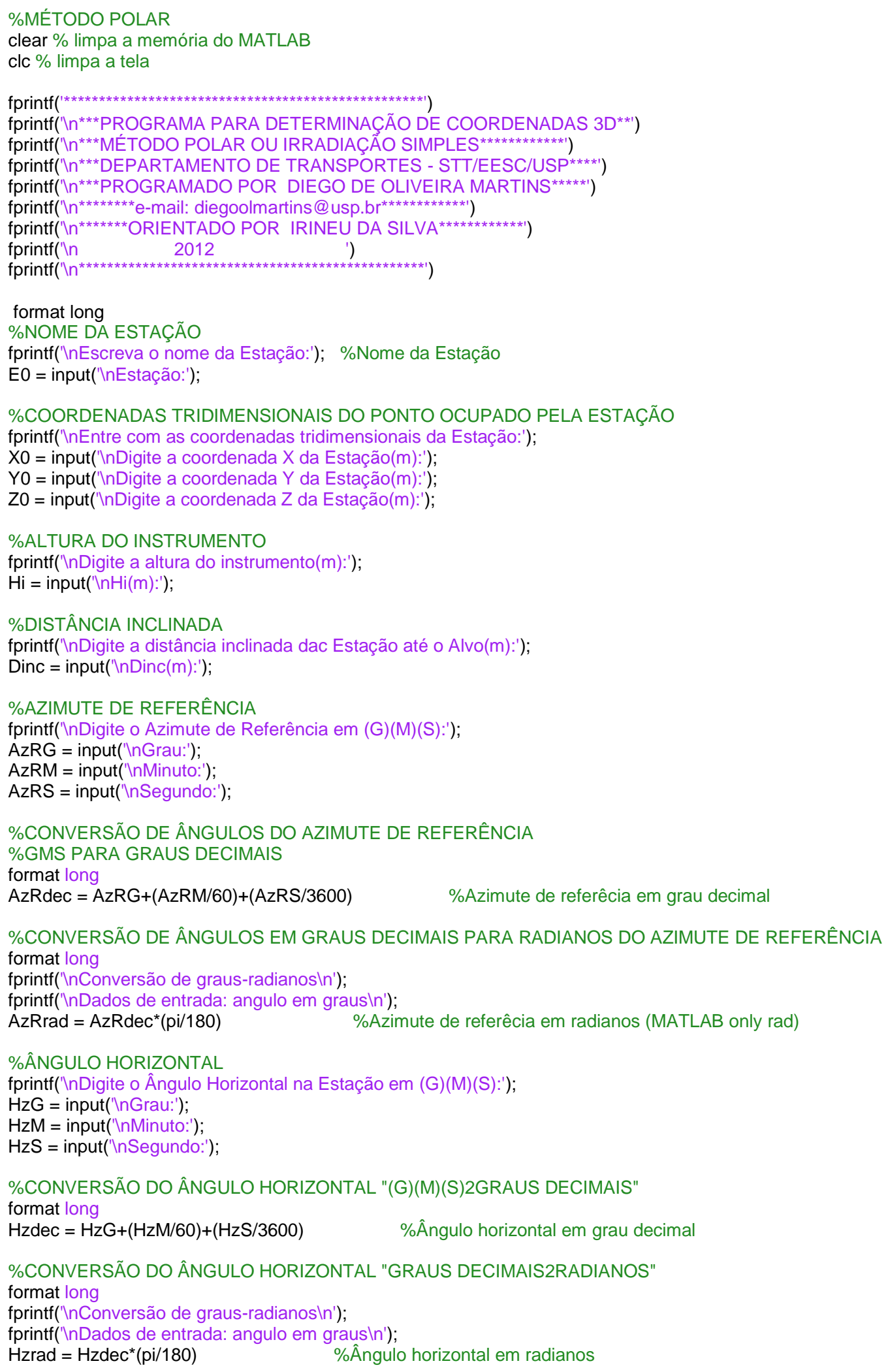


\%ÂNGULO ZENITAL

fprintf('ไnDigite o Ângulo Zenital da Estação em (G)(M)(S):');

ZenG = input('InGrau:');

ZenM = input('InMinuto:');

ZenS = input('InSegundo:');

\%CONVERSÃO DO ÂNGULO ZENITAL "(G)(M)(S)2GRAUS DECIMAIS"

format long

Zendec $=$ ZenG $+($ ZenM/60)+(ZenS/3600) \%Ângulo zenital em grau decimal

\%CONVERSÃO DO ÂNGULO ZENITAL "GRAUS DECIMAIS2RADIANOS"

format long

fprintf('ไnConversão do ângulo zenital "graus deciamis2radianos"'n');

fprintf('ไnDados de entrada: angulo em graus $\backslash n$ ');

Zenrad $=$ Zendec ${ }^{*}(\mathrm{pi} / 180) \quad \%$ Ângulo zenital em radianos

\%CÁLCULO DO AZIMUTE

format long

fprintf('InAzimute Estação - Alvo'):

AzAlvo $=$ AzRrad + Hzrad

\%REM ARREDONDAMENTO DO QUADRANTE(0-2pi $<=>0-360))$

AzAlvo $=\operatorname{rem}\left(\right.$ AzAlvo,$\left.\left(2^{*} \mathrm{pi}\right)\right)$

\%CÁLCULO DAS COORDENADAS 3D

format long

$\mathrm{XP}=\mathrm{X0}+$ (Dinc) $^{*} \sin \left(\right.$ Zenrad) ${ }^{*} \sin ($ AzAlvo)

$\mathrm{YP}=\mathrm{Y} 0+(\text { Dinc) })^{*} \sin \left(\right.$ Zenrad) ${ }^{*} \cos$ (AzAlvo)

$\mathrm{ZP}=\mathrm{Z0}+\mathrm{Hi}+$ Dinc ${ }^{*} \cos ($ Zenrad)

\%rever metodo para obter z

if Zenrad > (pi/2)

$\mathrm{ZP}=\mathrm{Z0}+$ Dinc $^{*} \cos ($ Zenrad $)$

else

$\mathrm{ZP}=\mathrm{ZO}+\mathrm{Hi}+$ Dinc ${ }^{*} \cos ($ Zenrad)

end

Zenrad $=\operatorname{rem}($ Zenrad,$(p i / 2))$

\%AJUSTAMENTO DAS OBSERVAÇÕES (propagação de erros e precisão)

\%CONSTANTE DE CONSISTENCIA: COEFICIENTE DE TRANSFORMAÇÃO DE SEXAGIMAL PARA \%SEGUNDOS (206264.8062"/rad)

ro $=648000 / p i()$;

\%MATRIZ JACOBIANA

$G=\left[\cos (\right.$ AzAlvo $)-\operatorname{Dinc}^{*}(\sin ($ AzAlvo $))$ $\sin ($ AzAlvo) Dinc*(cos(AzAlvo))];

\%MATRIZ

\%CÁLCULO DOS ERROS ESTIMADOS

dpDinc $=0.002+2^{*}($ Dinc/1000000); \%PRECISÃO LINEAR DA ESTACÃO TOTAL $(2 \mathrm{~mm}+2 \mathrm{ppm})$ $\mathrm{dpao}=\left(\left((0+0+(1 / 3600))^{*} \mathrm{pi}\right) / 180\right) ; \quad$ \%PRECISÃO ANGULAR DA ESTAÇÃO TOTAL (1")

$E x=\left[(d p D i n c)^{\wedge} 20\right.$

$\left.0(\mathrm{dpao} / \mathrm{ro})^{\wedge} 2\right]$

\%MATRIZ VARIANCIA-COVARIANCIA (MVC)

$M V C=G^{*} E x^{*} G^{\prime}$

\%PROPAGAÇÃO DE ERRO "DESVIO-PADRÃO" (SIGMA)(X,Y,Z)

format long

$\operatorname{sigmaX}=\operatorname{sqrt}(\operatorname{MVC}(1,1))$

sigmaY $=\operatorname{sqrt}(\mathrm{MVC}(2,2))$

$\left.\operatorname{sigmaZ}=\operatorname{sqrt}\left(\left(\left(\cos (\text { Zenrad })^{*} \mathrm{dpDinc}\right)^{\wedge} 2\right)+\left(- \text { Dinc }^{*} \sin (\text { Zenrad })\right)^{*} \mathrm{dpao} / \mathrm{ro}\right)^{\wedge} 2\right)$

\%PRECISÃO ESPACIAL DO PONTO

Spxyz $=\operatorname{sqrt}\left((\operatorname{sigmaX})^{\wedge} 2+(\operatorname{sigmaY})^{\wedge} 2+(\operatorname{sigmaZ})^{\wedge} 2\right) ;$ 
APÊNDICE D - Validação do método polar para os alvos estudados 
Tabela 24 - Dados observados e verificação da estabilidade da Base 1 (Método Polar - GPR112)

\section{MÉTODO POLAR - GPR112 (-7.10 mm)}

BASE 1

\begin{tabular}{|c|c|c|c|c|c|c|c|c|c|}
\hline \multirow[b]{2}{*}{ PONTOS } & \multicolumn{3}{|c|}{ DADOS OBSERVADOS } & \multicolumn{6}{|c|}{ ESTABILIDADE DA BASE "RECESSÃO" } \\
\hline & Azimute & Zenital & $\mathrm{Di}(\mathrm{m})$ & $X(m)$ & $\sigma_{X}(m m)$ & $\mathrm{Y}(\mathrm{m})$ & $\sigma_{Y}(\mathrm{~mm})$ & $Z(m)$ & $\sigma_{\mathrm{z}}(\mathrm{mm})$ \\
\hline GPRM00 & $15^{\circ} 35^{\prime} 09,2290 "$ & $84^{\circ} 10^{\prime} 39,7496^{\prime \prime}$ & 23,6765 & $1.000,0045$ & 1,5 & $4.999,9976$ & 0,5 & 99,9999 & 1,5 \\
\hline GPRM01 & $15^{\circ} 35^{\prime} 19,8276^{\prime \prime}$ & $84^{\circ} 10^{\prime} 51,3675^{\prime \prime}$ & 23,6771 & $1.000,0045$ & 1,4 & $4.999,9975$ & 0,5 & 99,9999 & 1,5 \\
\hline GPRM02 & $15^{\circ} 35^{\prime} 27,8297 "$ & $84^{\circ} 10^{\prime} 56,8414^{\prime \prime}$ & 23,6773 & $1.000,0046$ & 1,4 & $4.999,9975$ & 0,5 & 99,9999 & 1,5 \\
\hline GPRM03 & $15^{\circ} 35^{\prime} 38,2403^{\prime \prime}$ & $84^{\circ} 11^{\prime} 08,9221^{\prime \prime}$ & 23,6777 & $1.000,0044$ & 1,5 & $4.999,9974$ & 0,5 & 99,9999 & 1,5 \\
\hline GPRM04 & $15^{\circ} 35^{\prime} 40,4279^{\prime \prime}$ & $84^{\circ} 11^{\prime} 17,6384^{\prime \prime}$ & 23,6775 & $1.000,0046$ & 1,4 & $4.999,9974$ & 0,5 & 99,9999 & 1,5 \\
\hline GPRM05 & $15^{\circ} 35^{\prime} 45,2674^{\prime \prime}$ & $84^{\circ} 11^{\prime} 26,8598^{\prime \prime}$ & 23,6777 & $1.000,0047$ & 1,5 & $4.999,9974$ & 0,5 & 99,9999 & 1,5 \\
\hline GPRM06 & $15^{\circ} 36^{\prime} 20,6963 "$ & $84^{\circ} 12^{\prime} 10,1628^{\prime \prime}$ & 23,6789 & $1.000,0047$ & 1,4 & $4.999,9974$ & 0,5 & 99,9999 & 1,5 \\
\hline GPRM07 & $15^{\circ} 37^{\prime} 40,3512^{\prime \prime}$ & $84^{\circ} 13^{\prime} 39,5768^{\prime \prime}$ & 23,6810 & $1.000,0045$ & 1,5 & $4.999,9974$ & 0,5 & 99,9999 & 1,5 \\
\hline
\end{tabular}


Tabela 25 - Coordenadas e precisões ajustadas dos alvos (Método Polar - GPR112)

\begin{tabular}{lccccccc}
\hline \multicolumn{7}{c}{ COORDENADAS E PRECISÕES AJUSTADAS - GPR112 } \\
\hline PONTOS & $X(\mathrm{~m})$ & $\sigma_{X}(\mathrm{~mm})$ & $Y(\mathrm{~m})$ & $\sigma_{Y}(\mathrm{~mm})$ & $\mathrm{Z}(\mathrm{m})$ & $\sigma_{\mathrm{Z}}(\mathrm{mm})$ & $\sigma_{X Y Z}(\mathrm{~mm})$ \\
\hline GPRM00 & $1.006,3331$ & 1,9721 & $5.022,6858$ & 0,5500 & 102,4017 & $4,2582 \mathrm{E}-05$ & 2,0474 \\
GPRM01 & $1.006,3345$ & 1,9720 & $5.022,6861$ & 0,5501 & 102,4005 & $4,2534 \mathrm{E}-05$ & 2,0474 \\
GPRM02 & $1.006,3356$ & 1,9720 & $5.022,6861$ & 0,5502 & 102,3999 & $4,2512 \mathrm{E}-05$ & 2,0474 \\
GPRM03 & $1.006,3367$ & 1,9720 & $5.022,6862$ & 0,5503 & 102,3985 & $4,2462 \mathrm{E}-05$ & 2,0474 \\
GPRM04 & $1.006,3371$ & 1,9720 & $5.022,6861$ & 0,5503 & 102,3975 & $4,2426 \mathrm{E}-05$ & 2,0474 \\
GPRM05 & $1.006,3378$ & 1,9720 & $5.022,6862$ & 0,5504 & 102,3965 & $4,2389 \mathrm{E}-05$ & 2,0474 \\
GPRM06 & $1.006,3421$ & 1,9719 & $5.022,6868$ & 0,5507 & 102,3916 & $4,2212 \mathrm{E}-05$ & 2,0474 \\
GPRM07 & $1.006,3515$ & 1,9717 & $5.022,6873$ & 0,5515 & 102,3816 & $4,1847 \mathrm{E}-05$ & 2,0474 \\
\hline
\end{tabular}


Tabela 26 - Variação controlada, variação das coordenadas e diferença entre ambas (Método Polar - GPR112)

\begin{tabular}{cccccccc}
\hline & & & & \multicolumn{3}{c}{ DIFERENÇA ENTRE CONTROLE } \\
CONTROLE & \multicolumn{2}{c}{ VARIAÇÃO DAS COORDENADAS } & \multicolumn{3}{c}{ E VARIAÇÃO } \\
\hline Pontual $(\mathrm{mm})$ & Intervalo $(\mathrm{mm})$ & $\Delta \mathrm{X}(\mathrm{mm})$ & $\Delta \mathrm{Y}(\mathrm{mm})$ & $\Delta \mathrm{Z}(\mathrm{mm})$ & $\mathrm{X}(\mathrm{mm})$ & $\mathrm{Y}(\mathrm{mm})$ & $\mathrm{Z}(\mathrm{mm})$ \\
\hline 1,0 & $0,0-1,0$ & 1,4 & 0,3 & $-1,3$ & $-0,4$ & $-0,3$ & 0,7 \\
1,0 & $1,0-2,0$ & 1,1 & 0,0 & $-0,6$ & $-0,1$ & 0,0 & 1,0 \\
1,0 & $2,0-3,0$ & 1,1 & 0,1 & $-1,3$ & $-0,1$ & $-0,1$ & 0,9 \\
1,0 & $3,0-4,0$ & 0,4 & $-0,2$ & $-1,0$ & 0,6 & 0,2 & 1,2 \\
1,0 & $4,0-5,0$ & 0,7 & 0,1 & $-1,0$ & 0,3 & $-0,1$ & 0,9 \\
5,0 & $5,0-10,0$ & 4,4 & 0,5 & $-4,8$ & 0,6 & $-0,5$ & 0,2 \\
10,0 & $10,0-20,0$ & 9,4 & 0,6 & $-10,0$ & 0,6 & $-0,6$ & 0,0 \\
\hline
\end{tabular}




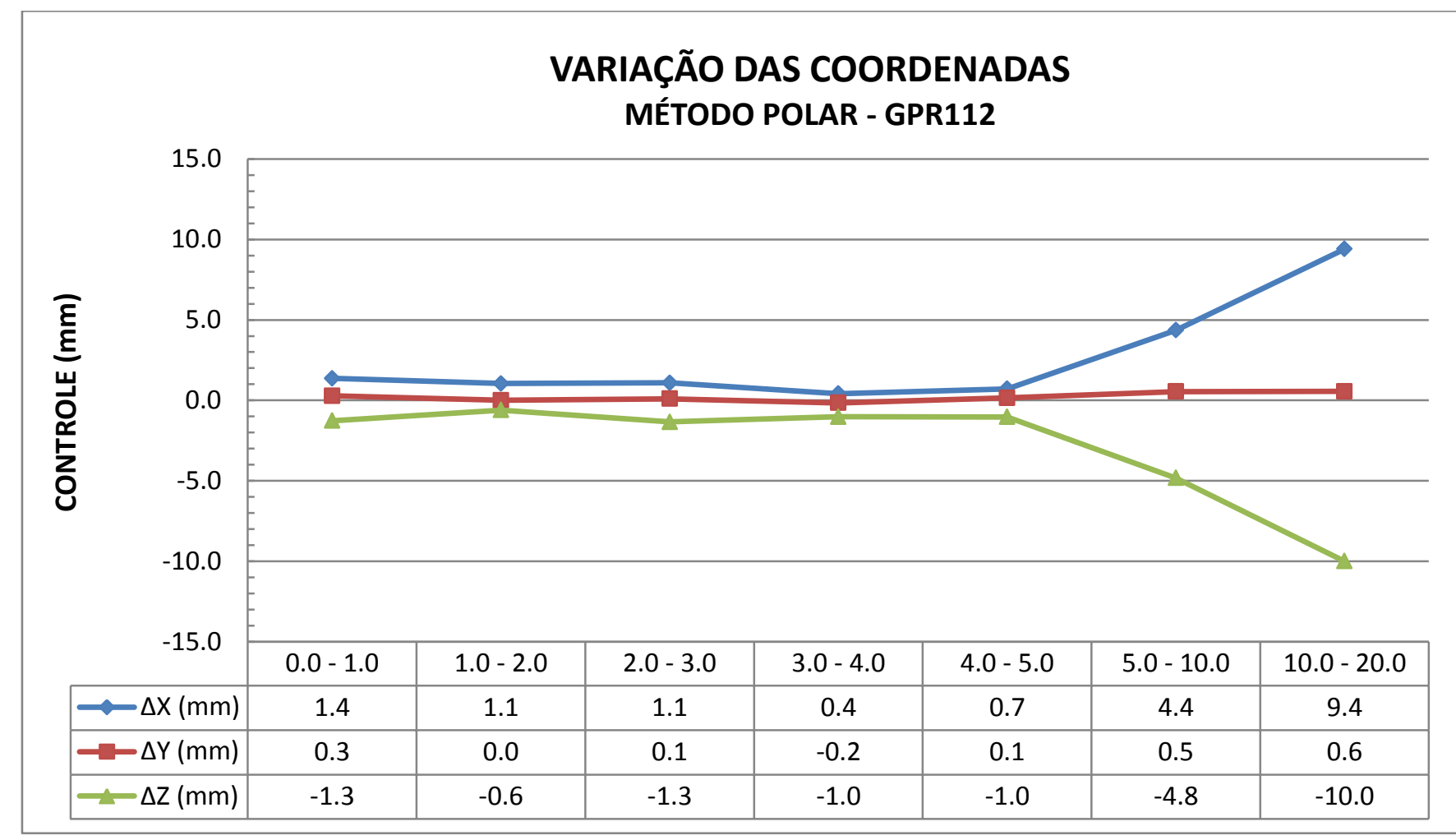

Figura 52 - Variação das coordenadas para o prisma GPR112 (Método Polar) 
Tabela 27 - Dados observados e verificação da estabilidade da Base 1 (Método Polar - GMP111-0)

\begin{tabular}{|c|c|c|c|c|c|c|c|c|c|}
\hline & \multicolumn{9}{|c|}{ MÉTODO POLAR - GMP111-0 (0.00 mm) } \\
\hline & \multicolumn{9}{|c|}{ BASE 1} \\
\hline & \multicolumn{3}{|c|}{ DADOS OBSERVADOS } & \multicolumn{6}{|c|}{ ESTABILIDADE DA BASE "RECESSÃO" } \\
\hline PONTOS & Azimute & Zenital & Di (m) & $X(m)$ & $\sigma_{x}(m m)$ & $\mathrm{Y}(\mathrm{m})$ & $\sigma_{Y}(\mathrm{~mm})$ & $Z(m)$ & $\sigma_{\mathrm{z}}(\mathrm{mm})$ \\
\hline GMPM00 & $15^{\circ} 34^{\prime} 40,0044^{\prime \prime}$ & $83^{\circ} 57^{\prime} 16,8620^{\prime \prime}$ & 23,6834 & $1.000,0045$ & 1,4 & $4.999,9977$ & 0,5 & 99,9999 & 1,5 \\
\hline GMPM01 & $15^{\circ} 34^{\prime} 50,2958^{\prime \prime}$ & $83^{\circ} 57^{\prime} 26,8583^{\prime \prime}$ & 23,6842 & $1.000,0046$ & 1,4 & $4.999,9976$ & 0,5 & 99,9999 & 1,5 \\
\hline GMPM02 & $15^{\circ} 34^{\prime} 52,6929^{\prime \prime}$ & $83^{\circ} 57^{\prime} 37,4900 "$ & 23,6841 & $1.000,0045$ & 1,4 & $4.999,9976$ & 0,5 & 99,9999 & 1,5 \\
\hline GMPM03 & $15^{\circ} 35^{\prime} 01,5785^{\prime \prime}$ & $83^{\circ} 57^{\prime} 45,2354 "$ & 23,6843 & $1.000,0044$ & 1,4 & $4.999,9977$ & 0,5 & 99,9999 & 1,5 \\
\hline GMPM04 & $15^{\circ} 35^{\prime} 02,8076 "$ & $83^{\circ} 57^{\prime} 54,1203^{\prime \prime}$ & 23,6845 & $1.000,0045$ & 1,4 & $4.999,9976$ & 0,5 & 99,9999 & 1,5 \\
\hline GMPM05 & $15^{\circ} 35^{\prime} 12,1816^{\prime \prime}$ & $83^{\circ} 58^{\prime} 02,5858 "$ & 23,6845 & $1.000,0043$ & 1,5 & $4.999,9977$ & 0,4 & 99,9999 & 1,5 \\
\hline GMPM06 & $15^{\circ} 35^{\prime} 49,8554^{\prime \prime}$ & $83^{\circ} 58^{\prime} 45,0138^{\prime \prime}$ & 23,6855 & $1.000,0045$ & 1,4 & $4.999,9975$ & 0,5 & 99,9999 & 1,5 \\
\hline GMPM07 & $15^{\circ} 37^{\prime} 06,7522 "$ & $84^{\circ} 00^{\prime} 15,3173^{\prime \prime}$ & 23,6878 & $1.000,0047$ & 1,4 & $4.999,9975$ & 0,5 & 99,9999 & 1,5 \\
\hline
\end{tabular}


Tabela 28 - Coordenadas e precisões ajustadas dos alvos (Método Polar - GMP111-0)

\section{COORDENADAS E PRECISÕES AJUSTADAS - GMP111-0}

\begin{tabular}{lccccccc}
\hline PONTOS & $X(\mathrm{~m})$ & $\sigma_{X}(\mathrm{~mm})$ & $Y(\mathrm{~m})$ & $\sigma_{Y}(\mathrm{~mm})$ & $\mathrm{Z}(\mathrm{m})$ & $\sigma_{Z}(\mathrm{~mm})$ & $\sigma_{X Y Z}(\mathrm{~mm})$ \\
\hline GMPM00 & $1.006,3292$ & 1,9722 & $5.022,6843$ & 0,5498 & 102,4941 & $4,5938 \mathrm{E}-05$ & 2,0474 \\
GMPM01 & $1.006,3307$ & 1,9721 & $5.022,6847$ & 0,5499 & 102,4931 & $4,5895 \mathrm{E}-05$ & 2,0474 \\
GMPM02 & $1.006,3309$ & 1,9721 & $5.022,6847$ & 0,5499 & 102,4918 & $4,5850 \mathrm{E}-05$ & 2,0474 \\
GMPM03 & $1.006,3318$ & 1,9721 & $5.022,6848$ & 0,5500 & 102,4910 & $4,5817 \mathrm{E}-05$ & 2,0474 \\
GMPM04 & $1.006,3321$ & 1,9721 & $5.022,6850$ & 0,5500 & 102,4900 & $4,5779 \mathrm{E}-05$ & 2,0474 \\
GMPM05 & $1.006,3330$ & 1,9721 & $5.022,6849$ & 0,5501 & 102,4890 & $4,5743 \mathrm{E}-05$ & 2,0474 \\
GMPM06 & $1.006,3377$ & 1,9720 & $5.022,6850$ & 0,5504 & 102,4843 & $4,5563 \mathrm{E}-05$ & 2,0474 \\
GMPM07 & $1.006,3473$ & 1,9718 & $5.022,6858$ & 0,5512 & 102,4742 & $4,5181 \mathrm{E}-05$ & 2,0474 \\
\hline
\end{tabular}


Tabela 29 - Variação controlada, variação das coordenadas e diferença entre ambas (Método Polar - GMP111-0)

\begin{tabular}{cccccccc}
\hline & \multicolumn{3}{c}{ CONTROLE } & \multicolumn{2}{c}{ VARIAÇÃO DAS COORDENADAS } & \multicolumn{3}{c}{ DIFERENÇA ENTRE CONTROLE } \\
\hline Pontual $(\mathrm{mm})$ & Intervalo $(\mathrm{mm})$ & $\Delta \mathrm{X}(\mathrm{mm})$ & $\Delta \mathrm{Y}(\mathrm{mm})$ & $\Delta \mathrm{Z}(\mathrm{mm})$ & $\mathrm{X}(\mathrm{mm})$ & $\mathrm{Y}(\mathrm{mm})$ & $\mathrm{Z}(\mathrm{mm})$ \\
\hline 1,0 & $0,0-1,0$ & 1,5 & 0,5 & $-1,1$ & $-0,5$ & $-0,5$ & 0,1 \\
1,0 & $1,0-2,0$ & 0,2 & 0,0 & $-1,2$ & 0,8 & 0,0 & 0,2 \\
1,0 & $2,0-3,0$ & 1,0 & 0,1 & $-0,9$ & 0,0 & $-0,1$ & 0,1 \\
1,0 & $3,0-4,0$ & 0,3 & 0,2 & $-1,0$ & 0,7 & $-0,2$ & 0,0 \\
1,0 & $4,0-5,0$ & 0,9 & $-0,1$ & $-1,0$ & 0,1 & 0,1 & 0,0 \\
5,0 & $5,0-10,0$ & 4,7 & 0,1 & $-4,7$ & 0,3 & $-0,1$ & 0,3 \\
10,0 & $10,0-20,0$ & 9,6 & 0,9 & $-10,1$ & 0,4 & $-0,9$ & $-0,1$ \\
\hline
\end{tabular}




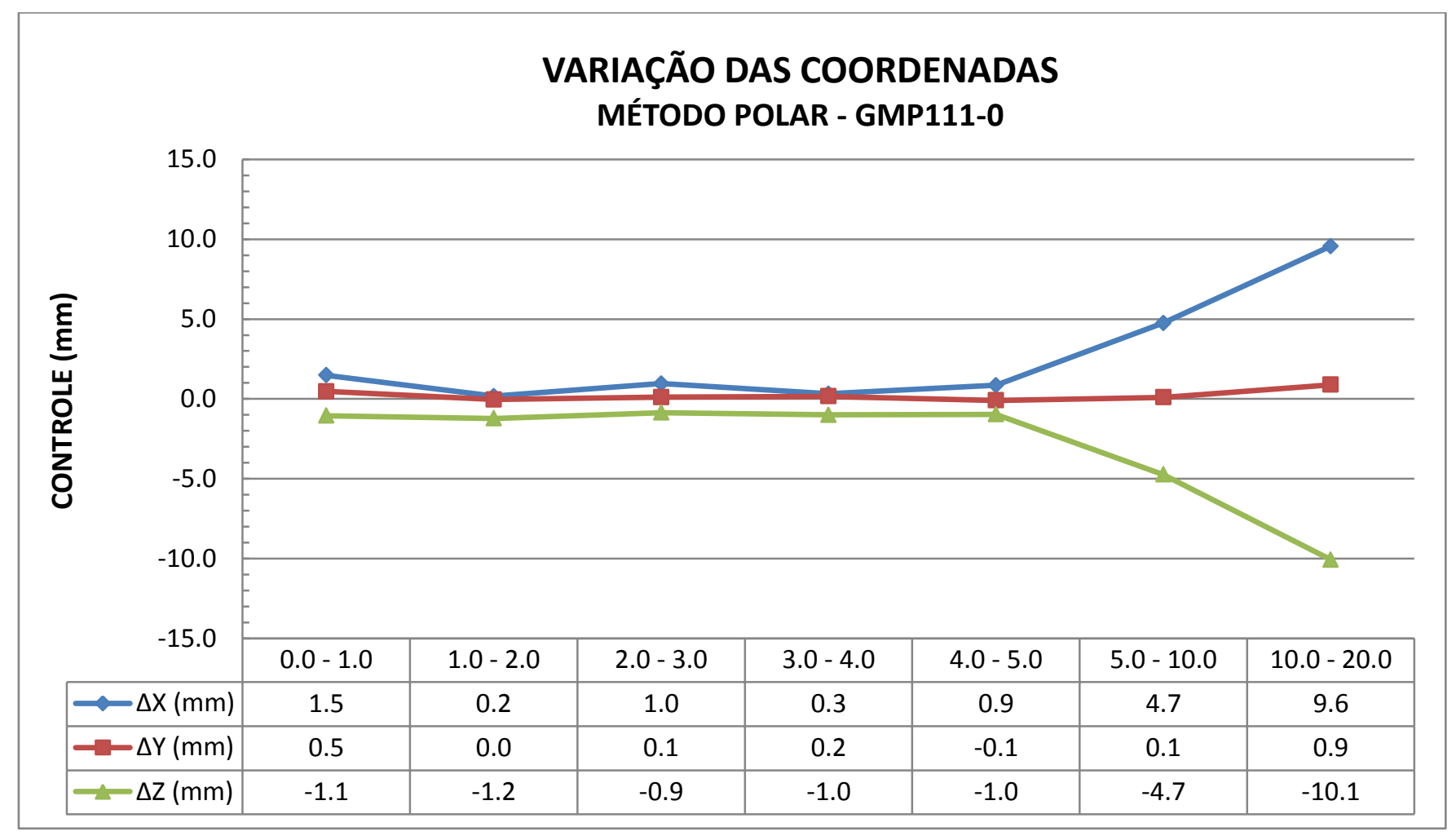

Figura 53 - Variação das coordenadas para o prisma GMP111-0 (Método Polar) 
Tabela 30 - Dados observados e verificação da estabilidade da Base 1 (Método Polar - GMP104)

\section{MÉTODO POLAR - GMP104 (8.90 mm)}

\section{BASE 1}

\begin{tabular}{|c|c|c|c|c|c|c|c|c|c|}
\hline \multirow[b]{2}{*}{ PONTOS } & \multicolumn{3}{|c|}{ DADOS OBSERVADOS } & \multicolumn{6}{|c|}{ ESTABILIDADE DA BASE "RECESSÃO" } \\
\hline & Azimute & Zenital & $\mathrm{Di}(\mathrm{m})$ & $X(m)$ & $\sigma_{x}(\mathrm{~mm})$ & $Y(m)$ & $\sigma_{Y}(\mathrm{~mm})$ & $Z(m)$ & $\sigma_{z}(\mathrm{~mm})$ \\
\hline GMPL00 & $15^{\circ} 34^{\prime} 58,2158^{\prime \prime}$ & $84^{\circ} 11^{\prime} 07,7288^{\prime \prime}$ & 23,6764 & $1.000,0046$ & 1,5 & $4.999,9976$ & 0,5 & 99,9999 & 1,5 \\
\hline GMPL01 & $15^{\circ} 35^{\prime} 11,1633^{\prime \prime}$ & $84^{\circ} 11^{\prime} 17,4850^{\prime \prime}$ & 23,6766 & $1.000,0045$ & 1,4 & $4.999,9976$ & 0,5 & 99,9999 & 1,5 \\
\hline GMPL02 & $15^{\circ} 35^{\prime} 16,8283^{\prime \prime}$ & $84^{\circ} 11^{\prime} 26,6141^{\prime \prime}$ & 23,6768 & $1.000,0044$ & 1,4 & $4.999,9977$ & 0,5 & 99,9998 & 1,5 \\
\hline GMPL03 & $15^{\circ} 35^{\prime} 21,4672 "$ & $84^{\circ} 11^{\prime} 35,6989^{\prime \prime}$ & 23,6772 & $1.000,0043$ & 1,5 & $4.999,9976$ & 0,6 & 99,9999 & 1,5 \\
\hline GMPL04 & $15^{\circ} 35^{\prime} 32,0822 "$ & $84^{\circ} 11^{\prime} 44,2433^{\prime \prime}$ & 23,6774 & $1.000,0043$ & 1,4 & $4.999,9977$ & 0,5 & 99,9999 & 1,5 \\
\hline GMPL05 & $15^{\circ} 35^{\prime} 34,1559^{\prime \prime}$ & $84^{\circ} 11^{\prime} 53,7687^{\prime \prime}$ & 23,6775 & $1.000,0045$ & 1,4 & $4.999,9977$ & 0,5 & 99,9999 & 1,5 \\
\hline GMPL06 & $15^{\circ} 36^{\prime} 11,4616^{\prime \prime}$ & $84^{\circ} 12^{\prime} 38,6385^{\prime \prime}$ & 23,6785 & $1.000,0044$ & 1,5 & $4.999,9976$ & 0,5 & 99,9999 & 1,5 \\
\hline GMPL07 & $15^{\circ} 37^{\prime} 31,6392 "$ & $84^{\circ} 14^{\prime} 05,9805^{\prime \prime}$ & 23,6808 & $1.000,0044$ & 1,5 & $4.999,9976$ & 0,5 & 99,9999 & 1,5 \\
\hline
\end{tabular}


Tabela 31 - Coordenadas e precisões ajustadas dos alvos (Método Polar - GMP104)

\begin{tabular}{lccccccc}
\hline \multicolumn{7}{c}{ COORDENADAS E PRECISÕES AJUSTADAS - GMP104 } \\
\hline PONTOS & $X(\mathrm{~m})$ & $\sigma_{X}(\mathrm{~mm})$ & $\mathrm{Y}(\mathrm{m})$ & $\sigma_{\mathrm{Y}}(\mathrm{mm})$ & $\mathrm{Z}(\mathrm{m})$ & $\sigma_{Z}(\mathrm{~mm})$ & $\sigma_{X Y Z}(\mathrm{~mm})$ \\
\hline GMPL00 & $1.006,3321$ & 1,9721 & $5.022,6864$ & 0,5499 & 102,3985 & 0,5499 & 2,0474 \\
GMPL01 & $1.006,3335$ & 1,9721 & $5.022,6863$ & 0,5501 & 102,3974 & $4,2427 \mathrm{E}-5$ & 2,0474 \\
GMPL02 & $1.006,3341$ & 1,9720 & $5.022,6865$ & 0,5501 & 102,3963 & $4,2390 \mathrm{E}-5$ & 2,0474 \\
GMPL03 & $1.006,3347$ & 1,9720 & $5.022,6868$ & 0,5502 & 102,3954 & $4,2352 \mathrm{E}-5$ & 2,0474 \\
GMPL04 & $1.006,3359$ & 1,9720 & $5.022,6868$ & 0,5503 & 102,3944 & $4,2318 \mathrm{E}-5$ & 2,0474 \\
GMPL05 & $1.006,3364$ & 1,9720 & $5.022,6870$ & 0,5503 & 102,3934 & $4,2279 \mathrm{E}-5$ & 2,0474 \\
GMPL06 & $1.006,3408$ & 1,9719 & $5.022,6872$ & 0,5506 & 102,3883 & $4,2095 \mathrm{E}-5$ & 2,0474 \\
GMPL07 & $1.006,3505$ & 1,9717 & $5.022,6879$ & 0,5514 & 102,3786 & $4,1740 \mathrm{E}-5$ & 2,0474 \\
\hline
\end{tabular}


Tabela 32 - Variação controlada, variação das coordenadas e diferença entre ambas (Método Polar - GMP104)

\begin{tabular}{cccccccc}
\hline & \multicolumn{3}{c}{ CONTROLE } & \multicolumn{2}{c}{ VARIAÇÃO DAS COORDENADAS } & \multicolumn{3}{c}{ DIFERENÇA ENTRE CONTROLE } \\
\hline Pontual $(\mathrm{mm})$ & Intervalo $(\mathrm{mm})$ & $\Delta \mathrm{X}(\mathrm{mm})$ & $\Delta \mathrm{Y}(\mathrm{mm})$ & $\Delta \mathrm{Z}(\mathrm{mm})$ & $\mathrm{X}(\mathrm{mm})$ & $\mathrm{Y}(\mathrm{mm})$ & $\mathrm{Z}(\mathrm{mm})$ \\
\hline 1,0 & $0,0-1,0$ & 1,4 & $-0,1$ & $-1,1$ & $-0,4$ & 0,1 & $-0,1$ \\
1,0 & $1,0-2,0$ & 0,6 & 0,2 & $-1,1$ & 0,4 & $-0,2$ & $-0,1$ \\
1,0 & $2,0-3,0$ & 0,5 & 0,2 & $-0,9$ & 0,5 & $-0,2$ & 0,1 \\
1,0 & $3,0-4,0$ & 1,2 & 0,1 & $-1,0$ & $-0,2$ & $-0,1$ & 0,1 \\
1,0 & $4,0-5,0$ & 0,5 & 0,1 & $-1,1$ & 0,5 & $-0,1$ & $-0,1$ \\
5,0 & $5,0-10,0$ & 4,4 & 0,2 & $-5,0$ & 0,6 & $-0,2$ & 0,0 \\
10,0 & $10,0-20,0$ & 9,7 & 0,7 & $-9,7$ & 0,3 & $-0,7$ & 0,3 \\
\hline
\end{tabular}




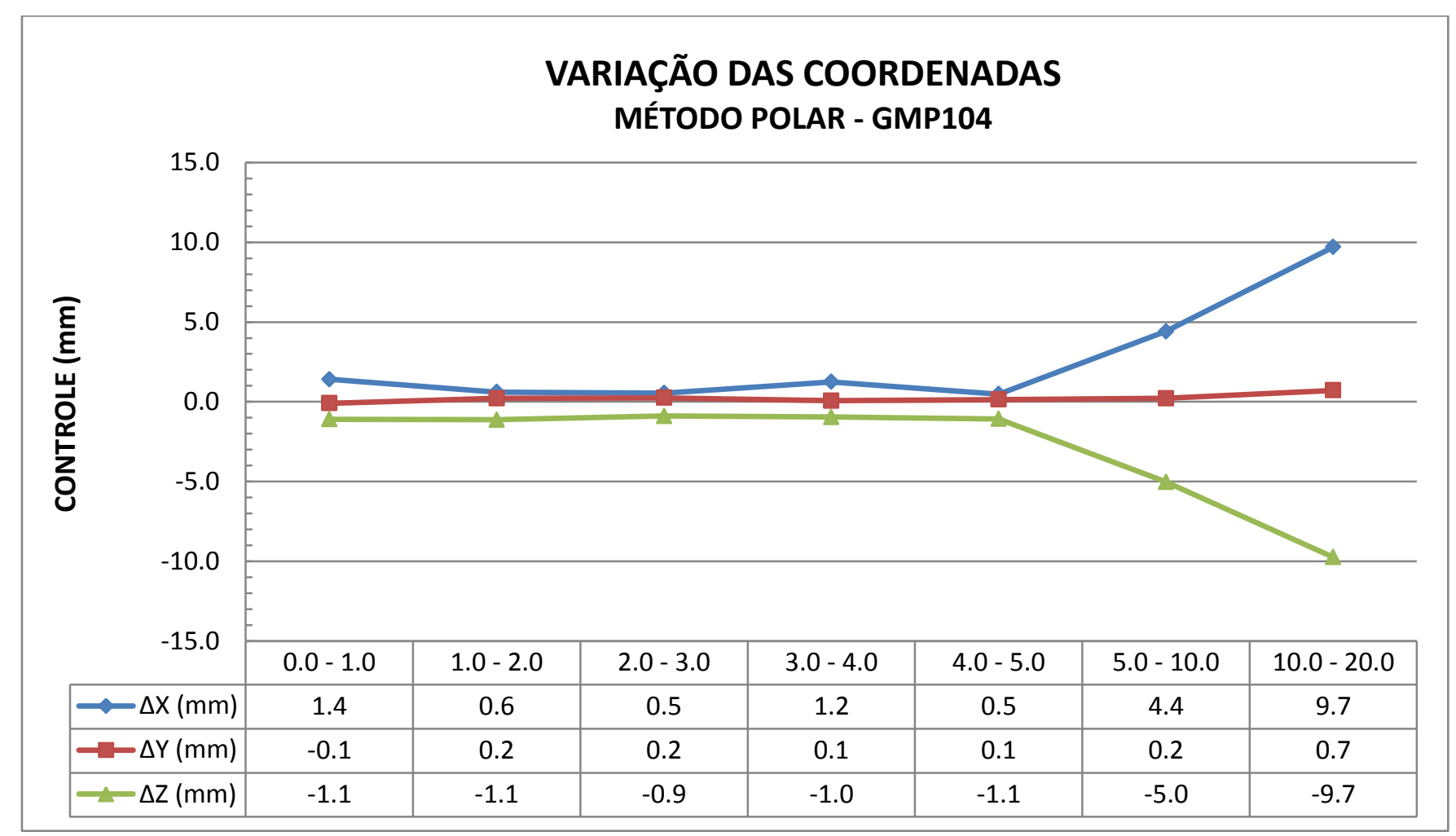

Figura 54 - Variação das coordenadas para o prisma GMP104 (Método Polar) 
Tabela 33 - Dados observados e verificação da estabilidade da Base 1 (Método Polar - GRZ101)

\begin{tabular}{|c|c|c|c|c|c|c|c|c|c|}
\hline \multirow[b]{3}{*}{ PONTOS } & \multicolumn{9}{|c|}{ MÉTODO POLAR - GRZ101 (30.0mm) } \\
\hline & \multicolumn{3}{|c|}{ DADOS OBSERVADOS } & \multicolumn{6}{|c|}{ ESTABILIDADE DA BASE "RECESSÃO" } \\
\hline & Azimute & Zenital & Di (m) & $X(m)$ & $\sigma_{x}(m m)$ & $\mathrm{Y}(\mathrm{m})$ & $\sigma_{Y}(\mathrm{~mm})$ & $\mathrm{Z}(\mathrm{m})$ & $\sigma_{Z}(\mathrm{~mm})$ \\
\hline GRZ00 & $15^{\circ} 35^{\prime} 10,9810^{\prime \prime}$ & $84^{\circ} 07^{\prime} 03,3306^{\prime \prime}$ & 23,6796 & $1.000,0044$ & 1,5 & $4.999,9976$ & 0,5 & 100,0000 & 1,5 \\
\hline GRZ02 & $15^{\circ} 35^{\prime} 19,7333^{\prime \prime}$ & $84^{\circ} 07^{\prime} 22,8338^{\prime \prime}$ & 23,6800 & $1.000,0044$ & 1,4 & $4.999,9976$ & 0,5 & 99,9999 & 1,5 \\
\hline GRZ03 & $15^{\circ} 35^{\prime} 36,4925^{\prime \prime}$ & $84^{\circ} 07^{\prime} 30,0421^{\prime \prime}$ & 23,6805 & $1.000,0043$ & 1,5 & $4.999,9977$ & 0,5 & 99,9999 & 1,5 \\
\hline GRZ04 & $15^{\circ} 35^{\prime} 37,0981^{\prime \prime}$ & $84^{\circ} 07^{\prime} 38,0044^{\prime \prime}$ & 23,6802 & $1.000,0046$ & 1,4 & $4.999,9976$ & 0,4 & 99,9999 & 1,5 \\
\hline GRZ05 & $15^{\circ} 35^{\prime} 38,3900^{\prime \prime}$ & $84^{\circ} 07^{\prime} 48,3516^{\prime \prime}$ & 23,6805 & $1.000,0045$ & 1,4 & $4.999,9977$ & 0,5 & 99,9999 & 1,5 \\
\hline
\end{tabular}


Tabela 34 - Coordenadas e precisões ajustadas dos alvos (Método Polar - GRZ101)

\begin{tabular}{cccccccc}
\hline \multicolumn{7}{c}{ COORDENADAS E PRECISÕES AJUSTADAS - GRZ101 } \\
\hline PONTOS & $X(\mathrm{~m})$ & $\sigma_{X}(\mathrm{~mm})$ & $\mathrm{Y}(\mathrm{m})$ & $\sigma_{Y}(\mathrm{~mm})$ & $\mathrm{Z}(\mathrm{m})$ & $\sigma_{Z}(\mathrm{~mm})$ & $\sigma_{X Y Z}(\mathrm{~mm})$ \\
\hline GRZ00 & $1.006,3334$ & 1,9721 & $5.022,6863$ & 0,5501 & 102,4269 & $4,3474 \mathrm{E}-5$ & 2,0474 \\
GRZ01 & $1.006,3343$ & 1,9720 & $5.022,6883$ & 0,5501 & 102,4255 & $4,3430 \mathrm{E}-5$ & 2,0474 \\
GRZ02 & $1.006,3345$ & 1,9720 & $5.022,6866$ & 0,5501 & 102,4246 & $4,3393 \mathrm{E}-5$ & 2,0474 \\
GRZ03 & $1.006,3364$ & 1,9720 & $5.022,6868$ & 0,5503 & 102,4238 & $4,3364 \mathrm{E}-5$ & 2,0474 \\
GRZ04 & $1.006,3367$ & 1,9720 & $5.022,6865$ & 0,5503 & 102,4229 & $4,3331 \mathrm{E}-5$ & 2,0474 \\
GRZ05 & $1.006,3369$ & 1,9720 & $5.022,6869$ & 0,5503 & 102,4217 & $4,3288 \mathrm{E}-5$ & 2,0474 \\
GRZ06 & $1.006,3420$ & 1,9719 & $5.022,6872$ & 0,5507 & 102,4169 & $4,3108 \mathrm{E}-5$ & 2,0474 \\
GRZ07 & $1.006,3517$ & 1,9717 & $5.022,6880$ & 0,5515 & 102,4066 & $4,2731 \mathrm{E}-5$ & 2,0474 \\
\hline
\end{tabular}


Tabela 35 - Variação controlada, variação das coordenadas e diferença entre ambas (Método Polar - GRZ101)

\begin{tabular}{cccccccc}
\hline & \multicolumn{3}{c}{ CONTROLE } & \multicolumn{2}{c}{ VARIAÇÃO DAS COORDENADAS } & \multicolumn{3}{c}{ DIFERENÇA ENTRE CONTROLE } \\
\hline Pontual $(\mathrm{mm})$ & Intervalo $(\mathrm{mm})$ & $\Delta \mathrm{X}(\mathrm{mm})$ & \multicolumn{1}{c}{$\Delta \mathrm{Y}(\mathrm{mm})$} & $\Delta \mathrm{Z}(\mathrm{mm})$ & $\mathrm{X}(\mathrm{mm})$ & $\mathrm{Y}(\mathrm{mm})$ & $\mathrm{Z}(\mathrm{mm})$ \\
\hline 1,0 & $0,0-1,0$ & 0,9 & 2,0 & $-1,3$ & 0,1 & $-2,0$ & $-0,3$ \\
1,0 & $1,0-2,0$ & 0,2 & $-1,6$ & $-1,0$ & 0,8 & 1,6 & 0,0 \\
1,0 & $2,0-3,0$ & 1,9 & 0,1 & $-0,8$ & $-0,9$ & $-0,1$ & 0,2 \\
1,0 & $3,0-4,0$ & 0,3 & $-0,3$ & $-0,9$ & 0,7 & 0,3 & 0,1 \\
1,0 & $4,0-5,0$ & 0,2 & 0,5 & $-1,2$ & 0,8 & $-0,5$ & $-0,2$ \\
5,0 & $5,0-10,0$ & 5,1 & 0,2 & $-4,8$ & $-0,1$ & $-0,2$ & 0,2 \\
10,0 & $10,0-20,0$ & 9,7 & 0,8 & $-10,2$ & 0,3 & $-0,8$ & $-0,2$ \\
\hline
\end{tabular}




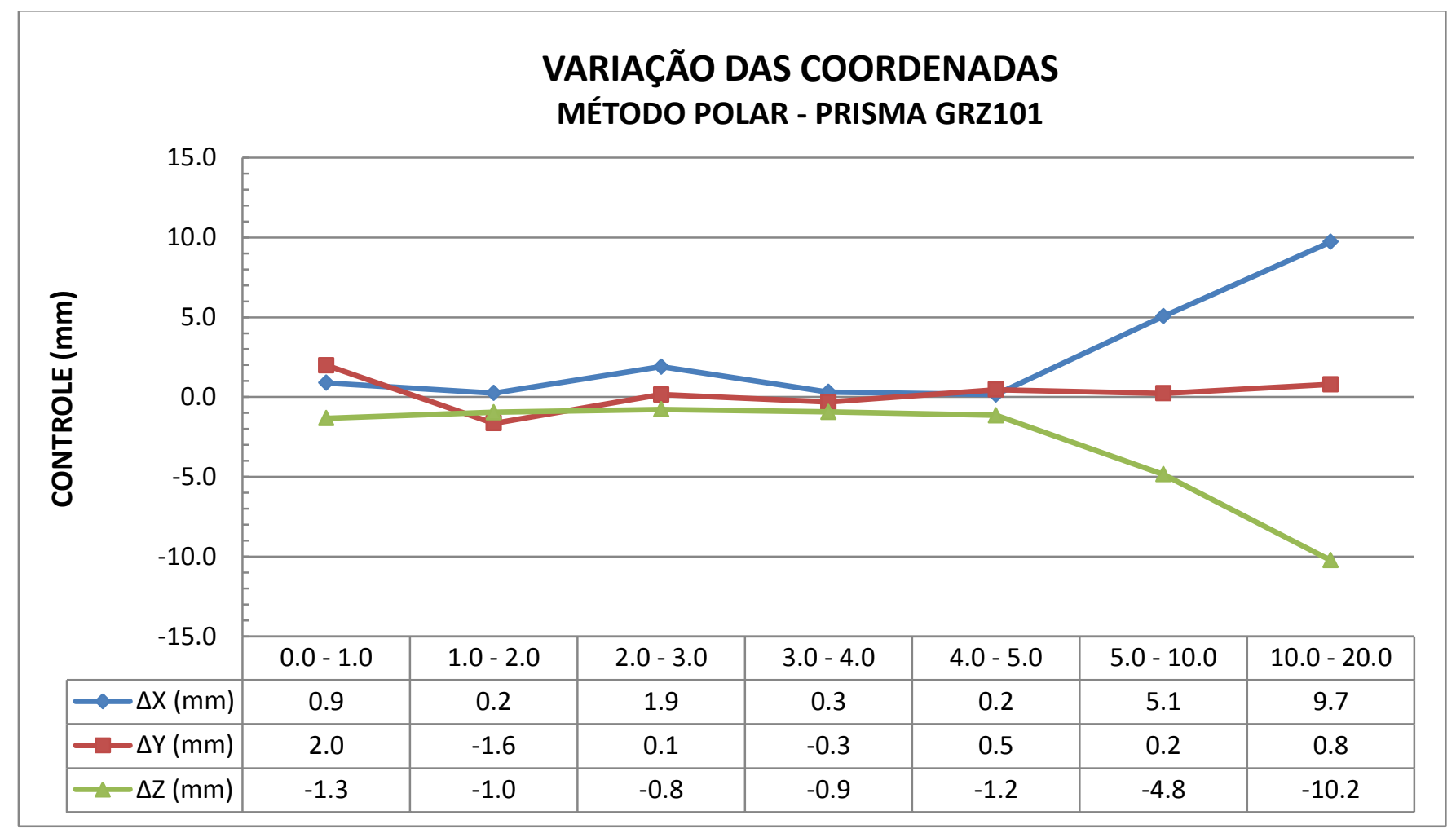

Figura 55 - Variação das coordenadas para o prisma GRZ101 (Método Polar) 
Tabela 36 - Dados observados e verificação da estabilidade da Base 1 (Método Polar - Fita Refletiva)

\begin{tabular}{|c|c|c|c|c|c|c|c|c|c|}
\hline & \multicolumn{9}{|c|}{ MÉTODO POLAR - FITA REFLETIVA (34.4 mm) } \\
\hline & \multicolumn{9}{|c|}{ BASE 1} \\
\hline & \multicolumn{3}{|c|}{ DADOS OBSERVADOS } & \multicolumn{6}{|c|}{ ESTABILIDADE DA BASE "RECESSÃO" } \\
\hline PONTOS & Azimute & Zenital & $\mathrm{Di}(\mathrm{m})$ & $X(m)$ & $\sigma_{X}(\mathrm{~mm})$ & $Y(m)$ & $\sigma_{Y}(\mathrm{~mm})$ & $Z(m)$ & $\sigma_{z}(\mathrm{~mm})$ \\
\hline FROO & $15^{\circ} 34^{\prime} 56,6784^{\prime \prime}$ & $84^{\circ} 27^{\prime} 26,3816^{\prime \prime}$ & 23,6634 & $1.000,0045$ & 1,4 & $4.999,9977$ & 0,5 & 99,9998 & 1,4 \\
\hline FR01 & $15^{\circ} 34^{\prime} 59,7940 "$ & $84^{\circ} 27^{\prime} 33,3982^{\prime \prime}$ & 23,6640 & $1.000,0045$ & 1,4 & $4.999,9975$ & 0,4 & 99,9999 & 1,5 \\
\hline FR02 & $15^{\circ} 35^{\prime} 13,3244^{\prime \prime}$ & $84^{\circ} 27^{\prime} 44,8378^{\prime \prime}$ & 23,6639 & $1.000,0044$ & 1,4 & $4.999,9975$ & 0,5 & 99,9999 & 1,5 \\
\hline FR03 & $15^{\circ} 35^{\prime} 23,5576 "$ & $84^{\circ} 27^{\prime} 57,3758^{\prime \prime}$ & 23,6643 & $1.000,0046$ & 1,5 & $4.999,9974$ & 0,5 & 99,9999 & 1,5 \\
\hline FR04 & $15^{\circ} 35^{\prime} 26,9878^{\prime \prime}$ & $84^{\circ} 28^{\prime} 00,2907^{\prime \prime}$ & 23,6645 & $1.000,0044$ & 1,5 & $4.999,9976$ & 0,5 & 99,9999 & 1,5 \\
\hline FR05 & $15^{\circ} 35^{\prime} 32,2639^{\prime \prime}$ & $84^{\circ} 28^{\prime} 15,7757^{\prime \prime}$ & 23,6648 & $1.000,0046$ & 1,5 & $4.999,9974$ & 0,5 & 99,9999 & 1,5 \\
\hline FR06 & $15^{\circ} 36^{\prime} 10,6850^{\prime \prime}$ & $84^{\circ} 29^{\prime} 02,1145^{\prime \prime}$ & 23,6657 & $1.000,0046$ & 1,4 & $4.999,9974$ & 0,5 & 99,9999 & 1,5 \\
\hline FR07 & $15^{\circ} 37^{\prime} 37,8931^{\prime \prime}$ & $84^{\circ} 30^{\prime} 26,3643^{\prime \prime}$ & 23,6680 & $1.000,0044$ & 1,4 & $4.999,9977$ & 0,5 & 99,9999 & 1,5 \\
\hline
\end{tabular}


Tabela 37 - Coordenadas e precisões ajustadas dos alvos (Método Polar - Fita Refletiva)

\begin{tabular}{cccccccc}
\hline \multicolumn{7}{c}{ COORDENADAS E PRECISÕES AJUSTADAS - FITA REFLETIVA } \\
\hline PONTOS & $X(\mathrm{~m})$ & $\sigma_{X}(\mathrm{~mm})$ & $\mathrm{Y}(\mathrm{m})$ & $\sigma_{Y}(\mathrm{~mm})$ & $\mathrm{Z}(\mathrm{m})$ & $\sigma_{Z}(\mathrm{~mm})$ & $\sigma_{X Y Z}(\mathrm{~mm})$ \\
\hline FR00 & $1.006,3313$ & 1,9721 & $5.022,6848$ & 0,5499 & 102,2854 & $3,8550 \mathrm{E}-5$ & 2,0473 \\
FR01 & $1.006,3319$ & 1,9721 & $5.022,6851$ & 0,5499 & 102,2847 & $3,8522 \mathrm{E}-5$ & 2,0473 \\
FR02 & $1.006,3333$ & 1,9720 & $5.022,6847$ & 0,5501 & 102,2834 & $3,8478 \mathrm{E}-5$ & 2,0473 \\
FR03 & $1.006,3347$ & 1,9720 & $5.022,6849$ & 0,5502 & 102,2820 & $3,8429 \mathrm{E}-5$ & 2,0473 \\
FR04 & $1.006,3350$ & 1,9720 & $5.022,6852$ & 0,5502 & 102,2817 & $3,8417 \mathrm{E}-5$ & 2,0473 \\
FR05 & $1.006,3359$ & 1,9720 & $5.022,6853$ & 0,5503 & 102,2800 & $3,8357 \mathrm{E}-5$ & 2,0473 \\
FR06 & $1.006,3405$ & 1,9719 & $5.022,6854$ & 0,5506 & 102,2748 & $3,8177 \mathrm{E}-5$ & 2,0473 \\
FR07 & $1.006,3507$ & 1,9717 & $5.022,6862$ & 0,5515 & 102,2654 & $3,7850 \mathrm{E}-5$ & 2,0473 \\
\hline
\end{tabular}


Tabela 38 - Variação controlada, variação das coordenadas e diferença entre ambas (Método Polar - Fita Refletiva)

\begin{tabular}{cccccccc}
\hline \multicolumn{1}{c}{ CONTROLE } & \multicolumn{2}{c}{ VARIAÇÃO DAS COORDENADAS } & \multicolumn{3}{c}{ DIFERENÇA ENTRE CONTROLE } \\
\hline Pontual $(\mathrm{mm})$ & Intervalo $(\mathrm{mm})$ & $\Delta \mathrm{X}(\mathrm{mm})$ & $\Delta \mathrm{Y}(\mathrm{mm})$ & $\Delta \mathrm{Z}(\mathrm{mm})$ & $\mathrm{X}(\mathrm{mm})$ & $\mathrm{Y}(\mathrm{mm})$ & $\mathrm{Z}(\mathrm{mm})$ \\
\hline 1,0 & $0,0-1,0$ & 0,5 & 0,4 & $-0,6$ & 0,5 & $-0,4$ & 0,4 \\
1,0 & $1,0-2,0$ & 1,4 & $-0,4$ & $-1,3$ & $-0,4$ & 0,4 & $-0,3$ \\
1,0 & $2,0-3,0$ & 1,5 & 0,1 & $-1,4$ & $-0,5$ & $-0,1$ & $-0,4$ \\
1,0 & $3,0-4,0$ & 0,2 & 0,3 & $-0,3$ & 0,8 & $-0,3$ & 0,7 \\
1,0 & $4,0-5,0$ & 0,9 & 0,1 & $-1,7$ & 0,1 & $-0,1$ & $-0,7$ \\
5,0 & $5,0-10,0$ & 4,6 & 0,2 & $-5,2$ & 0,4 & $-0,2$ & $-0,2$ \\
10,0 & $10,0-20,0$ & 10,3 & 0,7 & $-9,4$ & $-0,3$ & $-0,7$ & 0,6 \\
\hline
\end{tabular}




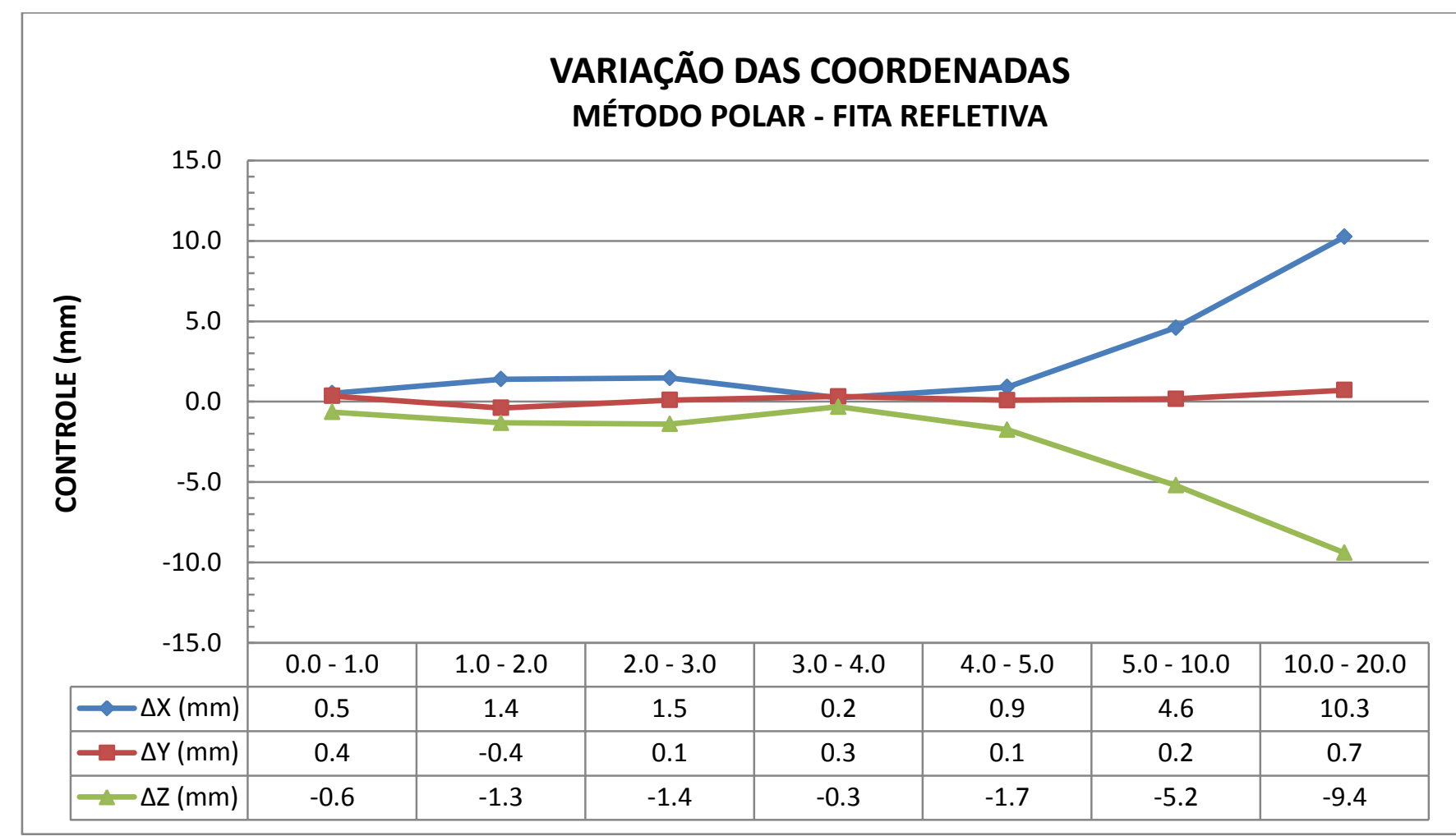

Figura 56 - Variação das coordenadas para a Fita Refletiva (Método Polar) 


\section{APÊNDICE E - Rotina computacional para determinações das coordenadas espaciais dos alvos por meio do método das distâncias mínimas}

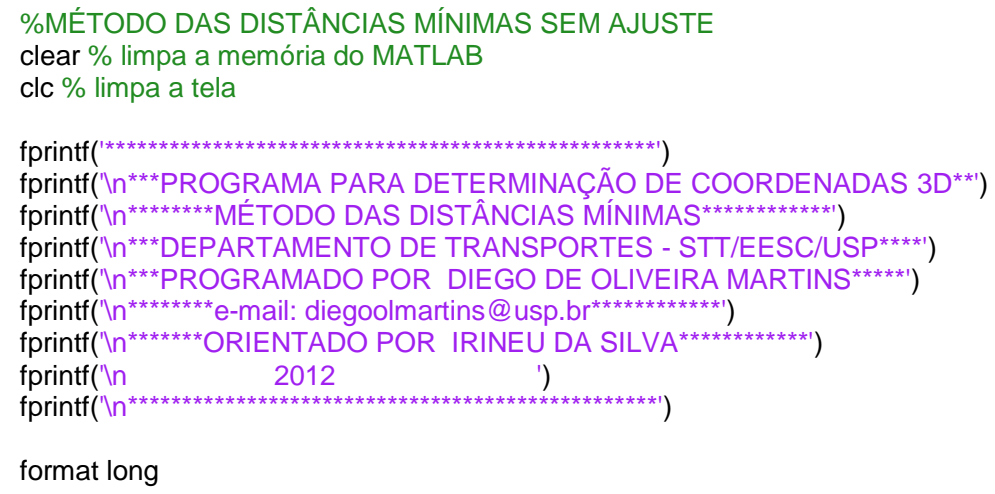


\%ÂNGULO ZENITAL NA PRIMEIRA ESTAČ̃̃O

fprintf('InDigite o Ângulo Zenital na primeira Estação(GMS):');

Zen1G = input('InGrau:');

Zen1M = input('InMinuto:');

Zen1S = input('InSegundo:');

\%CONVERSÃO DE ÂNGULOS DO ÂNGULO ZENITAL NA PRIMEIRA ESTAÇÃO

$\%$ GMS PARA GRAUS DECIMAIS

format short

Zen1dec $=$ Zen1G+(Zen1M/60)+(Zen1S/3600) \%Ângulo zenital 1 em grau decimal

\%CONVERSÃO DE ÂNGULOS EM GRAUS DECIMAIS PARA RADIANOS DO ÂNGULO ZENITAL NA PRIMEIRA ESTAÇÃO format long

fprintf('InConversão de graus-radianos $\backslash n ')$;

fprintf('\nDados de entrada: angulo em graus $\backslash n$ ');

Zen1rad $=$ Zen1 $\mathrm{dec}^{\star}(\mathrm{pi} / 180) \quad$ \%Ầngulo zenital 1 em radianos

\%DETERMINAÇÃO DAS COORDENADAS DOS VERSORES DA LINHA DE VISADA 1(a1, b1, c1)

b1 $=\sin ($ Zen1rad $){ }^{*} \cos ($ Az1Alvo);

a1 $=\sin ($ Zen1rad $) * \sin ($ Az1Alvo);

$\mathrm{c} 1=\cos ($ Zen1 $\mathrm{rad})$;

\%NOME DA SEGUNDA ESTAÇÃO

fprintf('InEscreva o nome da segunda Estação:'); \%Nome da primeira Estação

E2 = input('InEstação:');

\%COORDENADAS TRIDIMENSIONAIS NA SEGUNDA ESTAÇÃO

fprintf('InEntre com as coordenadas tridimensionais da segunda Estação:');

$\mathrm{X} 2$ = input('InDigite a coordenada $X$ da segunda Estação $(\mathrm{m}):$ :');

Y2 = input('ไnDigite a coordenada $Y$ da segunda Estação(m):');

Z2 = input('InDigite a coordenada Z da segunda Estação(m):');

\%ALTURA DO INSTRUMENTO NA SEGUNDA ESTAÇÃO hi=0 (referencia CO)

fprintf('InDigite a altura do instrumento na segunda Estação(m):');

Hi2 = input('ไnHi1(m):');

\%COORDENADAS DO CENTRO OPTICO DA PRIMEIRA ESTAÇÃO

$\mathrm{XCO} 2=\mathrm{X} 2$

$\mathrm{YCO} 2=\mathrm{Y} 2$

$\mathrm{ZCO} 2=\mathrm{Z} 2+\mathrm{Hi} 2$

\%ÂNGULO HORIZONTAL NA SEGUNDA ESTAÇÃO

fprintf('InDigite o Ângulo Horizontal na segunda Estação(GMS):');

Hz2G = input('InGrau:');

Hz2M = input('InMinuto:');

Hz2S = input('InSegundo:');

\%CONVERSÃO DE ÂNGULOS DO ÂNGULO HORIZONTAL NA SEGUNDA ESTAÇÃO

\%GMS PARA GRAUS DECIMAIS

format short

$\mathrm{Hz} 2 \mathrm{dec}=\mathrm{Hz2G}+(\mathrm{Hz2M} / 60)+(\mathrm{Hz2S} / 3600) \quad$ \%Ângulo horizontal 2 em grau decimal

\%CONVERSÃO DE ÂNGULOS EM GRAUS DECIMAIS PARA RADIANOS DO ÂNGULO HORIZONTAL NA SEGUNDA

ESTAÇÃO

format long

fprintf('\nConversão de graus-radianos $\backslash n ')$;

fprintf('\nDados de entrada: angulo em graus $\backslash n ')$;

$\mathrm{Hz2} \mathrm{rad}=\mathrm{Hz}_{2 \mathrm{dec}}(\mathrm{pi} / 180) \quad \%$ Ângulo horizontal $2 \mathrm{em}$ radianos

\%CÁLCULO DO AZIMUTE DA ESTAÇÃO 2 ATÉ O ALVO P

Az2Alvo $=\mathrm{Hz2rad}$

\%ÂNGULO ZENITAL NA SEGUNDA ESTAÇÃO

fprintf('InDigite o Ângulo Zenital na segunda Estação(GMS):');

Zen2G = input('InGrau:');

Zen2M = input('InMinuto:');

Zen2S = input('InSegundo:');

\%CONVERSÃO DE ÂNGULOS DO ÂNGULO ZENITAL NA PRIMEIRA ESTAÇÃO

$\%$ GMS PARA GRAUS DECIMAIS

format short 
Zen2dec $=$ Zen2G+(Zen2M/60)+(Zen2S/3600) \%Ângulo zenital 1 em grau decimal

\%CONVERSÃO DE ÂNGULOS EM GRAUS DECIMAIS PARA RADIANOS DO ÂNGULO ZENITAL NA SEGUNDA ESTAÇÃO format long

fprintf('\nConversão de graus-radianos $\backslash n ')$;

fprintf('\nDados de entrada: angulo em graus $\backslash n ')$;

Zen2rad $=$ Zen2dec $(\mathrm{pi} / 180) \quad \%$ Ângulo zenital 2 em radianos

\%DETERMINAÇÃO DAS COORDENADAS DOS VERSORES DA LINHA DE VISADA 2(a2, b2, c2)

b2 $=\sin \left(\right.$ Zen2rad ${ }^{*} \cos ($ Az2Alvo);

a2 $=\sin ($ Zen2rad) * $\sin ($ Az2Alvo);

c2 $=\cos ($ Zen2rad $)$;

\%DETERMINAÇÃO DAS DERIVADAS PARCIAIS EM FUNÇÃO DAS INCÓGNITAS

\%FORMULAÇÃO MATRICIAL

\%MATRIZ DOS COEFICIENTES DAS INCOGNITAS

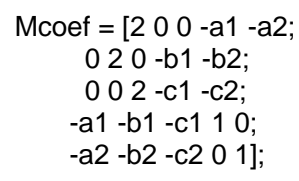

\%MATRIZ DOS TERMOS INDEPENDENTES

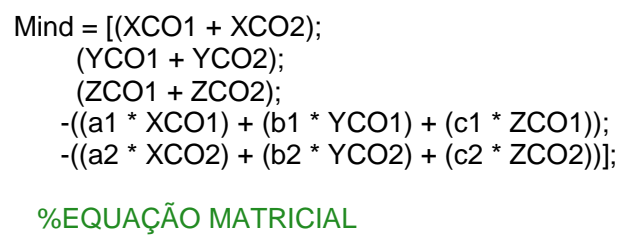




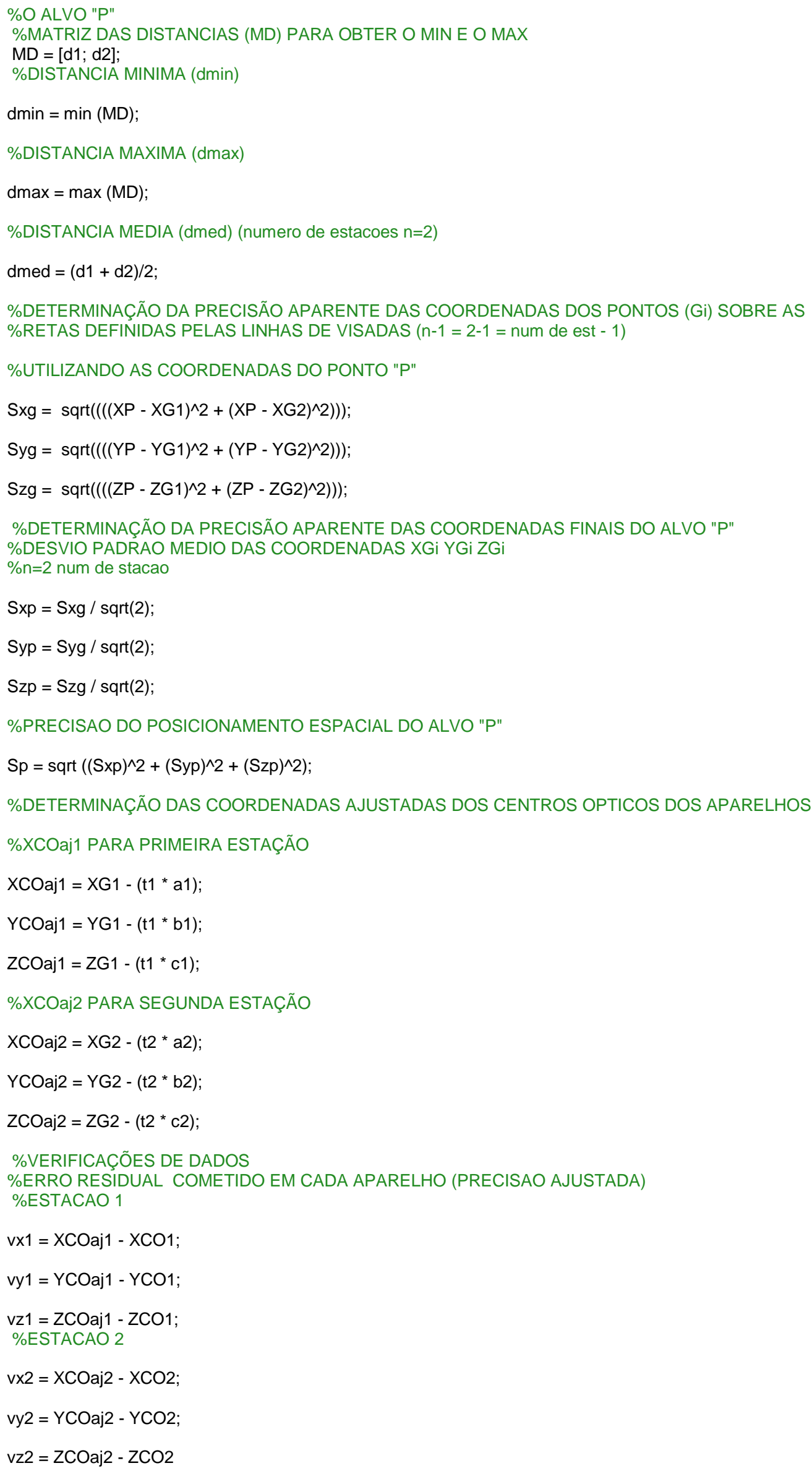


APÊNDICE F - Validação do método das distâncias mínimas para os alvos estudados 
Tabela 39 - Dados observados e verificação da estabilidade da Base 1 (Distância Mínima - GPR112)

\begin{tabular}{lcccccccc}
\hline \multicolumn{7}{c}{ MÉTODO DAS DISTÂNCIAS MíNIMAS - GPR112 (-7.10 mm) } \\
\hline \multicolumn{7}{c}{ BASE 1 } \\
\hline \multicolumn{7}{c}{ DADOS OBSERVADOS } & \multicolumn{7}{c}{ ESTABILIDADE DA BASE "RECESSÃO" } \\
\hline PONTOS & Azimute & Zenital & $X(\mathrm{~m})$ & $\sigma_{X}(\mathrm{~mm})$ & $Y(\mathrm{~m})$ & $\sigma_{Y}(\mathrm{~mm})$ & $\mathrm{Z}(\mathrm{m})$ & $\sigma_{Z}(\mathrm{~mm})$ \\
GPRM00 & $15^{\circ} 35^{\prime} 09,2290^{\prime \prime}$ & $84^{\circ} 10^{\prime} 39,7496^{\prime \prime}$ & $1.000,0045$ & 1,5 & $4.999,9976$ & 0,5 & 99,9999 & 1,5 \\
GPRM01 & $15^{\circ} 35^{\prime} 19,8276^{\prime \prime}$ & $84^{\circ} 10^{\prime} 51,3675^{\prime \prime}$ & $1.000,0045$ & 1,4 & $4.999,9975$ & 0,5 & 99,9999 & 1,5 \\
GPRM02 & $15^{\circ} 35^{\prime} 27,8297^{\prime \prime}$ & $84^{\circ} 10^{\prime} 56,8414^{\prime \prime}$ & $1.000,0046$ & 1,4 & $4.999,9975$ & 0,5 & 99,9999 & 1,5 \\
GPRM03 & $15^{\circ} 35^{\prime} 38,2403^{\prime \prime}$ & $84^{\circ} 11^{\prime} 08,9221^{\prime \prime}$ & $1.000,0044$ & 1,5 & $4.999,9974$ & 0,5 & 99,9999 & 1,5 \\
GPRM04 & $15^{\circ} 35^{\prime} 40,4279^{\prime \prime}$ & $84^{\circ} 11^{\prime} 17,6384^{\prime \prime}$ & $1.000,0046$ & 1,4 & $4.999,9974$ & 0,5 & 99,9999 & 1,5 \\
GPRM05 & $15^{\circ} 35^{\prime} 45,2674 "$ & $84^{\circ} 11^{\prime} 26,8598^{\prime \prime}$ & $1.000,0047$ & 1,5 & $4.999,9974$ & 0,5 & 99,9999 & 1,5 \\
GPRM06 & $15^{\circ} 36^{\prime} 20,6963^{\prime \prime}$ & $84^{\circ} 12^{\prime} 10,1628^{\prime \prime}$ & $1.000,0047$ & 1,4 & $4.999,9974$ & 0,5 & 99,9999 & 1,5 \\
GPRM07 & $15^{\circ} 37^{\prime} 40,3512 "$ & $84^{\circ} 13^{\prime} 39,5768^{\prime \prime}$ & $1.000,0045$ & 1,5 & $4.999,9974$ & 0,5 & 99,9999 & 1,5 \\
\hline
\end{tabular}


Tabela 40 - Dados observados e verificação da estabilidade da Base 2 (Distância Mínima - GPR112)

\begin{tabular}{|c|c|c|c|c|c|c|c|c|}
\hline \multicolumn{9}{|c|}{ BASE 2} \\
\hline \multirow[b]{2}{*}{ PONTOS } & \multicolumn{2}{|c|}{ DADOS OBSERVADOS } & \multicolumn{6}{|c|}{ ESTABILIDADE DA BASE "RECESSÃO" } \\
\hline & Azimute & Zenital & $X(m)$ & $\sigma_{X}(\mathrm{~mm})$ & $Y(m)$ & $\sigma_{Y}(\mathrm{~mm})$ & $Z(m)$ & $\sigma_{z}(\mathrm{~mm})$ \\
\hline GPRM00 & $342^{\circ} 49^{\prime} 13,9364^{\prime \prime}$ & $83^{\circ} 53^{\prime} 42,3465^{\prime \prime}$ & $1.013,1140$ & 1,5 & $5.000,7535$ & 0,6 & 99,9459 & 1,5 \\
\hline GPRM01 & $342^{\circ} 49^{\prime} 27,1427^{\prime \prime}$ & $83^{\circ} 53^{\prime} 54,0521^{\prime \prime}$ & $1.013,1140$ & 1,5 & $5.000,7534$ & 0,5 & 99,9459 & 1,5 \\
\hline GPRM02 & $342^{\circ} 49^{\prime} 37,1124 "$ & $83^{\circ} 53^{\prime} 58,9213^{\prime \prime}$ & $1.013,1138$ & 1,4 & $5.000,7537$ & 0,6 & 99,9459 & 1,5 \\
\hline GPRM03 & $342^{\circ} 49^{\prime} 47,0638^{\prime \prime}$ & $83^{\circ} 54^{\prime} 11,0112^{\prime \prime}$ & $1.013,1139$ & 1,4 & $5.000,7536$ & 0,6 & 99,9459 & 1,6 \\
\hline GPRM04 & $342^{\circ} 49^{\prime} 46,3278^{\prime \prime}$ & $83^{\circ} 54^{\prime} 19,5343^{\prime \prime}$ & $1.013,1140$ & 1,4 & $5.000,7538$ & 0,6 & 99,9456 & 1,5 \\
\hline GPRM05 & $342^{\circ} 49^{\prime} 55,2427^{\prime \prime}$ & $83^{\circ} 54^{\prime} 28,7357^{\prime \prime}$ & $1.013,1140$ & 1,4 & $5.000,7535$ & 0,5 & 99,9459 & 1,5 \\
\hline GPRM06 & $342^{\circ} 50^{\prime} 34,2637^{\prime \prime}$ & $83^{\circ} 55^{\prime} 09,2072 "$ & $1.013,1140$ & 1,5 & $5.000,7536$ & 0,6 & 99,9459 & 1,5 \\
\hline GPRM07 & $342^{\circ} 51^{\prime} 56,3621^{\prime \prime}$ & $83^{\circ} 56^{\prime} 36,6287^{\prime \prime}$ & $1.013,1140$ & 1,4 & $5.000,7535$ & 0,4 & 99,9459 & 1,5 \\
\hline
\end{tabular}


Tabela 41 - Coordenadas dos alvos e precisões aparentes (Distância Mínima - GPR112)

\begin{tabular}{lccccccc}
\hline \multicolumn{7}{c}{ COORDENADAS E PRECISÕES APARENTES } \\
\hline PONTOS & $X(\mathrm{~m})$ & $\sigma_{X}(\mathrm{~mm})$ & $Y(\mathrm{~m})$ & $\sigma_{\mathrm{Y}}(\mathrm{mm})$ & $\mathrm{Z}(\mathrm{m})$ & $\sigma_{Z}(\mathrm{~mm})$ & $\sigma_{X Y Z}(\mathrm{~mm})$ \\
\hline GPRM00 & $1.006,3333$ & 0,0024 & $5.022,6863$ & 0,0260 & 102,4015 & 0,2397 & 0,2411 \\
GPRM01 & $1.006,3347$ & 0,0027 & $5.022,6867$ & 0,0291 & 102,4002 & 0,2680 & 0,2696 \\
GPRM02 & $1.006,3357$ & 0,0028 & $5.022,6867$ & 0,0298 & 102,3996 & 0,2743 & 0,2759 \\
GPRM03 & $1.006,3369$ & 0,0030 & $5.022,6870$ & 0,0316 & 102,3983 & 0,2915 & 0,2933 \\
GPRM04 & $1.006,3371$ & 0,0029 & $5.022,6863$ & 0,0308 & 102,3972 & 0,2838 & 0,2855 \\
GPRM05 & $1.006,3379$ & 0,0028 & $5.022,6868$ & 0,0299 & 102,3962 & 0,2758 & 0,2774 \\
GPRM06 & $1.006,3423$ & 0,0019 & $5.022,6874$ & 0,0204 & 102,3915 & 0,1887 & 0,1898 \\
GPRM07 & $1.006,3517$ & 0,0022 & $5.022,6879$ & 0,0237 & 102,3815 & 0,2204 & 0,2217 \\
\hline
\end{tabular}


Tabela 42 - Variação controlada, variação das coordenadas e diferença entre ambas (Distância Mínima - GPR112)

\begin{tabular}{cccccccc}
\hline CONTROLE & \multicolumn{3}{c}{$\begin{array}{c}\text { DIFERENÇAS ENTRE } \\
\text { COORDENADAS }\end{array}$} & \multicolumn{2}{c}{$\begin{array}{c}\text { RESÍDUO ENTRE CONTROLE E } \\
\text { COORDENADAS }\end{array}$} \\
\hline Pontual $(\mathrm{mm})$ & Intervalo $(\mathrm{mm})$ & $\Delta \mathrm{X}(\mathrm{mm})$ & $\Delta \mathrm{Y}(\mathrm{mm})$ & $\Delta \mathrm{Z}(\mathrm{mm})$ & $\mathrm{X}(\mathrm{mm})$ & $\mathrm{Y}(\mathrm{mm})$ & $\mathrm{Z}(\mathrm{mm})$ \\
\hline 1,0 & $0,0-1,0$ & 1,4 & 0,4 & $-1,3$ & $-0,4$ & 0,6 & $-0,3$ \\
1,0 & $1,0-2,0$ & 1,1 & 0,0 & $-0,6$ & $-0,1$ & 1,0 & 0,4 \\
1,0 & $2,0-3,0$ & 1,1 & 0,3 & $-1,3$ & $-0,1$ & 0,7 & $-0,3$ \\
1,0 & $3,0-4,0$ & 0,3 & $-0,7$ & $-1,1$ & 0,7 & 1,7 & $-0,1$ \\
1,0 & $4,0-5,0$ & 0,8 & 0,5 & $-1,0$ & 0,2 & 0,5 & 0,0 \\
5,0 & $5,0-10,0$ & 4,4 & 0,6 & $-4,7$ & 0,6 & 4,4 & 0,3 \\
10,0 & $10,0-20,0$ & 9,4 & 0,5 & $-10,0$ & 0,6 & 0,6 & 0,0 \\
\hline
\end{tabular}




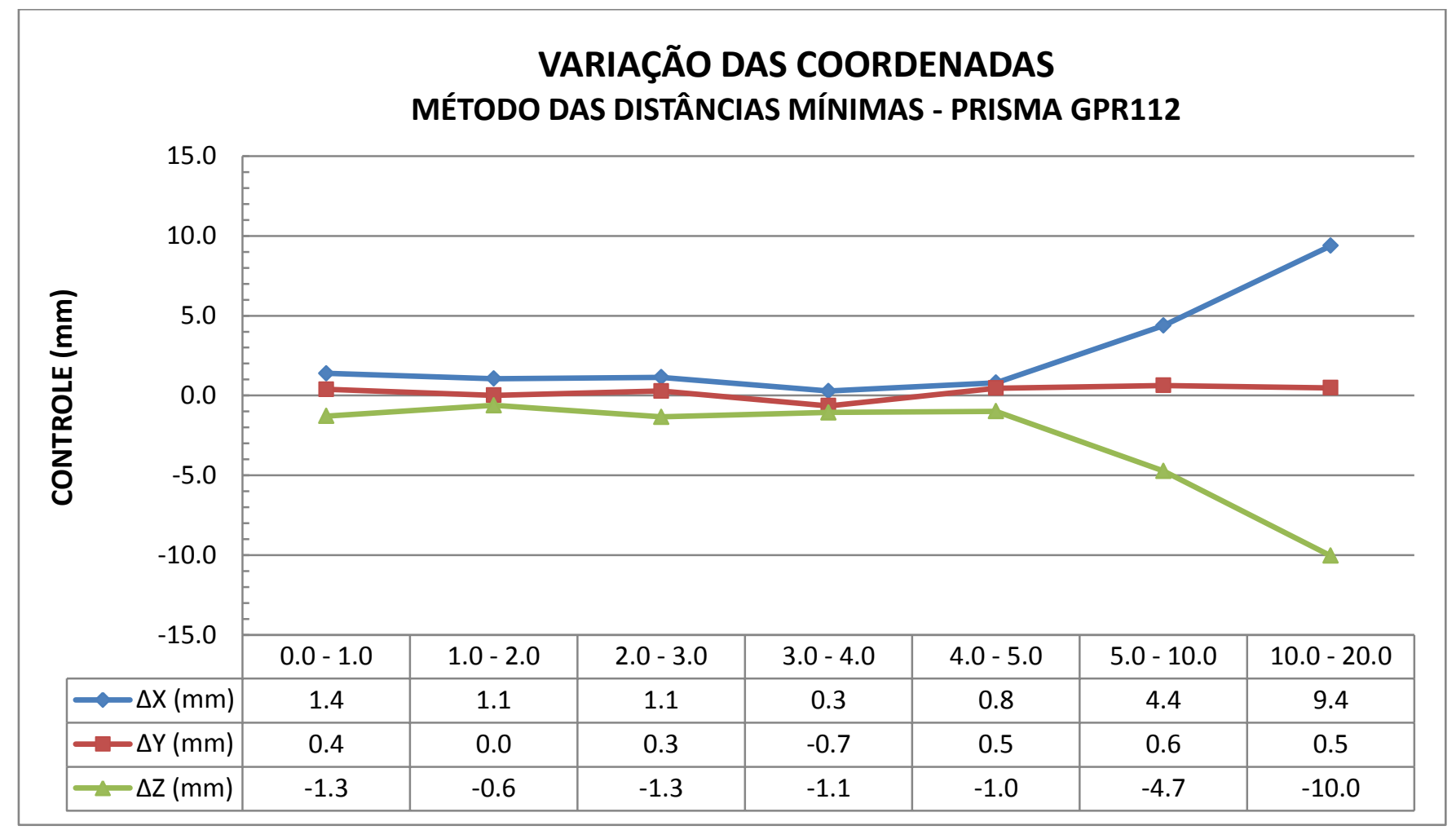

Figura 57 - Variação das coordenadas para o prisma GPR112 (Distância Mínima) 
Tabela 43 - Dados observados e verificação da estabilidade da Base 1 (Distância Mínima - GMP111-0)

MÉTODO DAS DISTÂNCIAS MÍNIMAS - GMP111-0 (0.00 mm)

\section{BASE 1}

\begin{tabular}{lcccccccc}
\hline & \multicolumn{2}{c}{ DADOS OBSERVADOS } & \multicolumn{5}{c}{ ESTABILIDADE DA BASE "RECESSÃO" } \\
\hline PONTOS & Azimute & Zenital & $X(\mathrm{~m})$ & $\sigma_{X}(\mathrm{~mm})$ & $\mathrm{Y}(\mathrm{m})$ & $\sigma_{Y}(\mathrm{~mm})$ & $\mathrm{Z}(\mathrm{m})$ & $\sigma_{Z}(\mathrm{~mm})$ \\
\hline GMPM00 & $15^{\circ} 34^{\prime} 40,0044^{\prime \prime}$ & $83^{\circ} 57^{\prime} 16,8620^{\prime \prime}$ & $1.000,0045$ & 1,4 & $4.999,9977$ & 0,5 & 99,9999 & 1,5 \\
GMPM01 & $15^{\circ} 34^{\prime} 50,2958^{\prime \prime}$ & $83^{\circ} 57^{\prime} 26,8583^{\prime \prime}$ & $1.000,0046$ & 1,4 & $4.999,9976$ & 0,5 & 99,9999 & 1,5 \\
GMPM02 & $15^{\circ} 34^{\prime} 52,6929^{\prime \prime}$ & $83^{\circ} 57^{\prime} 37,4900^{\prime \prime}$ & $1.000,0045$ & 1,4 & $4.999,9976$ & 0,5 & 99,9999 & 1,5 \\
GMPM03 & $15^{\circ} 35^{\prime} 01,5785^{\prime \prime}$ & $83^{\circ} 57^{\prime} 45,2354^{\prime \prime}$ & $1.000,0044$ & 1,4 & $4.999,9977$ & 0,5 & 99,9999 & 1,5 \\
GMPM04 & $15^{\circ} 35^{\prime} 02,8076 "$ & $83^{\circ} 57^{\prime} 54,1203^{\prime \prime}$ & $1.000,0045$ & 1,4 & $4.999,9976$ & 0,5 & 99,9999 & 1,5 \\
GMPM05 & $15^{\circ} 35^{\prime} 12,1816^{\prime \prime}$ & $83^{\circ} 58^{\prime} 02,5858^{\prime \prime}$ & $1.000,0043$ & 1,5 & $4.999,9977$ & 0,4 & 99,9999 & 1,5 \\
GMPM06 & $15^{\circ} 35^{\prime} 49,8554 "$ & $83^{\circ} 58^{\prime} 45,0138^{\prime \prime}$ & $1.000,0045$ & 1,4 & $4.999,9975$ & 0,5 & 99,9999 & 1,5 \\
GMPM07 & $15^{\circ} 37^{\prime} 06,7522^{\prime \prime}$ & $84^{\circ} 00^{\prime} 15,3173^{\prime \prime}$ & $1.000,0047$ & 1,4 & $4.999,9975$ & 0,5 & 99,9999 & 1,5 \\
\hline
\end{tabular}


Tabela 44 - Dados observados e verificação da estabilidade da Base 2 (Distância Mínima - GMP111-0)

\begin{tabular}{lcccccccc}
\hline \multicolumn{7}{c}{ BASE 2 } \\
\hline \multicolumn{7}{c}{ DADOS OBSERVADOS } & \multicolumn{7}{c}{ ESTABILIDADE DA BASE "RECESSÃO" } \\
\hline PONTOS & Azimute & Zenital & $X(\mathrm{~m})$ & $\sigma_{X}(\mathrm{~mm})$ & $Y(\mathrm{~m})$ & $\sigma_{Y}(\mathrm{~mm})$ & $\mathrm{Z}(\mathrm{m})$ & $\sigma_{\mathrm{Z}}(\mathrm{mm})$ \\
\hline GMPM00 & $342^{\circ} 50^{\prime} 02,2543^{\prime \prime}$ & $83^{\circ} 39^{\prime} 59,4056^{\prime \prime}$ & $1.013,1141$ & 1,5 & $5.000,7536$ & 0,5 & 99,9459 & 1,5 \\
GMPM01 & $342^{\circ} 50^{\prime} 19,7833^{\prime \prime}$ & $83^{\circ} 40^{\prime} 09,1615^{\prime \prime}$ & $1.013,1139$ & 1,5 & $5.000,7534$ & 0,5 & 99,9459 & 1,5 \\
GMPM02 & $342^{\circ} 50^{\prime} 20,8677^{\prime \prime}$ & $83^{\circ} 40^{\prime} 19,0393^{\prime \prime}$ & $1.013,1140$ & 1,5 & $5.000,7534$ & 0,6 & 99,9459 & 1,5 \\
GMPM03 & $342^{\circ} 50^{\prime} 29,7955^{\prime \prime}$ & $83^{\circ} 40^{\prime} 27,3486 "$ & $1.013,1140$ & 1,5 & $5.000,7535$ & 0,6 & 99,9459 & 1,5 \\
GMPM04 & $342^{\circ} 50^{\prime} 30,9121^{\prime \prime}$ & $83^{\circ} 40^{\prime} 36,9772 "$ & $1.013,1139$ & 1,4 & $5.000,7535$ & 0,6 & 99,9459 & 1,5 \\
GMPM05 & $342^{\circ} 50^{\prime} 38,4037^{\prime \prime}$ & $83^{\circ} 40^{\prime} 44,4649^{\prime \prime}$ & $1.013,1140$ & 1,5 & $5.000,7535$ & 0,5 & 99,9459 & 1,5 \\
GMPM06 & $342^{\circ} 51^{\prime} 22,6292^{\prime \prime}$ & $83^{\circ} 41^{\prime} 25,7247^{\prime \prime}$ & $1.013,1139$ & 1,4 & $5.000,7535$ & 0,6 & 99,9459 & 1,5 \\
GMPM07 & $342^{\circ} 52^{\prime} 43,6705^{\prime \prime}$ & $83^{\circ} 42^{\prime} 53,0515^{\prime \prime}$ & $1.013,1140$ & 1,5 & $5.000,7536$ & 0,5 & 99,9459 & 1,5 \\
\hline
\end{tabular}


Tabela 45 - Coordenadas dos alvos e precisões aparentes (Distância Mínima - GMP111-0)

COORDENADAS E PRECISÕES AJUSTADAS

\begin{tabular}{lccccccc}
\hline PONTOS & $X(\mathrm{~m})$ & $\sigma_{X}(\mathrm{~mm})$ & $Y(\mathrm{~m})$ & $\sigma_{Y}(\mathrm{~mm})$ & $Z(\mathrm{~m})$ & $\sigma_{Z}(\mathrm{~mm})$ & $\sigma_{X Y Z}(\mathrm{~mm})$ \\
\hline GMPM00 & $1.006,3342$ & 0,0024 & $5.022,7020$ & 0,0262 & 102,4958 & 0,2327 & 0,2342 \\
GMPM01 & $1.006,3357$ & 0,0026 & $5.022,7028$ & 0,0279 & 102,4948 & 0,2473 & 0,2489 \\
GMPM02 & $1.006,3359$ & 0,0020 & $5.022,7029$ & 0,0221 & 102,4936 & 0,1964 & 0,1977 \\
GMPM03 & $1.006,3369$ & 0,0026 & $5.022,7031$ & 0,0279 & 102,4927 & 0,2482 & 0,2498 \\
GMPM04 & $1.006,3371$ & 0,0030 & $5.022,7027$ & 0,0324 & 102,4916 & 0,2881 & 0,2899 \\
GMPM05 & $1.006,3380$ & 0,0025 & $5.022,7028$ & 0,0276 & 102,4907 & 0,2456 & 0,2472 \\
GMPM06 & $1.006,3429$ & 0,0029 & $5.022,7034$ & 0,0310 & 102,4860 & 0,2762 & 0,2779 \\
GMPM07 & $1.006,3523$ & 0,0028 & $5.022,7038$ & 0,0299 & 102,4759 & 0,2671 & 0,2688 \\
\hline
\end{tabular}


Tabela 46 - Variação controlada, variação das coordenadas e diferença entre ambas (Distância Mínima - GMP111-0)

\begin{tabular}{cccccccc}
\hline \multicolumn{2}{c}{ CONTROLE } & \multicolumn{3}{c}{$\begin{array}{c}\text { DIFERENÇAS ENTRE } \\
\text { COORDENADAS }\end{array}$} & \multicolumn{3}{c}{$\begin{array}{c}\text { RESíDUO ENTRE CONTROLE E } \\
\text { COORDENADAS }\end{array}$} \\
\hline Pontual $(\mathrm{mm})$ & Intervalo $(\mathrm{mm})$ & $\Delta \mathrm{X}(\mathrm{mm})$ & $\Delta \mathrm{Y}(\mathrm{mm})$ & $\Delta \mathrm{Z}(\mathrm{mm})$ & $\mathrm{X}(\mathrm{mm})$ & $\mathrm{Y}(\mathrm{mm})$ & $\mathrm{Z}(\mathrm{mm})$ \\
\hline 1,0 & $0,0-1,0$ & 1,6 & 0,7 & $-1,0$ & $-0,6$ & 0,3 & 0,0 \\
1,0 & $1,0-2,0$ & 0,2 & 0,1 & $-1,2$ & 0,8 & 0,9 & $-0,2$ \\
1,0 & $2,0-3,0$ & 1,0 & 0,2 & $-0,9$ & 0,0 & 0,8 & 0,1 \\
1,0 & $3,0-4,0$ & 0,2 & $-0,4$ & $-1,1$ & 0,8 & 1,4 & $-0,1$ \\
1,0 & $4,0-5,0$ & 0,9 & 0,2 & $-0,9$ & 0,1 & 0,8 & 0,1 \\
5,0 & $5,0-10,0$ & 4,9 & 0,6 & $-4,7$ & 0,1 & 4,4 & 0,3 \\
10,0 & $10,0-20,0$ & 9,4 & 0,4 & $-10,1$ & 0,6 & 0,6 & $-0,1$ \\
\hline
\end{tabular}




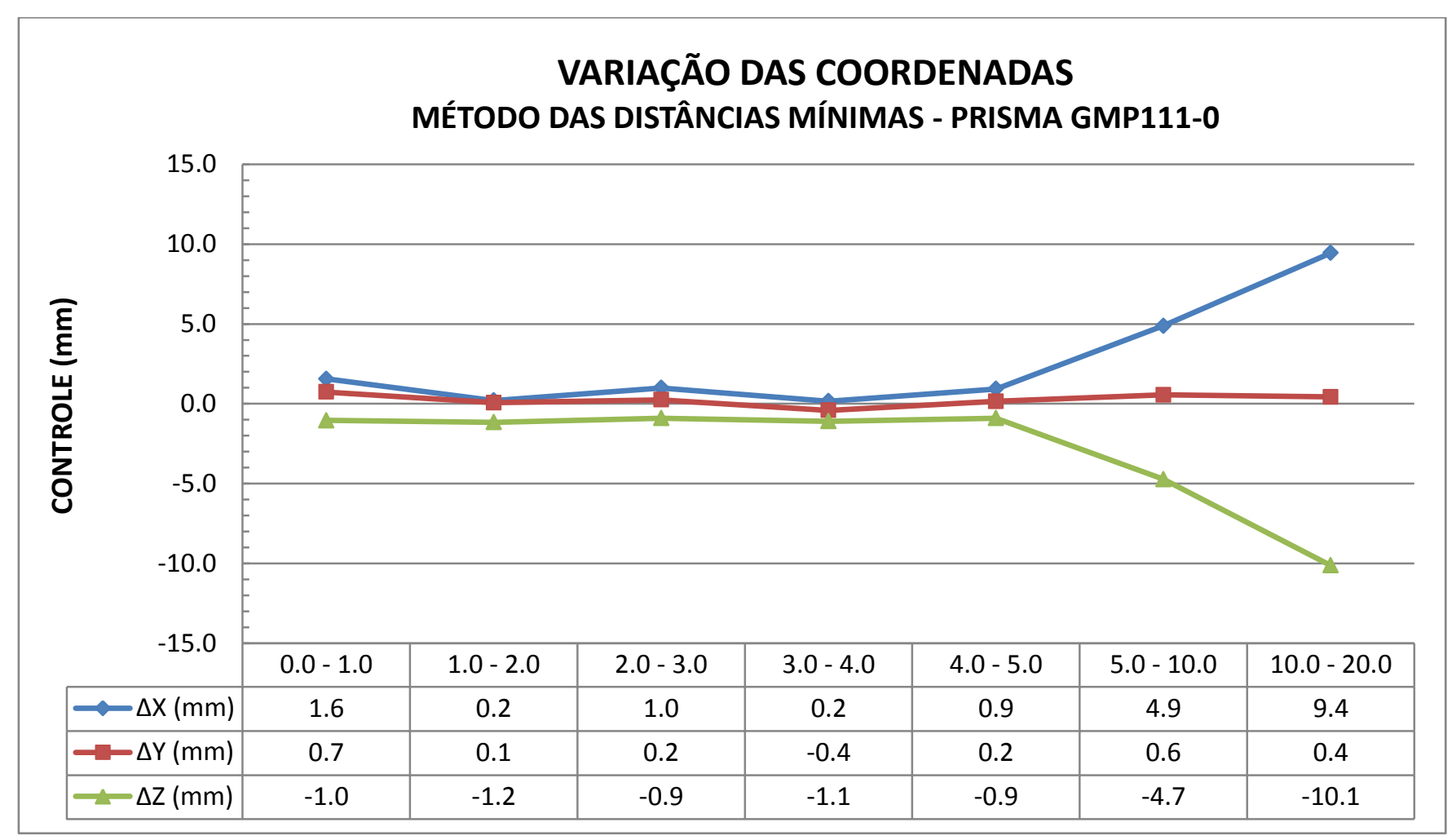

Figura 58 - Variação das coordenadas para o prisma GMP111-0 (Distância Mínima) 
Tabela 47 - Dados observados e verificação da estabilidade da Base 1 (Distância Mínima - GMP104)

MÉTODO DAS DISTÂNCIAS MÍNIMAS - GMP104 $(8.90$ mm)

\section{BASE 1}

\begin{tabular}{|c|c|c|c|c|c|c|c|c|}
\hline \multirow[b]{2}{*}{ PONTOS } & \multicolumn{2}{|c|}{ DADOS OBSERVADOS } & \multicolumn{6}{|c|}{ ESTABILIDADE DA BASE "RECESSÃO" } \\
\hline & Azimute & Zenital & $X(m)$ & $\sigma_{x}(\mathrm{~mm})$ & $Y(m)$ & $\sigma_{Y}(\mathrm{~mm})$ & $Z(m)$ & $\sigma_{z}(\mathrm{~mm})$ \\
\hline GMPL00 & $15^{\circ} 34^{\prime} 58,2158^{\prime \prime}$ & $84^{\circ} 11^{\prime} 07,7288^{\prime \prime}$ & $1.000,0046$ & 1,5 & $4.999,9976$ & 0,5 & 99,9999 & 1,5 \\
\hline GMPL01 & $15^{\circ} 35^{\prime} 11,1633^{\prime \prime}$ & $84^{\circ} 11^{\prime} 17,4850^{\prime \prime}$ & $1.000,0045$ & 1,4 & $4.999,9976$ & 0,5 & 99,9999 & 1,5 \\
\hline GMPL02 & $15^{\circ} 35^{\prime} 16,8283^{\prime \prime}$ & $84^{\circ} 11^{\prime} 26,6141^{\prime \prime}$ & $1.000,0044$ & 1,4 & 4.999,9977 & 0,5 & 99,9998 & 1,5 \\
\hline GMPL03 & $15^{\circ} 35^{\prime} 21,4672 "$ & $84^{\circ} 11^{\prime} 35,6989^{\prime \prime}$ & $1.000,0043$ & 1,5 & $4.999,9976$ & 0,6 & 99,9999 & 1,5 \\
\hline GMPL04 & $15^{\circ} 35^{\prime} 32,0822 "$ & $84^{\circ} 11^{\prime} 44,2433^{\prime \prime}$ & $1.000,0043$ & 1,4 & $4.999,9977$ & 0,5 & 99,9999 & 1,5 \\
\hline GMPL05 & $15^{\circ} 35^{\prime} 34,1559 "$ & $84^{\circ} 11^{\prime} 53,7687^{\prime \prime}$ & $1.000,0045$ & 1,4 & 4.999,9977 & 0,5 & 99,9999 & 1,5 \\
\hline GMPL06 & $15^{\circ} 36^{\prime} 11,4616^{\prime \prime}$ & $84^{\circ} 12^{\prime} 38,6385^{\prime \prime}$ & $1.000,0044$ & 1,5 & $4.999,9976$ & 0,5 & 99,9999 & 1,5 \\
\hline GMPL07 & $15^{\circ} 37^{\prime} 31,6392 "$ & $84^{\circ} 14^{\prime} 05,9805^{\prime \prime}$ & $1.000,0044$ & 1,5 & $4.999,9976$ & 0,5 & 99,9999 & 1,5 \\
\hline
\end{tabular}


Tabela 48 - Dados observados e verificação da estabilidade da Base 2 (Distância Mínima - GMP104)

\begin{tabular}{|c|c|c|c|c|c|c|c|c|}
\hline \multicolumn{9}{|c|}{ BASE 2} \\
\hline \multirow[b]{2}{*}{ PONTOS } & \multicolumn{2}{|c|}{ DADOS OBSERVADOS } & \multicolumn{6}{|c|}{ ESTABILIDADE DA BASE "RECESSÃO" } \\
\hline & Azimute & Zenital & $X(m)$ & $\sigma_{X}(\mathrm{~mm})$ & $Y(m)$ & $\sigma_{Y}(\mathrm{~mm})$ & $\mathrm{Z}(\mathrm{m})$ & $\sigma_{z}(\mathrm{~mm})$ \\
\hline GMPL00 & $342^{\circ} 49^{\prime} 51,7825^{\prime \prime}$ & $83^{\circ} 54^{\prime} 09,6713^{\prime \prime}$ & $1.013,1139$ & 1,5 & $5.000,7533$ & 0,5 & 99,9459 & 1,5 \\
\hline GMPL01 & $342^{\circ} 50^{\prime} 01,8644^{\prime \prime}$ & $83^{\circ} 54^{\prime} 20,3833^{\prime \prime}$ & $1.013,1141$ & 1,5 & $5.000,7535$ & 0,5 & 99,9459 & 1,5 \\
\hline GMPL02 & $342^{\circ} 50^{\prime} 07,9235^{\prime \prime}$ & $83^{\circ} 54^{\prime} 28,5022^{\prime \prime}$ & $1.013,1139$ & 1,5 & $5.000,7536$ & 0,4 & 99,9458 & 1,5 \\
\hline GMPL03 & $342^{\circ} 50^{\prime} 19,6600^{\prime \prime}$ & $83^{\circ} 54^{\prime} 36,6997 "$ & $1.013,1135$ & 1,3 & $5.000,7534$ & 0,5 & 99,9459 & 1,5 \\
\hline GMPL04 & $342^{\circ} 50^{\prime} 25,7112^{\prime \prime}$ & $83^{\circ} 54^{\prime} 45,9366^{\prime \prime}$ & $1.013,1139$ & 1,5 & $5.000,7535$ & 0,4 & 99,9459 & 1,5 \\
\hline GMPL05 & $342^{\circ} 50^{\prime} 27,7468^{\prime \prime}$ & $83^{\circ} 54^{\prime} 55,7237^{\prime \prime}$ & $1.013,1139$ & 1,5 & $5.000,7536$ & 0,6 & 99,9459 & 1,5 \\
\hline GMPL06 & $342^{\circ} 51^{\prime} 08,8540^{\prime \prime}$ & $83^{\circ} 55^{\prime} 38,5580^{\prime \prime}$ & $1.013,1139$ & 1,5 & $5.000,7536$ & 0,6 & 99,9459 & 1,5 \\
\hline GMPL07 & $342^{\circ} 52^{\prime} 31,4428^{\prime \prime}$ & $83^{\circ} 57^{\prime} 03,5035^{\prime \prime}$ & $1.013,1142$ & 1,5 & $5.000,7536$ & 0,6 & 99,9459 & 1,5 \\
\hline
\end{tabular}


Tabela 49 - Coordenadas dos alvos e precisões aparentes (Distância Mínima - GMP104)

\begin{tabular}{cccccccc}
\hline \multicolumn{7}{c}{ COORDENADAS E PRECISÕES AJUSTADAS } \\
\hline PONTOS & $X(\mathrm{~m})$ & $\sigma_{X}(\mathrm{~mm})$ & $Y(\mathrm{~m})$ & $\sigma_{Y}(\mathrm{~mm})$ & $\mathrm{Z}(\mathrm{m})$ & $\sigma_{Z}(\mathrm{~mm})$ & $\sigma_{X Y Z}(\mathrm{~mm})$ \\
\hline GMPL00 & $1.006,3347$ & 0,0018 & $5.022,6956$ & 0,0191 & 102,3993 & 0,1766 & 0,1776 \\
GMPL01 & $1.006,3361$ & 0,0027 & $5.022,6956$ & 0,0289 & 102,3981 & 0,2663 & 0,2678 \\
GMPL02 & $1.006,3366$ & 0,0022 & $5.022,6956$ & 0,0236 & 102,3970 & 0,2177 & 0,2190 \\
GMPL03 & $1.006,3373$ & 0,0018 & $5.022,6963$ & 0,0191 & 102,3962 & 0,1764 & 0,1774 \\
GMPL04 & $1.006,3385$ & 0,0023 & $5.022,6961$ & 0,0251 & 102,3952 & 0,2317 & 0,2331 \\
GMPL05 & $1.006,3389$ & 0,0025 & $5.022,6958$ & 0,0267 & 102,3941 & 0,2464 & 0,2479 \\
GMPL06 & $1.006,3434$ & 0,0021 & $5.022,6966$ & 0,0224 & 102,3891 & 0,2073 & 0,2085 \\
GMPL07 & $1.006,3531$ & 0,0023 & $5.022,6973$ & 0,0242 & 102,3794 & 0,2255 & 0,2268 \\
\hline
\end{tabular}


Tabela 50 - Variação controlada, variação das coordenadas e diferença entre ambas (Distância Mínima - GMP104)

\begin{tabular}{cccccccc}
\hline & \multicolumn{3}{c}{ CONTROLE } & \multicolumn{3}{c}{$\begin{array}{c}\text { DIFERENÇAS ENTRE } \\
\text { COORDENADAS }\end{array}$} & \multicolumn{2}{c}{$\begin{array}{c}\text { RESÍ́DO ENTRE CONTROLE E } \\
\text { COORDENADAS }\end{array}$} \\
\hline Pontual $(\mathrm{mm})$ & Intervalo $(\mathrm{mm})$ & $\Delta \mathrm{X}(\mathrm{mm})$ & $\Delta \mathrm{Y}(\mathrm{mm})$ & $\Delta \mathrm{Z}(\mathrm{mm})$ & $\mathrm{X}(\mathrm{mm})$ & $\mathrm{Y}(\mathrm{mm})$ & $\mathrm{Z}(\mathrm{mm})$ \\
\hline 1,0 & $0,0-1,0$ & 1,4 & 0,0 & $-1,2$ & $-0,4$ & 1,0 & $-0,2$ \\
1,0 & $1,0-2,0$ & 0,5 & 0,0 & $-1,1$ & 0,5 & 1,0 & $-0,1$ \\
1,0 & $2,0-3,0$ & 0,7 & 0,7 & $-0,8$ & 0,3 & 0,3 & 0,2 \\
1,0 & $3,0-4,0$ & 1,2 & $-0,2$ & $-1,0$ & $-0,2$ & 1,2 & 0,0 \\
1,0 & $4,0-5,0$ & 0,4 & $-0,3$ & $-1,1$ & 0,6 & 1,3 & $-0,1$ \\
5,0 & $5,0-10,0$ & 4,6 & 0,7 & $-4,9$ & 0,4 & 4,3 & 0,1 \\
10,0 & $10,0-20,0$ & 9,7 & 0,7 & $-9,8$ & 0,3 & 0,3 & 0,2 \\
\hline
\end{tabular}




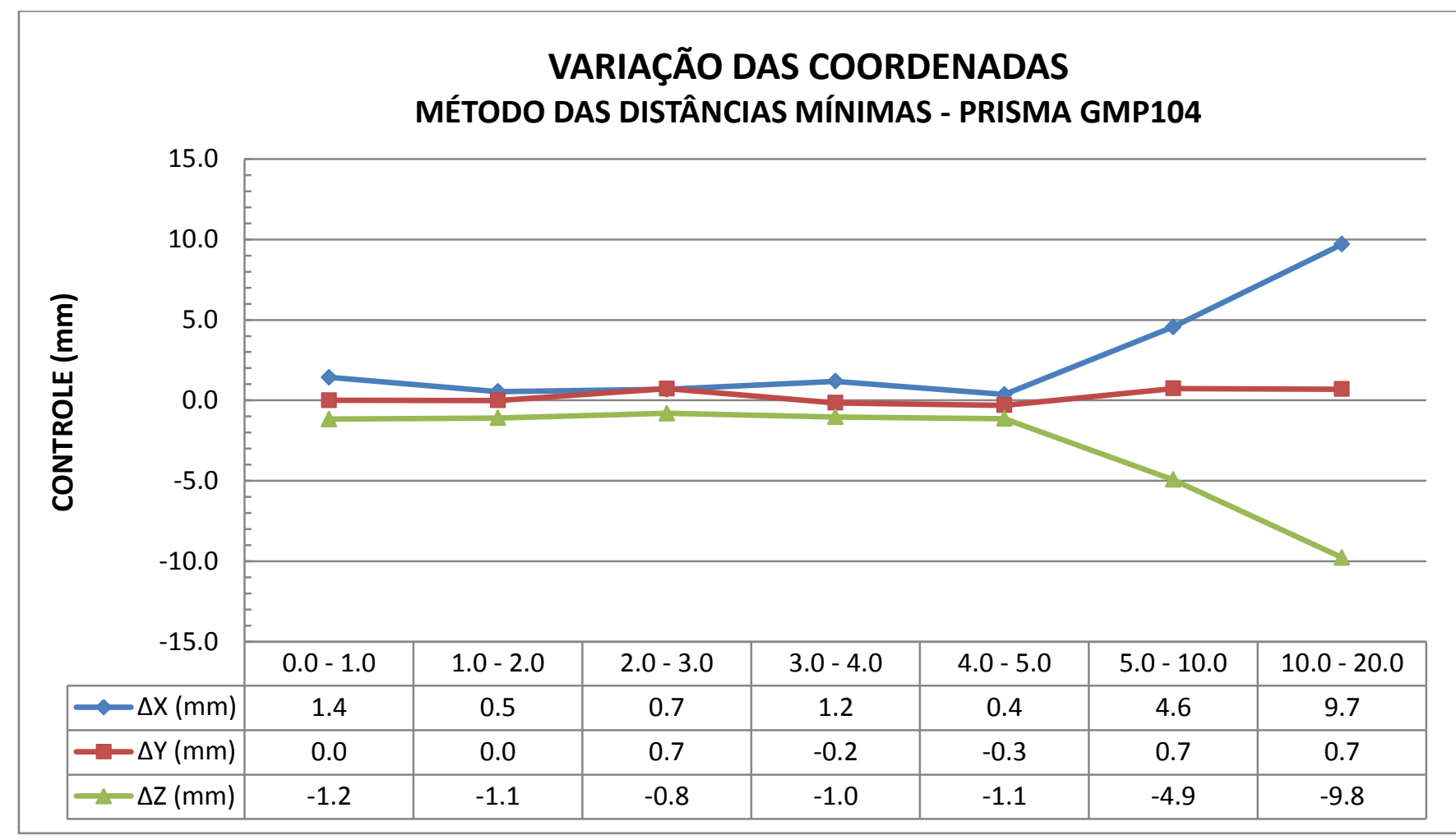

Figura 59 - Variação das coordenadas para o prisma GMP104 (Distância Mínima) 
Tabela 51 - Dados observados e verificação da estabilidade da Base 1 (Distância Mínima - GRZ101)

\begin{tabular}{|c|c|c|c|c|c|c|c|c|}
\hline \multicolumn{9}{|c|}{ MÉTODO DAS DISTÂNCIAS MÍNIMAS - GRZ101 (0.0mm) } \\
\hline \multicolumn{9}{|c|}{ BASE 1} \\
\hline \multicolumn{3}{|c|}{ DADOS OBSERVADOS } & \multicolumn{6}{|c|}{ ESTABILIDADE DA BASE "RECESSÃO" } \\
\hline PONTOS & Azimute & Zenital & $X(m)$ & $\sigma_{x}(m m)$ & $\mathrm{Y}(\mathrm{m})$ & $\sigma_{Y}(\mathrm{~mm})$ & $Z(m)$ & $\sigma_{\mathrm{Z}}(\mathrm{mm})$ \\
\hline GRZ00 & $15^{\circ} 35^{\prime} 10,9810^{\prime \prime}$ & $84^{\circ} 07^{\prime} 03,3306^{\prime \prime}$ & $1.000,0044$ & 1,5 & $4.999,9976$ & 0,5 & 100,0000 & 1,5 \\
\hline GRZ01 & $15^{\circ} 35^{\prime} 18,7146 "$ & $84^{\circ} 07^{\prime} 14,0777^{\prime \prime}$ & $1.000,0044$ & 1,4 & $4.999,9977$ & 0,5 & 99,9999 & 1,5 \\
\hline GRZ02 & $15^{\circ} 35^{\prime} 19,7333^{\prime \prime}$ & $84^{\circ} 07^{\prime} 22,8338^{\prime \prime}$ & $1.000,0044$ & 1,4 & $4.999,9976$ & 0,5 & 99,9999 & 1,5 \\
\hline GRZ03 & $15^{\circ} 35^{\prime} 36,4925 "$ & $84^{\circ} 07^{\prime} 30,0421^{\prime \prime}$ & $1.000,0043$ & 1,5 & $4.999,9977$ & 0,5 & 99,9999 & 1,5 \\
\hline GRZ04 & $15^{\circ} 35^{\prime} 37,0981^{\prime \prime}$ & $84^{\circ} 07^{\prime} 38,0044^{\prime \prime}$ & $1.000,0046$ & 1,4 & $4.999,9976$ & 0,4 & 99,9999 & 1,5 \\
\hline GRZ05 & $15^{\circ} 35^{\prime} 38,3900^{\prime \prime}$ & $84^{\circ} 07^{\prime} 48,3516^{\prime \prime}$ & $1.000,0045$ & 1,4 & $4.999,9977$ & 0,5 & 99,9999 & 1,5 \\
\hline GRZ06 & $15^{\circ} 36^{\prime} 21,1632 "$ & $84^{\circ} 08^{\prime} 31,8357^{\prime \prime}$ & $1.000,0044$ & 1,4 & $4.999,9976$ & 0,6 & 99,9999 & 1,5 \\
\hline GRZ07 & $15^{\circ} 37^{\prime} 40,6897^{\prime \prime}$ & $84^{\circ} 10^{\prime} 03,4119^{\prime \prime}$ & $1.000,0045$ & 1,4 & $4.999,9977$ & 0,5 & 99,9999 & 1,5 \\
\hline
\end{tabular}


Tabela 52 - Dados observados e verificação da estabilidade da Base 2 (Distância Mínima - GRZ101)

\begin{tabular}{ccccccccc}
\hline \multicolumn{7}{c}{ BASE 2 } \\
\hline \multicolumn{7}{c}{ DADOS OBSERVADOS } & \multicolumn{7}{c}{ ESTABILIDADE DA BASE "RECESSÃO" } \\
\hline PONTOS & Azimute & Zenital & $X(\mathrm{~m})$ & $\sigma_{X}(\mathrm{~mm})$ & $Y(\mathrm{~m})$ & $\sigma_{Y}(\mathrm{~mm})$ & $\mathrm{Z}(\mathrm{m})$ & $\sigma_{Z}(\mathrm{~mm})$ \\
\hline GRZ00 & $342^{\circ} 49^{\prime} 21,0292^{\prime \prime}$ & $83^{\circ} 49^{\prime} 50,5459^{\prime \prime}$ & $1.013,1140$ & 1,5 & $5.000,7531$ & 0,5 & 99,9459 & 1,5 \\
GRZ01 & $342^{\circ} 49^{\prime} 23,0446^{\prime \prime}$ & $8^{\circ} 49^{\prime} 59,2830^{\prime \prime}$ & $1.013,1144$ & 1,6 & $5.000,7535$ & 0,4 & 99,9459 & 1,5 \\
GRZ02 & $342^{\circ} 49^{\prime} 31,9328^{\prime \prime}$ & $8^{\circ} 50^{\prime} 09,0795^{\prime \prime}$ & $1.013,1140$ & 1,6 & $5.000,7535$ & 0,6 & 99,9459 & 1,5 \\
GRZ03 & $342^{\circ} 49^{\prime} 41,4397^{\prime \prime}$ & $8^{\circ} 50^{\prime} 18,6849^{\prime \prime}$ & $1.013,1141$ & 1,4 & $5.000,7537$ & 0,4 & 99,9459 & 1,5 \\
GRZ04 & $342^{\circ} 49^{\prime} 43,9450^{\prime \prime}$ & $8^{\circ} 50^{\prime} 25,3145^{\prime \prime}$ & $1.013,1146$ & 1,7 & $5.000,7536$ & 0,8 & 99,9459 & 1,5 \\
GRZ05 & $342^{\circ} 49^{\prime} 52,1264^{\prime \prime}$ & $83^{\circ} 50^{\prime} 33,8797^{\prime \prime}$ & $1.013,1139$ & 1,5 & $5.000,7535$ & 0,5 & 99,9459 & 1,5 \\
GRZ06 & $342^{\circ} 50^{\prime} 44,8146^{\prime \prime}$ & $8^{\circ} 51^{\prime} 17,1418^{\prime \prime}$ & $1.013,1133$ & 1,4 & $5.000,7529$ & 0,8 & 99,9459 & 1,5 \\
GRZ07 & $342^{\circ} 51^{\prime} 57,4058^{\prime \prime}$ & $83^{\circ} 52^{\prime} 45,8747^{\prime \prime}$ & $1.013,1141$ & 1,5 & $5.000,7538$ & 0,7 & 99,9459 & 1,5 \\
\hline
\end{tabular}


Tabela 53 - Coordenadas dos alvos e precisões aparentes (Distância Mínima - GRZ101)

\begin{tabular}{cccccccc}
\hline \multicolumn{7}{c}{ COORDENADAS E PRECISÕES AJUSTADAS } \\
\hline PONTOS & $X(\mathrm{~m})$ & $\sigma_{X}(\mathrm{~mm})$ & $Y(\mathrm{~m})$ & $\sigma_{Y}(\mathrm{~mm})$ & $\mathrm{Z}(\mathrm{m})$ & $\sigma_{Z}(\mathrm{~mm})$ & $\sigma_{X Y Z}(\mathrm{~mm})$ \\
\hline GPRC00 & $1.006,3337$ & 0,0028 & $5.022,6873$ & 0,0302 & 102,4272 & 0,2753 & 0,2770 \\
GPRC01 & $1.006,3345$ & 0,0043 & $5.022,6871$ & 0,0458 & 102,4260 & 0,4175 & 0,4200 \\
GPRC02 & $1.006,3349$ & 0,0036 & $5.022,6879$ & 0,0385 & 102,4251 & 0,3511 & 0,3532 \\
GPRC03 & $1.006,3365$ & 0,0018 & $5.022,6869$ & 0,0191 & 102,4240 & 0,1742 & 0,1753 \\
GPRC04 & $1.006,3370$ & 0,0026 & $5.022,6875$ & 0,0280 & 102,4232 & 0,2560 & 0,2576 \\
GPRC05 & $1.006,3372$ & 0,0038 & $5.022,6879$ & 0,0399 & 102,4222 & 0,3644 & 0,3666 \\
GPRC06 & $1.006,3423$ & 0,0031 & $5.022,6885$ & 0,0330 & 102,4173 & 0,3018 & 0,3036 \\
GPRC07 & $1.006,3518$ & 0,0029 & $5.022,6885$ & 0,0309 & 102,4070 & 0,2835 & 0,2852 \\
\hline
\end{tabular}


Tabela 54 - Variação controlada, variação das coordenadas e diferença entre ambas (Distância Mínima - GRZ101)

\begin{tabular}{cccccccc}
\hline & & \multicolumn{3}{c}{$\begin{array}{c}\text { DIFERENÇAS ENTRE } \\
\text { COORDENADAS }\end{array}$} & \multicolumn{2}{c}{$\begin{array}{c}\text { RESÍDUO ENTRE CONTROLE E } \\
\text { COORDENADAS }\end{array}$} \\
\hline Pontual $(\mathrm{mm})$ & Intervalo $(\mathrm{mm})$ & $\Delta \mathrm{X}(\mathrm{mm})$ & $\Delta \mathrm{Y}(\mathrm{mm})$ & $\Delta \mathrm{Z}(\mathrm{mm})$ & $\mathrm{X}(\mathrm{mm})$ & $\mathrm{Y}(\mathrm{mm})$ & $\mathrm{Z}(\mathrm{mm})$ \\
\hline 1,0 & $0,0-1,0$ & 0,0008 & $-0,2$ & $-1,2$ & 0,2 & 1,2 & $-0,2$ \\
1,0 & $1,0-2,0$ & 0,0004 & 0,8 & $-1,0$ & 0,6 & 0,2 & 0,0 \\
1,0 & $2,0-3,0$ & 0,0016 & $-1,0$ & $-1,1$ & $-0,6$ & 2,0 & $-0,1$ \\
1,0 & $3,0-4,0$ & 0,0006 & 0,6 & $-0,8$ & 0,4 & 0,4 & 0,2 \\
1,0 & $4,0-5,0$ & 0,0001 & 0,3 & $-1,1$ & 0,9 & 0,7 & $-0,1$ \\
5,0 & $5,0-10,0$ & 0,0052 & 0,6 & $-4,9$ & $-0,2$ & 4,4 & 0,1 \\
10,0 & $10,0-20,0$ & 0,0095 & 0,0 & $-10,3$ & 0,5 & 0,5 & $-0,3$ \\
\hline
\end{tabular}




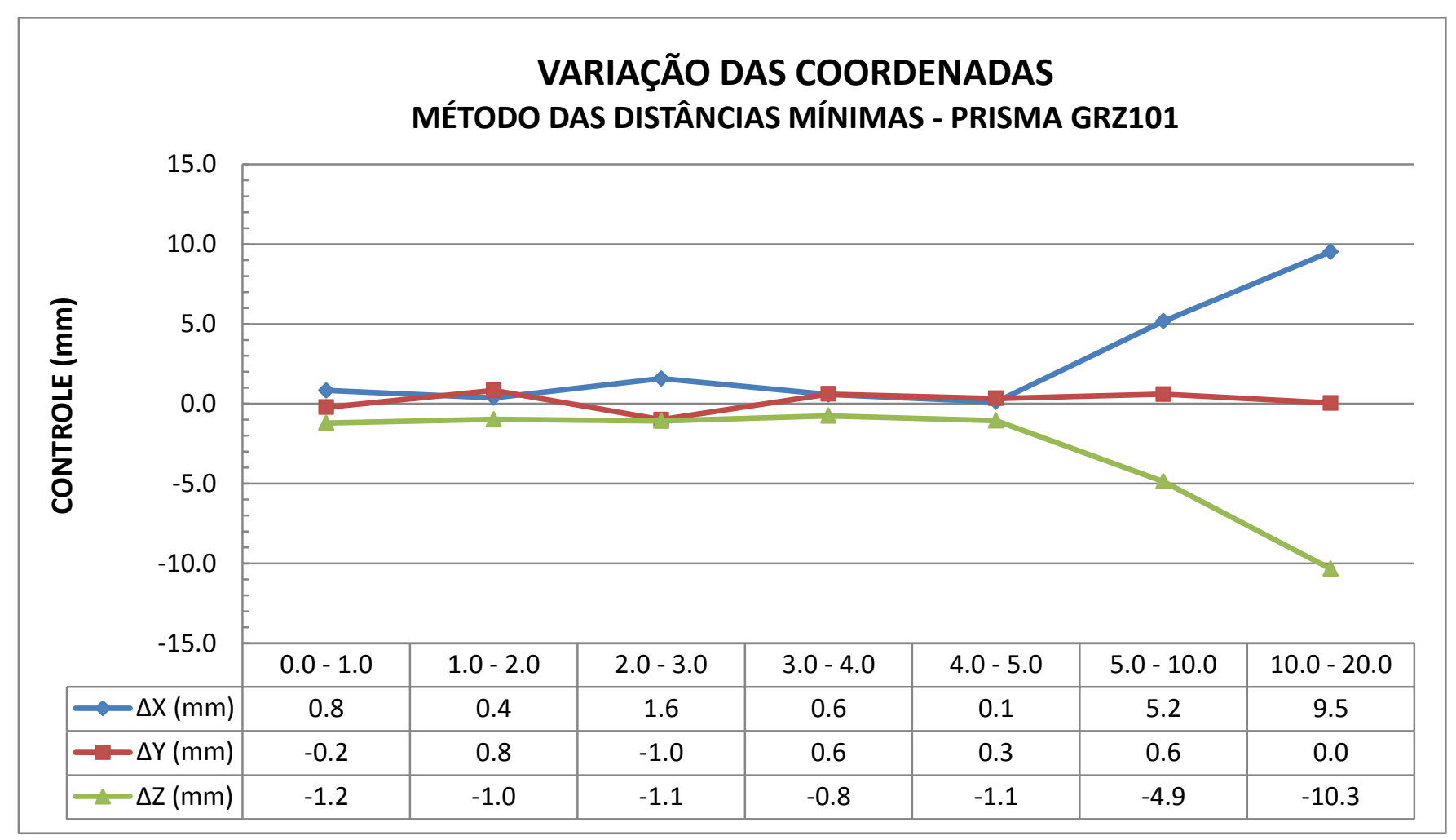

Figura 60 - Variação das coordenadas para o prisma GRZ101 (Distância Mínima) 
Tabela 55 - Dados observados e verificação da estabilidade da Base 1 (Distância Mínima - Fita Refletiva)

\begin{tabular}{|c|c|c|c|c|c|c|c|c|}
\hline \multicolumn{9}{|c|}{ MÉTODO DAS DISTÂNCIAS MÍNIMAS - FITA REFLETIVA (34.4mm) } \\
\hline \multicolumn{9}{|c|}{ BASE 1} \\
\hline \multicolumn{3}{|c|}{ DADOS OBSERVADOS } & \multicolumn{6}{|c|}{ ESTABILIDADE DA BASE "RECESSÃO" } \\
\hline PONTOS & Azimute & Zenital & $X(m)$ & $\sigma_{X}(\mathrm{~mm})$ & $\mathrm{Y}(\mathrm{m})$ & $\sigma_{Y}(\mathrm{~mm})$ & $\mathrm{Z}(\mathrm{m})$ & $\sigma_{\mathrm{Z}}(\mathrm{mm})$ \\
\hline FR00 & $15^{\circ} 34^{\prime} 56,6784^{\prime \prime}$ & $84^{\circ} 27^{\prime} 26,3816^{\prime \prime}$ & $1.000,0045$ & 1,4 & $4.999,9977$ & 0,5 & 99,9998 & 1,4 \\
\hline FR01 & $15^{\circ} 34^{\prime} 59,7940 "$ & $84^{\circ} 27^{\prime} 33,3982^{\prime \prime}$ & $1.000,0045$ & 1,4 & $4.999,9975$ & 0,4 & 99,9999 & 1,5 \\
\hline FR02 & $15^{\circ} 35^{\prime} 13,3244^{\prime \prime}$ & $84^{\circ} 27^{\prime} 44,8378^{\prime \prime}$ & $1.000,0044$ & 1,4 & $4.999,9975$ & 0,5 & 99,9999 & 1,5 \\
\hline FR03 & $15^{\circ} 35^{\prime} 23,5576 "$ & $84^{\circ} 27^{\prime} 57,3758^{\prime \prime}$ & $1.000,0046$ & 1,5 & $4.999,9974$ & 0,5 & 99,9999 & 1,5 \\
\hline FR04 & $15^{\circ} 35^{\prime} 26,9878 "$ & $84^{\circ} 28^{\prime} 00,2907^{\prime \prime}$ & $1.000,0044$ & 1,5 & $4.999,9976$ & 0,5 & 99,9999 & 1,5 \\
\hline FR05 & $15^{\circ} 35^{\prime} 32,2639^{\prime \prime}$ & $84^{\circ} 28^{\prime} 15,7757^{\prime \prime}$ & $1.000,0046$ & 1,5 & $4.999,9974$ & 0,5 & 99,9999 & 1,5 \\
\hline FR06 & $15^{\circ} 36^{\prime} 10,6850 "$ & $84^{\circ} 29^{\prime} 02,1145^{\prime \prime}$ & $1.000,0046$ & 1,4 & $4.999,9974$ & 0,5 & 99,9999 & 1,5 \\
\hline FR07 & $15^{\circ} 37^{\prime} 37,8931^{\prime \prime}$ & $84^{\circ} 30^{\prime} 26,3643^{\prime \prime}$ & $1.000,0044$ & 1,4 & $4.999,9977$ & 0,5 & 99,9999 & 1,5 \\
\hline
\end{tabular}


Tabela 56 - Dados observados e verificação da estabilidade da Base 2 (Distância Mínima - Fita Refletiva)

\begin{tabular}{|c|c|c|c|c|c|c|c|c|}
\hline \multicolumn{9}{|c|}{ BASE 2} \\
\hline \multirow[b]{2}{*}{ PONTOS } & \multicolumn{2}{|c|}{ DADOS OBSERVADOS } & \multicolumn{6}{|c|}{ ESTABILIDADE DA BASE "RECESSÃO" } \\
\hline & Azimute & Zenital & $X(m)$ & $\sigma_{X}(m m)$ & $Y(m)$ & $\sigma_{Y}(\mathrm{~mm})$ & $\mathrm{Z}(\mathrm{m})$ & $\sigma_{z}(\mathrm{~mm})$ \\
\hline FR00 & $342^{\circ} 48^{\prime} 51,0885^{\prime \prime}$ & $84^{\circ} 11^{\prime} 00,2146 "$ & $1.013,1143$ & 1,5 & $5.000,7536$ & 0,6 & 99,9458 & 1,5 \\
\hline FR01 & $342^{\circ} 48^{\prime} 53,8651^{\prime \prime}$ & $84^{\circ} 11^{\prime} 06,8993 "$ & $1.013,1138$ & 1,4 & $5.000,7535$ & 0,5 & 99,9459 & 1,5 \\
\hline FR02 & $342^{\circ} 49^{\prime} 06,4329 "$ & $84^{\circ} 11^{\prime} 23,1139 "$ & $1.013,1140$ & 1,6 & $5.000,7532$ & 0,6 & 99,9459 & 1,5 \\
\hline FR03 & $342^{\circ} 49^{\prime} 16,8890^{\prime \prime}$ & $84^{\circ} 11^{\prime} 25,9649 "$ & $1.013,1139$ & 1,5 & $5.000,7534$ & 0,7 & 99,9458 & 1,5 \\
\hline FR04 & $342^{\circ} 49^{\prime} 19,3800^{\prime \prime}$ & $84^{\circ} 11^{\prime} 32,2888^{\prime \prime}$ & $1.013,1144$ & 1,5 & $5.000,7538$ & 0,5 & 99,9459 & 1,5 \\
\hline FR05 & $342^{\circ} 49^{\prime} 21,8111^{\prime \prime}$ & $84^{\circ} 11^{\prime} 39,7079 "$ & $1.013,1143$ & 1,4 & $5.000,7538$ & 0,5 & 99,9458 & 1,5 \\
\hline FR06 & $342^{\circ} 50^{\prime} 17,4490^{\prime \prime}$ & $84^{\circ} 12^{\prime} 30,3708^{\prime \prime}$ & $1.013,1139$ & 1,4 & $5.000,7532$ & 0,5 & 99,9459 & 1,5 \\
\hline FR07 & $342^{\circ} 51^{\prime} 35,2470^{\prime \prime}$ & $84^{\circ} 13^{\prime} 59,6218 "$ & $1.013,1141$ & 1,4 & $5.000,7536$ & 0,4 & 99,9456 & 1,5 \\
\hline
\end{tabular}


Tabela 57 - Coordenadas dos alvos e precisões aparentes (Distância Mínima - Fita Refletiva)

\begin{tabular}{cccccccc}
\hline \multicolumn{7}{c}{ COORDENADAS E PRECISÕES AJUSTADAS } \\
\hline PONTOS & $X(\mathrm{~m})$ & $\sigma_{X}(\mathrm{~mm})$ & $Y(\mathrm{~m})$ & $\sigma_{Y}(\mathrm{~mm})$ & $\mathrm{Z}(\mathrm{m})$ & $\sigma_{Z}(\mathrm{~mm})$ & $\sigma_{X Y Z}(\mathrm{~mm})$ \\
\hline FR00 & $1.006,3314$ & 0,0052 & $5.022,6848$ & 0,0540 & 102,2849 & 0,5220 & 0,5248 \\
FR01 & $1.006,3315$ & 0,0051 & $5.022,6853$ & 0,0529 & 102,2841 & 0,5112 & 0,5139 \\
FR02 & $1.006,3330$ & 0,0078 & $5.022,6850$ & 0,0814 & 102,2825 & 0,7871 & 0,7914 \\
FR03 & $1.006,3343$ & 0,0033 & $5.022,6851$ & 0,0342 & 102,2816 & 0,3309 & 0,3327 \\
FR04 & $1.006,3349$ & 0,0048 & $5.022,6849$ & 0,0500 & 102,2812 & 0,4838 & 0,4864 \\
FR05 & $1.006,3354$ & 0,0008 & $5.022,6848$ & 0,0091 & 102,2797 & 0,0887 & 0,0892 \\
FR06 & $1.006,3406$ & 0,0033 & $5.022,6855$ & 0,0341 & 102,2745 & 0,3313 & 0,3331 \\
FR07 & $1.006,3503$ & 0,0090 & $5.022,6864$ & 0,0939 & 102,2643 & 0,9150 & 0,9198 \\
\hline
\end{tabular}


Tabela 58 - Variação controlada, variação das coordenadas e diferença entre ambas (Distância Mínima - Fita Refletiva)

\begin{tabular}{cccccccc}
\hline CONTROLE & \multicolumn{3}{c}{$\begin{array}{c}\text { DIFERENÇAS ENTRE } \\
\text { COORDENADAS }\end{array}$} & \multicolumn{2}{c}{$\begin{array}{c}\text { RESÍDUO ENTRE CONTROLE E } \\
\text { COORDENADAS }\end{array}$} \\
\hline Pontual $(\mathrm{mm})$ & Intervalo $(\mathrm{mm})$ & $\Delta \mathrm{X}(\mathrm{mm})$ & $\Delta \mathrm{Y}(\mathrm{mm})$ & $\Delta \mathrm{Z}(\mathrm{mm})$ & $\mathrm{X}(\mathrm{mm})$ & $\mathrm{Y}(\mathrm{mm})$ & $\mathrm{Z}(\mathrm{mm})$ \\
\hline 1,0 & $0,0-1,0$ & 0,1 & 0,4 & $-0,8$ & 0,9 & 0,6 & 0,2 \\
1,0 & $1,0-2,0$ & 1,5 & $-0,3$ & $-1,5$ & $-0,5$ & 1,3 & $-0,5$ \\
1,0 & $2,0-3,0$ & 1,3 & 0,1 & $-1,0$ & $-0,3$ & 0,9 & 0,0 \\
1,0 & $3,0-4,0$ & 0,5 & $-0,2$ & $-0,4$ & 0,5 & 1,2 & 0,6 \\
1,0 & $4,0-5,0$ & 0,6 & $-0,1$ & $-1,5$ & 0,4 & 1,1 & $-0,5$ \\
5,0 & $5,0-10,0$ & 5,2 & 0,7 & $-5,2$ & $-0,2$ & 4,3 & $-0,2$ \\
10,0 & $10,0-20,0$ & 9,7 & 0,9 & $-10,2$ & 0,3 & 0,3 & $-0,2$ \\
\hline
\end{tabular}




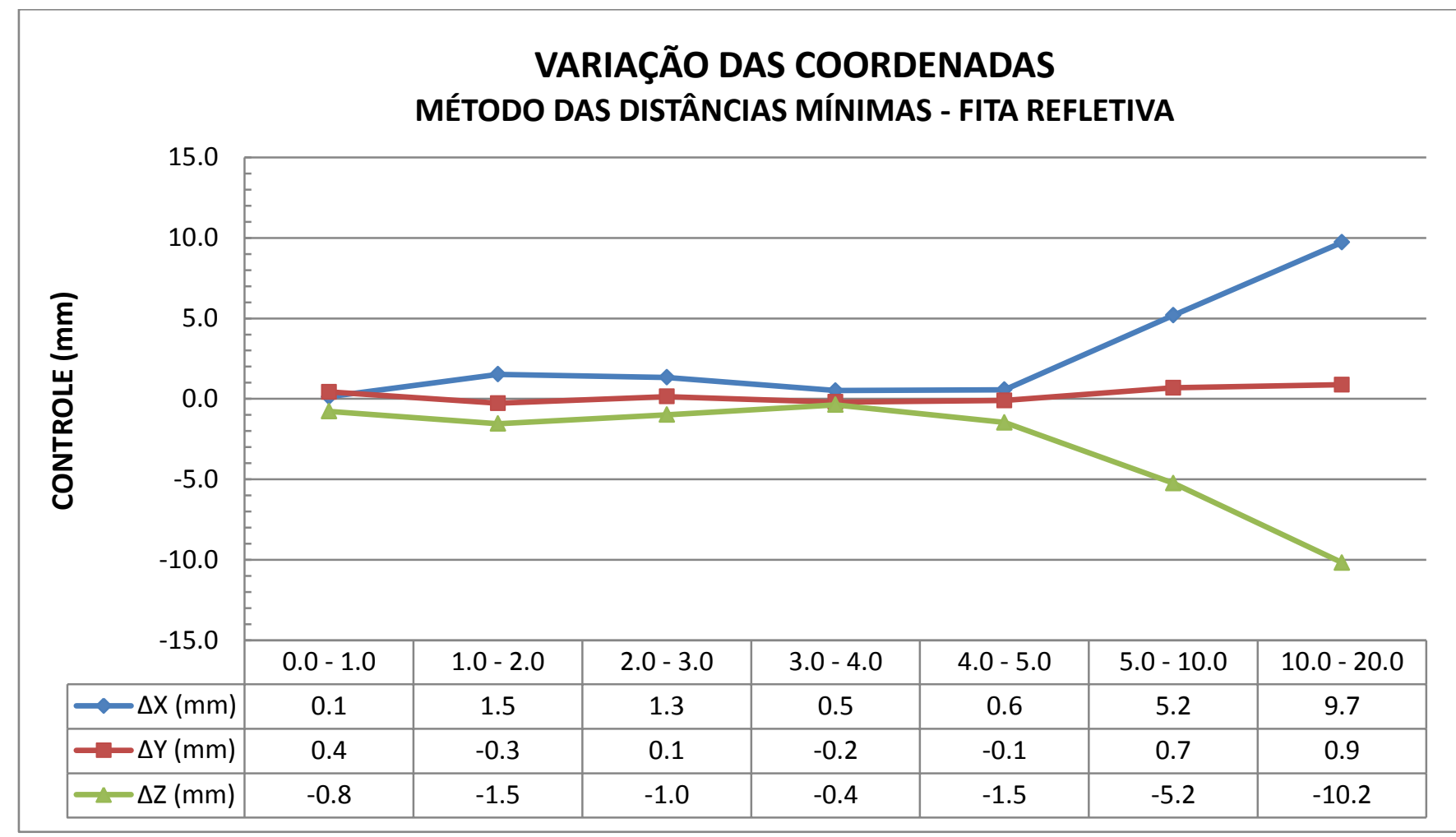

Figura 61 - Variação das coordenadas para Fita refletiva (Distância Mínima) 


\section{APÊNDICE G - Rotina computacional para determinações das coordenadas espaciais dos alvos por meio do método das distâncias mínimas com ajustamento das observações}

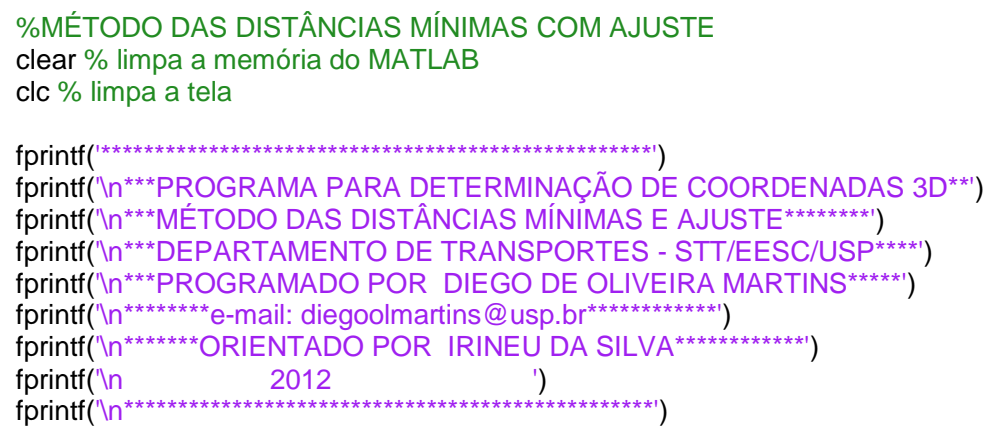

\section{format long}

\%DETERMINAÇÃO DAS EQUAÇÕES DAS RETAS DEFINIDAS PELAS LINHAS DE VISADAS DAS $\%(n=2)$ ESTAÇÕES ATÉ O ALVO P

\%NOME DA PRIMEIRA ESTAÇÃO

fprintf('ไnEscreva o nome da primeira Estação:'); \%Nome da primeira Estação

E1 = input('InEstação:');

\section{\%COORDENADAS TRIDIMENSIONAIS NA PRIMEIRA ESTAÇÃO}

fprintf('InEntre com as coordenadas tridimensionais da primeira Estação:');

$\mathrm{X} 1$ = input('InDigite a coordenada $\mathrm{X}$ da primeira Estação(m):');

Y1 = input('InDigite a coordenada Y da primeira Estação(m):');

Z1 = input('InDigite a coordenada Z da primeira Estação(m):');

\%ALTURA DO INSTRUMENTO NA PRIMEIRA ESTAÇÃO = hi=0 (referencia Centro

\%optico)

fprintf('InDigite a altura do instrumento na primeira Estação(m):');

Hi1 = input('InHi1(m):');

\section{\%COORDENADAS DO CENTRO OPTICO DA PRIMEIRA ESTAÇÃO}

$\mathrm{XCO} 1=\mathrm{X} 1$

$\mathrm{YCO} 1=\mathrm{Y} 1$

$\mathrm{ZCO} 1=\mathrm{Z} 1+\mathrm{Hi} 1$

\%ÂNGULO HORIZONTAL NA PRIMEIRA ESTAÇÃO EM RELACAO AO PO E P fprintf('InDigite o Ângulo Horizontal na primeira Estação(GMS):');

$\mathrm{Hz1G}=$ input('ไnGrau:');

Hz1M = input('InMinuto:');

Hz1S = input('InSegundo:');

\%CONVERSÃO DE ÂNGULOS DO ÂNGULO HORIZONTAL NA PRIMEIRA ESTAÇÃO

$\%$ GMS PARA GRAUS DECIMAIS

format short

$\mathrm{Hz} 1 \mathrm{dec}=\mathrm{Hz} 1 \mathrm{G}+(\mathrm{Hz} 1 \mathrm{M} / 60)+(\mathrm{Hz} 1 \mathrm{~S} / 3600) \quad$ \%Ângulo horizontal 1 em grau decimal

\%CONVERSÃO DE ÂNGULOS EM GRAUS DECIMAIS PARA RADIANOS DO ÂNGULO HORIZONTAL NA PRIMEIRA

ESTAÇÃO

format long

fprintf('\nConversão de graus-radianos $\backslash n ')$;

fprintf('\nDados de entrada: angulo em graus $\mid n ')$;

$\mathrm{Hz} 1 \mathrm{rad}=\mathrm{Hz} 1 \mathrm{dec}^{*}(\mathrm{pi} / 180)$

\%Ângulo horizontal 1 em radianos

Az1Alvo = Hz1rad;

\%ÂNGULO ZENITAL NA PRIMEIRA ESTAÇÃO

fprintf('InDigite o Ângulo Zenital na primeira Estação(GMS):');

Zen1G = input('InGrau:');

Zen1M = input('InMinuto:'); 
Zen1S = input('InSegundo:');

\%CONVERSÃO DE ÂNGULOS DO ÂNGULO ZENITAL NA PRIMEIRA ESTAÇÃO

$\%$ GMS PARA GRAUS DECIMAIS

format short

Zen1dec $=$ Zen1G+(Zen1M/60)+(Zen1S/3600) \%Ângulo zenital 1 em grau decimal

\%CONVERSÃO DE ÂNGULOS EM GRAUS DECIMAIS PARA RADIANOS DO ÂNGULO ZENITAL NA PRIMEIRA ESTAÇÃO

format long

fprintf('\nConversão de graus-radianos $\backslash n ')$;

fprintf('InDados de entrada: angulo em graus $\backslash n ')$;

Zen1 $\mathrm{rad}=$ Zen1 $\mathrm{dec}^{*}(\mathrm{pi} / 180) \quad \%$ Ângulo zenital $1 \mathrm{em}$ radianos

\%DETERMINAÇÃO DAS COORDENADAS DOS VERSORES DA LINHA DE VISADA 1(a1, b1, c1)

b1 $=\sin ($ Zen1rad $){ }^{*} \cos ($ Az1Alvo);

a1 $=\sin ($ Zen1rad) $* \sin ($ Az1Alvo);

$\mathrm{c} 1=\cos ($ Zen1 $\mathrm{rad})$;

\%NOME DA SEGUNDA ESTAÇÃO

fprintf('InEscreva o nome da segunda Estação:'); \%Nome da primeira Estação

E2 = input('InEstação:');

\%COORDENADAS TRIDIMENSIONAIS NA SEGUNDA ESTAÇÃO

fprintf('InEntre com as coordenadas tridimensionais da segunda Estação:');

X2 = input('InDigite a coordenada $X$ da segunda Estação(m):');

Y2 = input('InDigite a coordenada $Y$ da segunda Estação(m):');

Z2 = input('InDigite a coordenada Z da segunda Estação(m):');

\%ALTURA DO INSTRUMENTO NA SEGUNDA ESTAÇÃO hi=0 (referencia CO)

fprintf('InDigite a altura do instrumento na segunda Estação(m):');

$\mathrm{Hi2}=$ input('ไnHi1(m):');

\%COORDENADAS DO CENTRO OPTICO DA PRIMEIRA ESTAÇÃO

$\mathrm{XCO} 2=\mathrm{X} 2$

$\mathrm{YCO} 2=\mathrm{Y} 2$

$\mathrm{ZCO} 2=\mathrm{Z2}+\mathrm{Hi} 2$

\%ÂNGULO HORIZONTAL NA SEGUNDA ESTAÇÃO

fprintf('InDigite o Ângulo Horizontal na segunda Estação(GMS):');

$\mathrm{Hz2G}=$ input('ไnGrau:');

Hz2M = input('InMinuto:');

Hz2S = input('InSegundo:');

\%CONVERSÃO DE ÂNGULOS DO ÂNGULO HORIZONTAL NA SEGUNDA ESTAÇÃO

\%GMS PARA GRAUS DECIMAIS

format short

$\mathrm{Hz2dec}=\mathrm{Hz2G}+(\mathrm{Hz2M} / 60)+(\mathrm{Hz2S} / 3600) \quad$ \%Ângulo horizontal 2 em grau decimal

\%CONVERSÃO DE ÂNGULOS EM GRAUS DECIMAIS PARA RADIANOS DO ÂNGULO HORIZONTAL NA SEGUNDA

ESTAÇÃO

format long

fprintf('InConversão de graus-radianos $\backslash n ')$;

fprintf('InDados de entrada: angulo em graus $\backslash n ')$;

$\mathrm{Hz} 2 \mathrm{rad}=\mathrm{Hz}_{\mathrm{dec}}{ }^{*}(\mathrm{pi} / 180) \quad \%$ Ângulo horizontal 2 em radianos

Az2Alvo $=$ Hz2rad

\%ÂNGULO ZENITAL NA SEGUNDA ESTAÇÃO

fprintf('InDigite o Ângulo Zenital na primeira Estação(GMS):');

Zen2G = input('InGrau:');

Zen2M = input('InMinuto:');

Zen2S = input('InSegundo:');

\%CONVERSÃO DE ÂNGULOS DO ÂNGULO ZENITAL NA PRIMEIRA ESTAÇÃO

\%GMS PARA GRAUS DECIMAIS

format short

Zen2dec $=$ Zen2G+(Zen2M/60)+(Zen2S/3600) \%Ângulo zenital 1 em grau decimal

\%CONVERSÃO DE ÂNGULOS EM GRAUS DECIMAIS PARA RADIANOS DO ÂNGULO ZENITAL NA SEGUNDA ESTAÇÃO format long

fprintf('ไnConversão de graus-radianos $\backslash n ')$;

fprintf('InDados de entrada: angulo em graus $\backslash n ')$;

Zen2rad $=$ Zen2dec $(\mathrm{pi} / 180) \quad$ \%Ângulo zenital $2 \mathrm{em}$ radianos 
\%DETERMINAÇÃO DAS COORDENADAS DOS VERSORES DA LINHA DE VISADA 2(a2, b2, c2)

b2 $=\sin \left(\right.$ Zen2rad) ${ }^{*} \cos ($ Az2Alvo);
a2 $=\sin ($ Zen2rad $){ }^{*} \sin ($ Az2Alvo);

c2 $=\cos ($ Zen2rad $)$;

\%DETERMINAÇÃO DAS EQUAÇÕES DE ERROS

$\% \mathrm{MMQ} V=\mathrm{AX}-\mathrm{L}$

\%CADA COORDENADA DO VETOR DOS RESIDUOS REPRESENTA UMA FÇ DE 5 VARIAVEIS

$\%(\mathrm{XP}, \mathrm{YP}, \mathrm{ZP}, \mathrm{t} 1, \mathrm{t} 2)$

$\%$ MATRIZ A

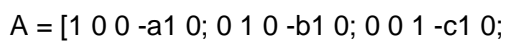

1000 -a2; 01100 -b2; 0010 -c2];

\%MATRIZ PESO "P" (ELb) (mm)

\%CÁLCULO DOS ERROS ESTIMADOS (SOMENTE ANGULOS, DEVIDO AOS DADOS DE ENTRADA $\%$ HZ E ZEN

$\%$ dpE1_P $=0.002+2^{*}($ doE1_P/1000000);

$\% d p E 2 \_P=0.002+2^{*}($ doE2_P/1000000);

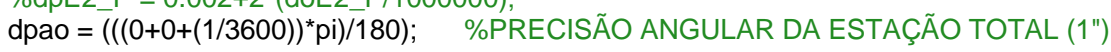

\%MATRIZ (ELb) PRECISÃO DO LEVANTAMENTO DA REDE DE AJUST PRECISAO DE (X1,

$\%$ Y1, Z1 E X2, Y2 , Z2) ENCONTRA NA MVC DDA REDE

\%PODE-SE USAR A MATRIZ PESO COMO IDENTIDADE OU UNITARIA NA DIAGONAL
$E L b=\left[(\text { dpao })^{\wedge} 2000000\right.$
0 (dpao)^2 00000
00 (dpao)^2 000 ;
000 (dpao)^2 00
$0000(\mathrm{dpao})^{\wedge} 20$;
000000 (dpao)^2];

\%MATRIZ PESO "P"

$P=\operatorname{inv}(E L b)$;

\%MATRIZ I (NÃO EXISTE VARIACAO, SOMENTE ENTRA COORD DO CO)

$\mathrm{I}=$ [XCO1;
YCO1;
ZCO1;
XCO2;
YCO2;
ZCO2];

\%AJUSTAMENTO DE OBSERVAÇÕES

\%CALCULO DE N E n

$N=A^{\prime *} P * A ;$

$\mathrm{n}=\mathrm{A}^{\prime *} \mathrm{P} * \mathrm{l}$

\%COORDENADAS DO VETOR INCOGNITA "X"

$\mathrm{X}=\operatorname{inv}(\mathrm{N}){ }^{*} \mathrm{n}$;

\%MATRIZ DOS RESIDUOS

$V=A * X-I$

\%VARIANCIA A POSTERIORI OU PRECISAO DAS DETERMINACOES

\%NESTE CASO PARTICULAR TEMOS QUE O NUMERO DE EQUACOES DE ERRO n=6 E NUMERO DE INCOGNITAS u=5 $\mathrm{S} 02=\left(V^{\prime} * P^{*} V\right) / 6-5$

\%MATRIZ "KxX" VARIANCIA DAS INCOGNITAS AJUSTADAS(CALCULO DA PRECISAO DAS INC)

$\mathrm{Kxx}=\operatorname{inv}(\mathrm{N})$; 
\%MATRIZ "KII" MATRIZ VARIANCIA COVARIANCIA DAS OBSERVAÇÕES

$\mathrm{KII}=\operatorname{inv}(\mathrm{P})$;

\%MATRIZ VARIANCIA COVARIANCIA DAS OBSERVACOES COMPENSADAS K BARRA II

$\% " K m l l "$

$\mathrm{Kmll}=\mathrm{S} 02{ }^{*} \operatorname{inv}(\mathrm{P})$;

\%MATRIZ DOS RESIDUOS

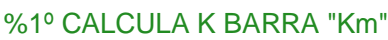

$\mathrm{Km}=\mathrm{A}^{*} \operatorname{inv}(\mathrm{N}){ }^{*} \mathrm{~A}^{\prime} ;$

$\% 2$ CALCULA A MATRIZ DOS RESIDUOS

$\mathrm{Kvv}=\operatorname{inv}(\mathrm{P})-\mathrm{Km}$;

\% AS PRECISOES DAS COORDENADAS DO ALVO "P" = S BARRA "Sm"

$\mathrm{Sm}=\operatorname{diag}(\mathrm{Kxx})$;

$\mathrm{Sp}=\operatorname{sqrt}\left(\mathrm{Sm}(1,1)^{\wedge} 2+\mathrm{Sm}(2,1)^{\wedge} 2+\mathrm{Sm}(3,1)^{\wedge} 2\right) ;$ 
APÊNDICE H - Validação do método das distâncias mínimas com ajustamento das observações para os alvos estudados 
Tabela 59 - Dados observados e verificação da estabilidade da Base 1 (Distância Mínima e Ajuste - GPR112)

\begin{tabular}{lcccccccc}
\hline \multicolumn{7}{c}{ MÉTODO DAS DISTÂNCIAS MíNIMAS E AJUSTE - GPR112 (-7.10 mm) } \\
\hline \multicolumn{7}{c}{ BASE 1 } \\
\hline \multicolumn{7}{c}{ DADOS OBSERVADOS } & \multicolumn{5}{c}{ ESTABILIDADE DA BASE "RECESSÃO" } \\
\hline PONTOS & Azimute & Zenital & $X(\mathrm{~m})$ & $\sigma_{X}(\mathrm{~mm})$ & $\mathrm{Y}(\mathrm{m})$ & $\sigma_{Y}(\mathrm{~mm})$ & $\mathrm{Z}(\mathrm{m})$ & $\sigma_{\mathrm{Z}}(\mathrm{mm})$ \\
\hline GPRM00 & $15^{\circ} 35^{\prime} 09,2290^{\prime \prime}$ & $84^{\circ} 10^{\prime} 39,7496^{\prime \prime}$ & $1.000,0045$ & 1,5 & $4.999,9976$ & 0,5 & 99,9999 & 1,5 \\
GPRM01 & $1^{\circ} 35^{\prime} 19,8276^{\prime \prime}$ & $84^{\circ} 10^{\prime} 51,3675^{\prime \prime}$ & $1.000,0045$ & 1,4 & $4.999,9975$ & 0,5 & 99,9999 & 1,5 \\
GPRM02 & $15^{\circ} 35^{\prime} 27,8297^{\prime \prime}$ & $84^{\circ} 10^{\prime} 56,8414^{\prime \prime}$ & $1.000,0046$ & 1,4 & $4.999,9975$ & 0,5 & 99,9999 & 1,5 \\
GPRM03 & $15^{\circ} 35^{\prime} 38,2403^{\prime \prime}$ & $84^{\circ} 11^{\prime} 08,9221^{\prime \prime}$ & $1.000,0044$ & 1,5 & $4.999,9974$ & 0,5 & 99,9999 & 1,5 \\
GPRM04 & $15^{\circ} 35^{\prime} 40,4279 "$ & $84^{\circ} 11^{\prime} 17,6384^{\prime \prime}$ & $1.000,0046$ & 1,4 & $4.999,9974$ & 0,5 & 99,9999 & 1,5 \\
GPRM05 & $15^{\circ} 35^{\prime} 45,2674 "$ & $84^{\circ} 11^{\prime} 26,8598^{\prime \prime}$ & $1.000,0047$ & 1,5 & $4.999,9974$ & 0,5 & 99,9999 & 1,5 \\
GPRM06 & $15^{\circ} 36^{\prime} 20,6963^{\prime \prime}$ & $84^{\circ} 12^{\prime} 10,1628^{\prime \prime}$ & $1.000,0047$ & 1,4 & $4.999,9974$ & 0,5 & 99,9999 & 1,5 \\
GPRM07 & $15^{\circ} 37^{\prime} 40,3512^{\prime \prime}$ & $84^{\circ} 13^{\prime} 39,5768^{\prime \prime}$ & $1.000,0045$ & 1,5 & $4.999,9974$ & 0,5 & 99,9999 & 1,5 \\
\hline
\end{tabular}


Tabela 60 - Dados observados e verificação da estabilidade da Base 2 (Distância Mínima e Ajuste - GPR112)

\begin{tabular}{|c|c|c|c|c|c|c|c|c|}
\hline \multicolumn{9}{|c|}{ BASE 2} \\
\hline \multicolumn{3}{|c|}{ DADOS OBSERVADOS } & \multicolumn{6}{|c|}{ ESTABILIDADE DA BASE "RECESSÃO" } \\
\hline PONTOS & Azimute & Zenital & $X(m)$ & $\sigma_{X}(\mathrm{~mm})$ & $\mathrm{Y}(\mathrm{m})$ & $\sigma_{Y}(\mathrm{~mm})$ & $\mathrm{Z}(\mathrm{m})$ & $\sigma_{Z}(\mathrm{~mm})$ \\
\hline GPRM00 & $342^{\circ} 49^{\prime} 13,9364^{\prime \prime}$ & $83^{\circ} 53^{\prime} 42,3465^{\prime \prime}$ & $1.013,1140$ & 1,5 & $5.000,7535$ & 0,6 & 99,9459 & 1,5 \\
\hline GPRM01 & $342^{\circ} 49^{\prime} 27,1427^{\prime \prime}$ & $83^{\circ} 53^{\prime} 54,0521^{\prime \prime}$ & $1.013,1140$ & 1,5 & $5.000,7534$ & 0,5 & 99,9459 & 1,5 \\
\hline GPRM02 & $342^{\circ} 49^{\prime} 37,1124^{\prime \prime}$ & $83^{\circ} 53^{\prime} 58,9213^{\prime \prime}$ & $1.013,1138$ & 1,4 & $5.000,7537$ & 0,6 & 99,9459 & 1,5 \\
\hline GPRM03 & $342^{\circ} 49^{\prime} 47,0638^{\prime \prime}$ & $83^{\circ} 54^{\prime} 11,0112^{\prime \prime}$ & $1.013,1139$ & 1,4 & $5.000,7536$ & 0,6 & 99,9459 & 1,6 \\
\hline GPRM04 & $342^{\circ} 49^{\prime} 46,3278 "$ & $83^{\circ} 54^{\prime} 19,5343^{\prime \prime}$ & $1.013,1140$ & 1,4 & $5.000,7538$ & 0,6 & 99,9456 & 1,5 \\
\hline GPRM05 & $342^{\circ} 49^{\prime} 55,2427^{\prime \prime}$ & $83^{\circ} 54^{\prime} 28,7357^{\prime \prime}$ & $1.013,1140$ & 1,4 & $5.000,7535$ & 0,5 & 99,9459 & 1,5 \\
\hline GPRM06 & $342^{\circ} 50^{\prime} 34,2637^{\prime \prime}$ & $83^{\circ} 55^{\prime} 09,2072 "$ & $1.013,1140$ & 1,5 & $5.000,7536$ & 0,6 & 99,9459 & 1,5 \\
\hline GPRM07 & $342^{\circ} 51^{\prime} 56,3621^{\prime \prime}$ & $83^{\circ} 56^{\prime} 36,6287^{\prime \prime}$ & $1.013,1140$ & 1,4 & $5.000,7535$ & 0,4 & 99,9459 & 1,5 \\
\hline
\end{tabular}


Tabela 61 - Coordenadas dos alvos e precisões aparentes (Distância Mínima e Ajuste - GPR112)

\begin{tabular}{lccccccc}
\hline \multicolumn{7}{c}{ COORDENADAS E PRECISÕES AJUSTADAS } \\
\hline PONTOS & $X(\mathrm{~m})$ & $\sigma_{X}(\mathrm{~mm})$ & $\mathrm{Y}(\mathrm{m})$ & $\sigma_{\mathrm{Y}}(\mathrm{mm})$ & $\mathrm{Z}(\mathrm{m})$ & $\sigma_{Z}(\mathrm{~mm})$ & $\sigma_{X Y Z}(\mathrm{~mm})$ \\
\hline GPRM00 & $1.006,3333$ & $1,2782 \mathrm{E}-8$ & $5.022,6863$ & $1,4769 \mathrm{E}-7$ & 102,4015 & $1,3364 \mathrm{E}-8$ & $1,4885 \mathrm{E}-7$ \\
GPRM01 & $1.006,3347$ & $1,2782 \mathrm{E}-8$ & $5.022,6867$ & $1,4770 \mathrm{E}-7$ & 102,4002 & $1,3363 \mathrm{E}-8$ & $1,4885 \mathrm{E}-7$ \\
GPRM02 & $1.006,3357$ & $1,2781 \mathrm{E}-8$ & $5.022,6867$ & $1,4770 \mathrm{E}-7$ & 102,3996 & $1,3362 \mathrm{E}-8$ & $1,4886 \mathrm{E}-7$ \\
GPRM03 & $1.006,3369$ & $1,2781 \mathrm{E}-8$ & $5.022,6870$ & $1,4770 \mathrm{E}-7$ & 102,3983 & $1,3360 \mathrm{E}-8$ & $1,4886 \mathrm{E}-7$ \\
GPRM04 & $1.006,3371$ & $1,2781 \mathrm{E}-8$ & $5.022,6863$ & $1,4770 \mathrm{E}-7$ & 102,3971 & $1,3359 \mathrm{E}-8$ & $1,4885 \mathrm{E}-7$ \\
GPRM05 & $1.006,3379$ & $1,2781 \mathrm{E}-8$ & $5.022,6868$ & $1,4771 \mathrm{E}-7$ & 102,3962 & $1,3357 \mathrm{E}-8$ & $1,4886 \mathrm{E}-7$ \\
GPRM06 & $1.006,3423$ & $1,2780 \mathrm{E}-8$ & $5.022,6874$ & $1,4771 \mathrm{E}-7$ & 102,3915 & $1,3351 \mathrm{E}-8$ & $1,4887 \mathrm{E}-7$ \\
GPRM07 & $1.006,3517$ & $1,2779 \mathrm{E}-8$ & $5.022,6879$ & $1,4772 \mathrm{E}-7$ & 102,3815 & $1,3338 \mathrm{E}-8$ & $1,4887 \mathrm{E}-7$ \\
\hline
\end{tabular}


Tabela 62 - Variação controlada, variação das coordenadas e diferença entre ambas (Distância Mínima e Ajuste - GPR112)

\begin{tabular}{cccccccc}
\hline & & \multicolumn{3}{c}{$\begin{array}{c}\text { DIFERENÇAS ENTRE } \\
\text { CONTROLE }\end{array}$} & \multicolumn{2}{c}{ COORDENADAS AJUSTADAS } & \multicolumn{2}{c}{$\begin{array}{c}\text { RESÍDUO ENTRE CONTROLE E } \\
\text { COORDENADAS }\end{array}$} \\
\hline Pontual $(\mathrm{mm})$ & Intervalo $(\mathrm{mm})$ & $\Delta \mathrm{X}(\mathrm{mm})$ & $\Delta \mathrm{Y}(\mathrm{mm})$ & $\Delta \mathrm{Z}(\mathrm{mm})$ & $\mathrm{X}(\mathrm{mm})$ & $\mathrm{Y}(\mathrm{mm})$ & $\mathrm{Z}(\mathrm{mm})$ \\
\hline 1,0 & $0,0-1,0$ & 1,4 & 0,4 & $-1,3$ & $-0,4$ & 0,6 & $-0,3$ \\
1,0 & $1,0-2,0$ & 1,1 & 0,0 & $-0,6$ & $-0,1$ & 1,0 & 0,4 \\
1,0 & $2,0-3,0$ & 1,1 & 0,3 & $-1,3$ & $-0,1$ & 0,7 & $-0,3$ \\
1,0 & $3,0-4,0$ & 0,3 & $-0,6$ & $-1,2$ & 0,7 & 1,6 & $-0,2$ \\
1,0 & $4,0-5,0$ & 0,8 & 0,5 & $-0,8$ & 0,2 & 0,5 & 0,2 \\
5,0 & $5,0-10,0$ & 4,4 & 0,6 & $-4,7$ & 0,6 & 04,4 & 0,3 \\
10,0 & $10,0-20,0$ & 9,4 & 0,5 & $-10,0$ & 0,6 & 0,6 & 0,0
\end{tabular}




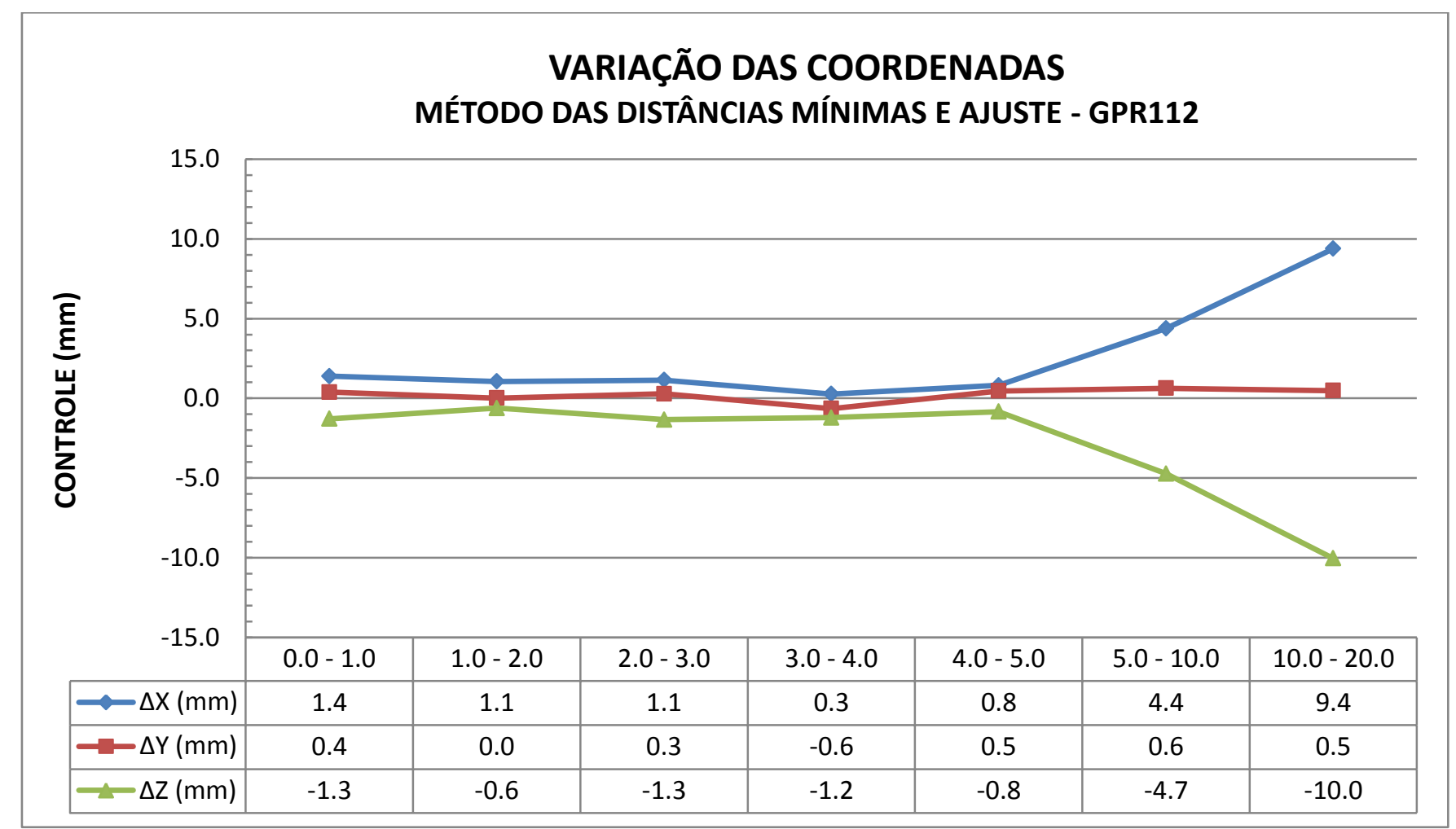

Figura 62 - Variação das coordenadas para o alvo GPR112 (Distância Mínima e Ajuste) 
Tabela 63 - Dados observados e verificação da estabilidade da Base 1 (Distância Mínima e Ajuste - GMP111-0)

\begin{tabular}{|c|c|c|c|c|c|c|c|c|}
\hline \multicolumn{9}{|c|}{ MÉTODO DAS DISTÂNCIAS MÍNIMAS E AJUSTE - GMP111-0 (0.00 mm) } \\
\hline \multicolumn{9}{|c|}{ BASE 1} \\
\hline \multicolumn{3}{|c|}{ DADOS OBSERVADOS } & \multicolumn{6}{|c|}{ ESTABILIDADE DA BASE "RECESSÃO" } \\
\hline PONTOS & Azimute & Zenital & $X(m)$ & $\sigma_{X}(m m)$ & $Y(m)$ & $\sigma_{Y}(\mathrm{~mm})$ & $\mathrm{Z}(\mathrm{m})$ & $\sigma_{Z}(\mathrm{~mm})$ \\
\hline GMPM00 & $15^{\circ} 34^{\prime} 40,0044^{\prime \prime}$ & $83^{\circ} 57^{\prime} 16,8620^{\prime \prime}$ & $1.000,0045$ & 1,4 & $4.999,9977$ & 0,5 & 99,9999 & 1,5 \\
\hline GMPM01 & $15^{\circ} 34^{\prime} 50,2958^{\prime \prime}$ & $83^{\circ} 57^{\prime} 26,8583^{\prime \prime}$ & $1.000,0046$ & 1,4 & $4.999,9976$ & 0,5 & 99,9999 & 1,5 \\
\hline GMPM02 & $15^{\circ} 34^{\prime} 52,6929^{\prime \prime}$ & $83^{\circ} 57^{\prime} 37,4900^{\prime \prime}$ & $1.000,0045$ & 1,4 & $4.999,9976$ & 0,5 & 99,9999 & 1,5 \\
\hline GMPM03 & $15^{\circ} 35^{\prime} 01,5785^{\prime \prime}$ & $83^{\circ} 57^{\prime} 45,2354^{\prime \prime}$ & $1.000,0044$ & 1,4 & $4.999,9977$ & 0,5 & 99,9999 & 1,5 \\
\hline GMPM04 & $15^{\circ} 35^{\prime} 02,8076 "$ & $83^{\circ} 57^{\prime} 54,1203^{\prime \prime}$ & $1.000,0045$ & 1,4 & $4.999,9976$ & 0,5 & 99,9999 & 1,5 \\
\hline GMPM05 & $15^{\circ} 35^{\prime} 12,1816 "$ & $83^{\circ} 58^{\prime} 02,5858^{\prime \prime}$ & $1.000,0043$ & 1,5 & $4.999,9977$ & 0,4 & 99,9999 & 1,5 \\
\hline GMPM06 & $15^{\circ} 35^{\prime} 49,8554^{\prime \prime}$ & $83^{\circ} 58^{\prime} 45,0138^{\prime \prime}$ & $1.000,0045$ & 1,4 & $4.999,9975$ & 0,5 & 99,9999 & 1,5 \\
\hline GMPM07 & $15^{\circ} 37^{\prime} 06,7522^{\prime \prime}$ & $84^{\circ} 00^{\prime} 15,3173^{\prime \prime}$ & $1.000,0047$ & 1,4 & $4.999,9975$ & 0,5 & 99,9999 & 1,5 \\
\hline
\end{tabular}


Tabela 64 - Dados observados e verificação da estabilidade da Base 2 (Distância Mínima e Ajuste - GMP111-0)

\begin{tabular}{|c|c|c|c|c|c|c|c|c|}
\hline \multicolumn{9}{|c|}{ BASE 2} \\
\hline \multicolumn{3}{|c|}{ DADOS OBSERVADOS } & \multicolumn{6}{|c|}{ ESTABILIDADE DA BASE "RECESSÃO" } \\
\hline PONTOS & Azimute & Zenital & $X(m)$ & $\sigma_{X}(\mathrm{~mm})$ & $\mathrm{Y}(\mathrm{m})$ & $\sigma_{Y}(\mathrm{~mm})$ & $\mathrm{Z}(\mathrm{m})$ & $\sigma_{Z}(\mathrm{~mm})$ \\
\hline GMPM00 & $342^{\circ} 50^{\prime} 02,2543^{\prime \prime}$ & $83^{\circ} 39^{\prime} 59,4056^{\prime \prime}$ & $1.013,1141$ & 1,5 & $5.000,7536$ & 0,5 & 99,9459 & 1,5 \\
\hline GMPM01 & $342^{\circ} 50^{\prime} 19,7833^{\prime \prime}$ & $83^{\circ} 40^{\prime} 09,1615^{\prime \prime}$ & $1.013,1139$ & 1,5 & $5.000,7534$ & 0,5 & 99,9459 & 1,5 \\
\hline GMPM02 & $342^{\circ} 50^{\prime} 20,8677^{\prime \prime}$ & $83^{\circ} 40^{\prime} 19,0393 "$ & $1.013,1140$ & 1,5 & $5.000,7534$ & 0,6 & 99,9459 & 1,5 \\
\hline GMPM03 & $342^{\circ} 50^{\prime} 29,7955^{\prime \prime}$ & $83^{\circ} 40^{\prime} 27,3486 "$ & $1.013,1140$ & 1,5 & $5.000,7535$ & 0,6 & 99,9459 & 1,5 \\
\hline GMPM04 & $342^{\circ} 50^{\prime} 30,9121^{\prime \prime}$ & $83^{\circ} 40^{\prime} 36,9772^{\prime \prime}$ & $1.013,1139$ & 1,4 & $5.000,7535$ & 0,6 & 99,9459 & 1,5 \\
\hline GMPM05 & $342^{\circ} 50^{\prime} 38,4037^{\prime \prime}$ & $83^{\circ} 40^{\prime} 44,4649^{\prime \prime}$ & $1.013,1140$ & 1,5 & $5.000,7535$ & 0,5 & 99,9459 & 1,5 \\
\hline GMPM06 & $342^{\circ} 51^{\prime} 22,6292^{\prime \prime}$ & $83^{\circ} 41^{\prime} 25,7247^{\prime \prime}$ & $1.013,1139$ & 1,4 & $5.000,7535$ & 0,6 & 99,9459 & 1,5 \\
\hline GMPM07 & $342^{\circ} 52^{\prime} 43,6705^{\prime \prime}$ & $83^{\circ} 42^{\prime} 53,0515^{\prime \prime}$ & $1.013,1140$ & 1,5 & $5.000,7536$ & 0,5 & 99,9459 & 1,5 \\
\hline
\end{tabular}


Tabela 65 - Coordenadas dos alvos e precisões aparentes (Distância Mínima e Ajuste - GMP111-0)

\begin{tabular}{lccccccc}
\hline \multicolumn{7}{c}{ COORDENADAS E PRECISÕES AJUSTADAS } \\
\hline PONTOS & $X(\mathrm{~m})$ & $\sigma_{X}(\mathrm{~mm})$ & $Y(\mathrm{~m})$ & $\sigma_{Y}(\mathrm{~mm})$ & $\mathrm{Z}(\mathrm{m})$ & $\sigma_{Z}(\mathrm{~mm})$ & $\sigma_{X Y Z}(\mathrm{~mm})$ \\
\hline GMPM00 & $1.006,3342$ & $1,2779 \mathrm{E}-8$ & $5.022,7020$ & $1,4788 \mathrm{E}-7$ & 102,4958 & $1,3492 \mathrm{E}-8$ & $1,4904 \mathrm{E}-7$ \\
GMPM01 & $1.006,3357$ & $1,2779 \mathrm{E}-8$ & $5.022,7028$ & $1,4790 \mathrm{E}-7$ & 102,4948 & $1,3490 \mathrm{E}-8$ & $1,4906 \mathrm{E}-7$ \\
GMPM02 & $1.006,3359$ & $1,2779 \mathrm{E}-8$ & $5.022,7029$ & $1,4790 \mathrm{E}-7$ & 102,4936 & $1,3489 \mathrm{E}-8$ & $1,4906 \mathrm{E}-7$ \\
GMPM03 & $1.006,3369$ & $1,2779 \mathrm{E}-8$ & $5.022,7031$ & $1,4790 \mathrm{E}-7$ & 102,4927 & $1,3488 \mathrm{E}-8$ & $1,4906 \mathrm{E}-7$ \\
GMPM04 & $1.006,3371$ & $1,2779 \mathrm{E}-8$ & $5.022,7027$ & $1,4790 \mathrm{E}-7$ & 102,4916 & $1,3486 \mathrm{E}-8$ & $1,4906 \mathrm{E}-7$ \\
GMPM05 & $1.006,3380$ & $1,2779 \mathrm{E}-8$ & $5.022,7028$ & $1,4789 \mathrm{E}-7$ & 102,4907 & $1,3485 \mathrm{E}-8$ & $1,4905 \mathrm{E}-7$ \\
GMPM06 & $1.006,3429$ & $1,2778 \mathrm{E}-8$ & $5.022,7034$ & $1,4791 \mathrm{E}-7$ & 102,4860 & $1,3478 \mathrm{E}-8$ & $1,4907 \mathrm{E}-7$ \\
GMPM07 & $1.006,3523$ & $1,2777 \mathrm{E}-8$ & $5.022,7038$ & $1,4792 \mathrm{E}-7$ & 102,4759 & $1,3465 \mathrm{E}-8$ & $1,4908 \mathrm{E}-7$ \\
\hline
\end{tabular}


Tabela 66 - Variação controlada, variação das coordenadas e diferença entre ambas (Distância Mínima e Ajuste - GMP111-0)

\begin{tabular}{cccccccc}
\hline \multicolumn{2}{c}{ CONTROLE } & \multicolumn{3}{c}{$\begin{array}{c}\text { DIFERENCSAS ENTRE } \\
\text { COORDENADAS AJUSTADAS }\end{array}$} & \multicolumn{3}{c}{$\begin{array}{c}\text { RESíDUO ENTRE CONTROLE E } \\
\text { COORDENADAS }\end{array}$} \\
\hline Pontual $(\mathrm{mm})$ & Intervalo $(\mathrm{mm})$ & $\Delta \mathrm{X}(\mathrm{mm})$ & $\Delta \mathrm{Y}(\mathrm{mm})$ & $\Delta \mathrm{Z}(\mathrm{mm})$ & $\mathrm{X}(\mathrm{mm})$ & $\mathrm{Y}(\mathrm{mm})$ & $\mathrm{Z}(\mathrm{mm})$ \\
\hline 1,0 & $0,0-1,0$ & 1,6 & 0,7 & $-1,0$ & $-0,6$ & 0,3 & 0,0 \\
1,0 & $1,0-2,0$ & 0,2 & 0,1 & $-1,2$ & 0,8 & 0,9 & $-0,2$ \\
1,0 & $2,0-3,0$ & 1,0 & 0,2 & $-0,9$ & 0,0 & 0,8 & 0,1 \\
1,0 & $3,0-4,0$ & 0,2 & $-0,4$ & $-1,1$ & 0,8 & 1,4 & $-0,1$ \\
1,0 & $4,0-5,0$ & 0,9 & 0,2 & $-0,9$ & 0,1 & 0,8 & 0,1 \\
5,0 & $5,0-10,0$ & 4,9 & 0,6 & $-4,7$ & 0,1 & 4,4 & 0,3 \\
10,0 & $10,0-20,0$ & 9,4 & 0,4 & $-10,1$ & 0,6 & 0,6 & $-0,1$ \\
\hline
\end{tabular}




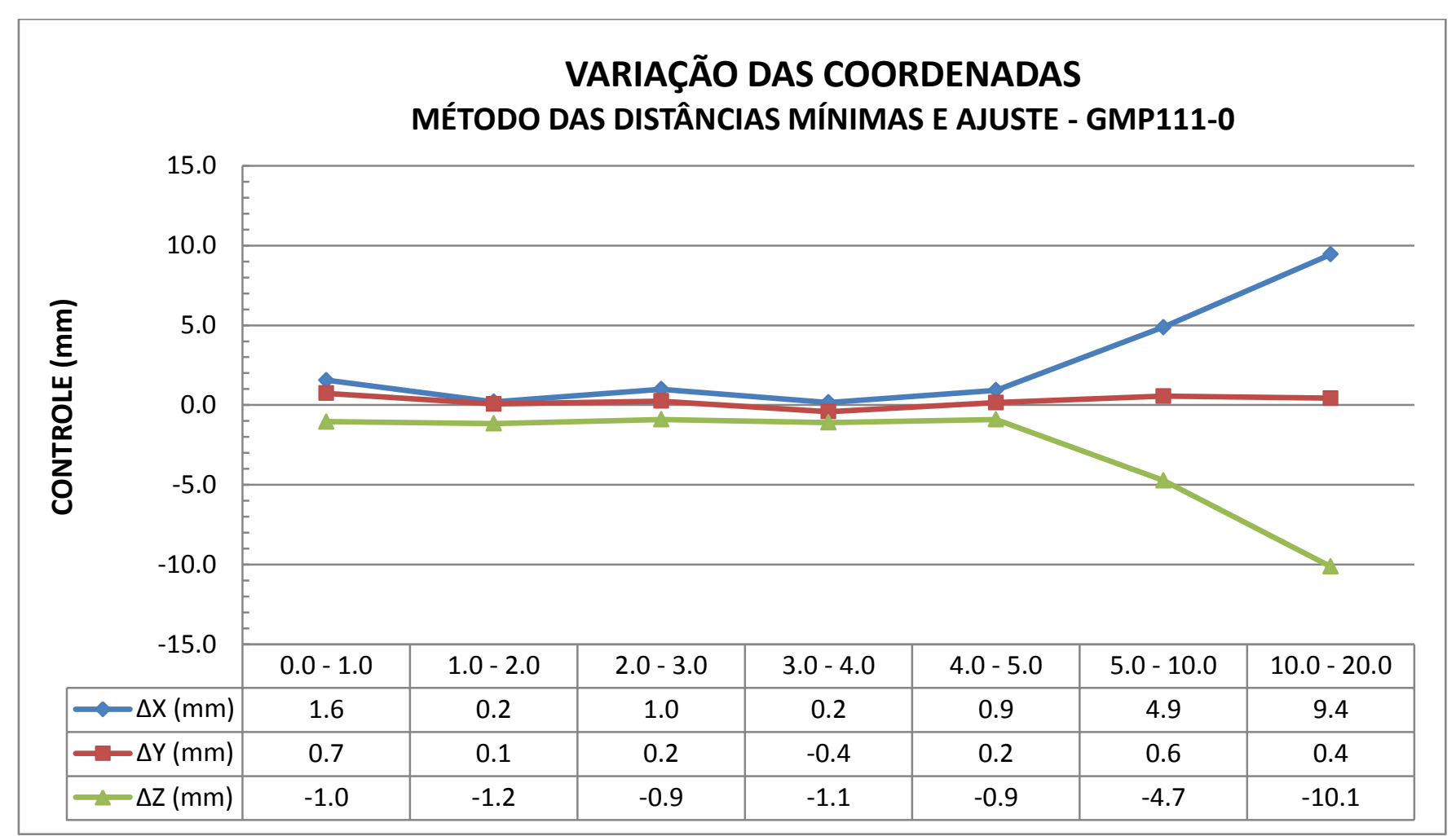

Figura 63 - Variação das coordenadas para o alvo GMP111-0 (Distância Mínima e Ajuste) 
Tabela 67 - Dados observados e verificação da estabilidade da Base 1 (Distância Mínima e Ajuste - GMP104)

MÉTODO DAS DISTÂNCIAS MÍNIMAS E AJUSTE - GMP104 $(8.90 \mathrm{~mm})$

\section{BASE 1}

\begin{tabular}{lcccccccc}
\hline & \multicolumn{2}{c}{ DADOS OBSERVADOS } & \multicolumn{5}{c}{ ESTABILIDADE DA BASE "RECESSÃO" } \\
\hline PONTOS & Azimute & Zenital & $X(\mathrm{~m})$ & $\sigma_{X}(\mathrm{~mm})$ & $\mathrm{Y}(\mathrm{m})$ & $\sigma_{Y}(\mathrm{~mm})$ & $\mathrm{Z}(\mathrm{m})$ & $\sigma_{\mathrm{Z}}(\mathrm{mm})$ \\
\hline GMPL00 & $15^{\circ} 34^{\prime} 58,2158^{\prime \prime}$ & $84^{\circ} 11^{\prime} 07,7288^{\prime \prime}$ & $1.000,0046$ & 1,5 & $4.999,9976$ & 0,5 & 99,9999 & 1,5 \\
GMPL01 & $15^{\circ} 35^{\prime} 11,1633^{\prime \prime}$ & $84^{\circ} 11^{\prime} 17,4850^{\prime \prime}$ & $1.000,0045$ & 1,4 & $4.999,9976$ & 0,5 & 99,9999 & 1,5 \\
GMPL02 & $1^{\circ} 35^{\prime} 16,8283^{\prime \prime}$ & $84^{\circ} 11^{\prime} 26,6141^{\prime \prime}$ & $1.000,0044$ & 1,4 & $4.999,9977$ & 0,5 & 99,9998 & 1,5 \\
GMPL03 & $15^{\circ} 35^{\prime} 21,4672 "$ & $84^{\circ} 11^{\prime} 35,6989^{\prime \prime}$ & $1.000,0043$ & 1,5 & $4.999,9976$ & 0,6 & 99,9999 & 1,5 \\
GMPL04 & $15^{\circ} 35^{\prime} 32,0822^{\prime \prime}$ & $84^{\circ} 11^{\prime} 44,2433^{\prime \prime}$ & $1.000,0043$ & 1,4 & $4.999,9977$ & 0,5 & 99,9999 & 1,5 \\
GMPL05 & $1^{\circ} 35^{\prime} 34,1559 "$ & $84^{\circ} 11^{\prime} 53,7687^{\prime \prime}$ & $1.000,0045$ & 1,4 & $4.999,9977$ & 0,5 & 99,9999 & 1,5 \\
GMPL06 & $15^{\circ} 36^{\prime} 11,4616^{\prime \prime}$ & $84^{\circ} 12^{\prime} 38,6385^{\prime \prime}$ & $1.000,0044$ & 1,5 & $4.999,9976$ & 0,5 & 99,9999 & 1,5 \\
GMPL07 & $15^{\circ} 37^{\prime} 31,6392 "$ & $84^{\circ} 14^{\prime} 05,9805^{\prime \prime}$ & $1.000,0044$ & 1,5 & $4.999,9976$ & 0,5 & 99,9999 & 1,5 \\
\hline
\end{tabular}


Tabela 68 - Dados observados e verificação da estabilidade da Base 2 (Distância Mínima e Ajuste - GMP104)

\begin{tabular}{|c|c|c|c|c|c|c|c|c|}
\hline \multicolumn{9}{|c|}{ BASE 2} \\
\hline \multicolumn{3}{|c|}{ DADOS OBSERVADOS } & \multicolumn{6}{|c|}{ ESTABILIDADE DA BASE "RECESSÃO" } \\
\hline PONTOS & Azimute & Zenital & $X(m)$ & $\sigma_{x}(m m)$ & $Y(m)$ & $\sigma_{Y}(\mathrm{~mm})$ & $\mathrm{Z}(\mathrm{m})$ & $\sigma_{Z}(\mathrm{~mm})$ \\
\hline GMPL00 & $342^{\circ} 49^{\prime} 51,7825^{\prime \prime}$ & $83^{\circ} 54^{\prime} 09,6713^{\prime \prime}$ & $1.013,1139$ & 1,5 & $5.000,7533$ & 0,5 & 99,9459 & 1,5 \\
\hline GMPL01 & $342^{\circ} 50^{\prime} 01,8644^{\prime \prime}$ & $83^{\circ} 54^{\prime} 20,3833^{\prime \prime}$ & $1.013,1141$ & 1,5 & $5.000,7535$ & 0,5 & 99,9459 & 1,5 \\
\hline GMPL02 & $342^{\circ} 50^{\prime} 07,9235^{\prime \prime}$ & $83^{\circ} 54^{\prime} 28,5022 "$ & $1.013,1139$ & 1,5 & $5.000,7536$ & 0,4 & 99,9458 & 1,5 \\
\hline GMPL03 & $342^{\circ} 50^{\prime} 19,6600^{\prime \prime}$ & $83^{\circ} 54^{\prime} 36,6997 "$ & $1.013,1135$ & 1,3 & $5.000,7534$ & 0,5 & 99,9459 & 1,5 \\
\hline GMPL04 & $342^{\circ} 50^{\prime} 25,7112^{\prime \prime}$ & $83^{\circ} 54^{\prime} 45,9366^{\prime \prime}$ & $1.013,1139$ & 1,5 & $5.000,7535$ & 0,4 & 99,9459 & 1,5 \\
\hline GMPL05 & $342^{\circ} 50^{\prime} 27,7468^{\prime \prime}$ & $83^{\circ} 54^{\prime} 55,7237^{\prime \prime}$ & $1.013,1139$ & 1,5 & $5.000,7536$ & 0,6 & 99,9459 & 1,5 \\
\hline GMPL06 & $342^{\circ} 51^{\prime} 08,8540^{\prime \prime}$ & $83^{\circ} 55^{\prime} 38,5580 "$ & $1.013,1139$ & 1,5 & $5.000,7536$ & 0,6 & 99,9459 & 1,5 \\
\hline GMPL07 & $342^{\circ} 52^{\prime} 31,4428^{\prime \prime}$ & $83^{\circ} 57^{\prime} 03,5035^{\prime \prime}$ & $1.013,1142$ & 1,5 & $5.000,7536$ & 0,6 & 99,9459 & 1,5 \\
\hline
\end{tabular}


Tabela 69 - Coordenadas dos alvos e precisões aparentes (Distância Mínima e Ajuste - GMP104)

\begin{tabular}{cccccccc}
\hline \multicolumn{7}{c}{ COORDENADAS E PRECISÕES AJUSTADAS } \\
\hline PONTOS & $X(\mathrm{~m})$ & $\sigma_{X}(\mathrm{~mm})$ & $Y(\mathrm{~m})$ & $\sigma_{Y}(\mathrm{~mm})$ & $\mathrm{Z}(\mathrm{m})$ & $\sigma_{Z}(\mathrm{~mm})$ & $\sigma_{X Y Z}(\mathrm{~mm})$ \\
\hline GMPL00 & $1.006,3347$ & $1,2781 \mathrm{E}-8$ & $5.022,6956$ & $1,4781 \mathrm{E}-7$ & 102,3993 & $1,3361 \mathrm{E}-8$ & $1,4896 \mathrm{E}-7$ \\
GMPL01 & $1.006,3361$ & $1,2781 \mathrm{E}-8$ & $5.022,6956$ & $1,4780 \mathrm{E}-7$ & 102,3981 & $1,3360 \mathrm{E}-8$ & $1,4896 \mathrm{E}-7$ \\
GMPL02 & $1.006,3366$ & $1,2781 \mathrm{E}-8$ & $5.022,6956$ & $1,4781 \mathrm{E}-7$ & 102,3970 & $1,3358 \mathrm{E}-8$ & $1,4896 \mathrm{E}-7$ \\
GMPL03 & $1.006,3373$ & $1,2780 \mathrm{E}-8$ & $5.022,6963$ & $1,4782 \mathrm{E}-7$ & 102,3962 & $1,3357 \mathrm{E}-8$ & $1,4897 \mathrm{E}-7$ \\
GMPL04 & $1.006,3385$ & $1,2780 \mathrm{E}-8$ & $5.022,6961$ & $1,4781 \mathrm{E}-7$ & 102,3952 & $1,3356 \mathrm{E}-8$ & $1,4896 \mathrm{E}-7$ \\
GMPL05 & $1.006,3389$ & $1,2780 \mathrm{E}-8$ & $5.022,6958$ & $1,4781 \mathrm{E}-7$ & 102,3941 & $1,3354 \mathrm{E}-8$ & $1,4896 \mathrm{E}-7$ \\
GMPL06 & $1.006,3434$ & $1,2779 \mathrm{E}-8$ & $5.022,6966$ & $1,4782 \mathrm{E}-7$ & 102,3891 & $1,3348 \mathrm{E}-8$ & $1,4897 \mathrm{E}-7$ \\
GMPL07 & $1.006,3531$ & $1,2778 \mathrm{E}-8$ & $5.022,6973$ & $1,4783 \mathrm{E}-7$ & 102,3794 & $1,3335 \mathrm{E}-8$ & $1,4898 \mathrm{E}-7$ \\
\hline
\end{tabular}


Tabela 70 - Variação controlada, variação das coordenadas e diferença entre ambas (Distância Mínima e Ajuste - GMP104)

\begin{tabular}{cccccccc}
\hline \multicolumn{2}{c}{ CONTROLE } & \multicolumn{3}{c}{$\begin{array}{c}\text { DIFERENCSAS ENTRE } \\
\text { COORDENADAS AJUSTADAS }\end{array}$} & \multicolumn{3}{c}{ RESíDUO ENTRE CONTROLE E } \\
COORDENADAS
\end{tabular}




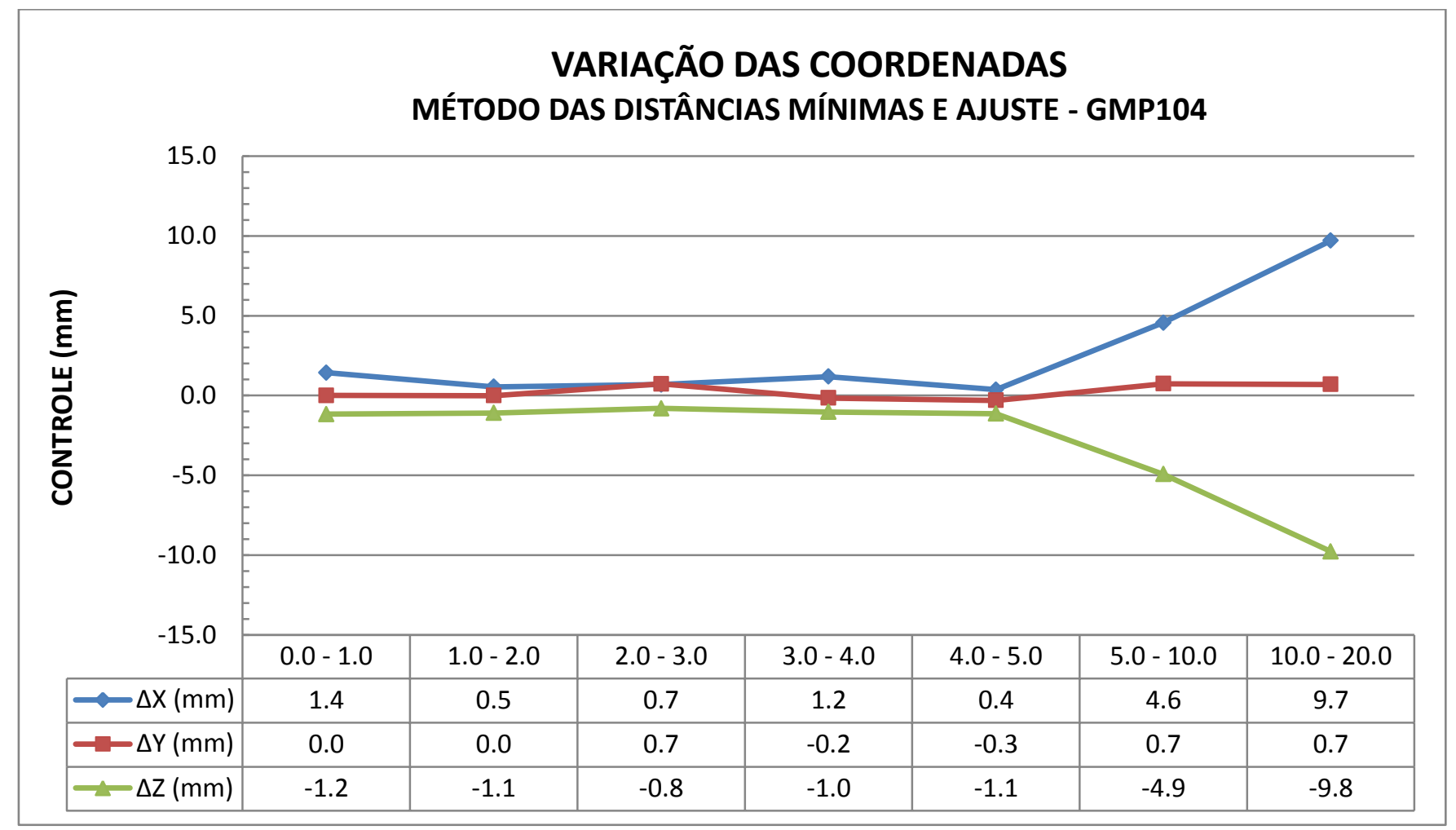

Figura 64 - Variação das coordenadas para o alvo GMP104 (Distância Mínima e Ajuste) 
Tabela 71 - Dados observados e verificação da estabilidade da Base 1 (Distância Mínima e Ajuste - GRZ101)

\begin{tabular}{|c|c|c|c|c|c|c|c|c|}
\hline \multicolumn{9}{|c|}{ MÉTODO DAS DISTÂNCIAS MÍNIMAS - GRZ101 (0.0mm) } \\
\hline \multicolumn{9}{|c|}{ BASE 1} \\
\hline \multicolumn{3}{|c|}{ DADOS OBSERVADOS } & \multicolumn{6}{|c|}{ ESTABILIDADE DA BASE "RECESSÃO" } \\
\hline PONTOS & Azimute & Zenital & $X(m)$ & $\sigma_{x}(\mathrm{~mm})$ & $Y(m)$ & $\sigma_{Y}(\mathrm{~mm})$ & $\mathrm{Z}(\mathrm{m})$ & $\sigma_{z}(\mathrm{~mm})$ \\
\hline GRZ00 & $15^{\circ} 35^{\prime} 10,9810^{\prime \prime}$ & $84^{\circ} 07^{\prime} 03,3306^{\prime \prime}$ & $1.000,0044$ & 1,5 & $4.999,9976$ & 0,5 & 100,0000 & 1,5 \\
\hline GRZ01 & $15^{\circ} 35^{\prime} 18,7146^{\prime \prime}$ & $84^{\circ} 07^{\prime} 14,0777^{\prime \prime}$ & $1.000,0044$ & 1,4 & $4.999,9977$ & 0,5 & 99,9999 & 1,5 \\
\hline GRZ02 & $15^{\circ} 35^{\prime} 19,7333^{\prime \prime}$ & $84^{\circ} 07^{\prime} 22,8338^{\prime \prime}$ & $1.000,0044$ & 1,4 & $4.999,9976$ & 0,5 & 99,9999 & 1,5 \\
\hline GRZ03 & $15^{\circ} 35^{\prime} 36,4925^{\prime \prime}$ & $84^{\circ} 07^{\prime} 30,0421^{\prime \prime}$ & $1.000,0043$ & 1,5 & $4.999,9977$ & 0,5 & 99,9999 & 1,5 \\
\hline GRZ04 & $15^{\circ} 35^{\prime} 37,0981^{\prime \prime}$ & $84^{\circ} 07^{\prime} 38,0044^{\prime \prime}$ & $1.000,0046$ & 1,4 & $4.999,9976$ & 0,4 & 99,9999 & 1,5 \\
\hline GRZ05 & $15^{\circ} 35^{\prime} 38,3900^{\prime \prime}$ & $84^{\circ} 07^{\prime} 48,3516^{\prime \prime}$ & $1.000,0045$ & 1,4 & $4.999,9977$ & 0,5 & 99,9999 & 1,5 \\
\hline GRZ06 & $15^{\circ} 36^{\prime} 21,1632^{\prime \prime}$ & $84^{\circ} 08^{\prime} 31,8357^{\prime \prime}$ & $1.000,0044$ & 1,4 & $4.999,9976$ & 0,6 & 99,9999 & 1,5 \\
\hline GRZ07 & $15^{\circ} 37^{\prime} 40,6897^{\prime \prime}$ & $84^{\circ} 10^{\prime} 03,4119^{\prime \prime}$ & $1.000,0045$ & 1,4 & $4.999,9977$ & 0,5 & 99,9999 & 1,5 \\
\hline
\end{tabular}


Tabela 72 - Dados observados e verificação da estabilidade da Base 2 (Distância Mínima e Ajuste - GRZ101)

\begin{tabular}{|c|c|c|c|c|c|c|c|c|}
\hline \multicolumn{9}{|c|}{ BASE 2} \\
\hline \multicolumn{3}{|c|}{ DADOS OBSERVADOS } & \multicolumn{6}{|c|}{ ESTABILIDADE DA BASE "RECESSÃO" } \\
\hline PONTOS & Azimute & Zenital & $X(m)$ & $\sigma_{X}(m m)$ & $\mathrm{Y}(\mathrm{m})$ & $\sigma_{Y}(\mathrm{~mm})$ & $\mathrm{Z}(\mathrm{m})$ & $\sigma_{Z}(\mathrm{~mm})$ \\
\hline GRZ00 & $342^{\circ} 49^{\prime} 21,0292^{\prime \prime}$ & $83^{\circ} 49^{\prime} 50,5459^{\prime \prime}$ & $1.013,1140$ & 1,5 & $5.000,7531$ & 0,5 & 99,9459 & 1,5 \\
\hline GRZ01 & $342^{\circ} 49^{\prime} 23,0446^{\prime \prime}$ & $83^{\circ} 49^{\prime} 59,2830 "$ & $1.013,1144$ & 1,6 & $5.000,7535$ & 0,4 & 99,9459 & 1,5 \\
\hline GRZ02 & $342^{\circ} 49^{\prime} 31,9328^{\prime \prime}$ & $83^{\circ} 50^{\prime} 09,0795^{\prime \prime}$ & $1.013,1140$ & 1,6 & $5.000,7535$ & 0,6 & 99,9459 & 1,5 \\
\hline GRZ03 & $342^{\circ} 49^{\prime} 41,4397^{\prime \prime}$ & $83^{\circ} 50^{\prime} 18,6849 "$ & $1.013,1141$ & 1,4 & $5.000,7537$ & 0,4 & 99,9459 & 1,5 \\
\hline GRZ04 & $342^{\circ} 49^{\prime} 43,9450^{\prime \prime}$ & $83^{\circ} 50^{\prime} 25,3145^{\prime \prime}$ & $1.013,1146$ & 1,7 & $5.000,7536$ & 0,8 & 99,9459 & 1,5 \\
\hline GRZ05 & $342^{\circ} 49^{\prime} 52,1264^{\prime \prime}$ & $83^{\circ} 50^{\prime} 33,8797^{\prime \prime}$ & $1.013,1139$ & 1,5 & $5.000,7535$ & 0,5 & 99,9459 & 1,5 \\
\hline GRZ06 & $342^{\circ} 50^{\prime} 44,8146^{\prime \prime}$ & $83^{\circ} 51^{\prime} 17,1418 "$ & $1.013,1133$ & 1,4 & $5.000,7529$ & 0,8 & 99,9459 & 1,5 \\
\hline GRZ07 & $342^{\circ} 51^{\prime} 57,4058 "$ & $83^{\circ} 52^{\prime} 45,8747^{\prime \prime}$ & $1.013,1141$ & 1,5 & $5.000,7538$ & 0,7 & 99,9459 & 1,5 \\
\hline
\end{tabular}


Tabela 73 - Coordenadas dos alvos e precisões aparentes (Distância Mínima e Ajuste - GRZ101)

\begin{tabular}{lccccccc}
\hline \multicolumn{7}{c}{ COORDENADAS E PRECISÕES AJUSTADAS } \\
\hline PONTOS & $X(\mathrm{~m})$ & $\sigma_{X}(\mathrm{~mm})$ & $\mathrm{Y}(\mathrm{m})$ & $\sigma_{\mathrm{Y}}(\mathrm{mm})$ & $\mathrm{Z}(\mathrm{m})$ & $\sigma_{Z}(\mathrm{~mm})$ & $\sigma_{X Y Z}(\mathrm{~mm})$ \\
\hline GPRC00 & $1.006,3337$ & $1,2781 \mathrm{E}-8$ & $5.022,6873$ & $1,4770 \mathrm{E}-7$ & 102,4272 & $1,3398 \mathrm{E}-8$ & $1,4886 \mathrm{E}-7$ \\
GPRC01 & $1.006,3345$ & $1,2781 \mathrm{E}-8$ & $5.022,6871$ & $1,4769 \mathrm{E}-7$ & 102,4260 & $1,3397 \mathrm{E}-8$ & $1,4885 \mathrm{E}-7$ \\
GPRC02 & $1.006,3349$ & $1,2781 \mathrm{E}-8$ & $5.022,6879$ & $1,4771 \mathrm{E}-7$ & 102,4251 & $1,3396 \mathrm{E}-8$ & $1,4887 \mathrm{E}-7$ \\
GPRC03 & $1.006,3365$ & $1,2781 \mathrm{E}-8$ & $5.022,6869$ & $1,4769 \mathrm{E}-7$ & 102,4240 & $1,3394 \mathrm{E}-8$ & $1,4885 \mathrm{E}-7$ \\
GPRC04 & $1.006,3370$ & $1,2781 \mathrm{E}-8$ & $5.022,6875$ & $1,4770 \mathrm{E}-7$ & 102,4232 & $1,3393 \mathrm{E}-8$ & $1,4885 \mathrm{E}-7$ \\
GPRC05 & $1.006,3372$ & $1,2781 \mathrm{E}-8$ & $5.022,6879$ & $1,4771 \mathrm{E}-7$ & 102,4222 & $1,3392 \mathrm{E}-8$ & $1,4887 \mathrm{E}-7$ \\
GPRC06 & $1.006,3423$ & $1,2780 \mathrm{E}-8$ & $5.022,6885$ & $1,4774 \mathrm{E}-7$ & 102,4173 & $1,3385 \mathrm{E}-8$ & $1,4889 \mathrm{E}-7$ \\
GPRC07 & $1.006,3518$ & $1,2779 \mathrm{E}-8$ & $5.022,6885$ & $1,4772 \mathrm{E}-7$ & 102,4070 & $1,3372 \mathrm{E}-8$ & $1,4888 \mathrm{E}-7$ \\
\hline
\end{tabular}


Tabela 74 - Variação controlada, variação das coordenadas e diferença entre ambas (Distância Mínima e Ajuste - GRZ101)

\begin{tabular}{cccccccc}
\hline \multicolumn{2}{c}{ CONTROLE } & \multicolumn{3}{c}{$\begin{array}{c}\text { DIFERENÇAS ENTRE } \\
\text { COORDENADAS AJUSTADAS }\end{array}$} & \multicolumn{3}{c}{ RESíDUO ENTRE CONTROLE E } \\
COORDENADAS
\end{tabular}




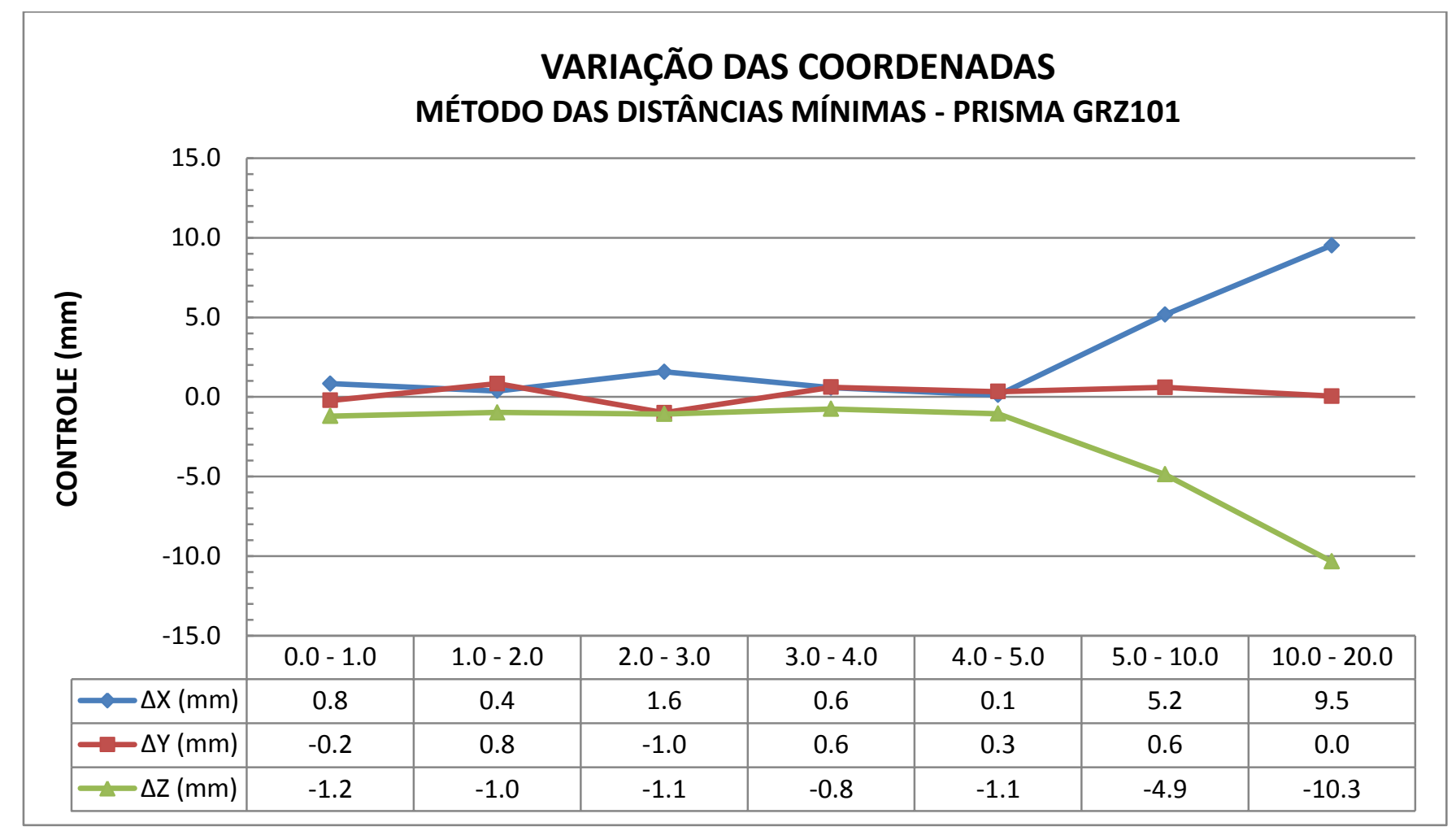

Figura 65 - Variação das coordenadas para o alvo GRZ101 (Distância Mínima e Ajuste) 
Tabela 75 - Dados observados e verificação da estabilidade da Base 1 (Distância Mínima e Ajuste - Fita Refletiva)

MÉTODO DAS DISTÂNCIAS MÍNIMAS E AJUSTE - FITA REFLETIVA (34.4 mm)

\section{BASE 1}

\begin{tabular}{|c|c|c|c|c|c|c|c|c|}
\hline \multirow[b]{2}{*}{ PONTOS } & \multicolumn{2}{|c|}{ DADOS OBSERVADOS } & \multicolumn{6}{|c|}{ ESTABILIDADE DA BASE "RECESSÃO" } \\
\hline & Azimute & Zenital & $X(m)$ & $\sigma_{x}(m m)$ & $Y(m)$ & $\sigma_{Y}(\mathrm{~mm})$ & $\mathrm{Z}(\mathrm{m})$ & $\sigma_{Z}(\mathrm{~mm})$ \\
\hline RF00 & $15^{\circ} 34^{\prime} 56,6784^{\prime \prime}$ & $84^{\circ} 27^{\prime} 26,3816^{\prime \prime}$ & $1.000,0045$ & 1,4 & $4.999,9977$ & 0,5 & 99,9998 & 1,4 \\
\hline RF01 & $15^{\circ} 34^{\prime} 59,7940^{\prime \prime}$ & $84^{\circ} 27^{\prime} 33,3982^{\prime \prime}$ & $1.000,0045$ & 1,4 & $4.999,9975$ & 0,4 & 99,9999 & 1,5 \\
\hline RF02 & $15^{\circ} 35^{\prime} 13,3244^{\prime \prime}$ & $84^{\circ} 27^{\prime} 44,8378^{\prime \prime}$ & $1.000,0044$ & 1,4 & $4.999,9975$ & 0,5 & 99,9999 & 1,5 \\
\hline RF03 & $15^{\circ} 35^{\prime} 23,5576^{\prime \prime}$ & $84^{\circ} 27^{\prime} 57,3758^{\prime \prime}$ & $1.000,0046$ & 1,5 & $4.999,9974$ & 0,5 & 99,9999 & 1,5 \\
\hline RF04 & $15^{\circ} 35^{\prime} 26,9878^{\prime \prime}$ & $84^{\circ} 28^{\prime} 00,2907^{\prime \prime}$ & $1.000,0044$ & 1,5 & $4.999,9976$ & 0,5 & 99,9999 & 1,5 \\
\hline RF05 & $15^{\circ} 35^{\prime} 32,2639^{\prime \prime}$ & $84^{\circ} 28^{\prime} 15,7757^{\prime \prime}$ & $1.000,0046$ & 1,5 & $4.999,9974$ & 0,5 & 99,9999 & 1,5 \\
\hline RF06 & $15^{\circ} 36^{\prime} 10,6850^{\prime \prime}$ & $84^{\circ} 29^{\prime} 02,1145^{\prime \prime}$ & $1.000,0046$ & 1,4 & $4.999,9974$ & 0,5 & 99,9999 & 1,5 \\
\hline RF07 & $15^{\circ} 37^{\prime} 37,8931^{\prime \prime}$ & $84^{\circ} 30^{\prime} 26,3643^{\prime \prime}$ & $1.000,0044$ & 1,4 & $4.999,9977$ & 0,5 & 99,9999 & 1,5 \\
\hline
\end{tabular}


Tabela 76 - Dados observados e verificação da estabilidade da Base 2 (Distância Mínima e Ajuste - Fita Refletiva)

\begin{tabular}{|c|c|c|c|c|c|c|c|c|}
\hline \multicolumn{9}{|c|}{ BASE 2} \\
\hline \multicolumn{3}{|c|}{ DADOS OBSERVADOS } & \multicolumn{6}{|c|}{ ESTABILIDADE DA BASE "RECESSÃO" } \\
\hline PONTOS & Azimute & Zenital & $X(m)$ & $\sigma_{X}(\mathrm{~mm})$ & $\mathrm{Y}(\mathrm{m})$ & $\sigma_{\mathrm{Y}}(\mathrm{mm})$ & $Z(m)$ & $\sigma_{Z}(\mathrm{~mm})$ \\
\hline RF00 & $342^{\circ} 48^{\prime} 51,0885^{\prime \prime}$ & $84^{\circ} 11^{\prime} 00,2146^{\prime \prime}$ & $1.013,1143$ & 1,5 & $5.000,7536$ & 0,6 & 99,9458 & 1,5 \\
\hline RF01 & $342^{\circ} 48^{\prime} 53,8651^{\prime \prime}$ & $84^{\circ} 11^{\prime} 06,8993 "$ & $1.013,1138$ & 1,4 & $5.000,7535$ & 0,5 & 99,9459 & 1,5 \\
\hline RF02 & $342^{\circ} 49^{\prime} 06,4329^{\prime \prime}$ & $84^{\circ} 11^{\prime} 23,1139^{\prime \prime}$ & $1.013,1140$ & 1,6 & $5.000,7532$ & 0,6 & 99,9459 & 1,5 \\
\hline RF03 & $342^{\circ} 49^{\prime} 16,8890^{\prime \prime}$ & $84^{\circ} 11^{\prime} 25,9649^{\prime \prime}$ & $1.013,1139$ & 1,5 & $5.000,7534$ & 0,7 & 99,9458 & 1,5 \\
\hline RF04 & $342^{\circ} 49^{\prime} 19,3800^{\prime \prime}$ & $84^{\circ} 11^{\prime} 32,2888^{\prime \prime}$ & $1.013,1144$ & 1,5 & $5.000,7538$ & 0,5 & 99,9459 & 1,5 \\
\hline RF05 & $342^{\circ} 49^{\prime} 21,8111^{\prime \prime}$ & $84^{\circ} 11^{\prime} 39,7079 "$ & $1.013,1143$ & 1,4 & $5.000,7538$ & 0,5 & 99,9458 & 1,5 \\
\hline RF06 & $342^{\circ} 50^{\prime} 17,4490^{\prime \prime}$ & $84^{\circ} 12^{\prime} 30,3708^{\prime \prime}$ & $1.013,1139$ & 1,4 & $5.000,7532$ & 0,5 & 99,9459 & 1,5 \\
\hline RF07 & $342^{\circ} 51^{\prime} 35,2470^{\prime \prime}$ & $84^{\circ} 13^{\prime} 59,6218^{\prime \prime}$ & $1.013,1141$ & 1,4 & $5.000,7536$ & 0,4 & 99,9456 & 1,5 \\
\hline
\end{tabular}


Tabela 77 - Coordenadas dos alvos e precisões aparentes (Distância Mínima e Ajuste - Fita Refletiva)

\begin{tabular}{cccccccc}
\hline \multicolumn{7}{c}{ COORDENADAS E PRECISÕES AJUSTADAS } \\
\hline PONTOS & $X(\mathrm{~m})$ & $\sigma_{X}(\mathrm{~mm})$ & $Y(\mathrm{~m})$ & $\sigma_{Y}(\mathrm{~mm})$ & $\mathrm{Z}(\mathrm{m})$ & $\sigma_{Z}(\mathrm{~mm})$ & $\sigma_{X Y Z}(\mathrm{~mm})$ \\
\hline RF00 & $1.006,3314$ & $1,2783 \mathrm{E}-8$ & $5.022,6849$ & $1,4767 \mathrm{E}-7$ & 102,2849 & $1,3213 \mathrm{E}-8$ & $1,4881 \mathrm{E}-7$ \\
RF01 & $1.006,3315$ & $1,2783 \mathrm{E}-8$ & $5.022,6851$ & $1,4767 \mathrm{E}-7$ & 102,2841 & $1,3212 \mathrm{E}-8$ & $1,4881 \mathrm{E}-7$ \\
RF02 & $1.006,3330$ & $1,2783 \mathrm{E}-8$ & $5.022,6850$ & $1,4766 \mathrm{E}-7$ & 102,2825 & $1,3210 \mathrm{E}-8$ & $1,4880 \mathrm{E}-7$ \\
RF03 & $1.006,3343$ & $1,2783 \mathrm{E}-8$ & $5.022,6851$ & $1,4766 \mathrm{E}-7$ & 102,2816 & $1,3209 \mathrm{E}-8$ & $1,4880 \mathrm{E}-7$ \\
RF04 & $1.006,3349$ & $1,2783 \mathrm{E}-8$ & $5.022,6848$ & $1,4766 \mathrm{E}-7$ & 102,2812 & $1,3208 \mathrm{E}-8$ & $1,4880 \mathrm{E}-7$ \\
RF05 & $1.006,3354$ & $1,2783 \mathrm{E}-8$ & $5.022,6846$ & $1,4766 \mathrm{E}-7$ & 102,2797 & $1,3207 \mathrm{E}-8$ & $1,4880 \mathrm{E}-7$ \\
RF06 & $1.006,3406$ & $1,2782 \mathrm{E}-8$ & $5.022,6854$ & $1,4770 \mathrm{E}-7$ & 102,2745 & $1,3200 \mathrm{E}-8$ & $1,4884 \mathrm{E}-7$ \\
RF07 & $1.006,3503$ & $1,2781 \mathrm{E}-8$ & $5.022,6865$ & $1,4768 \mathrm{E}-7$ & 102,2643 & $1,3187 \mathrm{E}-8$ & $1,4881 \mathrm{E}-7$ \\
\hline
\end{tabular}


Tabela 78 - Variação controlada, variação das coordenadas e diferença entre ambas (Distância Mínima e Ajuste - Fita Refletiva)

\begin{tabular}{cccccccc}
\hline & & \multicolumn{2}{c}{$\begin{array}{c}\text { DIFERENÇAS ENTRE } \\
\text { CONTROLE }\end{array}$} & \multicolumn{2}{c}{ COORDENADAS AJUSTADAS } & \multicolumn{2}{c}{$\begin{array}{c}\text { RESÍDUO ENTRE CONTROLE E } \\
\text { COORDENADAS }\end{array}$} \\
\hline Pontual $(\mathrm{mm})$ & Intervalo $(\mathrm{mm})$ & $\Delta \mathrm{X}(\mathrm{mm})$ & $\Delta \mathrm{Y}(\mathrm{mm})$ & $\Delta \mathrm{Z}(\mathrm{mm})$ & $\mathrm{X}(\mathrm{mm})$ & $\mathrm{Y}(\mathrm{mm})$ & $\mathrm{Z}(\mathrm{mm})$ \\
\hline 1,0 & $0,0-1,0$ & 0,1 & 0,1 & $-0,8$ & 0,9 & 0,9 & 0,2 \\
1,0 & $1,0-2,0$ & 1,5 & $-0,1$ & $-1,5$ & $-0,5$ & 1,1 & $-0,5$ \\
1,0 & $2,0-3,0$ & 1,3 & 0,1 & $-1,0$ & $-0,3$ & 0,9 & 0,0 \\
1,0 & $3,0-4,0$ & 0,5 & $-0,3$ & $-0,4$ & 0,5 & 1,3 & 0,6 \\
1,0 & $4,0-5,0$ & 0,6 & $-0,2$ & $-1,5$ & 0,4 & 1,2 & $-0,5$ \\
5,0 & $5,0-10,0$ & 5,2 & 0,8 & $-5,2$ & $-0,2$ & 4,2 & $-0,2$ \\
10,0 & $10,0-20,0$ & 9,7 & 1,1 & $-10,2$ & 0,3 & 0,3 & $-0,2$ \\
\hline
\end{tabular}




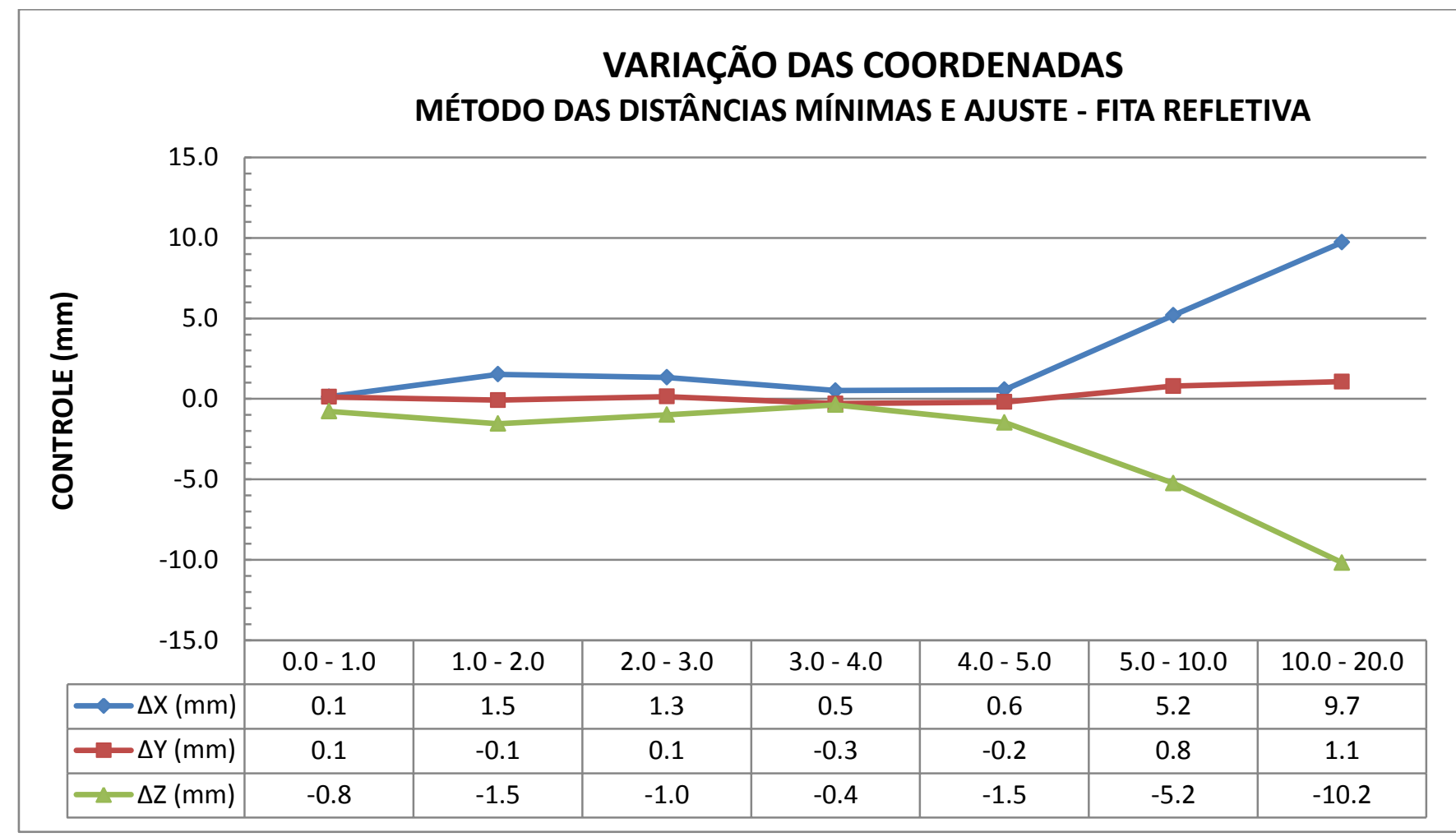

Figura 66 - Variação das coordenadas para Fita refletiva (Distância Mínima e Ajuste) 


\title{
ANEXO A - Certificado de serviço da TCRA 1201+ (Leica Heerbrugg)
}

\section{Producer Inspection Certificate M}

in accordance with DIN 55350-18-4.2.2

\author{
Product: TCRA1201+ R400 \\ Article no.: 750675 \\ Serial no.: 241101 \\ Inspection date: October 26, 2011 /October 24, 2011 \\ Ordered by: COMERCIAL E IMPORTADORA WILD LTDA, SAO CARLOS \\ BRAZIL \\ Your order number: \\ Customer: \\ 1. Specifications: \\ a) Distance Measurement to reflector (circular prism) \\ Standard deviation of a single measurement (ISO 17123-4): $1 \mathrm{~mm}+1.5 \mathrm{ppm}$ \\ 2. Test results: \\ a) Distance Measurement to reflector (circular prism) \\ Distance Standard Deviation $\mathrm{m}_{0}$ : $\quad 0.16 \mathrm{~mm}$ \\ Distance Linearity:
}

3. Certificate: We hereby certify that the product described has been tested and complies with the specifications and test results as stated above.

The test equipment used is traceable to national standards or to recognized procedures. This is established by our Quality Management System, audited to ISO 9001:2008 by an independent national accredited body.

Leica Geosystems AG

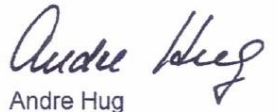

Andre Hug

Central Technical Service
October 26, 201

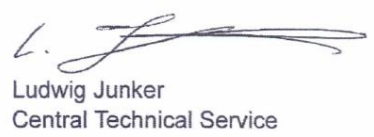


Measurement Report

Distance Measurement to reflector (circular prism)

\section{Distance Standard Deviation}

$\begin{array}{ll}\text { Product } & : \text { TCRA1201+ R400 } \\ \text { Serial no. } & : 241101 \\ \text { Inspection date } & : \text { October 26, 2011 } \\ \text { Inspected by } & : \text { MET }\end{array}$

$\begin{array}{ll}\text { Temperature } & : 13.7^{\circ} \mathrm{C} \\ \text { Pressure } & : 966.5 \mathrm{hpa} \\ \text { Humidity } & : 55 \% \\ \text { Target } & : \text { GPH1P }\end{array}$

- Additive constant valid for standard equipment (prism holder and circular prism)

- Measuring procedure and calculations according ISO 17123-4

- Number of measured distances: 21

- Degree of freedom $=14$

\begin{tabular}{|c|c|c|c|c|c|c|}
\hline & $\begin{array}{c}\text { Measured dis- } \\
\text { tance }\end{array}$ & $\begin{array}{c}\text { Atm. \& geom. } \\
\text { corrected } \\
\text { distance } \\
{[\mathrm{m}]}\end{array}$ & Residual & $\begin{array}{c}\text { Adjusted dis- } \\
\text { tance }\end{array}$ & Temperature & Weight \\
\hline [m] $]$ & {$[\mathrm{m}]$} & & \\
$0-1$ & 19.5041 & 19.5044 & 0.0 & 19.5045 & 14.0 & 1.0 \\
$0-2$ & 48.5103 & 48.5110 & 0.2 & 48.5113 & 14.2 & 1.0 \\
$0-3$ & 116.5027 & 116.5045 & 0.1 & 116.5046 & 14.1 & 1.0 \\
$0-4$ & 283.9924 & 283.9968 & -0.1 & 283.9967 & 14.2 & 1.0 \\
$0-5$ & 370.0024 & 370.0081 & -0.2 & 370.0080 & 14.4 & 1.0 \\
$0-6$ & 501.5036 & 501.5113 & 0.0 & 501.5113 & 14.2 & 1.0 \\
$1-2$ & 29.0063 & 29.0067 & 0.0 & & 13.4 & 1.0 \\
$1-3$ & 96.9987 & 97.0001 & 0.0 & & 13.4 & 1.0 \\
$1-4$ & 264.4883 & 264.4922 & 0.0 & & 13.6 & 1.0 \\
$1-5$ & 350.4983 & 350.5035 & -0.1 & & 13.8 & 1.0 \\
$1-6$ & 481.9993 & 482.0066 & 0.2 & & 14.0 & 1.0 \\
$2-3$ & 67.9925 & 67.9935 & -0.2 & & 13.0 & 1.0 \\
$2-4$ & 235.4819 & 235.4853 & 0.1 & & 13.1 & 1.0 \\
$2-5$ & 321.4919 & 321.4965 & 0.2 & & 13.1 & 1.0 \\
$2-6$ & 452.9934 & 452.9999 & 0.1 & & 13.2 & 1.0 \\
$3-4$ & 167.4897 & 167.4922 & -0.1 & & 13.7 & 1.0 \\
$3-5$ & 253.4994 & 253.5031 & 0.2 & & 13.6 & 1.0 \\
$3-6$ & 385.0013 & 385.0069 & -0.2 & & 13.4 & 1.0 \\
$4-5$ & 86.0101 & 86.0114 & -0.1 & & 13.8 & 1.0 \\
$4-6$ & 217.5113 & 217.5146 & 0.0 & & 13.9 & 1.0 \\
$5-6$ & 131.5012 & 131.5032 & 0.1 & & 14.0 & 1.0 \\
\hline
\end{tabular}

Standard deviation of a single measurement $\mathrm{m}_{0}$

Additive constant AC 


\section{Measurement Report}

Distance Measurement to reflector (circular prism)

\section{Distance Linearity}

$\begin{array}{ll}\text { Product } & \text { : TCRA1201+ R400 } \\ \text { Serial no. } & : 241101 \\ \text { Inspection date } & \text { : October 24, } 2011 \\ \text { Inspected by } & \text { : LMART }\end{array}$

$\begin{array}{ll}\text { Temperature } & : 21.5^{\circ} \mathrm{C} \\ \text { Pressure } & : 960.7 \mathrm{hpa} \\ \text { Humidity } & : 33 \% \text { r.h. } \\ \text { Target } & : \text { GPR1 }\end{array}$

Additive constant for the Leica Geosystems circular prism GPR1, is set to zero (0 mm).

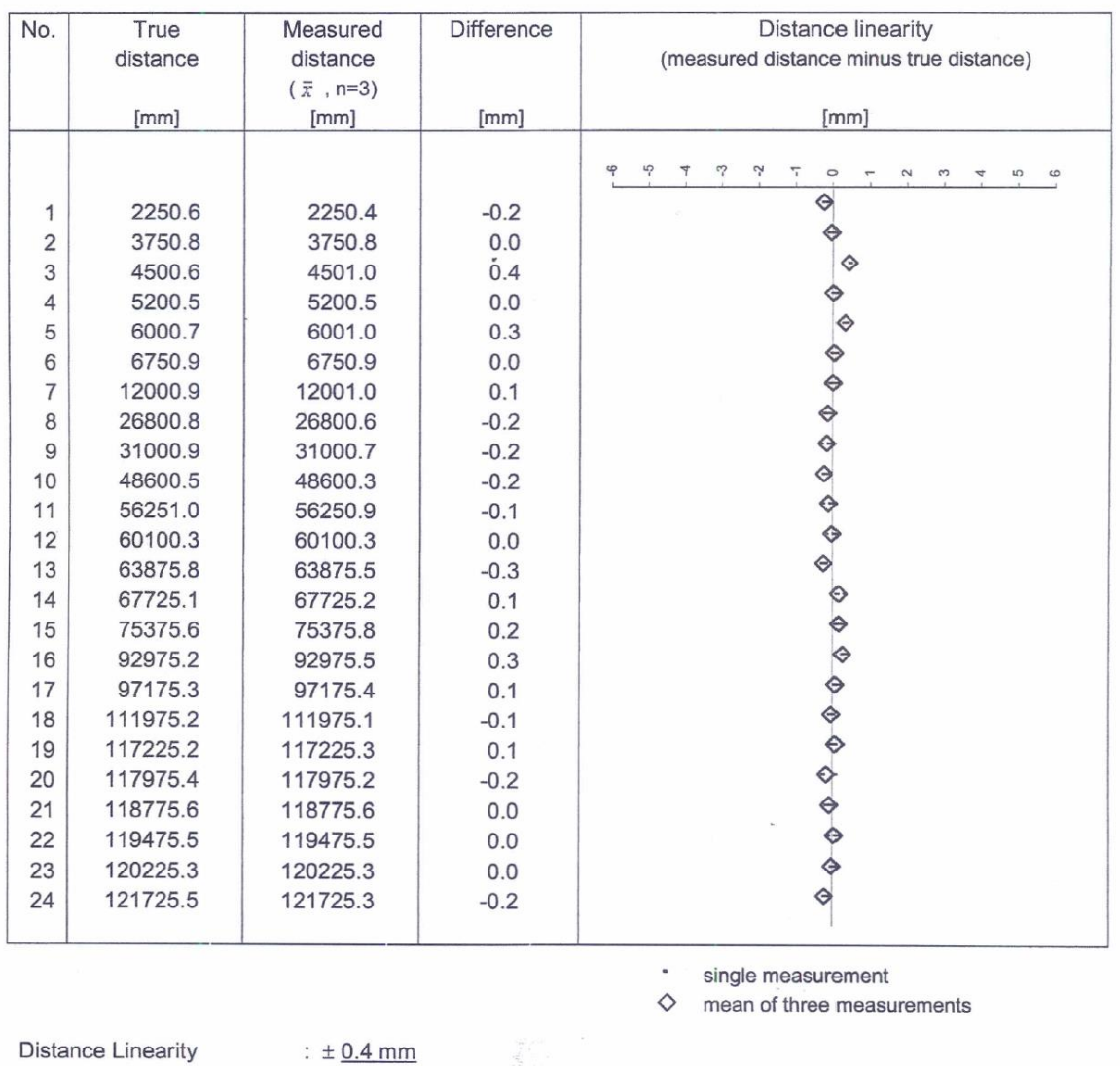

Page 3/3 500610020.doc 
ANEXO B - Certificado de serviço da TCA 1201+ (Wild Comercial)

\title{
Certificado de Serviço
}

\author{
Equipamento: TCR 1201+ \\ Número de Artigo: 754306 \\ Número de Série: 240941 \\ Data da verificação: outubro 25,2012 \\ Requisitante: ESCOLA DE ENGENHARIA DE S.CARLOS - USP \\ BRASIL \\ Ordem de Serviço: $\quad$ 0599/12 \\ Cliente: ESCOLA DE ENGENHARIA DE S.CARLOS - USP \\ 1. Especificaçōes Técnicas: De acordo com o manual do usuário que acompanha o equipamento.
2. Certificado: Certificamos que o equipamento acima descrito foi testado e que está em conformidade com os resultados dos testes efetuados, atendendo \\ as especificações técnicas contidas no manual do usuário.
}

Comercial e Importadora Wild Ltda Centro de Serviços

São Carlos, São Paulo, Brasil

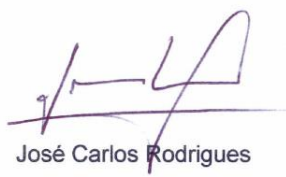

$25 / 10 / 2012$

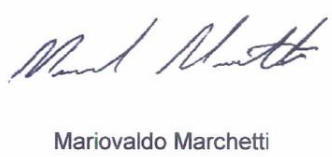

Mariovaldo Marchetti

A Comercial e Importadora Wild está qualificada como Centro de Serviço Autorizado pela Leica Geosystems AG.
A Leica Geosystems AG, Heerbrugg possui um Sistema de Gerenciamento em conformidade com os padröes da ISO9001:2000 I ISO14001:1996 (Reg Nr 10471-8)

Leica Geosystems AG Heinrich-Wild-Strasse CH-9435 Heerbrugg 
ORDEM DE SERVICO

LOCAL DE ENVIO DO EQUIPAMENTO PARA CONSERTO

OFICINA: LEICA PQ. TEC. - SÃO CARLOS - SP.

EQUIPAMENTO RECEBIDO POR: AUREA
- when it has to be right

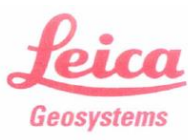

N. ORDEM DE SERVICCO: 0599/12

DADOS DO CLIENTE

EMPRESA: ESCOLA DE ENGENHARIA DE S.CARLOS - USP

E-MAIL: rosalis@sc.usp.br

CONTATO: SEÇÃO DE COMPRAS

EQUIPAMENTO

TIPO: ESTAÇÃO TOTAL

MODELO: TCR 1201+

No SÉRIE: 240941

GARANTIA DO EQUIPAMENTO: [ ] OK

DATA COMPRA:

NOTA FISCAL:

APARÊNCIA DO EQUIPAMENTO, DEFEITOS OU DESGASTES VISÍVEIS:

BOA

PROBLEMAS ALEGADOS:

PROBLEMA NA MEDIÇÃO(EDM), REV. GERAL

PROBLEMAS IDENTIFICADOS:

VERIFICAÇÃO NO EDM;

ATUALIZAÇÃO DO FW;

ATR PAROU DE FUNCIONAR. 
PARECER TÉCNICO:

LAUD NA PLACA PRINCIPAL;

CHECK-UP DAS FUNÇÕES;

AJUSTE GERAL.

SERVIÇOS EXECUTADOS:

- Revisão geral.

- Testes de entrada.

- Inicialização de sistema.

- Ajuste de todo o sistema mecânico.

- Checagem de calibração.

- Verificação dos eixos vertical e horizontal.

- Verificação dos botões de chamadas.

- Checagem da frequiência do EDM de acordo com a tolerância.

- Ajuste do call signal de acordo com as especificações de fábrica.

- Limpeza do equipamento incluindo estojo.

- Emissão do relatório de serviço.

- Emissão do Certificado de Serviço.

OBSERVAÇÕES:

TRAZIDA PELA SR. DIEGO COM DECLARAÇÃO DE TRANSITO.

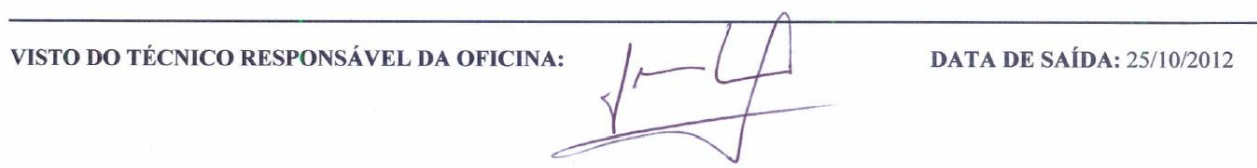


ANEXO C - Certificado de serviço da TCRA 1201+ (Wild Comercial)

\title{
Certificado de Serviço
}

\author{
Equipamento: TCRA 1201 R400 \\ Número de Artigo: 754314 \\ Número de Série: 241101 \\ Data da verificação: novembro 01,2012 \\ Requisitante: ESCOLA DE ENGENHARIA DE S.CARLOS - USP \\ BRASIL \\ Ordem de Serviço: $\quad$ 0602/12 \\ Cliente: ESCOLA DE ENGENHARIA DE S.CARLOS - USP \\ 1. Especificações Técnicas: De acordo com o manual do usuário que acompanha o equipamento. \\ 2. Certificado: Certificamos que o equipamento acima descrito foi testado e que está \\ em conformidade com os resultados dos testes efetuados, atendendo \\ as especificações técnicas contidas no manual do usuário. \\ Comercial e Importadora Wild Ltda \\ Centro de Serviços \\ $01 / 11 / 2012$ \\ Săo Carlos, São Paulo, Brasil
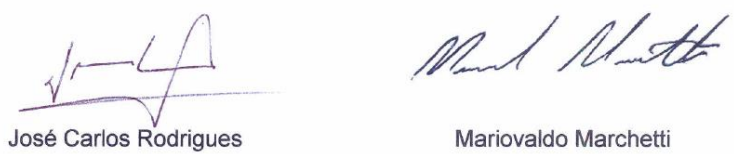 \\ Mariovaldo Marchetti
}

A Comercial e Importadora Wild está qualificada como Centro de Serviço Autorizado pela Leica Geosystems AC.

A Leica Geosystems AG, Heerbrugg possui um Sistema de Gerenciamento em conformidade com os padrőes da ISO9001:2000 I ISO14001:1996 (Reg Nr 10471-8). 
ORDEM DE SERVICO

LOCAL DE ENVIO DO EQUIPAMENTO PARA CONSERTO OFICINA: LEICA PQ. TEC. - SÃO CARLOS - SP.

EQUIPAMENTO RECEBIDO POR: AUREA
- when it has to be right

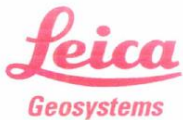

No. ORDEM DE SERVIÇO: 0602/12

DATA DE ENTRADA: $25 / 10 / 2012$

DADOS DO CLIENTE

EMPRESA: ESCOLA DE ENGENHARIA DE S.CARLOS - USP

E-MAIL: rosalis@sc.usp.br CONTATO: SEÇÃO DE COMPRAS

\begin{tabular}{lll}
\hline $\begin{array}{l}\text { EQUIPAMENTO } \\
\text { TIPO: ESTAÇÃO TOTAL }\end{array}$ & MODELO: TCRA 1201 R400 & No SÉRIE: 241101 \\
\hline GARANTIA DO EQUIPAMENTO: & I J J OK & DATA COMPRA:
\end{tabular}

APARÊNCIA DO EQUIPAMENTO, DEFEITOS OU DESGASTES VISÍVEIS: BOA

PROBLEMAS ALEGADOS:

DIFERENÇA NO MEDIÇÃO DO EDM.REV. GERAL

PROBLEMAS IDENTIFICADOS:

REVISÃO GERAL 
- PARECER TÉCNICO:

CHECK-UP DAS FUNÇÕES;

AJ. GERAL.

SERVIÇOS EXECUTADOS:

- Revisão geral.

- Testes de entrada.

- Inicialização de sistema.

- Ajuste de todo o sistema mecânico.

- Checagem de calibração.

- Verificação dos eixos vertical e horizontal.

- Verificação dos botões de chamadas.

- Checagem da frequência do EDM de acordo com a tolerância.

- Ajuste do call signal de acordo com as especificações de fábrica.

- Limpeza do equipamento incluindo estojo.

- Emissão do relatório de serviço.

- Emissão do Certificado de Serviço.

OBSERVACÕES

TRAZIDA PELO SR. DIEGO.

VISTO DO TÉCNICO RESPONSÁVEL DA OFICINA:

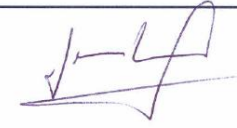

DATA DE SAÍDA: 01/11/2012 


\section{ANEXO D - Projeto do suporte ajustável para alvos refletores}

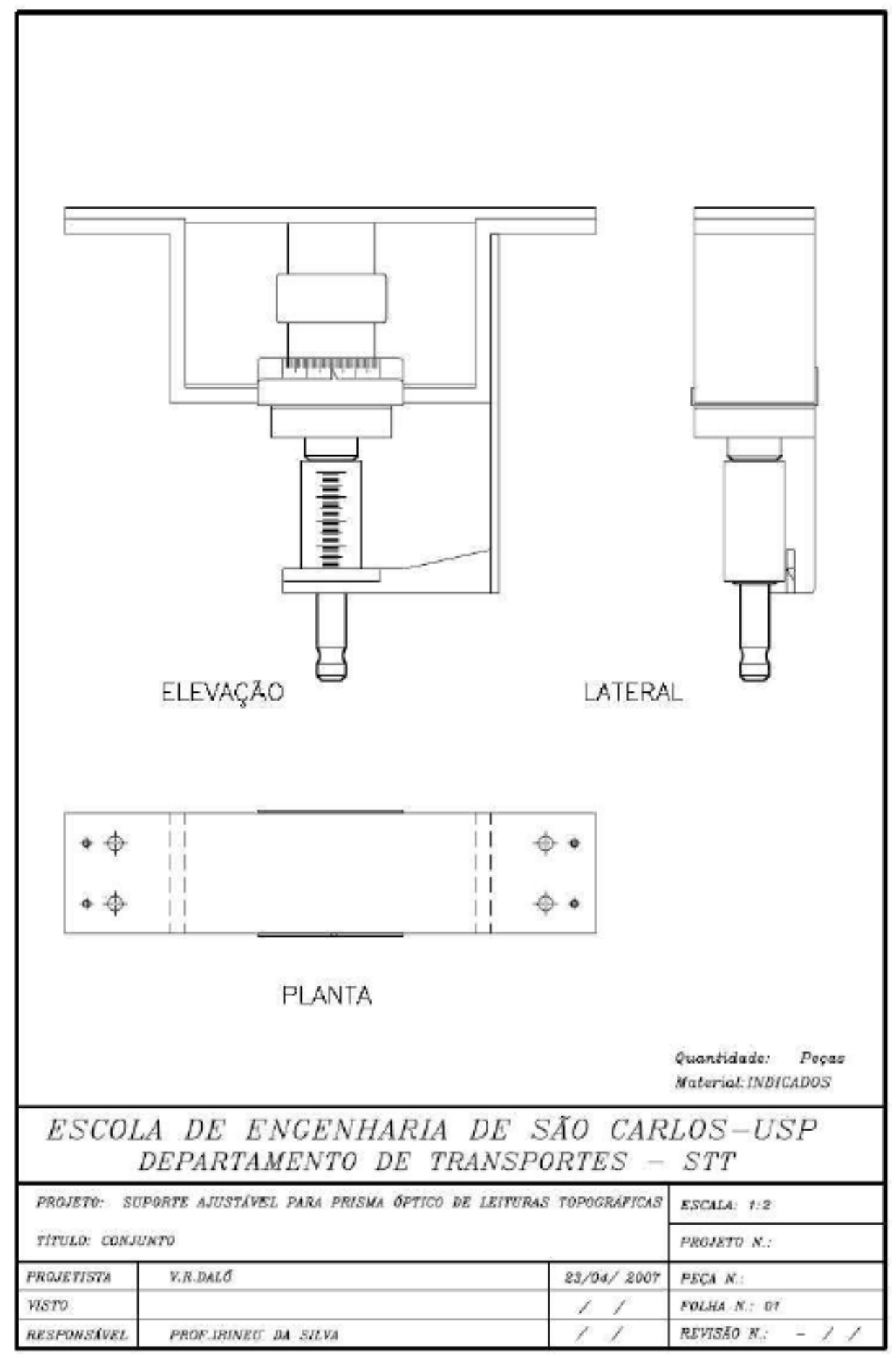




\section{ANEXO E - Projeto do suporte para fitas refletivas}

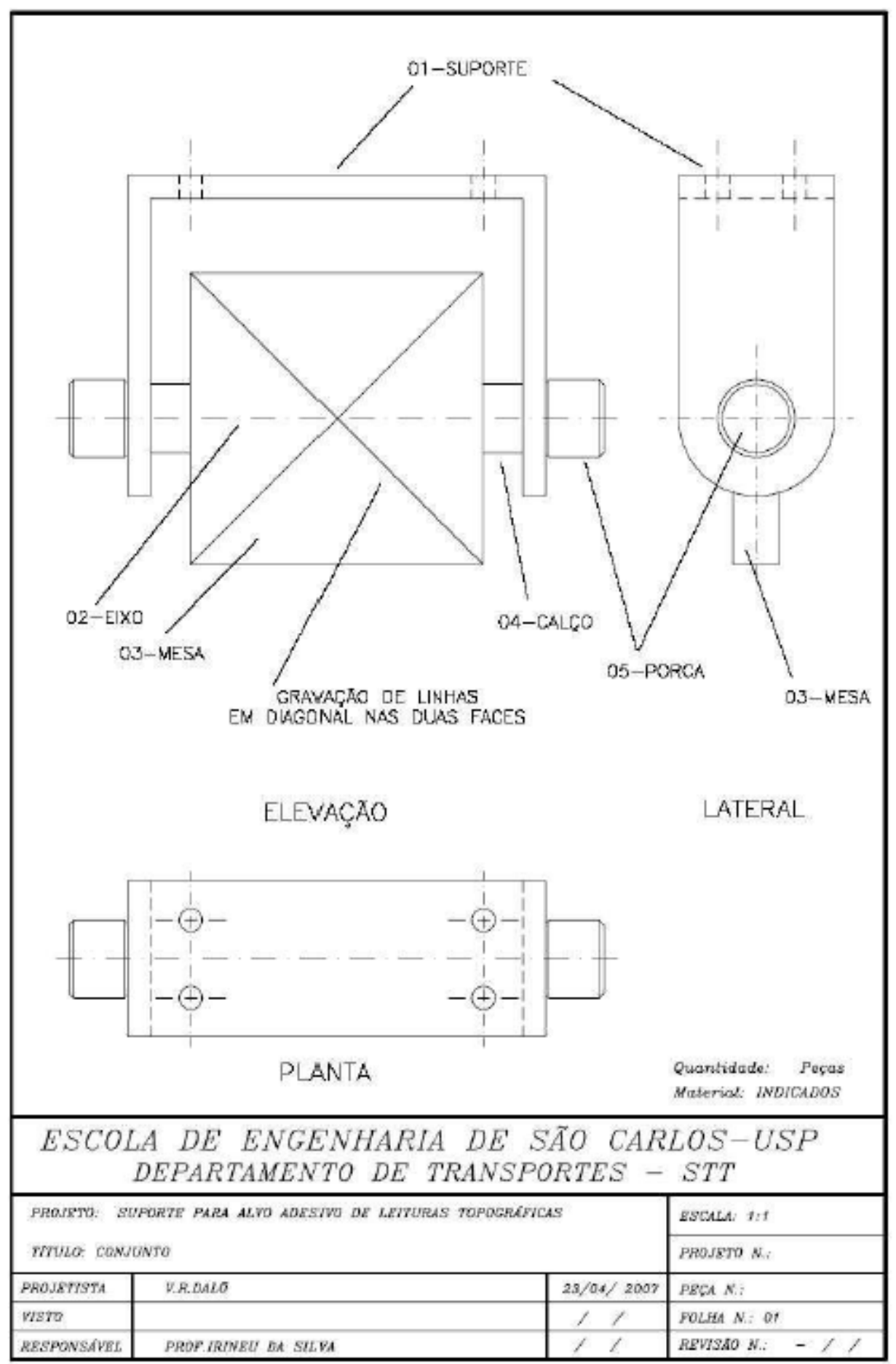

